$$
\text { DOE/ET/4063 - } 1(\text { VO1.1) }
$$

MASTER

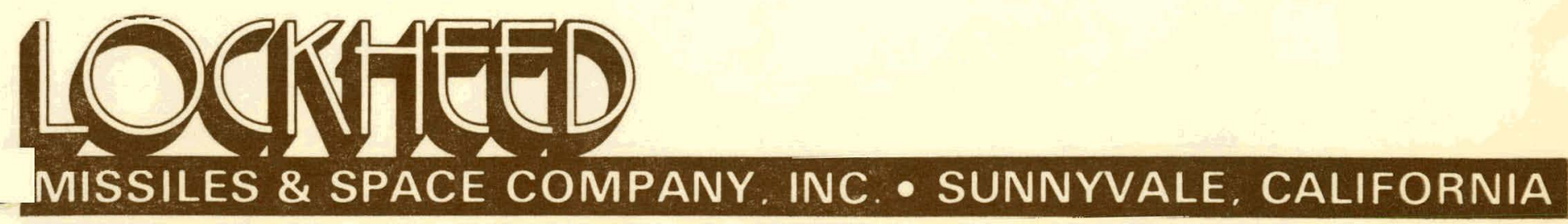




\section{DISCLAIMER}

This report was prepared as an account of work sponsored by an agency of the United States Government. Neither the United States Government nor any agency Thereof, nor any of their employees, makes any warranty, express or implied, or assumes any legal liability or responsibility for the accuracy, completeness, or usefulness of any information, apparatus, product, or process disclosed, or represents that its use would not infringe privately owned rights. Reference herein to any specific commercial product, process, or service by trade name, trademark, manufacturer, or otherwise does not necessarily constitute or imply its endorsement, recommendation, or favoring by the United States Government or any agency thereof. The views and opinions of authors expressed herein do not necessarily state or reflect those of the United States Government or any agency thereof. 


\section{DISCLAIMER}

Portions of this document may be illegible in electronic image products. Images are produced from the best available original document. 


\title{
DOE/ET/4063--1 (NO1.1)
}

\author{
Tromiceson \\ PORTIONS OF THIS REPORT ARE ILLEGIBLE。 It \\ has been reprocucs i rom the best available \\ copy to permit the broadestpossible avail- \\ abli1ty.
}

OTEC PLATFORM CONFIGURATION AND

INTEGRATION STUDY -

FINAL REPORT

VOLUME 1

SYSTEMS ENGINEERING

AND INTEGRATION

APRII $1978 \quad$ LMSC-D623756

Prepared for

UNITED STATES DEPARTMENT OF ENERGY

DIVISION OF SOLAR ENERGY

Under Contract EG-77-C-01-4063

Prepared by

OCEAN SYSTEMS

LOCKHEED MISSILE'S \& SPACE COMPANY, NNC.

A SUBSIDIARY OF LOCKHEED CORPORATION

\section{Supported by}

EARL AND WRIGHT

MORRIS GURALNICK ASSOCIATES, INC. HYDRONAUTICS INCORPORATED
BECHTEL CORPORATION

T. Y. LIN INTERNATIONAL TUNED SPHERE INTERNATIONAL, INC.

This repor was prepared os an account of work This Untied Ceatoo nor the United States Department of Energy, nor any of their employees, nor any of dieh 
THIS PAGE

\section{WAS INTENTIONALLY LEFT BLANK}




\section{FOREWORD}

The OTEC Platform Configuration and Integration Study was performed by Lockheed Missiles \& Space Company, Incorporated, under DOE Contract EG $-77-C-01-4063$. Supporting Lockheed in this work were six subcontractors: Bechtel Corporation; Earl \& Wright Consulting Engineers; Hydronautics, Incorporated; Morris Guralnick Associates, Incorporated; Tuned Sphere International, Incorporated; and T.Y. Lin International.

The final report is comprised of four separately bound volumes, as follows:

Volume $0^{\circ}$ EXECUTTVE SUMMMARY

Volume 1 SYSTEMS ENGINEERING AND INTEGRATION

describes the systems integration and evaluation of six OTEC platform configurations and recommendations for the most satisfactory configuration for an OTEC commercial plant

Volume 2 TECHNICAL CONCEPT describes the conceptual designs of two platform configurations for a 400-MW(e) (net) commercial plant

Volume 3 PROJECT PLAN presents the project plan for an OTEC demonstration plant 
THIS PAGE

\section{WAS INTENTIONALLY LEFT BLANK}


CONTENTS OF REPORT

Section

Page

VOLUME 0 EXECUTIVE SUMMARY

VOLUME 1 SYSTEMS ENGINEERING AND INTEGRATION

1 INTRODUCTION AND SUMMARY ' $1-1$

2 OPTIMUM INTEGRATED OTEC COMMERCIAL PLANT SYSTEM 2-1

2.1 Methodology 2-2

2.2 Interface Considerations - 2-3

2.3 Most Satisfactory Component Options 2-12

2.4 Platform Options 2-115

2.5 Optimum Plant System for New Orleans Site 2-253

$\begin{array}{ll}2.6 \text { Sensitivity to Requirements } & 2-294\end{array}$

3 EFFECT OF STTE VARIATION ON OPTIMUM PLANT SYSTEM $3-1$

3. 1 Ocean System Variations Between Sites 3-1

4 IMPACT OF TECHNICAL ADVANCES 4-1

4. 1 Heat Exchanger Selection 4-1

4.2 Demisters $4-4$

5 SUMMARY OF CONCLUSIONS - 5-1

VOLUME 2 TECHNICAL CONCEPT

1. INTRODUCTION AND SUMMLARY 1-1

2 DESCRIPTION OF INTEGRATED SYSTEMS $2-1$

3. DESCRIPTION OF CONCEPTUAL DESIGN OF SHIP 3-1

4 DESCRIPTION OF CONCEPTUAL DESIGN OF SPAR $\quad$ - $4-1$

5 DISCUSSION OF RESULTS . , , 5-1

6 SUMMARY OF CONCLUSIONS $\quad 6-1$

VOLUME 3 PROJECT PLAN

1 OTEC DEMONSTRATION PLANT $1-1$ 
THIS PAGE

\section{WAS INTENTIONALLY LEFT BLANK}


CONTENTS OF VOLUME 1

Section

Page

FOREWORD iii

1 INTRODUCTION 1-1

2 OPTIMUM INTEGRATED OTEC COMMERCIAL PLANT SYSTEM $2-1$

2.1 Methodology 2-2

2.2 Interface Considerations 2-3

2.2.1 CWP/Hull Interface Requirement $\quad 2-4$

2.2.2 CWP/Support-Facilities Interface Requirement $2-6$

2.2.3 Hull/Support-Facilities Interface Requirement 2-8

2.2.4 Power-System/Hull Interface Requirement (Motions) 2-9

2.2.5 Power $-S y s t e m /$ Hull Interface Requirement (Maintenance) 2-10

2.3 Most Satisfactory Component Options 2-12

2. 3.1 Power System. 2-13

2.3.2 Energy Transfer System 2-39

2. 3.3 Seawater System $2-66$

2.3.4 Position-Control System 2-101

2.4 Platform Options $\quad$ 2-115

2.4.1. Ship Configuration 2-117

2.4.2 Circular Barge Configuration 2-141

2.4.3 Semisubmersible Configuration 2-156

2.4.4 Tuned Sphere Configuration 2-176

2.4.5 Submersible Configuration 2-195

2.4.6 Spar Configuration $\quad 2-210$

2.4.7 Spar - Det3ohable Power Module . 2-233

2.4.8. Prestressed Concrete Hull 2-246

2.5 Optimum Plant System for New Orleans Site 2-253

2.5.1 Plant Costs 2-254

2.5.2 System Optimization 2-271 
2.6 Sensitivity to Requirements

$2-294$

2.6.1 Major Construction in U.S.

$2-294$

2.6.2 Power System Component Layout Within the Hull

$2-294$

2.6.3 Continual Operational Ability of Power Cycle

2-295

3 EFFECT OF SITE VARIATION ON OPTIMUM PLANT SYSTEM

3. 1 Ocean System Variations Between Sites

3.1.1 Seawater System

3.1.2 Pogition-Keeping System

4 IMPACT OF TECHNICAL ADVANCES

4.1 Heat Exchanger Selection

4.1.1. Vertical Exchanger Selection

4-1

4.1.2 Plate-Fin Heat Exchangers

$4-4$

4. 2 Demisters

$4-4$

5 SUMMARY OF CONCLUSIONS 
Section 1

INTRODUCTION

The economic success of an Ocean Thermal Energy Conversion (OTEC) system is highly dependent on a platform which provides adequate support for the power system, accommodates reliably the cold water pipe, and is most cost effective. This report presents the results of a study conducted for the Department of Energy to assess six generic types of platforms to determine the most satisfactory platform for several potential sites. The six platform configurations are ship, circular barge, semisubmersible, Tuned Sphere, submersible, and spar. These represent directional and symmetric types of platforms which operate on the surface; at the interface, and submerged. The five sites for this study were primarily New Orleans, Keahole Point (Hawaii), Brazil, and secondarily Key West and Puerto Rico. Electrical transmission of energy by submarine cable is the planned form of energy transmission for all sites except Brazil, where chemical conversion is to be the method of transmission.

Designs based on the six generic platform configurations are illustrated in Fig. 1-1 as arranged for 100-MW(e). (Net) output of the OTEC plant. As a primary design guideline for the cold water system, the discharge of the cold water has been specified to be below the 100-meter depth. The design arrangements shown in this phase of the study have separate discharges of the warm and cold water with the warm water being discharged into the mixed layer relying upon the mean ocean current to effect transport of the discharge to avoid recirculation into the warm water intake. If a mixed (combined warm and cold water) discharge is required, minor revisions will be required to the internal arrangements and an enlarged discharge duct will accommodate this potential requirement.

This study is devoted to the platform (or ocean systems) of the OTEC plant which is chiefly comprised of the hull and structure, the seawater system, the position control system, and miscellaneous support/assembly systems. The principal elements in the work breakdown structure for the commercial plant are presented in Fig. 1-2. The 
Fig. $1-1$

PLATFORM CONFIGURATIONS 10OMW(e) NET (INTERNAL POWER SYSTEM)

芯
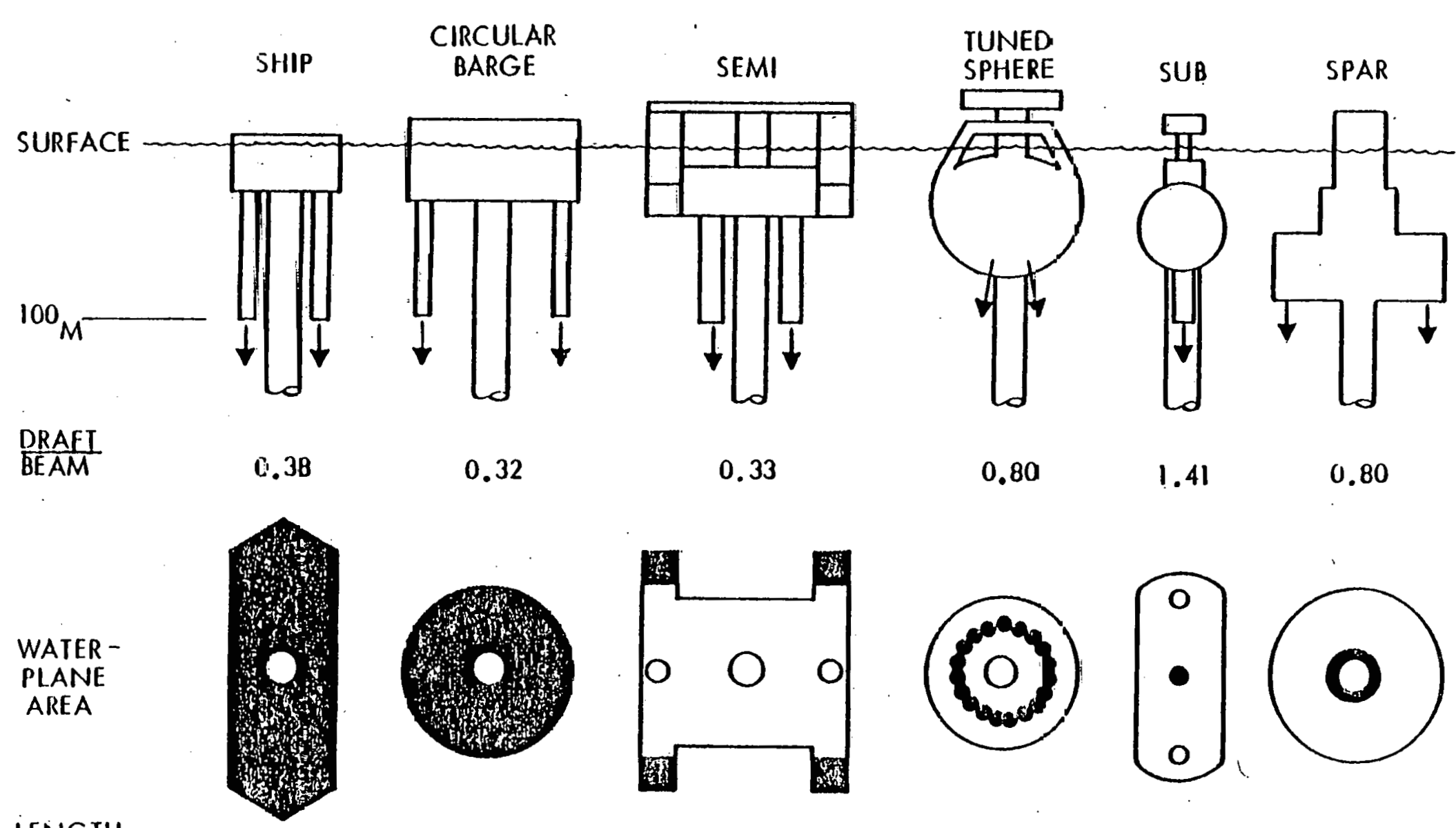

0.33

0.80

1.41

0.80

LENGIH

BEAM

DISPLACEMENT

OUTPUT
2.5

2.74 TONNES KWW
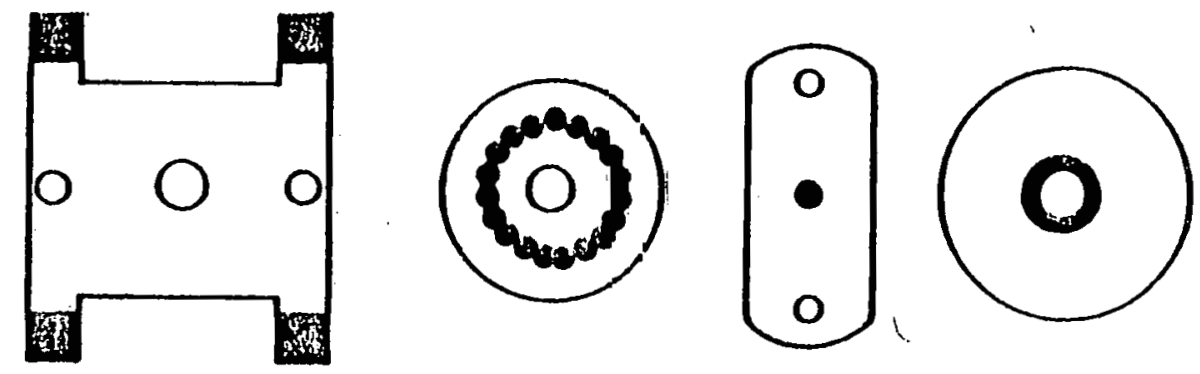

1.1

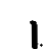

2.37

i

3.49

2.82

2.46

3.35 


\section{- MAJOR COMPONENTS}

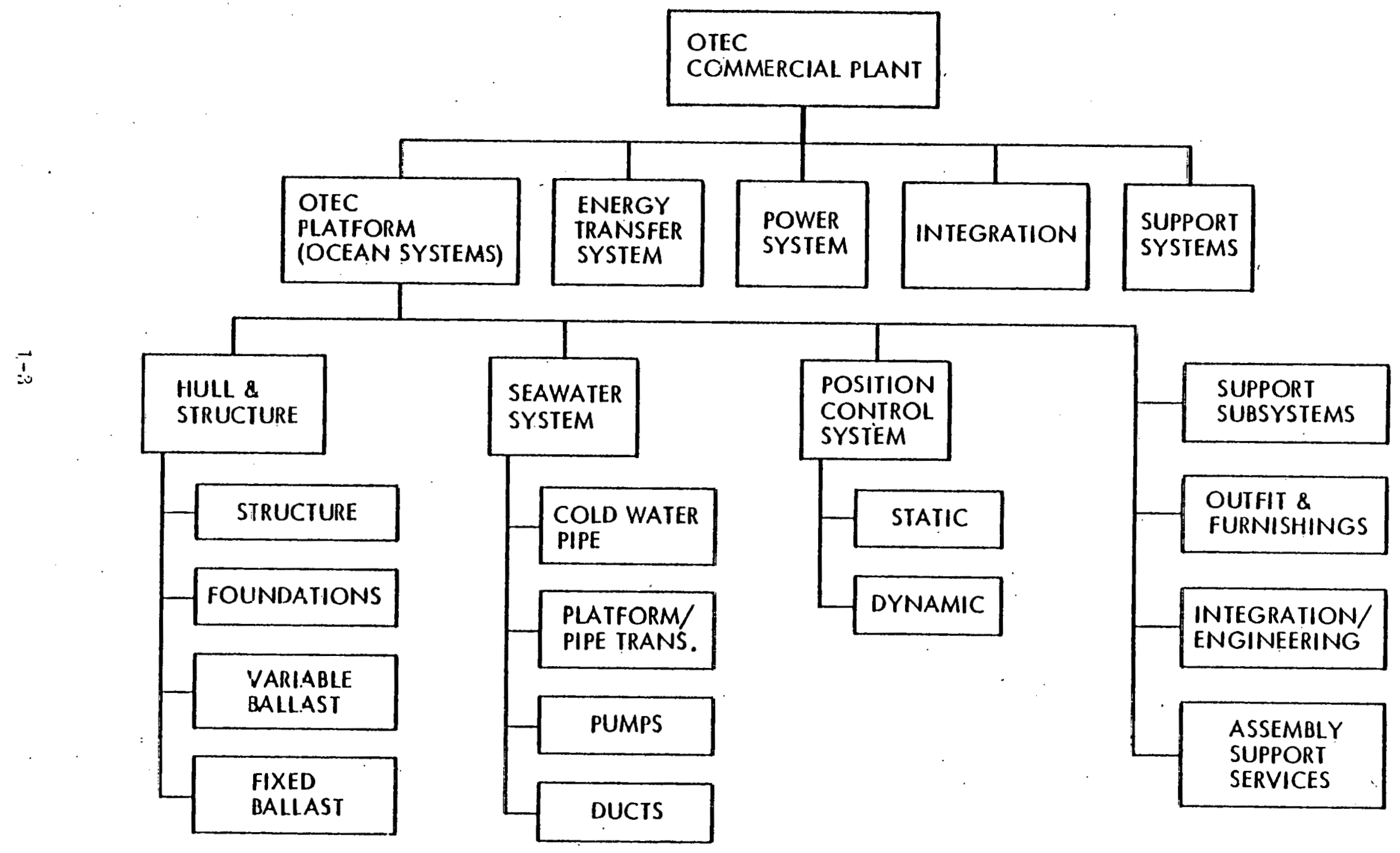


assessment of the six platform configurations was conducted utilizing a baseline plant [100-MW(e) (Net)] and site (New Orleans) with variations from the baseline to cover the range of interested platforms and sites. The functional flow of this approach is shown in Fig. 1-3. The power systems components for this study were defined by DOE and are outlined in Section 2.3.1 of this report.

The requirements for the OTEC platform are detailed in Ref. 1 and are highlighted below:

1. Major components will be constructed in U.S. facilities.

2. Operational life of 40 years at sea shall be projected.

3. The platform must be capable of connection to the electrical transmission system at all times.

4. The maximum watch circle of the platform shall be 5 percent of the water depth.

5. The platform must survive a 100-year storm.

6. The platform must be constructable and operable under prevailing codes and rules.

7. The platform must accommodate a power system and seawater systems.

Section 2 of this report presents the analyses, design, and supporting data for the evaluation of the most satisfactory platforms for the commercial OTEC plant. Section 3 presents a discussion of the effect of the variation in the parameters defining a site on the optimum systems or platform configuration. Section 4 presents an evaluation of the impact of technical advance of the power system on platform evaluations. Section 5 is a summary of project results.

\section{Reference}

1. Lockheed Missiles \& Space Company, Inc., OTEC Platform Configuration and Integration, Vol. 1 Systems and Requirements Analyses and Vol. 2 System Evaluation Plan, LMSC-D564067-A, Aug 1977 


\section{APPROACH TO COMMERCIAL PLANT STUDY}

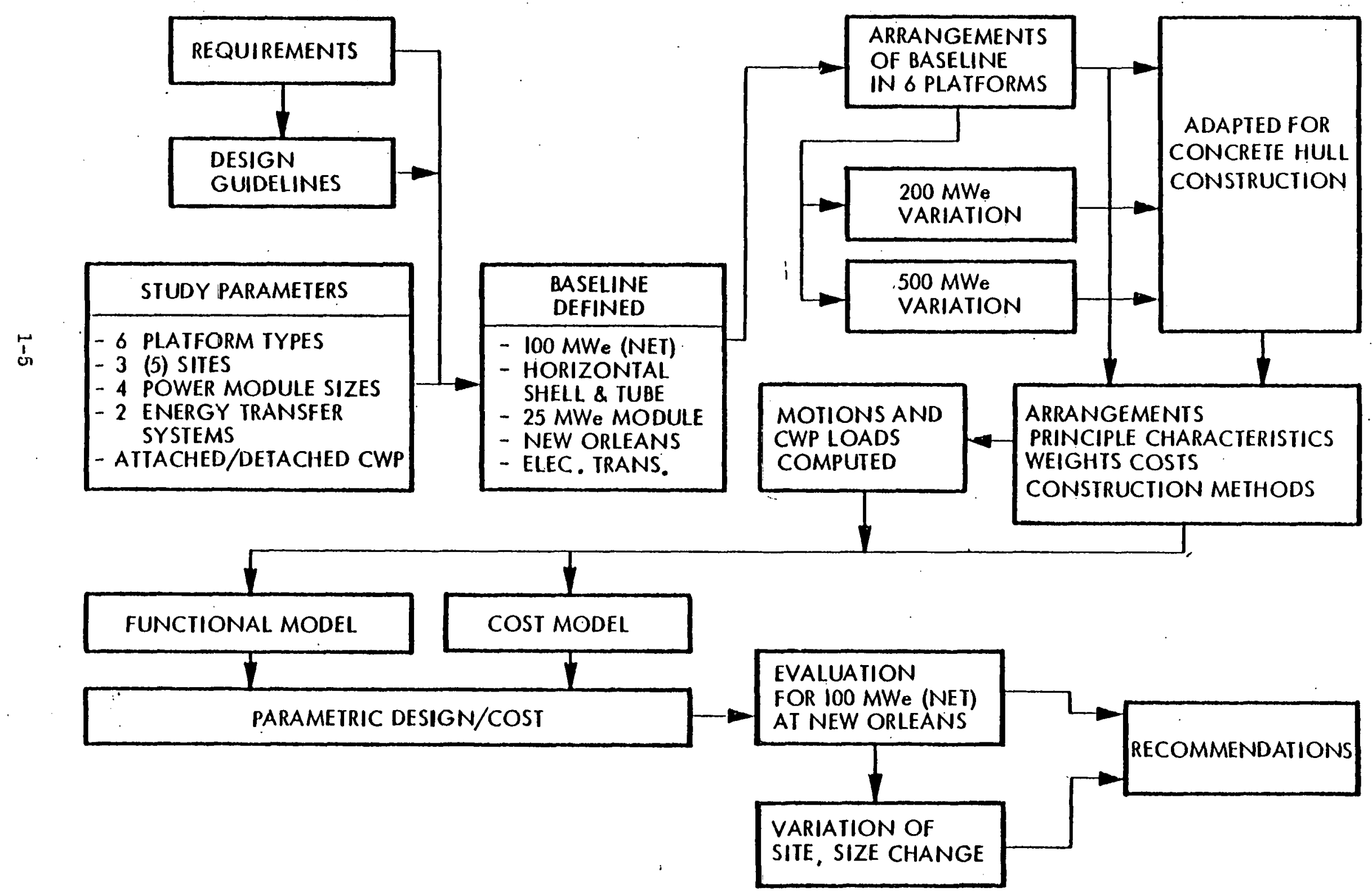


Section 2

OPTIMUM INTEGRATED OTEC COMMERCIAL PLANT SYSTEM

The primary objective of this report is the description and documentation of optimum OTEC commercial plant systems which integrate the several systems and subsystems of the platform and the power system. The most satisfactory component options and the methodology for their selection are described in Section 2.3. The key interface requirements which either drove the selection of components or have been derived for the selected components are presented in Section 2.2. The platform options are defined separately from the other components in Section 2.4. The optimum plant system for the New Orleans site is derived in Section 2.5. 


\subsection{METHODOLOGY}

The large number and range of parameters to be evaluated for the OTEC platforms, sites, power systems, etc., have been addressed by use of a method involving baseline designs (and parameters) and a large data base. These data are available for use in each assessment and for subsequent utilization of the results of this project. The most relevant data is included within Section 2 of this report. Three volumes of appendixes are also included with this report, which presents the entire engineering data trail for each of the component options. 


\subsection{INTERFACE CONSIDERATIONS}

Fundamental to the accomplishment of a system integration is the analysis and design of effective interfaces. Without these the system remains just a collection of major elements. The objective here is to create the system interface requirements which, when satisfied, will assure the creation of a well-integrated system. Because the objective of the OTEC Study is configuration discrimination, or relative evaluation leading to design candidate selection, those requirements which aid in the evaluation process are given special attention. These are called "drivers" and are shown as number 1 priority on Fig. 2-1.

Figure 2-1 presents interface pairs and priorities. The left-hand column lists the major OTEC system elements and their WBS numbers. For purposes of this figure, it is assumed that a given interface requirement is derived from some functional requirement for an element in that column. The headings for the remainder of the

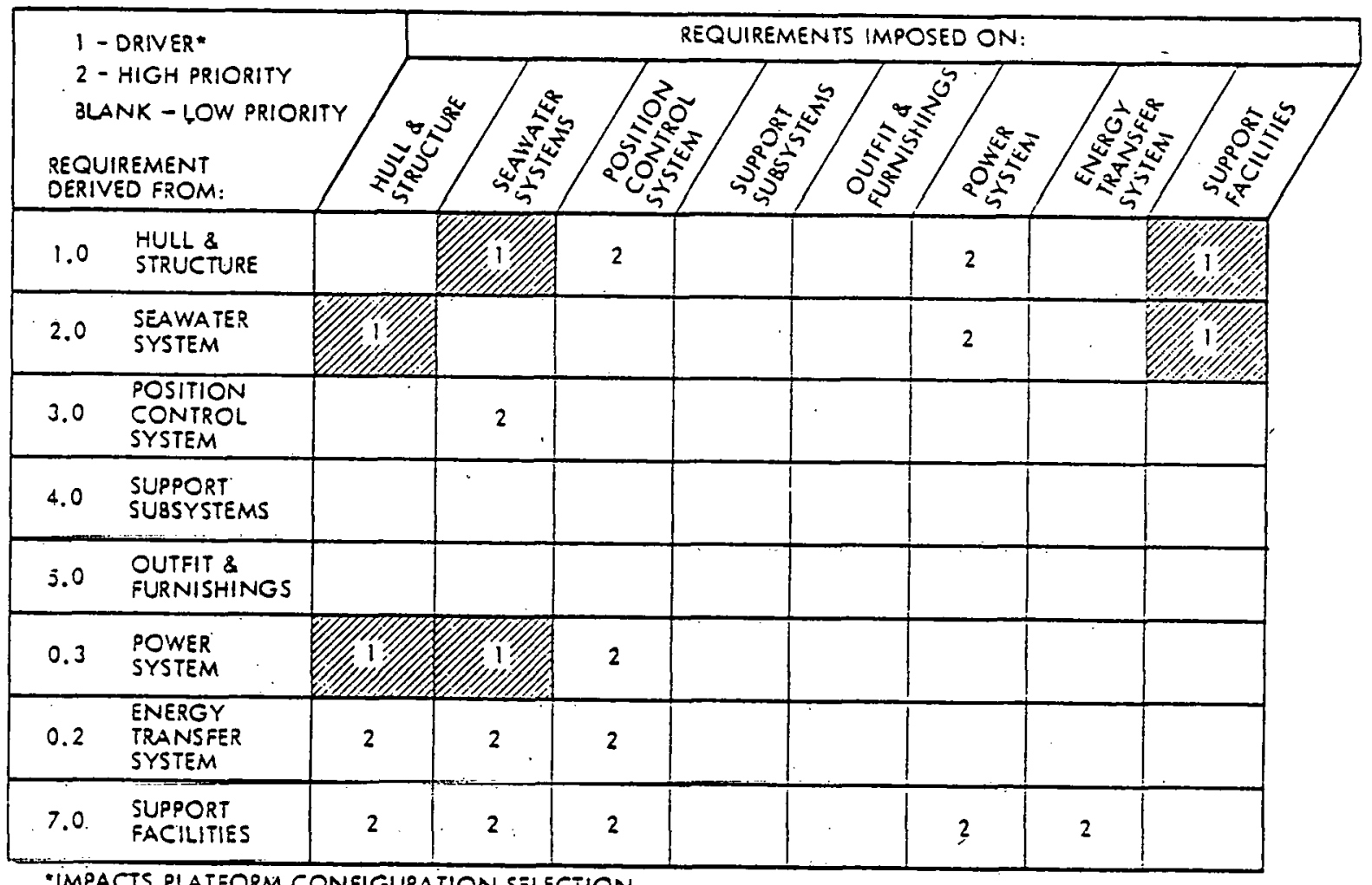

- IMPACTS PLATFORM CONFIGURATION SELECTION.

Fig. 2-1 Interface Pairs and Priorities 
columns are identical to those for the rows; and the boxes at their intersections represent interfaces between component pairs. If one selected, say, Seawater System, from the left-hand column and Power System from the column headings, the box at ineir intersection represents those interfaces for which the requirement is derived from Seawater System and is imposed on the Power System. Those boxes, cross-hatched and containing a number 1 , are considered to be interface drivers; those containing a 2 , high-priority interfaces but not drivers, and the remainder are of minor importance. A discussion on the platform impact of each of the interface requirement drivers is plesented below.

\subsubsection{CWP-Hull Intertace Requirement}

A requirement for the CWP-Hull interface is to provide an adequate attachment for the CWP. In order to properly define this interface, it is necessary to determine the motions to which it is subjected and the bending stress. The hull motion data are presented in Table 2-1. They represent extreme weather motions (wave height $=58.1 \mathrm{ft}$ ) for a

Table 2-1

HULL MOTIONS AFFECTING CWP (58-FT WAVE)

\begin{tabular}{|c|c|c|c|c|c|c|}
\hline & Ship & Barge & Semi & $\begin{array}{l}\text { Tlined } \\
\text { Sphere }\end{array}$ & Sub & Spar \\
\hline \multicolumn{7}{|l|}{ Significant Amplitude } \\
\hline Heave Motion (m) & 9.8 & 12.3 & 3.4 & $\underline{0}, \dot{y}$ & 3.4 & 2,5 \\
\hline Heave Acceleration $\left(\mathrm{m} / \mathrm{sec}^{2}\right)$ & 3.1 & 2.2 & 0.9 & 1.2 & 1.0 & 0.6 \\
\hline Surge Motion (m) & 4.5 & 6.1 & 3.5 & 3.8 & 3.8 & 2.7 \\
\hline Roll/Pitch Motion (deg) & 14.8 & 12.5 & 3.5 & 5.7 & 10.5 & 2.5 \\
\hline Max, Bending Moment $\left(\mathrm{lb}-\mathrm{ft} \times 10^{-9}\right) *$ & 0.9 & 1.5 & 0.8 & 1.0 & 0.9 & 1.2 \\
\hline
\end{tabular}

*For an effective CWP modulus of $0.3 \times 10^{6} \mathrm{psi}$. 
100-MW(e) plant. For this plant size the CWP submerged will weigh 25,000 long tons (assuming concrete) and will have a $58 \mathrm{ft}$ outside diameter. A steel pipe would weigh approximately half the concrete pipe weight.

The effectiveness of the CWP-Hull interface as a configuration discriminator is quite apparent from a cursory review of the data. In summary, the platform motions and consequent bending moment at the interface is high for surface platforms (ship and barge). Although pitch motion for the ship is a minimal value, roll will not be. Other factors which should be considered in the evaluation of the impact of the interface include the material employed in construction and the high cost which would be incurred through development and implementation of the complex attachment which would be required to isolate the CWP from the plant motions.

Although presented in greater detail elsewhere in the report, it may be of interest to look at an example CWP-Hull interface to achieve a clearer picture of what may be involved. Figure 2-2 shows a simple sketch of a relatively simple attachment

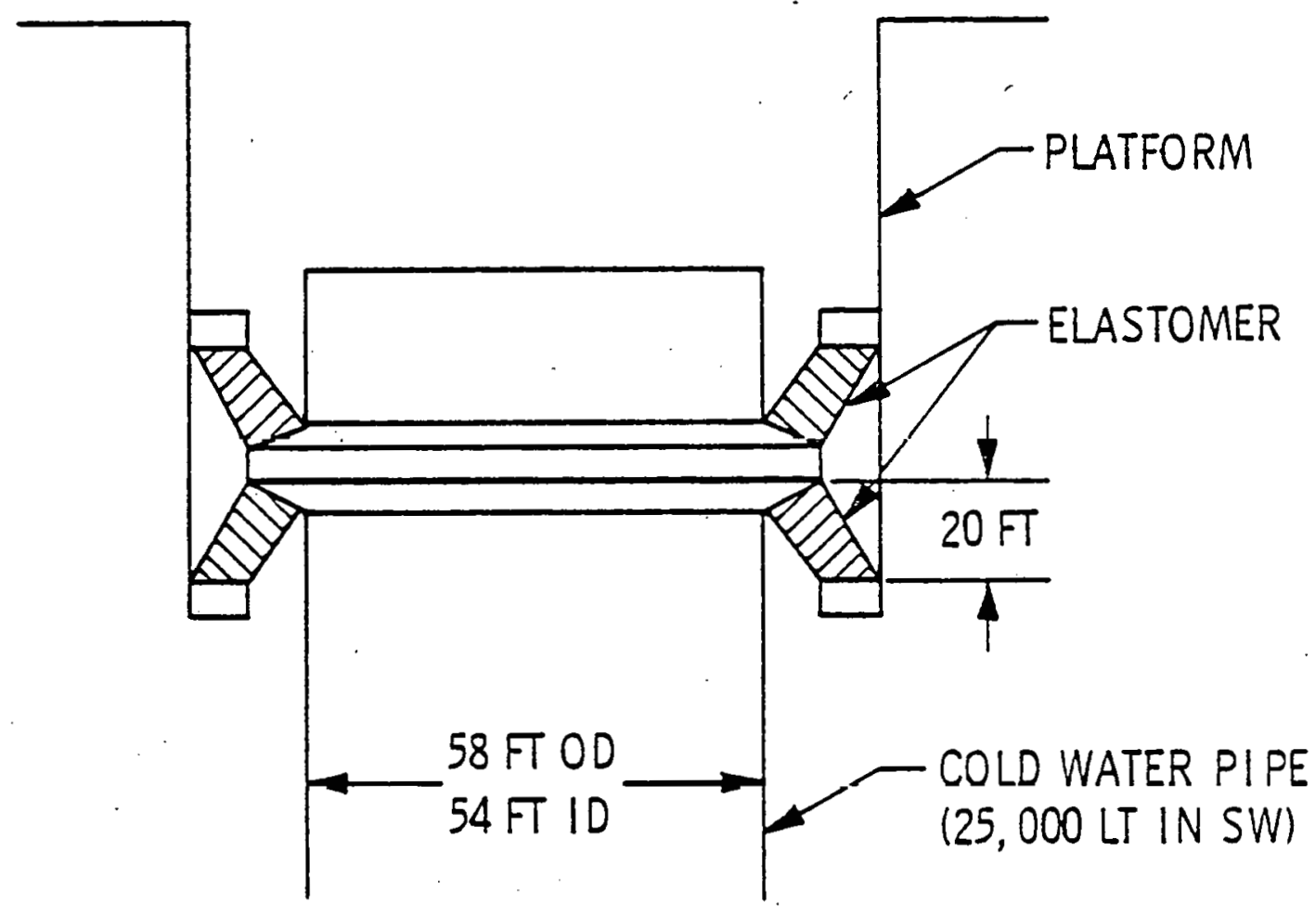

Fig. 2-2 CWP - Platform Interface 
consisting of 20-ft rings of stiff elastomer. Such an attachment will minimize angular motion but will have little effect on heave.

\subsubsection{CWP/Support-Facilities Interface Requirement}

A requirement for the CWP Support Facilities interface is to provide adequate means for physical handling of the CWP during on-site deployment. To define this interface it is necessary to know the weight of the CWP (58,000 LT for the $100 \mathrm{MW}(e)$ plant and 245,000 LT for the $500 \mathrm{MW}$ (e) plant assuming concrete and the external diameter (58 $\mathrm{ft}$ for the 100-MW(e) plant and 115 ft for the $5 n n-M W(0)$ plant). Because of the great weight of the CWP, it must be lifted and lowered into the platform bull in sections. One of the largest operational cranes is the ODIN derrick ship, the dimensions and lifting capacity of which are presented in Table 2-2. Assuming a lift of 2,000 LT per CWP section, some 30 lifts will be required to deploy the pipe for the 100-MW(e) plant. These operations will be affected by the overall height of the platform, which determines the depth to which each section of pipe must be lowered and even assuming that all platform configurations are surfaced during CWP deployment. Hull heights are presented in Table 2-3. Based on these data it is concluded that the surface platforms will present a leș difficult CWP handling prọhlem.

if the platform is designed to allow the CWP to be floated into place, the facilities interface problem just discussed is no longer a major concern. Full designs providing an opening large enough to admit the CWP floated vertically have not been examined sufficiently to incorporate into this document but should be considered for inclusion in the next phase of the study. 
Table 2-2

ODIN DERRICK SHIP

BARGE PRINCIPAL DIMENSIONS

LENGTH OVERALL

$17.8 .45 \mathrm{~m}$

(585 FT - 6 (N)

LENGTH BETWEEN P.P. $1.74 .75 \mathrm{~m}$ $(573 \mathrm{FT}-4(\mathrm{~N})$

BREADTH $42.70 \mathrm{~m}$ (140 FT $-1-1 / 8$ IN)

DEPTH $16.48 \mathrm{~m}$ $(54 \mathrm{FT}-1-3 / 16 \mathrm{IN})$

DRAUGHT $12.00 \mathrm{~m}$ (39 FT - 4-1/2 IN)

CRANE LIFTING CAPACITY

MAINHOIST FIXED CRANE 2680 LT AT $80 \mathrm{FT}-105 \mathrm{FT}$ MAINHOIST REVOLVING CRANE 2410 LT $80 \mathrm{FT}$ - $105 \mathrm{FT}$

Table 2-3

PLATFORM HEIGHT (M)

\begin{tabular}{|l|c|c|c|}
\hline Plant & 100 MW(e) & 200 MW(e) & 500 MW(e) \\
\hline Ship & 32 & .32 & 56 \\
Barge & 43 & 50 & 105 \\
Seml & 65 & 85 & 105 \\
Tuned Sphere & 55 & 71 & \\
Sub & 49 & 49 & 110 \\
Spar & 105 & 110 & 120 \\
\hline
\end{tabular}




\section{2. $3 \mathrm{Hull} /$ Support-Facilities Interface Requirement}

A similar requirement to that discussed just previously is imposed on the Manufacturing Support Facilities by the Hull. In order to define this interface it is necessary, as a minimum, to establish maximum and minimum Hull dimensions. These are presented in Table 2-4 for both the 100-MW(e) and 500-MW(e) plants. Because of the Government

Table 2-4

HULL SIZE DATA

\begin{tabular}{|c|c|c|c|c|c|c|}
\hline Item & Ship & Barge & Semi & $\begin{array}{r}\text { Tuned } \\
\text { Sphere }\end{array}$ & Sub & Spar \\
\hline $100 \mathrm{MW}(\mathrm{e})$ & & & & & & \\
Max Dim (m) & 165 & 98 & 132 & 91 & 116 & 100 \\
Min Dim (m) & 66 & 98 & 120 & 91 & 49 & 100 \\
\hline 500 MW(e) & & & & & & \\
Max Dim (m) & 356 & 149 & 216 & 175 & 335 & 156 \\
$\operatorname{Min} \operatorname{Dim}(\mathrm{m})$ & 82 & 149 & 162 & 175 & 119 & 156 \\
\hline
\end{tabular}

imposed restriction to use of only U.S. manufacturing facilities, there is an incompatibility between platform size and available facilities. The largest U.S. construction facility is the General Dynamics, Quincy Division graving dock at Quincy, Massachusetts. This graving dock is actually two docks which, when the separator between them is removied, opens up into a large facility of $267 \mathrm{~m} \times 91 \mathrm{~m} \times 7 \mathrm{~m}$.

A comparison with the data of Table 2-4 shows that the barge, semi-submersible, and spar 100-MW(e) configurations cannot fit into the dock area without some form of modularization. Alternatively, these platforms could conceivably be constructed in stages or constructed on site. A look at the 500-MW(e) size data demonstrates the incompatibility of all configurations with the graving dock and the consequent necessity 
for modularization; or, as suggested for the 100-MW(e) plants, constructed in stages or on site. Another alternative, of course, is the construction of a new and larger facility at an increased capital cost for the platform.*

\subsubsection{Power-System/Hull Interface Requirement (Motions)}

Two Power System - Hull interface requirements are discussed. The first, addressed in this section, is concerned with the effect of hull motions on the performance of the heat exchangers. The second, discussed in the next section, is concerned with the availability of equipment laydown space and access through the hull to the heat exchangers sufficient to allow their removal.

Regarding the impact of hull motions on the Power System heat exchangers, it has been estimated (and is being verified) that $3^{\circ}-5^{\circ}$ of angular motion will cause the heat exchangers to reach their acceptable limit in degradation of performance. No comparable limit has been established for heave acceleration. Hull motions are presented demonstrating the effect of $58 \mathrm{ft}$ and $20 \mathrm{ft}$ waves on $100-\mathrm{MWW}(\mathrm{e})$ platforms in Table 2-5.

Table 2-5

HULL MOTIONS AFFECTING HEAT EXCHANGERS

\begin{tabular}{|c|c|c|c|c|c|c|}
\hline & SHIP & BARGE & SEMI & $\begin{array}{l}\text { TUNED } \\
\text { SPHERE }\end{array}$ & SUB & SPAR \\
\hline \multicolumn{7}{|l|}{ ANGULAR MOTION $1{ }^{\circ}$} \\
\hline $58 \mathrm{rT}$ WAVE & 14.8 & 12.5 & 3.5 & 5.7 & 10.5 & 2.5 \\
\hline ZOF WAVE & 2.2 & 1.9 & 0.7 & 0.5 & 0.7 & 0.3 \\
\hline \multicolumn{7}{|l|}{ MEAVE ACCEL (M/SEC $C^{2}$ ) } \\
\hline S8 FT WAVE & 3.1 & 2.2 & 0.9 & 1.2 & 10 & 0.6 \\
\hline 2OF WAVE & 0.6 & 0.5 & 0.2 & 0.3 & 0.2 & 0.1 \\
\hline \multicolumn{7}{|c|}{ ALOWABLE LIMIT ON HX } \\
\hline AVE, MOTION ( $\left.{ }^{\circ}\right)$ & BEST E & STIMAT & IT PRE & ENT IS $3^{\circ}$ & & \\
\hline ACCEL OF GRAVITY & 0.16 & $3.2 \mathrm{FT} / \mathrm{S}$ & $c^{2} \cdot 1$ & $M / S E C^{2}$ & & \\
\hline
\end{tabular}

*A larger graving dock, capable of handling all plant sizes discussed in this report is being constructed at Jacksonville, Florida for Off-Shore Power Systems. Its dimensions will be: Length - $5300 \mathrm{ft}$ and width - $550 \mathrm{ft}$. 
From the data presented it is readily observed that, for the 58 -ft extreme seas wave, the ship and barge configuration motions exceed the estimated maximum allowable. For the 20-ft wave, the situation improves dramatically, but the barge motions remain only marginally acceptable.' An identical situation exists in heave, al though the seriousness of the heaving of surface platforms on the heat exchanger is unknown. Decoupling of the hull from the heat exchangers to minimize motions of the latter would require highly complex support foundation which would prove quite costly.

\subsubsection{Power-System/Hull Interface Requirement (Maintenance)}

The interface requirement imposed on the Hull by the Power System is for adequate laydown area for elements such as the turbogenerator cover and access through the Hull to the heat exchangers to allow their removal for refurbishment or replacement. The minimum laydown area requirement and the minimum access diameters for 5,8 , $12-1 / 2$, and $25 \mathrm{MW}(\mathrm{e})$ heat exchangers is presented in Table 2-6.

Table 2-6

LAYDOWN AND ACCESS AREAS

\begin{tabular}{|c|c|c|c|c|}
\hline Item & $1-5 \mathrm{MW}$ & $1-8 \mathrm{MW}$ & $1-12-1 / 2 \mathrm{MW}$ & $1-25 \mathrm{MW}$ \\
\hline Power System HX's & & & & \\
Min Loydown Area $(\mathrm{Ft})^{2}$ & $40 \times 9$ & $50 \times 11$ & $64 \times 12$ & $92 \times 12$ \\
Min HX Access Diam $(F t)$ & 22 & 26 & 30 & 38 \\
\hline
\end{tabular}

It may be of interest to note that access diameters for removal of a complete 25-MW(e) Power System unit would vary from 160 to $80 \mathrm{ft}$, the former relating to a five-j-NTW(e) heat exchanger package and the latter to a one-25-MW(e) package. These values are so large and their respective weights so great $\left(\approx 5000\right.$ LT' $^{\prime}$ ) that no serious consideration has been given to these access areas.

If it is possible to use the same laydown area for several j-MW(e) heat exchangers this could be a substantial plus for their use over larger heat exchanger sizes. 
Similarly, if the same access area can be employed to extract several 5-MW(e) heat exchangers, again this size may be a better choice than a larger one. Conversely, where complex 5-MW(e) heat exchanger arrangem ents are required, maintenance will be difficult and the larger heat exchanger sizes may be advantageous.

It is probably unnecessary to comment that the employment of external detachable module heat exchangers would largely eliminate this interface problem. 


\subsection{MOST SATISFACTORY COMPONENT OPTIONS}

The preferred OTEC plant configuration will be that one which combines the best features of all systems and subsystems in package which is most viable from a cost, rișk, and schedule standpoint. At this stage in the design process it is essential to identify the several most reasonable alternatives for each system and to set a measure of importance on the system or on the alternatives. A high cost system may have high and low risk alternatives, and may have only a small range of cost variation among the alternatives. From this activity will spring messages to the designer, the planner, the analyst, and the interface coordinator. The purpose of this Section is to present these alternatives for the OTEC commercial plant, to present quantified statements about the alternatives, and to recommend options for components to be used in the comparative assessment of six platform types. Later Sections ( 3 and 4 ) examine the effects of variations in some of the most important of these components as they affect the evaluation of the most satisfactory OTEC commercial plants for five potential sites and two forward energy transmissions (electrical transmission and chemical production, $\mathrm{NH}_{3}$ ). 


\subsubsection{Power System}

This section summarizes the Power System sizing data furnished to the naval architects for their use in configuration pre-conceptual design. It includes volume and weight requirements and general arrangements for $5,8,12-1 / 2$, and $25 \mathrm{MW}(\mathrm{e})$ internal horizontal and vertical heat exchangers along with alternative concepts for external detachable power modules. Estimates of laydown areas in access areas for Power System maintenance and repair are presented in Section 2.2 .

The detachable module is given special attention in Section 2.3 .1 .2 because of the following attributes:

- It serves to eliminate large internal areas and volumes required for maintenance and replacement of internal components.

- It eliminates the need for large crane lifting capacity.

- Water boxes can be eliminated through selection of external detachable modules.

- It provides for ease of module installation and replacement.

- A marked reduction in size and cost of the Spar platform is possible employing detachable modules.

2.3.1.1 Baseline Power System. The baseline Power System is a 25-MW(e) module made up of $5,8,12-1 / 2$, or $25 \mathrm{MW}(e)$ horizontal heat exchangers, internally mounted (shirtsleeve environment). The sizing and cost data for both these and the vertical heat exchangers were developed by Gilbert Associates and furnished to Lockheed by the Government. (See Refs. (1) and (2).) These data have been reworked into a usable form for use by the naval architects and are presented in Table 2-7. Note that vertical heat exchanger data are also includer in this table.

Whether made up of $5,8,12-1 / 2$, or $25 \mathrm{MW}(\mathrm{e})$.heat exchanger sub-modules, the ultimate package will be a 25 MW(e) Power System packaged module. These modules were developed as Power System envelopes by Lockheed and furnished to the naval architects 
as package volumes for incorporation into their platform configuration pre-conceptual designs. Sketches leading to specification of packaged module envelopes are presented in Figs. 2-3, 2-4, 2-5 and 2-6, and 2-7 and 2-8 for the 25-MW(e) modules made of $5,8,12-1 / 2$, and $25 \mathrm{MW}(\mathrm{e})$ sub-modules, respectively. Two arrangements of the $12-1 / 2$ and $25 \mathrm{MW}(\mathrm{e})$ sub-modules were layed out to determine which of the alternatives was best adapted to a given platform configuration.

Based on the data presented in Table 2-7 and the package envelopes presented in the figures just discussed, total areas, volumes, and costs were generated for 25MW(e) modules and for packaged modules. See Tables 2-8, 2-9, 2-10 and 2-11 which present these data for $5,8,12-1 / 2$, and $25 \mathrm{MW}(\mathrm{e})$ sub-modules, respectively. 
Table 2-7

POWER SYS'T EM COMPONENTS SIZE AND COST

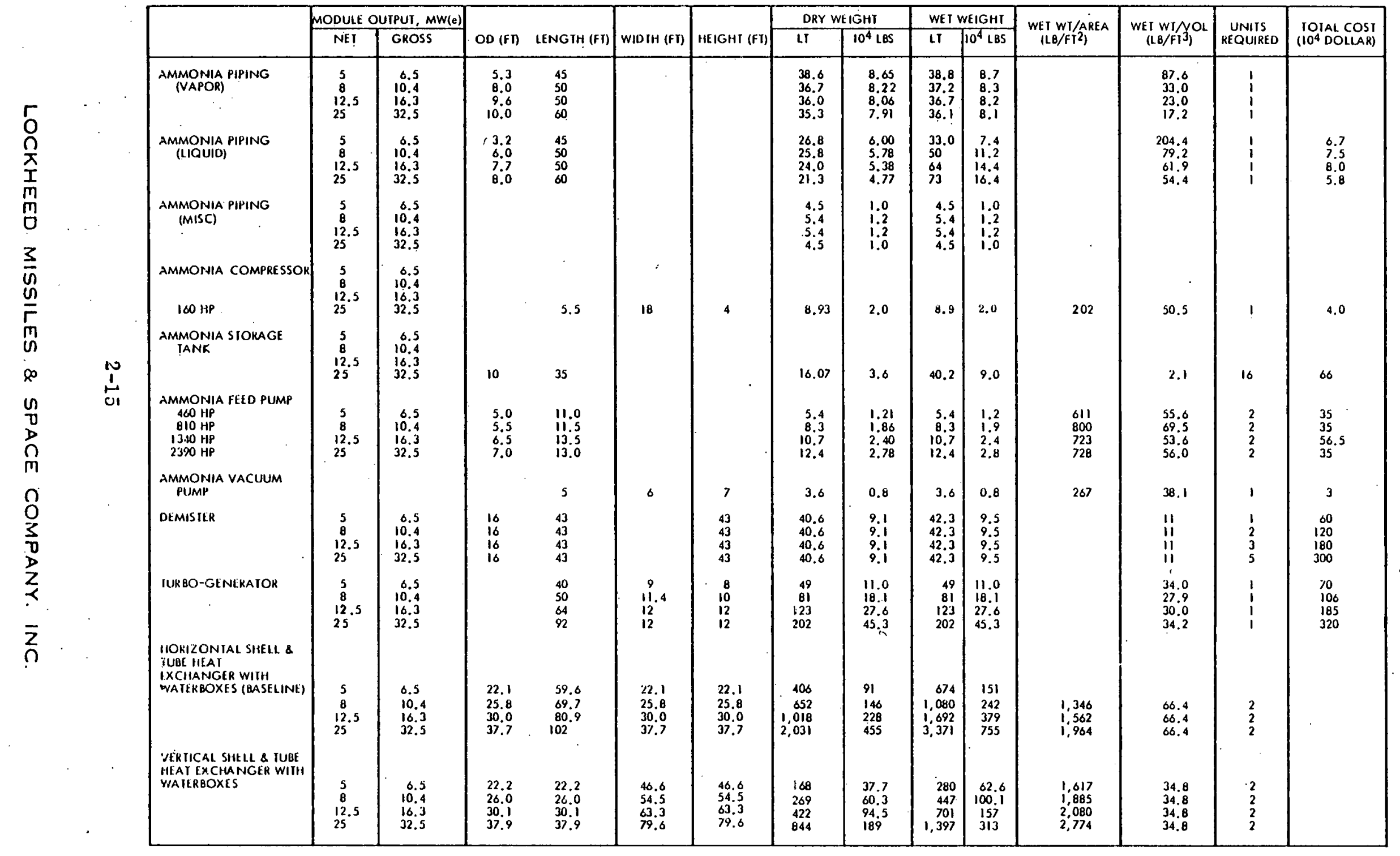




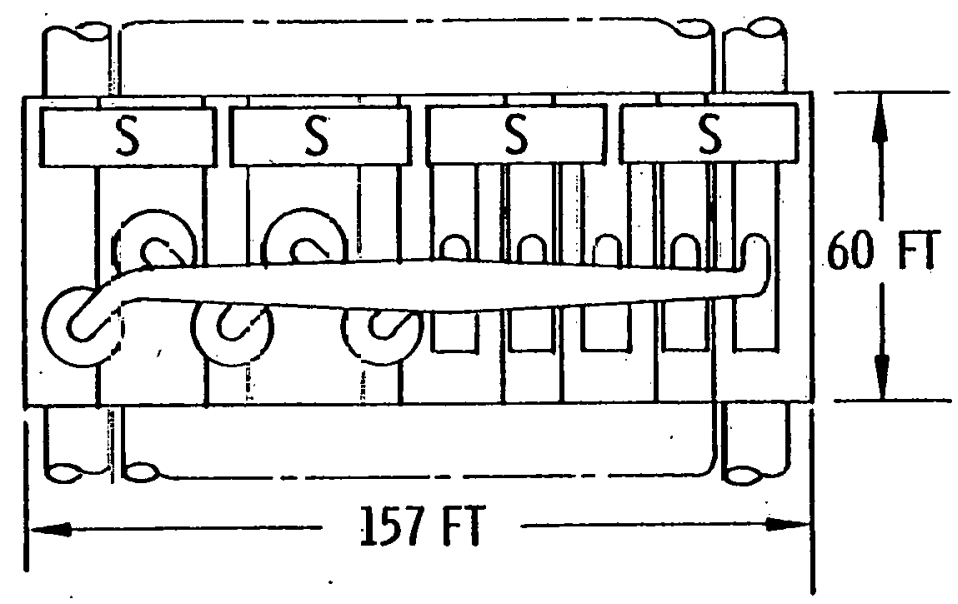

LEGEND:

$P=$ AMMONIA FEED PUMP

$\mathrm{S}=\mathrm{NH}_{3}$ STORAGE TANK

$C=$ CONDENSER, 5 MW(e)

$D=$ BEMISTER, 5 MW(e)

E - EVAPORATOR, 5 MW(e)

$T=$ TURBOSENERATOR, $5 \mathrm{MW}(\mathrm{e})$

$\underset{1}{10}$

SCALE: 1 IN $=40 \mathrm{FT}$

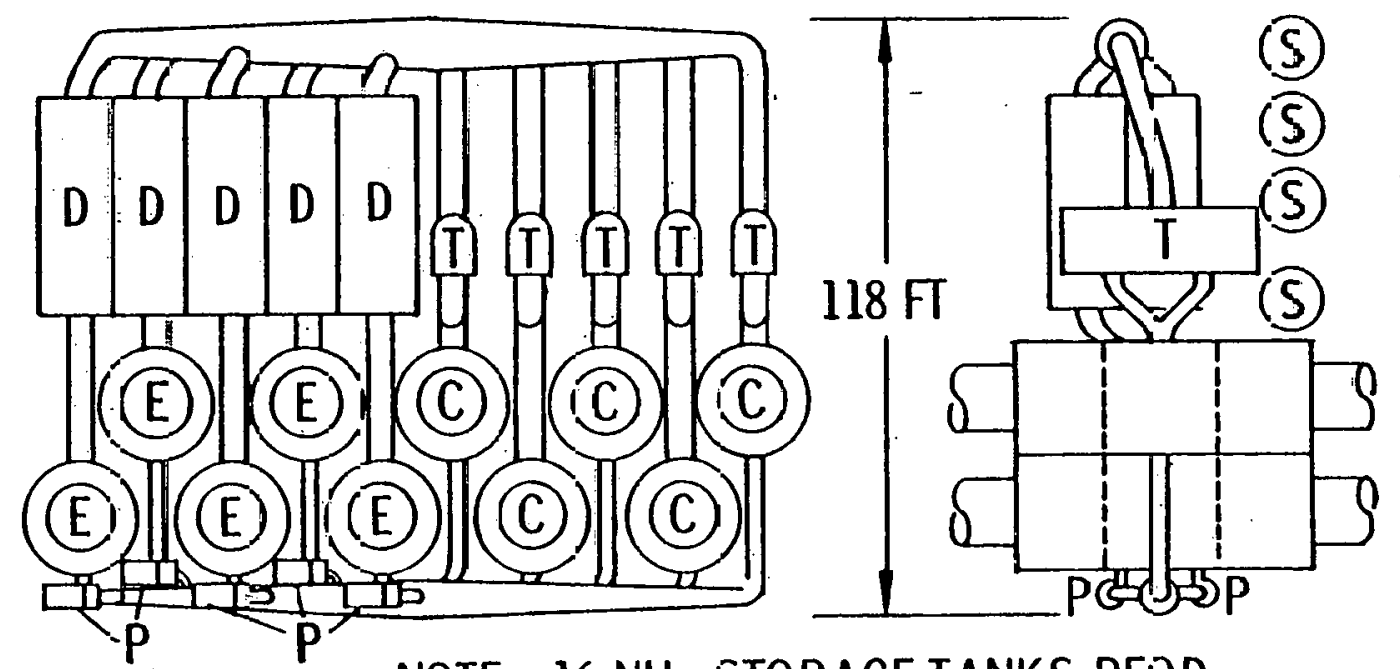

NOTE: $16 \mathrm{NH}_{3}$ STORAGE TANKS REQD; NOT SHOWN IN ALL VIEWS

rig. 2-3 Packaged 25-MW(e) Net Power System. Uni:s are 5-MW(e) net 


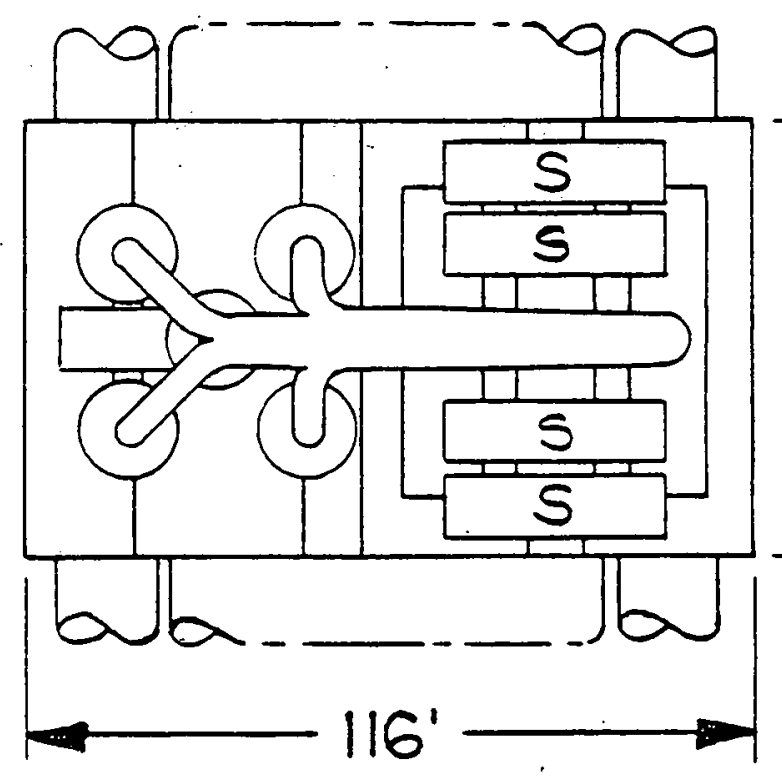

\section{SCALE : $1^{\prime \prime}=40^{\prime}$}

$P=\frac{\text { LEGEND: }}{\text { AMMONIA FEED PUMP }}$

$\mathrm{S}=\mathrm{NH}_{3}$ STORAGE TANK

$C=$ CONDENSER, 8 MW

$D=$ DEMISTER, $5 \mathrm{MWe}$

$E=E V A P O R A T O R, 8 \mathrm{MWe}$

$T=$ TURBOGENERATOR, $8 \mathrm{MWe}$

$M=$ MANIFOLD
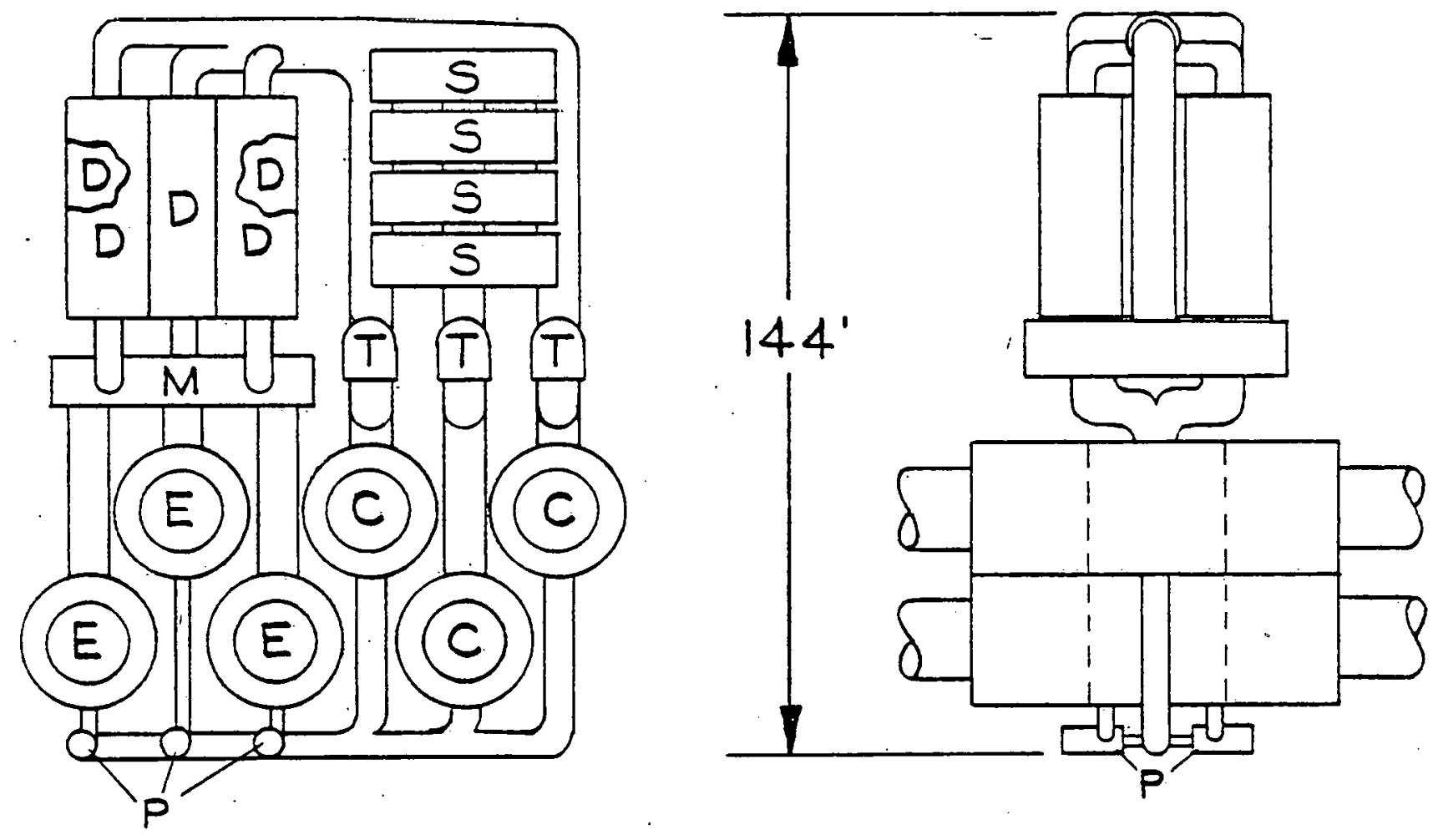

NOTE : $16 \mathrm{NH}_{3}$ STORAGE TANKS REQ'D, NOT SHOWN IN ALL VIEWS.

Fig. 2-4 Packaged 25-MWW(e) Net Power System.' Units are $8 \mathrm{NW}(\mathrm{e})$ net 


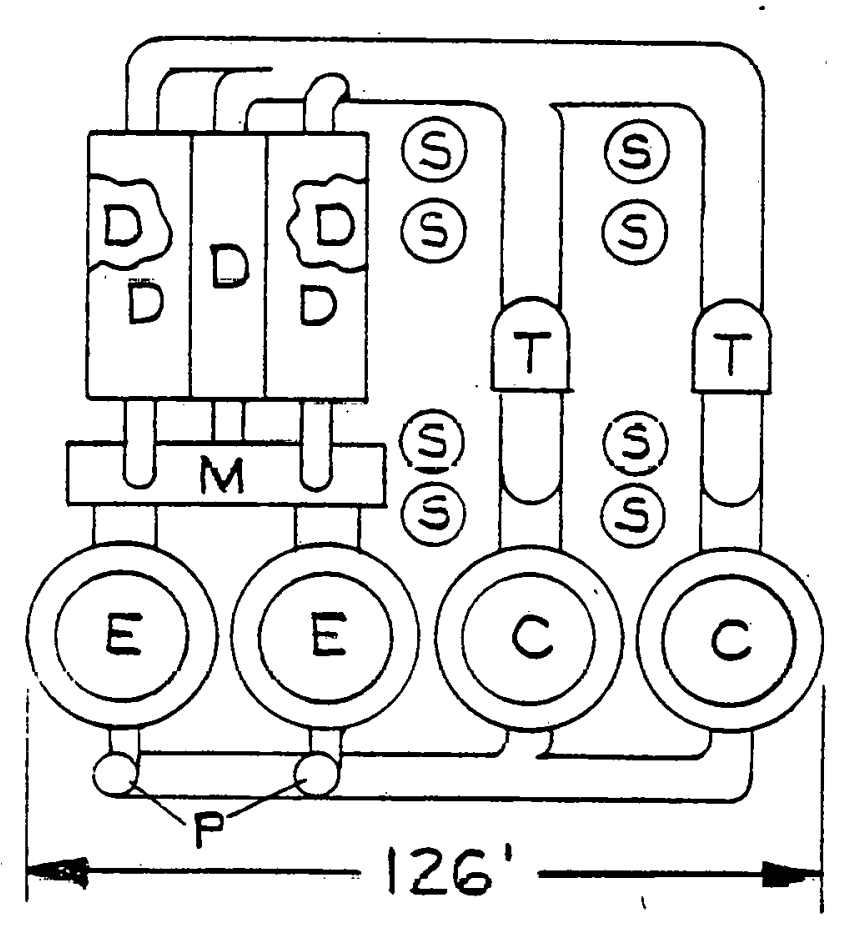

SCALE : $1^{\prime \prime}=40^{\prime}$
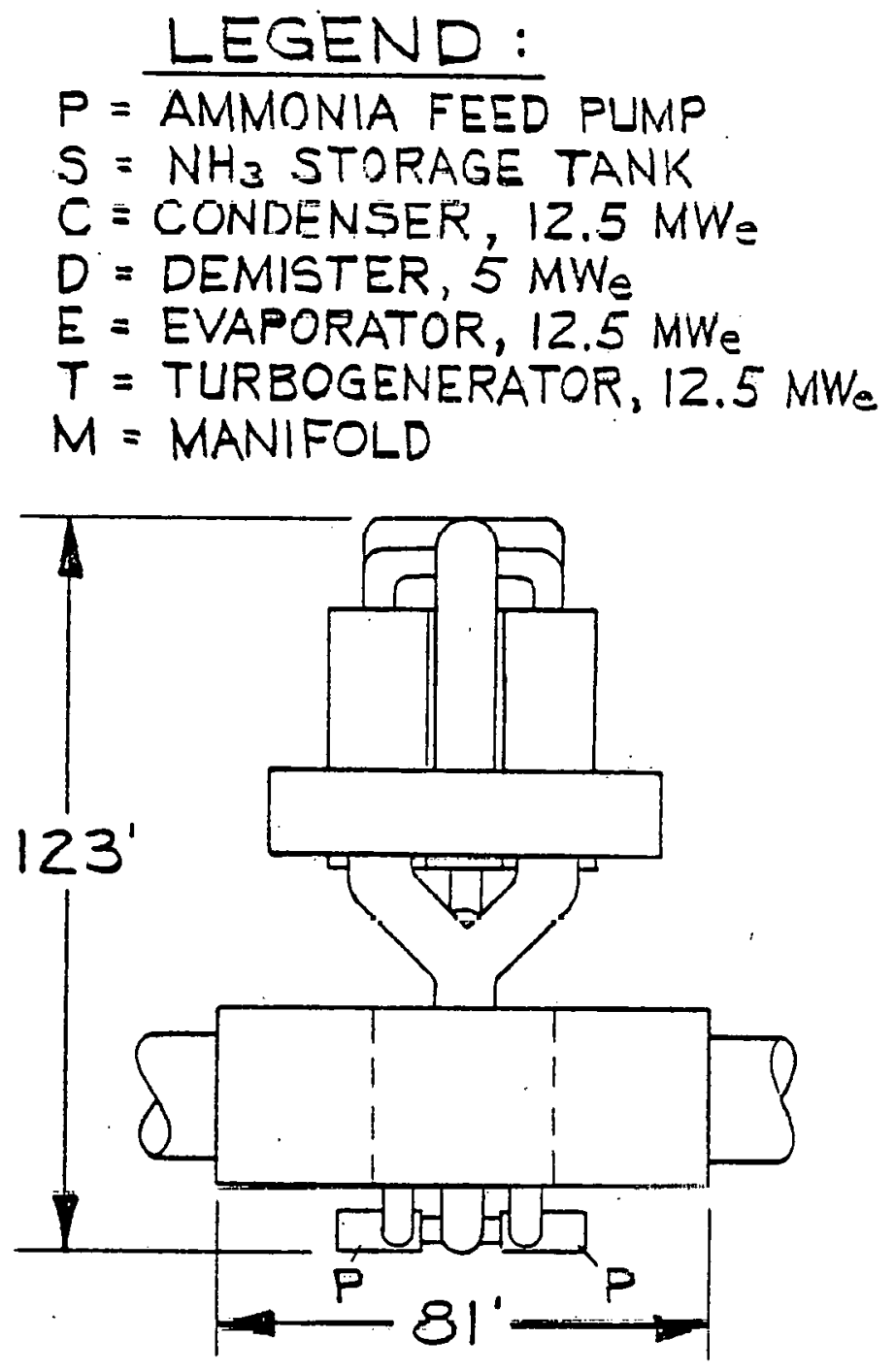

NOTE: $16 \mathrm{NH} 3$ STORAGE TANKS REQ'D, NOT SHOWN IN ALL VIEWS.

Fig. 2-5 Packaged 25-MWW(e) Net Power System. Units are 12-1/2 MWW(e) net 

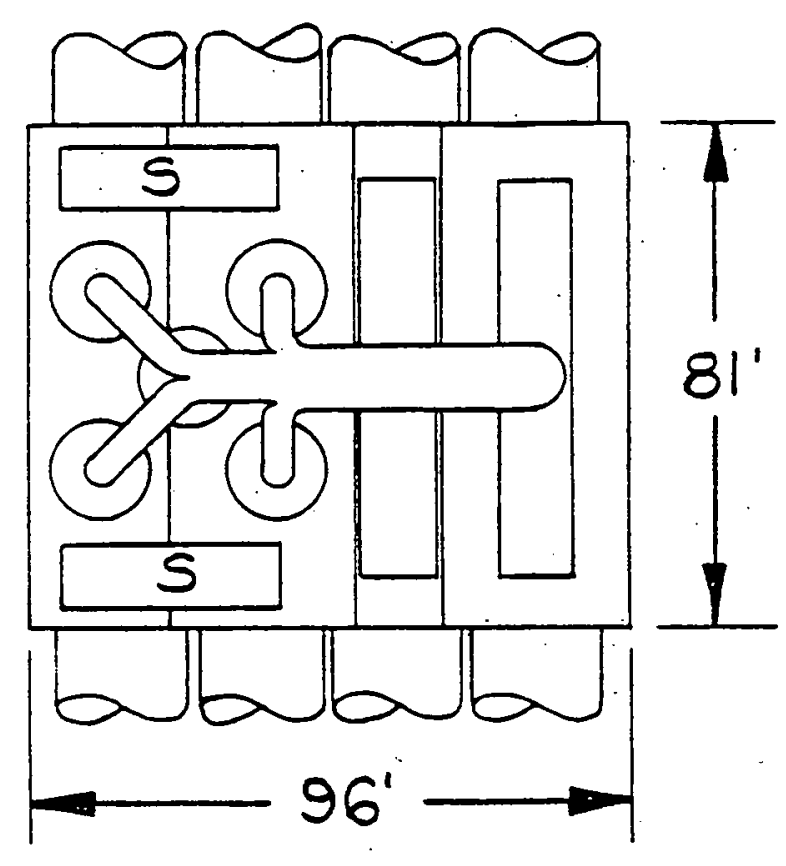

\section{SCALE : $1^{\prime \prime}=40^{\circ}$}
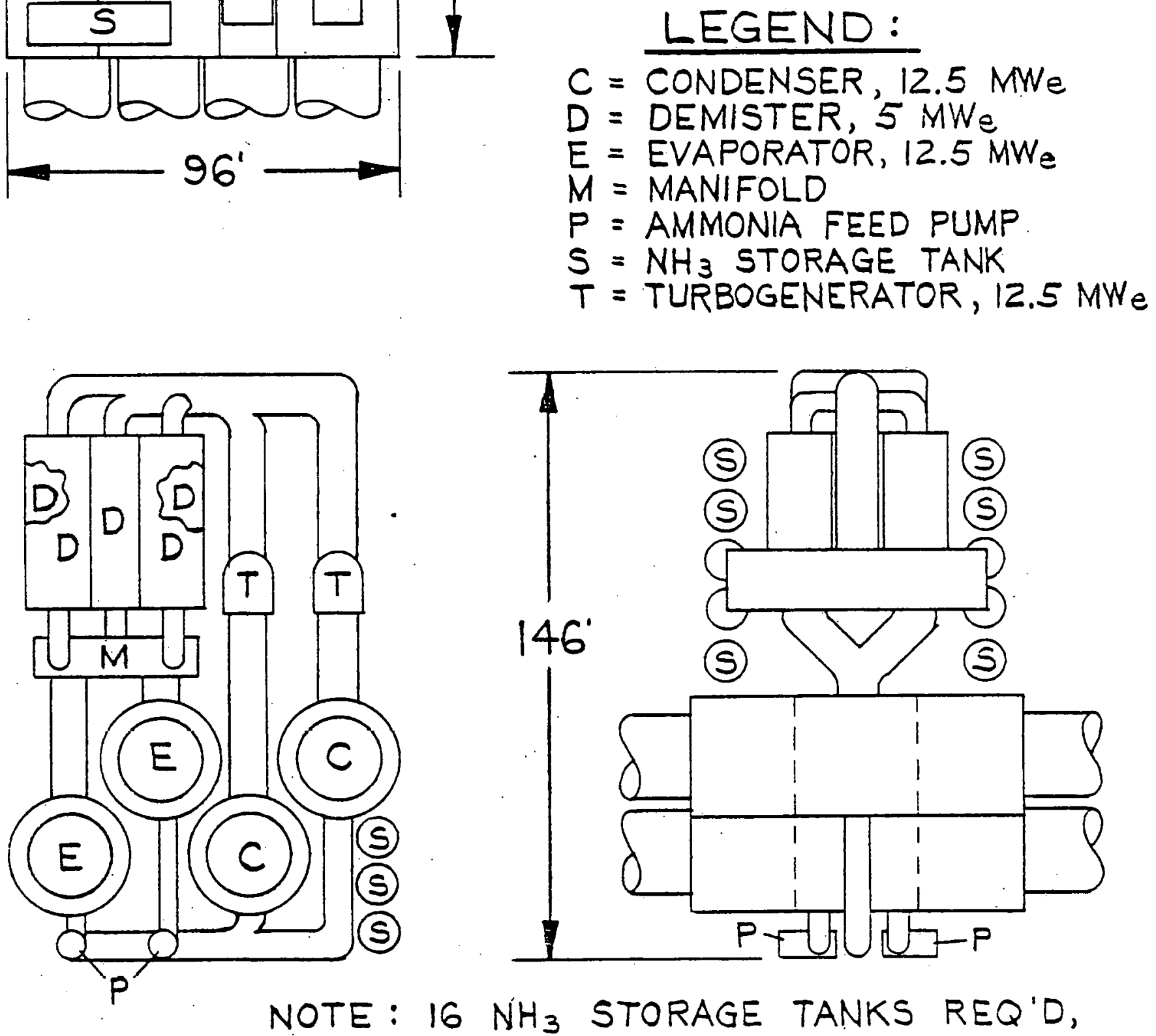

\section{NOTE: $16 \mathrm{NH}_{3}$ STORAGE TANKS REQ'D, NOT FULLY SHOWN IN ALL VIEWS.}

Fig. 2-6 Packaged 25-MW(e) Net Power System. Units are 12-1/2 MWV(e) net. 


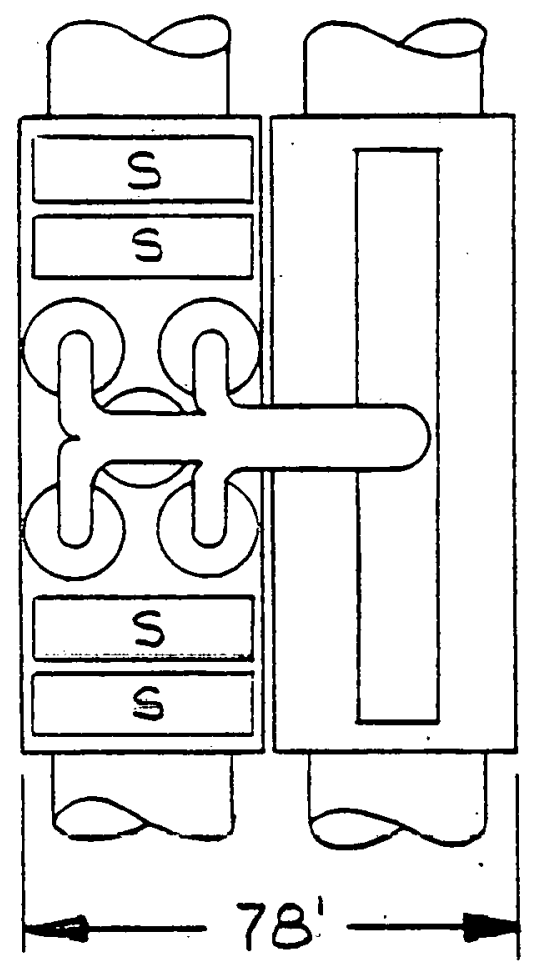

SCALE : 1" $=40^{\prime}$

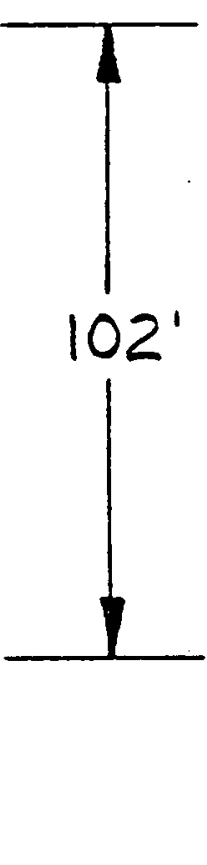

$C=\frac{\text { LEGEND: }}{\text { CONDENSER , } 25 \mathrm{MWe}}$

$D=$ DEMISTER, $5 \mathrm{MWe}$

$E=$ EVAPORATOR, $25 \mathrm{MWe}$

$T=$ TURBOGENERATOR, $25 \mathrm{MWe}$

$P=A M M O N I A$ FEED PUMP

$S=\mathrm{NH}_{3}$ STORAGE TANK
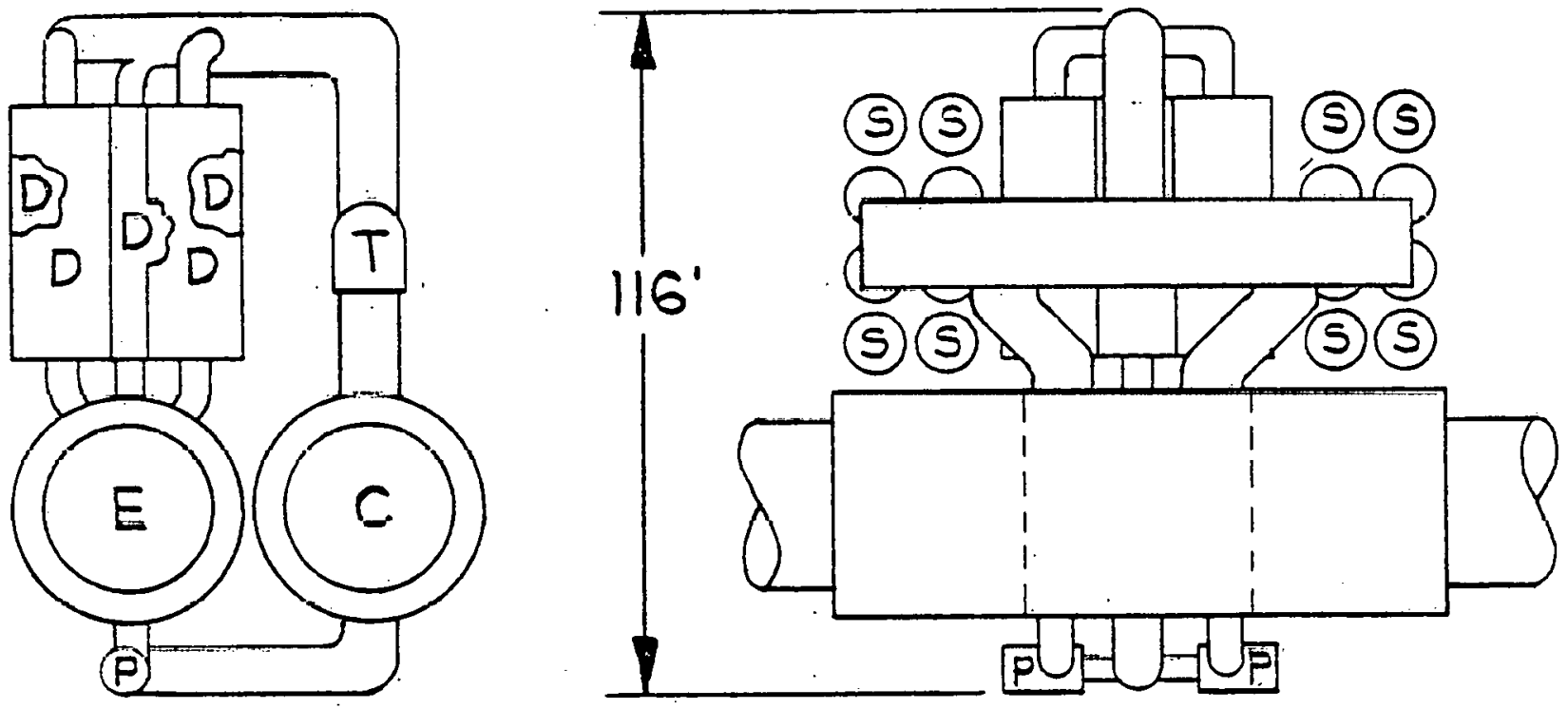

NOTE: $16 \mathrm{NH}_{3}$ STORAGE TANKS REQ'D, NOT SHOWN IN ALL VIEWS.

Fig. 2-7 Packaged 25-MW(e) Net Power System. Units are $25 \mathrm{MW}(\mathrm{e})$ net 

LEGEND:
$C=$ CONDENSER, $25 \mathrm{MWe}$
$D=$ DEMISTER, $5 \mathrm{MWe}$
$E=$ EVAPORATOR, $25 \mathrm{MWe}$
$T=$ TURBOGENERATOR, $25 \mathrm{MWe}$
$P=$ AMMONIA FEED PUMP

SCALE: $1^{\prime \prime}=40^{\prime}$
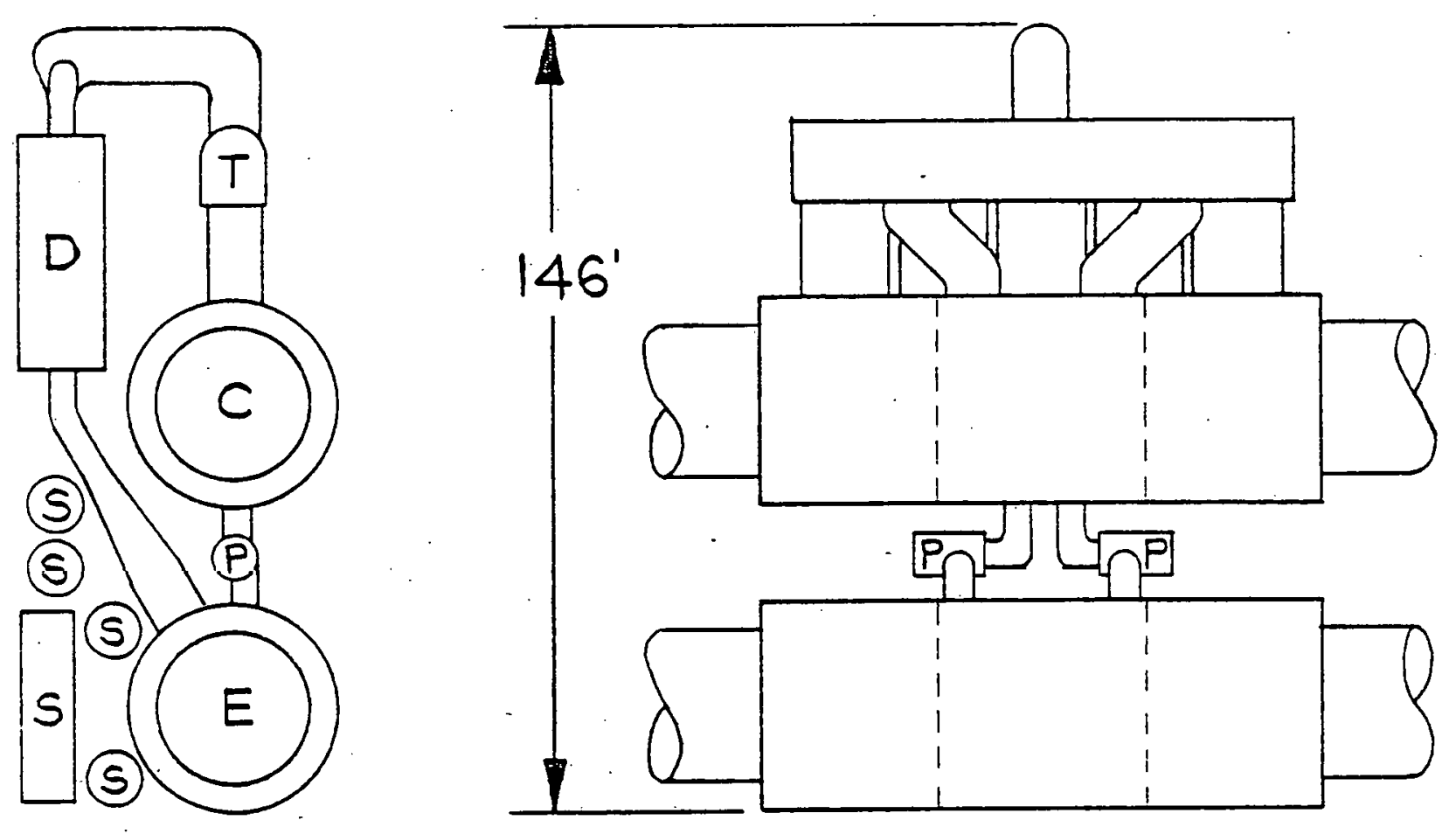

NOTE : $16 . \mathrm{NH}_{3}$ STORAGE TANKS REQ'D, NOT SHOWN IN ALL VIEWS.

Fig. 2-8 Packaged 25-MW(e) Net Power System. Units are $25 \mathrm{MW}(\mathrm{e})$ net. 
Table 2-8

CHARACTERISTICS OF POWER SYST EM MODULE - 5-MW(e) NET, INT SRNALLY MOUNTED CONVENTIONAL HORIZONTAL SHELL/TUBE HEAT EXCHANGERS

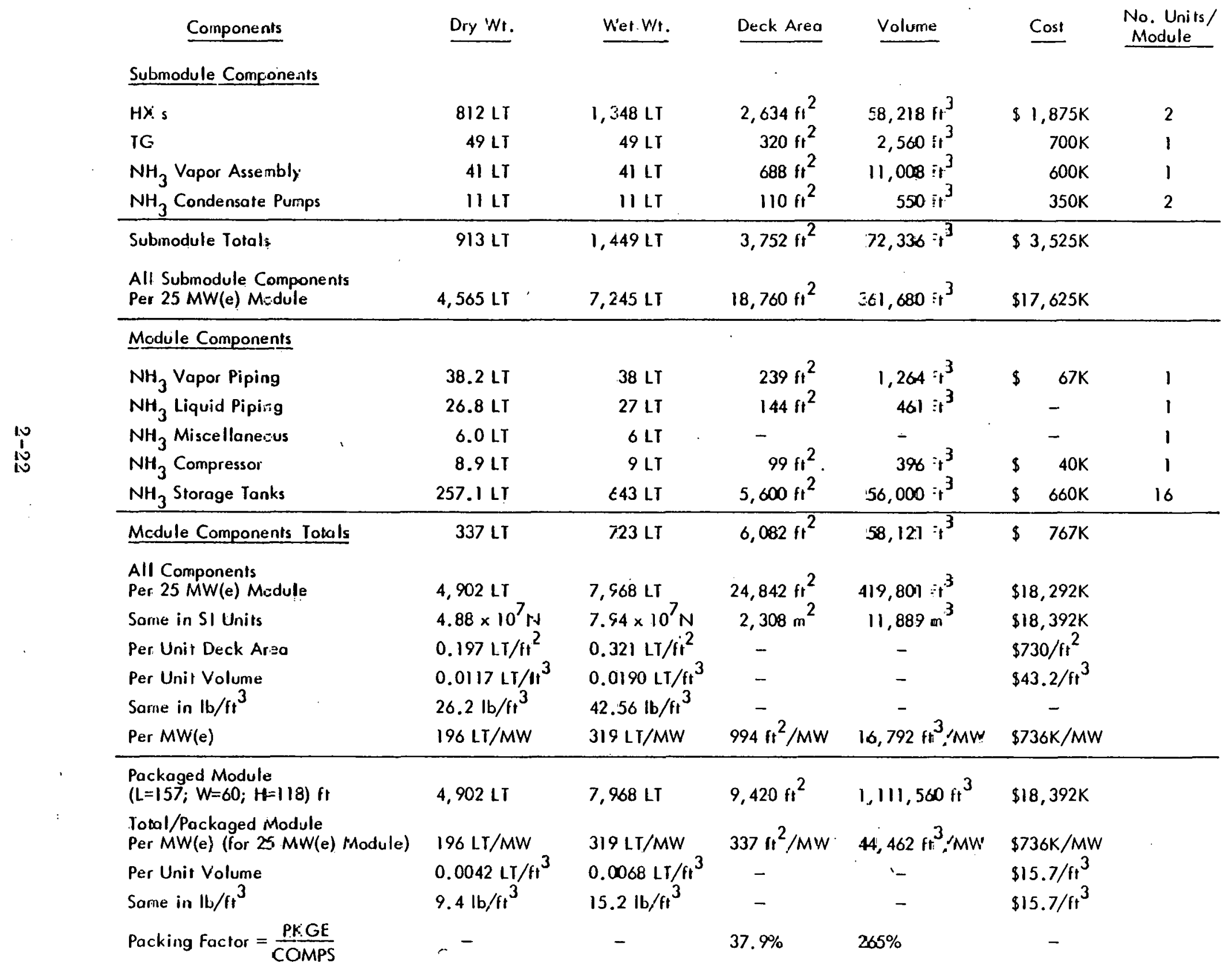


Table 2-9

CHARACTERISTICS OF POWER STYSTEM MUDULE - 8-MW(e) NET INTERNALLY MOUNTED CONVENTIONAL HÖHIZONTAT. SHELL/TUBE HEAT EXCHANGERS

$\begin{array}{lllll}\text { Components } & \text { Dry Wt. Wet Wt. Deck Area } & \text { Volume } & \text { Cost } & \begin{array}{c}\text { No. Unitsi } \\ \text { Module }\end{array}\end{array}$

Submodule Components

\begin{tabular}{|c|c|c|c|c|c|c|}
\hline$H X_{s}$ & I, $304 \mathrm{LT}$ & $2,160 \mathrm{LT}$ & $3,596 \mathrm{ft}^{2}$ & $92,790 \mathrm{ft}^{3}$ & $\$ 3,008 \mathrm{~K}$ & 2 \\
\hline TG & $81 \mathrm{LT}$ & $81 \mathrm{LT}$ & $500 \mathrm{ft}^{2}$ & $5,000 \mathrm{ft}^{3}$ & $1,060 \mathrm{~K}$ & 1 \\
\hline $\mathrm{NH}_{3}$ Vapor Assembly & $8 ! \mathrm{LT}$ & $81 \mathrm{LT}$ & $1,376 \mathrm{ft}^{2}$ & $22,016 \mathrm{ft}^{3}$ & $\mathrm{I}, 200 \mathrm{~K}$ & 2 \\
\hline Submodule Totals & $\mathrm{I}, 483 \mathrm{LT}$ & $2,339 \mathrm{LT}$ & $5,599 \mathrm{ft}^{2}$ & $120,502 \mathrm{ft}^{3}$ & $\$ 5,618 \mathrm{~K}$ & \\
\hline
\end{tabular}

Module Components

\begin{tabular}{|c|c|c|c|c|c|c|c|}
\hline $\mathrm{NH}_{3}$ Vapor Piping & $36.8 \mathrm{LT}$ & $37 ! \mathrm{T}$ & $400 \mathrm{ft}^{2}$ & $3,200 \mathrm{ft}^{3}$ & $\$$ & $75 K$ & 1 \\
\hline $\mathrm{NH}_{3}$ Liquid Piping & $25.8 \mathrm{LT}$ & $26 \mathrm{LT}$ & $300 \mathrm{ft}^{2}$ & $1,800 \mathrm{ft}^{3}$ & $\$$ & - & 1 \\
\hline $\mathrm{NH}_{3}$ Miscellaneous & $6.0 \mathrm{LT}$ & $6 \mathrm{LT}$ & - & - & & - & 1 \\
\hline $\mathrm{NH}_{3}$ Sicrage Tanks & $257.1 \mathrm{LT}$ & $643.2 \mathrm{LT}$ & $5,600 \mathrm{ft}^{2}$ & $56,000 \mathrm{ft}^{3}$ & $\$$ & $660 \mathrm{~K}$ & 16 \\
\hline Module Components Totals & $334.6 \mathrm{LT}$ & $721 \mathrm{LT}$ & $6,399 \mathrm{ft}^{2}$ & $61,396 \mathrm{ft}^{3}$ & $\$$ & $775 \mathrm{~K}$ & \\
\hline
\end{tabular}

All Components

Per 25 MW(e) Module

$4,784 \mathrm{LT} \quad 7,738 \mathrm{LT} \quad 23,196 \mathrm{ft}^{2} \quad 422,902 \mathrm{ft}^{3} \quad \$ 17,630 \mathrm{~K}$

Same in SI Units

$4.77 \times 10^{7} \mathrm{~N} \quad \cdot 7.71 \times 10^{7} \mathrm{~N} \quad 2,155 \mathrm{~m}^{2} \quad 11,977 \mathrm{~m}^{3} \quad \$ 17,630 \mathrm{~K}$

Per Unit Deck Area

Per Unit Volume

Same in $\mathrm{Ib} / \mathrm{ft}^{3}$

$0.206 \mathrm{Lr} / \mathrm{ft}^{2}$

$7.71 \times 10^{7} \mathrm{~N}$

-

$0.0133 \mathrm{LT} / \mathrm{ft}^{3}$

$29.8 \mathrm{lb} / \mathrm{ft}^{3}$

$0.0183 \mathrm{LT} / \mathrm{ft}^{3}$

$-$

$\$ 760 / \mathrm{ft}^{2}$

Per MW(e)

$111 \mathrm{LT} / \mathrm{MW}$

$41 \mathrm{lb} / \mathrm{ft}^{3}$

$-$

$310 \mathrm{LT} / \mathrm{MW}$

270

$-$

$\$ 41.7 / \mathrm{ft}^{3}$

Packaged Module

$(L=157 ; N=60 ; H=118) \mathrm{ft}$

$4,784 \mathrm{LT}$

$7,738 \mathrm{LT}$

$8,120 \mathrm{ft}^{2}$

$16,916 \mathrm{ft}^{3} / \mathrm{MW}$

$\$ 41.7 / \mathrm{ft}^{3}$

Total/Paskaged Module Per MW(e) (for 25 MW(e) Module)

Per Unil Volume

Same in $\mathrm{lb} / \mathrm{fr}^{3}$

$111 \mathrm{LT} / \mathrm{MW}$

$0.0039 \mathrm{LT} / \mathrm{ft}^{3}$

Packing Factor $=\frac{\text { PKGE }}{\text { COMPS }}$

$8.75 \mathrm{lb} / \mathrm{ft}^{3}$

$310 \mathrm{LT} / \mathrm{MW}$

$325 \mathrm{fr}^{2} / \mathrm{MW}$

$1,169,280 \mathrm{ft}^{3}$

$\$ 17,630 \mathrm{~K}$

$0.0063 \mathrm{LT} / \mathrm{f}$

$14.1 \mathrm{lb} / \mathrm{ft}^{3}$

$46,771 \mathrm{ft}^{3} / \mathrm{MW}$

$\$ 705 \mathrm{~K} / \mathrm{MW}$

$-$

$-$

$35 \%$

$276 \%$

$\$ 15.0 / \mathrm{ft}^{3}$

$\$ 15.0 / \mathrm{ft}^{3}$ 
Table 2-10

CHARACTIRISTICS CF POWER SYSTEM MODULE - 12.5-MW(e) NET INTERNALLY MOUNTED CONVENTIONAL. HORIZONTAL SHELL/TUBE HEAT EYCHANGERS

\section{Components}

Submodule Components

$\mathrm{HXs}$

TG.

$\mathrm{NH}_{3}$ Vapor Assemtly

$\mathrm{NH}_{3}$ Condensate Pumps

Submodule Totals

All Submodule Eomponerits

Per 25-MW(e) Module

Module Componenis

$\mathrm{NH}_{3}$ Vapor Piping

$\mathrm{NH}_{3}$ Liquid Piping

$\mathrm{NH}_{3}$ Miscellañeous

$\mathrm{NH}_{3}$ Compressor

$\mathrm{NH}_{3}$ Storage ronks

Module Components Totals

All Components

Per 25 MW(e) Module

Some in SI Units

Per Unit Deck Area

Per Unit Volumie

Same in $\mathrm{lb} / \mathrm{fr}^{3}$

Per MW(e)

Pockaged Module

$(I=157 ; W=60 ; \mathrm{H}=118) \mathrm{ft}$

Total/Packaged Module

Per MW(e) (for 25 .MW(e: Madule)

Per. Unit Volune

Same in $\mathrm{lb} / \mathrm{ft}^{3}$

Packing Factor $=\frac{\text { PKGE }}{\text { COMPS }}$
Dri wis.

Net Wt.

Deck Area

$\underline{\text { Volume }}$

Cost No. Units

\begin{tabular}{rrrrrr}
$2,063 \mathrm{LT}$ & $3.386 \mathrm{LT}$ & $4,854 \mathrm{ft}^{2}$ & $145,020 \mathrm{ft}^{3}$ & $\$ 4,461 \mathrm{~K}$ & 2 \\
$123 \mathrm{LT}$ & $123 \mathrm{LT}$ & $768 \mathrm{ft}^{2}$ & $9,2 \mathrm{io} \mathrm{ft}$ & $1,850 \mathrm{~K}$ & 1 \\
$122 \mathrm{LT}$ & $122 \mathrm{LT}$ & $2,064 \mathrm{ft}^{2}$ & $33,02 \mathrm{ft}^{3}$ & $1,800 \mathrm{~K}$ & 3 \\
$21 \mathrm{LT}$ & $21 \mathrm{LT}$ & $176 \mathrm{ft}^{2}$ & $1,14 \mathrm{i} \mathrm{f}^{3}$ & $565 \mathrm{~K}$ & 2 \\
\hline $2,302 \mathrm{LT}$ & $3.652 \mathrm{LT}$ & $7,862 \mathrm{ft}^{2}$ & $189,00 \mathrm{ft}^{3}$ & $\$ 8,678 \mathrm{~K}$ & \\
& & & & & \\
$4,602 \mathrm{LT}$ & $7.304 \mathrm{LT}$ & $15,724 \mathrm{ft}^{2}$ & $378,002 \mathrm{ft}^{3}$ & $\$ 17,355 \mathrm{~K}$
\end{tabular}

\begin{tabular}{|c|c|c|c|c|}
\hline 4,934 LIT & $8.022 \mathrm{LT}$ & $22,288 \mathrm{ft}^{2}$ & $441.97 \mathrm{Ft}^{3}$ & $\$ 18,335 K$ \\
\hline $4.92 \times 10^{7} \mathrm{v}$ & $7.99 \times 10^{7} \mathrm{~N}$ & $2,070 \mathrm{~m}^{2}$ & $12,51 ? n^{3}$ & $\$ 18,135 K$ \\
\hline $0.221 \mathrm{LT} / \mathrm{f}^{2}$ & $0.360 \mathrm{LT} / \mathrm{ft}^{2}$ & - & - & $\$ 814 / \mathrm{r}^{2}$ \\
\hline $0.1121 \mathrm{~T} / \mathrm{K}^{3}$ & $0.182 \mathrm{LT} / \mathrm{ft}^{3}$ & - & - & $\$ 41 / \mathrm{ft}^{3}$ \\
\hline $25.1 \mathrm{lb} /$ it $^{3}$ & $40.8 \mathrm{lb} / \mathrm{ft}^{3}$ & - & - & $\$ 41 / \mathrm{ft}^{3}$ \\
\hline 197 LTAMN & $321 \mathrm{LT} / \mathrm{MW}$ & $892 \mathrm{ft}^{2} / \mathrm{MW}$ & $17,679 \mathrm{fi}^{3} / \mathrm{NiW}$ & $\$ 725 \mathrm{~K} / \mathrm{MW}$ \\
\hline $4,934 \cup T$ & $8.022 \mathrm{LT}$ & $11,826 \mathrm{ft}^{2}$ & $1,135,29.0 \mathrm{ft}^{3}$ & $\$ 18,135 K$ \\
\hline 197 LT'MN' & $321 \mathrm{LT} / \mathrm{MW}$ & $473 \mathrm{ft}^{3} / \mathrm{MW}$ & $45,412 \mathrm{fi}^{3} / \mathrm{NiW}$ & $\$ 725 \mathrm{~K} / \mathrm{MW}$ \\
\hline $0.0041 \mathrm{LT} / \mathrm{t}^{3}$ & $0.0067 \mathrm{LT} / \mathrm{ft}^{3}$ & - & - & $\$ 15.2 / \mathrm{fr}^{3}$ \\
\hline $9.18 \mathrm{lt} / \mathrm{ft}^{3}$ & $15.0 \mathrm{lb} / \mathrm{ft}^{3}$ & - & - & $\$ 15.2 / \mathrm{ft}^{3}$ \\
\hline
\end{tabular}


Table 2-11

CHARACTERISTICS CF POWER SYSTEM MODULE - 25-MW(c) NET INTERNALLY MOUNTED CONVENTIONAL HORIZONTAL SHELL/TUBE HEAT EXCHANGERS

Components Dry Wr. Wet Wt. Deck Area Volume $\underline{\text { Cost }}$ Module

Submodule Components

\begin{tabular}{|c|c|c|c|c|c|c|}
\hline$H X_{s}$ & $4,062 \mathrm{LT}$ & $6,742 \mathrm{LT}$ & $7,690 \mathrm{ft}^{2}$ & $289,944 \mathrm{ft}^{3}$ & $\$ 8,675 \mathrm{~K}$ & 2 \\
\hline TG & $202 \mathrm{LT}$ & $202 \mathrm{LT}$ & $1,104 \mathrm{ft}^{2}$ & $13,248 \mathrm{ft}^{3}$ & $3,200 \mathrm{~K}$ & 1 \\
\hline $\mathrm{NH}_{3}$ Vapor Assembly & $203 \mathrm{LT}$ & $203 \mathrm{LT}$ & $3,440 \mathrm{ft}^{2}$ & $55,040 \mathrm{ft}^{3}$ & $3,000 K^{\prime}$ & 5 \\
\hline $\mathrm{NH}_{3}$ Condensate Pumps & $25 \mathrm{LT}$ & $25 \mathrm{LT}$ & $182 \mathrm{ft}^{2}$ & $1,274 \mathrm{ft}^{3}$ & $350 \mathrm{~K}-$ & 2 \\
\hline Submodule Touals & 4, $492 \mathrm{LT}$ & $7,172 \mathrm{LT}$ & $12,416 \mathrm{ft}^{2}$ & $395,506 \mathrm{ft}^{3}$ & $\$ 15,225 \mathrm{~K}$ & \\
\hline $\begin{array}{l}\text { All Submodule Components } \\
\text { Per } 25 \mathrm{MW}(\mathrm{e}) \text { Module }\end{array}$ & 4, 492 LT & $7,172 \mathrm{LT}$ & $12,416 \mathrm{ft}^{2}$ & $395,506 \mathrm{ft}^{3}$ & $\$ 15,225 K$ & \\
\hline
\end{tabular}

Module Components

\begin{tabular}{|c|c|c|c|c|c|c|}
\hline $\begin{array}{l}\mathrm{NH}_{3} \text { Vapor Piping } \\
\mathrm{NH}_{3} \text { Liquid Piping } \\
\mathrm{NH}_{3} \text { Miscellaneous } \\
\mathrm{NH}_{3} \text { Compress or } \\
\mathrm{NH}_{3} \text { Storage Tanks }\end{array}$ & $\begin{array}{r}37 \mathrm{LT} \\
21 \mathrm{LT} \\
4 \mathrm{LT} \\
9 \mathrm{LT} \\
257 \mathrm{LT} \\
\end{array}$ & $\begin{array}{r}37 \mathrm{LT} \\
21 \mathrm{LT} \\
4 \mathrm{LT} \\
9 \mathrm{LT} \\
643 \mathrm{LT} \\
\end{array}$ & $\begin{array}{r}660 \mathrm{ft}^{2} \\
540 \mathrm{ft}^{2} \\
-\quad \\
99 \mathrm{ft}^{2} \\
5,600 \mathrm{ft}^{2} \\
\end{array}$ & $\begin{array}{l}7,260 \mathrm{ft}^{3} \\
4,860 \mathrm{ft}^{3} \\
- \\
396 \mathrm{ft}^{3} \\
56,000 \mathrm{ft}^{3} \\
\end{array}$ & 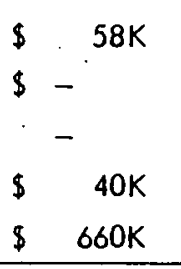 & $\begin{array}{r}1 \\
1 \\
1 \\
1 \\
16\end{array}$ \\
\hline Module Components Totals & 328 LT & $7 / 4$ LT & $6,899 \mathrm{ft}^{2}$ & $68,516 \mathrm{ft}^{3}$ & $\$ 758 K$ & \\
\hline $\begin{array}{l}\text { All Componenis } \\
\text { Per } 25 \mathrm{MiW}(\mathrm{e}) \text { Module }\end{array}$ & $4,820 \mathrm{LT}$ & $7,886 \mathrm{LT}$ & $19,315 \mathrm{ft}^{2}$ & $464,022 \mathrm{ft}^{3}$ & $\$ 15,983 \mathrm{~K}$ & \\
\hline Some in SI Units & $4.85 \times 10^{7} \mathrm{~N}$ & $7.86 \times 10^{7} \mathrm{~N}$ & $1.794 m^{3}$ & $13,141 \mathrm{~m}^{3}$ & $\$ 15,983 \mathrm{~K}$ & \\
\hline Per Unit Deck Area & $0.250 \mathrm{LT} / \mathrm{ft}^{2}$ & $0.408 \mathrm{LT} / \mathrm{ft}^{2}$ & - & - & $\$ 827 / \mathrm{ft}^{2}$ & \\
\hline Per Unit Volume & $0.0103 \mathrm{LT} / \mathrm{ft}^{3}$ & $0.0170 \mathrm{LT} / \mathrm{ft}^{3}$ & - & - & $\$ 34.4 / \mathrm{fr}^{3}$ & \\
\hline Same in $\mathrm{b} / \mathrm{ft}$ & $23.1 \mathrm{lb} / \mathrm{ft}^{3}$ & $38.1 \mathrm{lb} / \mathrm{ft}^{3}$ & - & - & - & \\
\hline $\operatorname{Per} M W(e)$ & $193 \mathrm{LT} / \mathrm{MW}$ & $315 \mathrm{LT} / \mathrm{MW}$ & $773 \mathrm{ft}^{2} / \mathrm{MW}$ & $18,561 \mathrm{fr}^{3} / \mathrm{MW}$ & $\$ 639 \mathrm{~K} / \mathrm{MW}$ & \\
\hline $\begin{array}{l}\text { Packaged Module } \\
(L=157 ; W=60 ; H=118) \mathrm{ft}\end{array}$ & $4,820 \mathrm{LT}$ & $7,886 \mathrm{LT}$ & $7,956 \mathrm{ft}^{2}$ & $922,896 \mathrm{ft}^{3}$ & \multicolumn{2}{|l|}{$\$ 15 ; 983 K$} \\
\hline $\begin{array}{l}\text { Total/Pa:kaged Module } \\
\text { Per MW( }=\text { (for } 25 \mathrm{MW}(e) \text { Module) }\end{array}$ & $193 \mathrm{LT} / \mathrm{MW}$ & $315 \mathrm{LT} / \mathrm{MW}$ & $318 \mathrm{LT} / \mathrm{MW}$ & $36,916 \mathrm{fr}^{3}$ & \multirow{3}{*}{\multicolumn{2}{|c|}{$\begin{array}{l}\$ 639 \mathrm{~K} / \mathrm{MW} \\
\$ 16.4 / \mathrm{ft}^{3} \\
\$ 16.4 / \mathrm{ft}^{3}\end{array}$}} \\
\hline Per Unit Volume & $0.0049 \mathrm{LT}_{3} / \mathrm{ft}^{3}$ & $0.0081 \mathrm{LT} / \mathrm{ft}^{3}$ & - & . $\quad-$ & & \\
\hline Same in $\mathrm{lb} / \mathrm{ft}^{\mathrm{J}}$ & $11 \mathrm{lb} / \mathrm{ft}^{\mathrm{O}}$ & $18.1 \mathrm{lb} / \mathrm{ft}^{3}$ & - & - & & \\
\hline Packing Fuctor $=\frac{P K G E}{\text { COMPS }}$ & - & - & $41.2 \%$ & $199 \%$ & - & \\
\hline
\end{tabular}


In order to correctly interpret these tables, it is desirable to clarify definitions of several key elements. These are as follows:

- Sub-Module Components - These are the Power System components which vary in size, weight, and/or cost with the size of the heat exchanger.

- Module Components - These are the components which are fixed for a 25-MW(e) Power System and independent of the heat exchanger employed.

- Packaged Module - This is the envelope generated through "optimum" arrangement of Power System components.

The data are presented in terms of sub-module components and totals first followed by module components and the cumulative totals for a 25-MW(e) module. The data set at the bottom of the table sizes and costs the packaged module, using the dimensions called out in the brackets. It is interesting to note that sizes, weights, and costs do, not vary markedly between the 5, 8, 12-1/2, and $25 \mathrm{MW}(\mathrm{e})$ sub-module packages; but in general the 25-MW(e) package employing 25-MW(e) heat exchangers tends to be the smallest, lightest, and least costly.

\subsubsection{Alternative Power Systems.}

(a) Vertical Heat Exchangers

The data supplied in Table 2-7 for verlical heat exchangers was uscd to generate a set of tables similar to 2-8 to 2-11 inclusive. Again, although the 25-MW(e) heat exchanger module is lightest and smallest, the improvement over the 5,8, and $12-1 / 2$ MWV(e) heat exchanger modules is not dramatic. (See Tables $2-1 \%$ to $2-15$ inclusive). In comparing these tables with those for the horizontal heat exchanges, it is apparent that the latter are lairger and heavier than the vertical.

(b) Detachable Modules

Up to this point the heat exchangers under discussion have been internal to the platform. Certain configurations, particularly the Spar, are most cost-effective when coupled with detachable module Power Systems having external heat exchangers. 
A summary of the analysis performed in support of detachable modules is presented below.

(a). $500 \mathrm{MW}(\mathrm{e})$ Plant Configuration

Two types of external power modules are presented as typical of 500-MW(e) designs resulting from the given set of components. The considerations which most strongly influence the design are:

- Reasonable seawater routing through the platform and power module, i.e., most direct path, minimum resistance, and minimum structure for seawater ducting

- Reasonable ammonia vapor routing, i.e., minimum duct length and minimum bends. Mist extractor requirements force compromises on this objective

- Structural integrity and producibility

- Towability

- Maintainability through ready access to maintained components

- Minimum recirculation of evaporator efflux back to warm water inlet

The requirements lead to an axisymmetric arrangement with ten wedge shaped power module stations positioned radially around the control platform core. Two 25-MW(e) capacity power modules, or a single dual 50-MW(e) capacity power module, are fitted into each station. This dictates a slender vertical arrangement within the power module. The baseline arrangement uses 20 each of the 25-MW(e)-size horizontal cylindrical evaporators and condensers. Alternative arrangements, using vertical cylindrical heat exchangers, or spherical heat exchangers of either orientation, are discussed briefly.

Two power modules with horizontal cylindrical 25-MW(e) heat exchangers were configured - one type with a single evaporator and condenser, the other a dual 50-MW(e) capacity module with one pair each of evaporators and condensers. Platform layouts suitable for each type are presented. In addition, two vertical heat exchanger modules were sketched to illustrate the effect of this arrangement on platform design. 
Table 2-12

CHARACTERISTICS OF POWER SYS TEM MODULE - 5-MW(e) NET INTERNALLY MOUNTED CONVENTIONAL VERTICAL SHELL/TUBE HEAT EXCHIANGERS

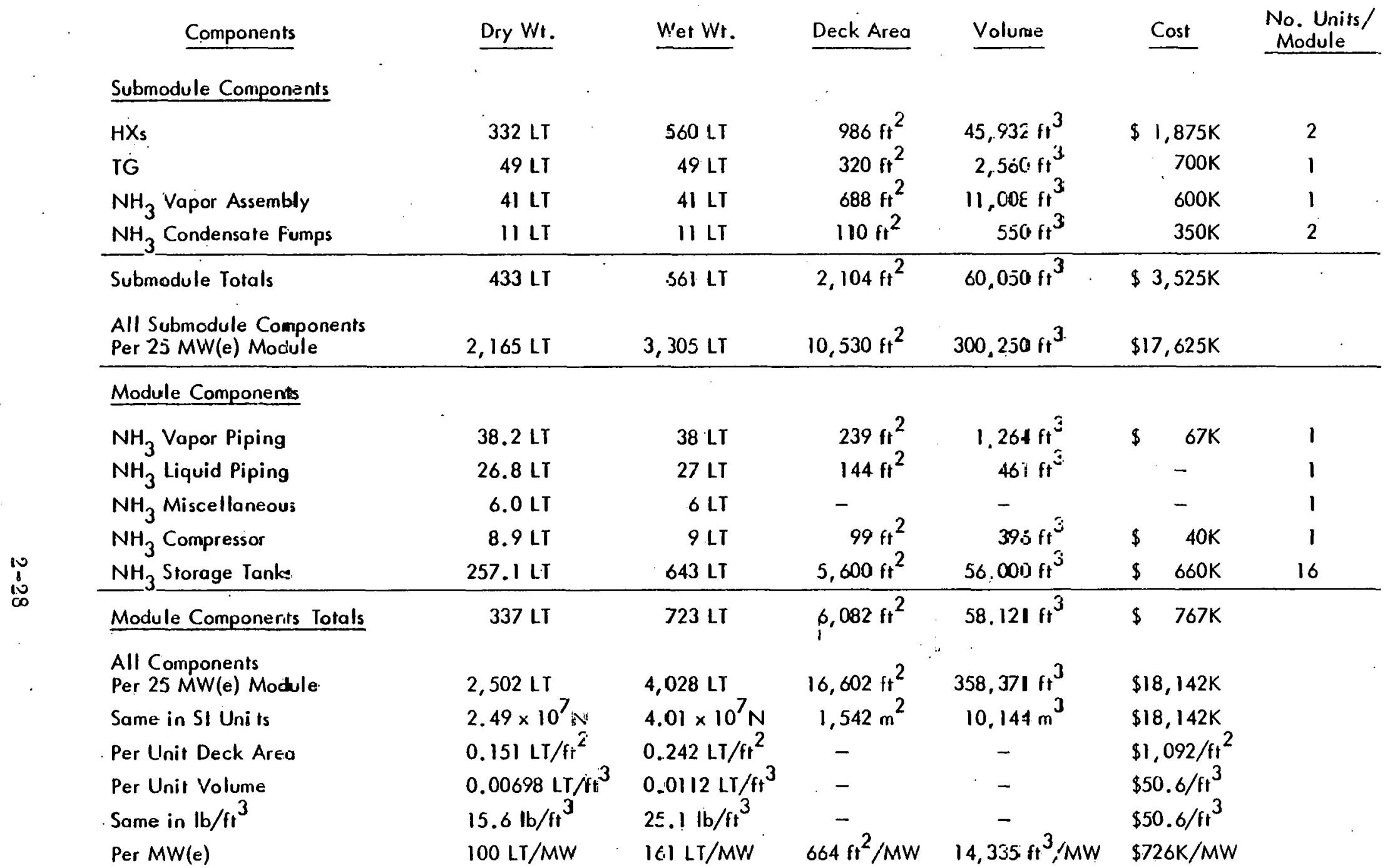


Table 2-13

CHLARACTERISTICS OF POWER SYSTEM MODULE-8-MW(e) NET INTERNALLY MOUNTED CONVENTIONAL VERTICAL SHELL/TUBE HEAT EXCHANGERS

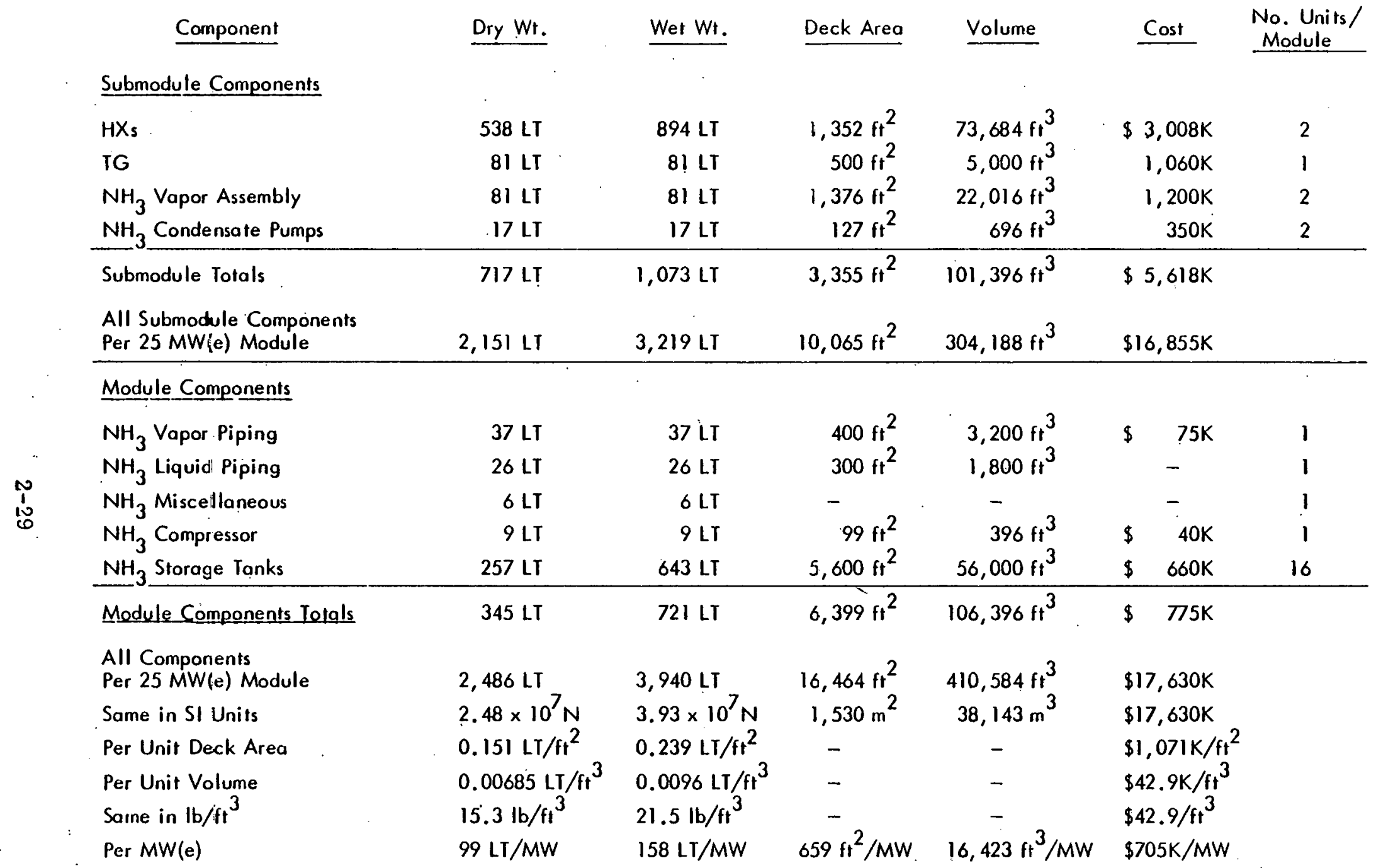


Table 2-14

CHAIRACTERISTICS OF POWER SYSTEM MODULE - 12.5-MW(ei NET INTERNALLY MOUNTED CONVENTIONAL VERTICAL SHELL,TUBE HEAT EXCHANGERS

\begin{tabular}{|c|c|c|c|c|c|c|}
\hline Component & Dry Wt. & Wet Wt. & Deck Area & Volume & Cost & $\begin{array}{l}\text { No. Units/ } \\
\text { Module }\end{array}$ \\
\hline \multicolumn{7}{|l|}{ Submodule Composents } \\
\hline$H X_{s}$ & $844 \mathrm{LT}$ & 1,402 LT & $1,812 \mathrm{ft}^{2}$ & $114,70 \mathrm{gt} \mathrm{ft}^{3}$ & $\$ 4,461 \mathrm{~K}$ & 2 \\
\hline TG & $123 \mathrm{LT}$ & $123 \mathrm{LT}$ & $768 \mathrm{ft}^{2}$ & $9,21 \leq \mathrm{fl}^{3}$ & $1,850 \mathrm{~K}$ & $\mathbf{l}$ \\
\hline $\mathrm{NH}_{3}$ Vapor Assembly & $122 \mathrm{LT}$ & $122 \mathrm{LT}$ & $2,064 \mathrm{fi}^{2}$ & $33, \mathrm{C} 24 \mathrm{ft}^{3}$ & $1,800 K$ & 3 \\
\hline $\mathrm{NH}_{3}$ Condensate Fumps & $21 \mathrm{LT}$ & $21 \mathrm{LT}$ & $176 \mathrm{ft}^{2}$ & $1,14 \pi \mathrm{ft}^{\mathrm{J}}$ & $565 K$ & 2 \\
\hline Submodule Tolals & $1,110 \mathrm{LT}$ & $1,668 \mathrm{LT}$ & $4,820 \mathrm{ft}^{2}$ & $158, \mathrm{col} \mathrm{ft}^{3}$ & $\$ 8,678 \mathrm{~K}$ & \\
\hline $\begin{array}{l}\text { All Submodule Campanents } \\
\text { Per } 25 \mathrm{MW}(\mathrm{e}) \text { Module }\end{array}$ & $2,220 \mathrm{LT}$ & $3,336 \mathrm{LT}$ & $9,640 \mathrm{ft}^{2}$ & $316,162 \mathrm{ft}^{3}$ & $\$ 17,355 \mathrm{~K}$ & \\
\hline
\end{tabular}

Module Components

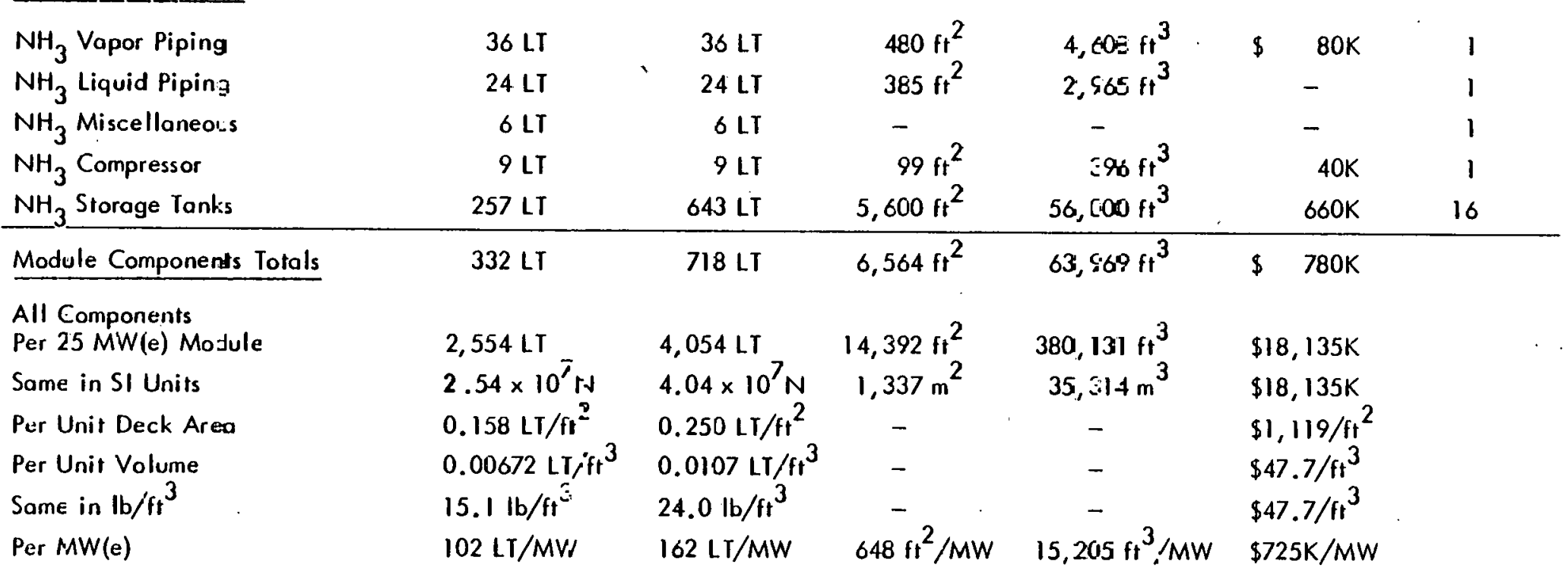


Table 2-15

CHARACTERISTICS OF POWER SYSTEM MODULE - 25-MW(e) NET INTERNALLY MOUNTED CONVENTIONAL VLRTICAL SHELL/TUBE HEAT EXCHANGERS

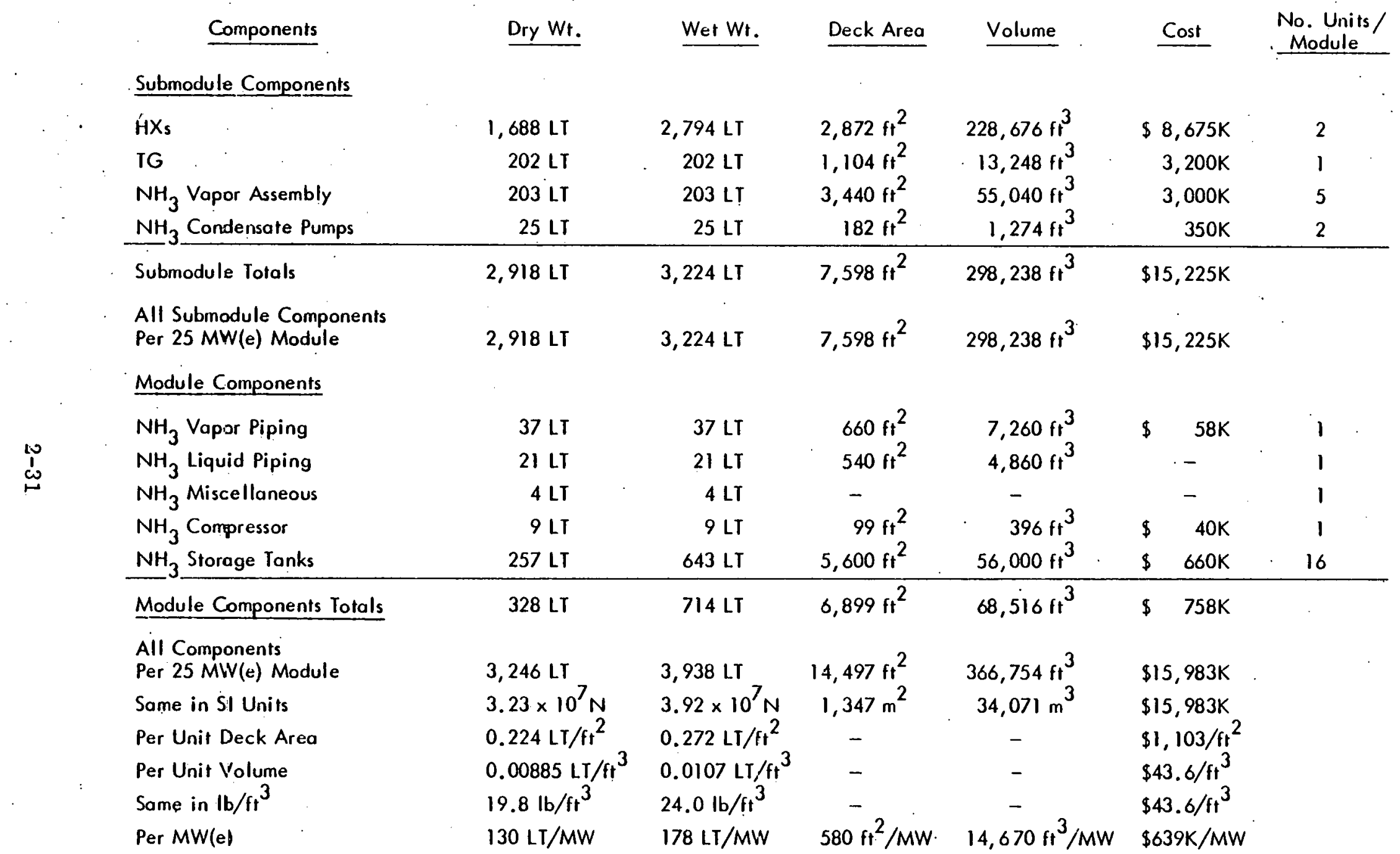




\section{(1) 25-MW(e) Power Module}

This arrangement has the required slender configuration and provides the most compact and direct routing of ammonia vapor. However, it requires interlacing of seawater delivery paths since the locations of evaporator and condenser are inverted relative to the thermal gradient, as shown in Fig. 2-9.

25 MW(e) POWER

SYSTEM MODULE.

20 EACH ATTACHED AROUND

CORE IN TWO LEVELS OF 10
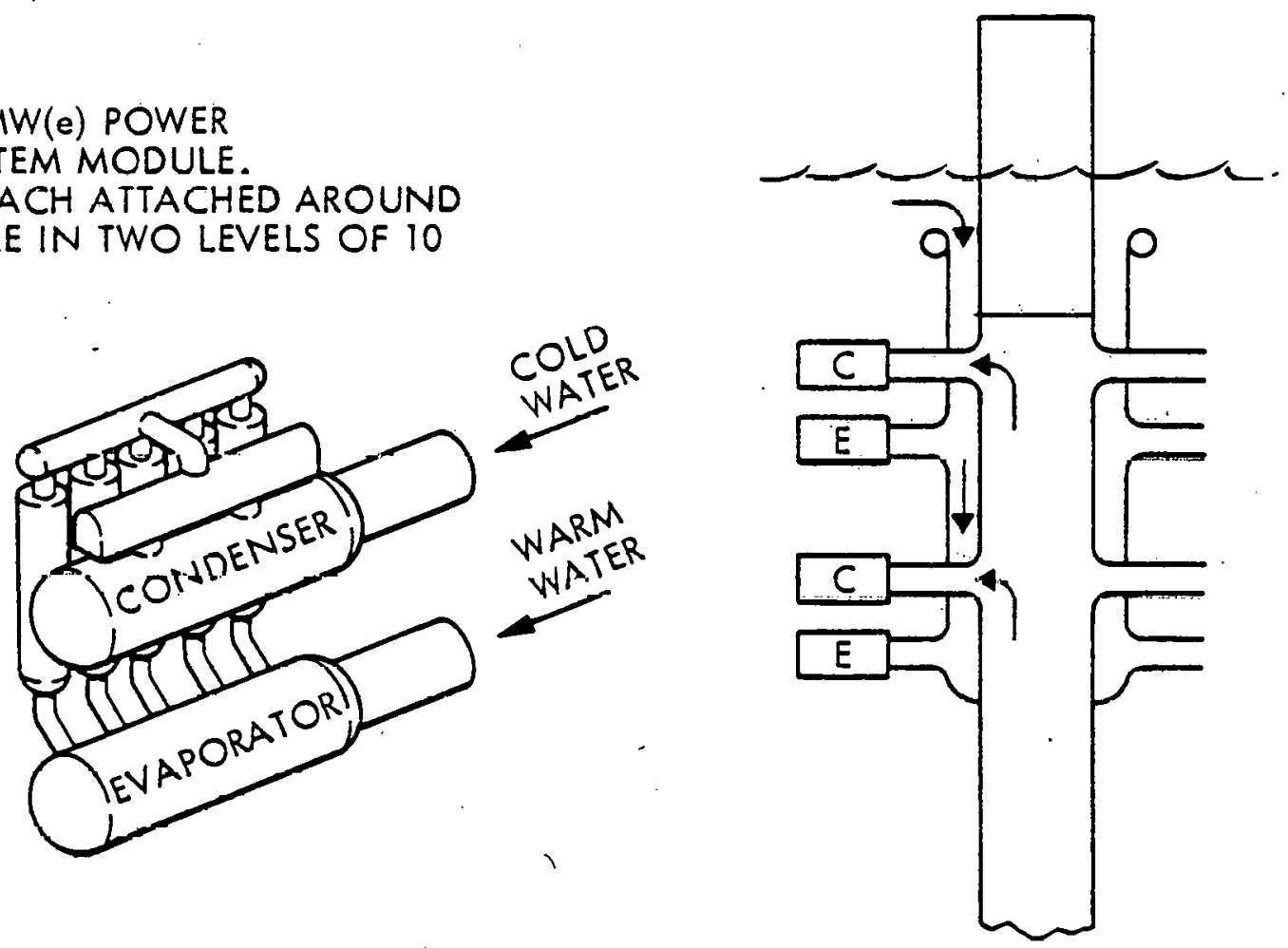

a. Component layout

' b. Spar buoy platform arrangement and seawater flow routing

Fig. 2-9 25-MWV(e) Power Module Application 
The seawater routing requirement is accommodated by the arrangement shown on the right. The advantages $(+)$ and disadvantages $(-)$ of this arrangement are:

- Requires more platform structure than equivalent non-inverted power module (-).

- Has higher seawater flow losses (-)

- Is adaptable to any arrangement of heat exchangers $(+)$

- May reduce recirculation through interactions of heat exchanger effluxes in inverted locations $(+)$

No structural interconnections, buoyancy requirements, or deployment considerations have been worked out for this power module. However, no difficulties in these areas are foreseen.

(2) 50-MW(e), Dual-25 Power Module Application

The 50-MW(e) dual-25. power module is shown in Fig. 2-10. The considerations leading to this arrangement are:

- Slender profile to allow close packing around control core

- Most direct seawater routing

- Acceptable configuration for towing

- Turbogenerators and pumps contained within pressure hulls for manned access

- Feasibility of direct structural interconnection of components

- Directness of ammonia flow paths compromised in favor of other objectives

A suggestcd structural concept is shown in Fig. 2-11. The cylindrical modules can be fabricated in a relatively shallow protected site and floated to deeper water for assembly. Assembly is done sequentially with all work taking place at or near the surface, the spar buoy being gradually submerged as the vertical stacking of modules proceeds.

This arrangement is adaptable to a variety of power module layouts. It provides space in the central core or in a "top-hat" above the waterline for manned and process equipment spaces. Alternatively, the spar can be completely passive, containing only buoyancy spares, seawater ducting, and mooring. 


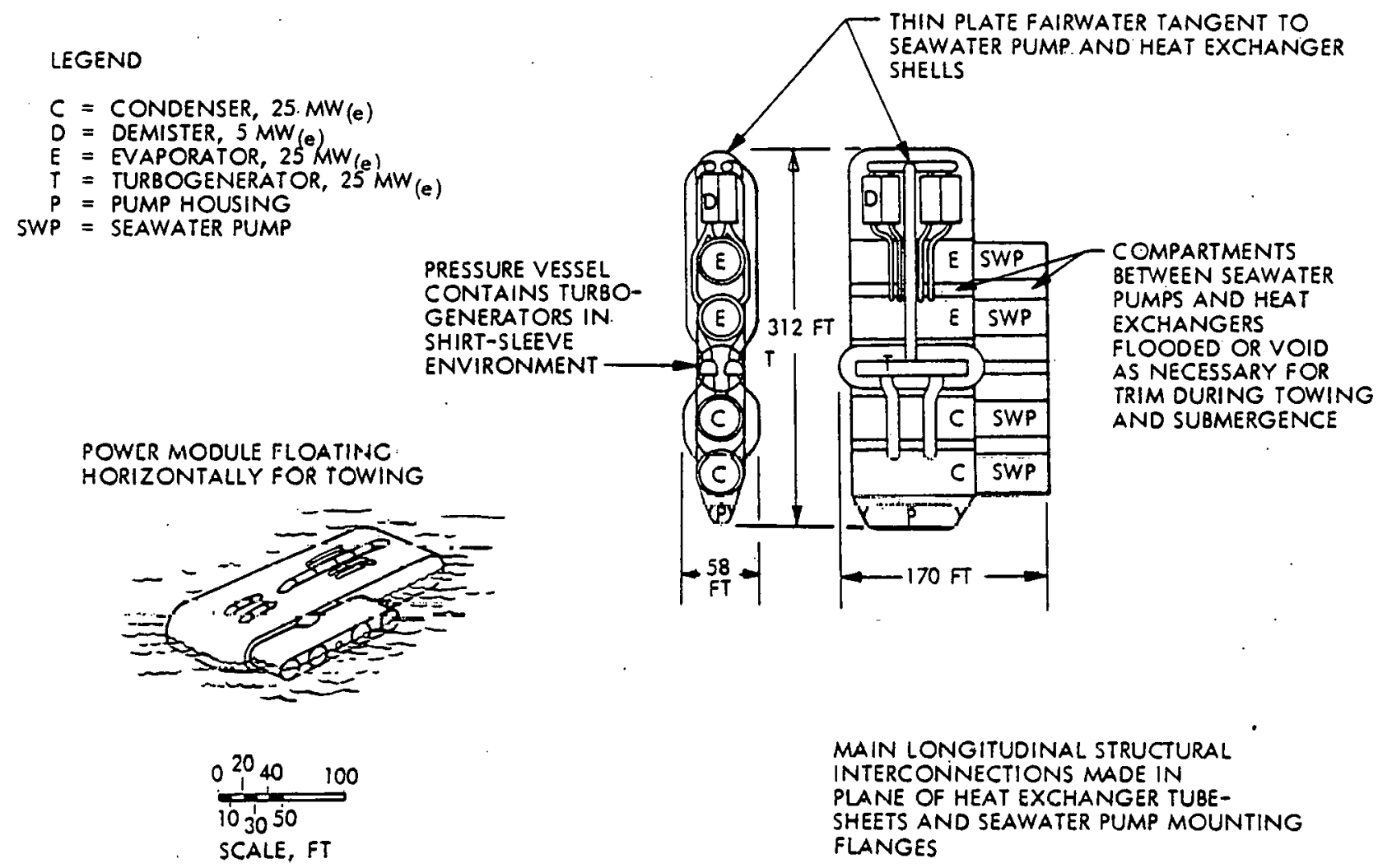

Fig. 2-10 50-MW(e) Net External Power System Module.

Units are 25-MW(e) net horizontal

(3) Vertical Heat Exchanger Power Modules

Layouts were prepared for $50 \mathrm{MW}(\mathrm{e})$ dual-25 power modules with vertical heat exchangers. Figure 2-12 shows the cylindrical type as described in Table 2-7.

- Places equipment at a greater depth, particularly cold seawater pumps (-)

- Heat exchanger inlets and outlets in most advantageous orientation to avoid rooiroulation $(+)$

- Component arrangement lends itself to power module structural integrity and a good towing configuration $(+)$

- The platform contains no warm seawater ducting so may be reduced to the ultimate simplicity - a cold water pipe and buoyancy tank $(+)$ 


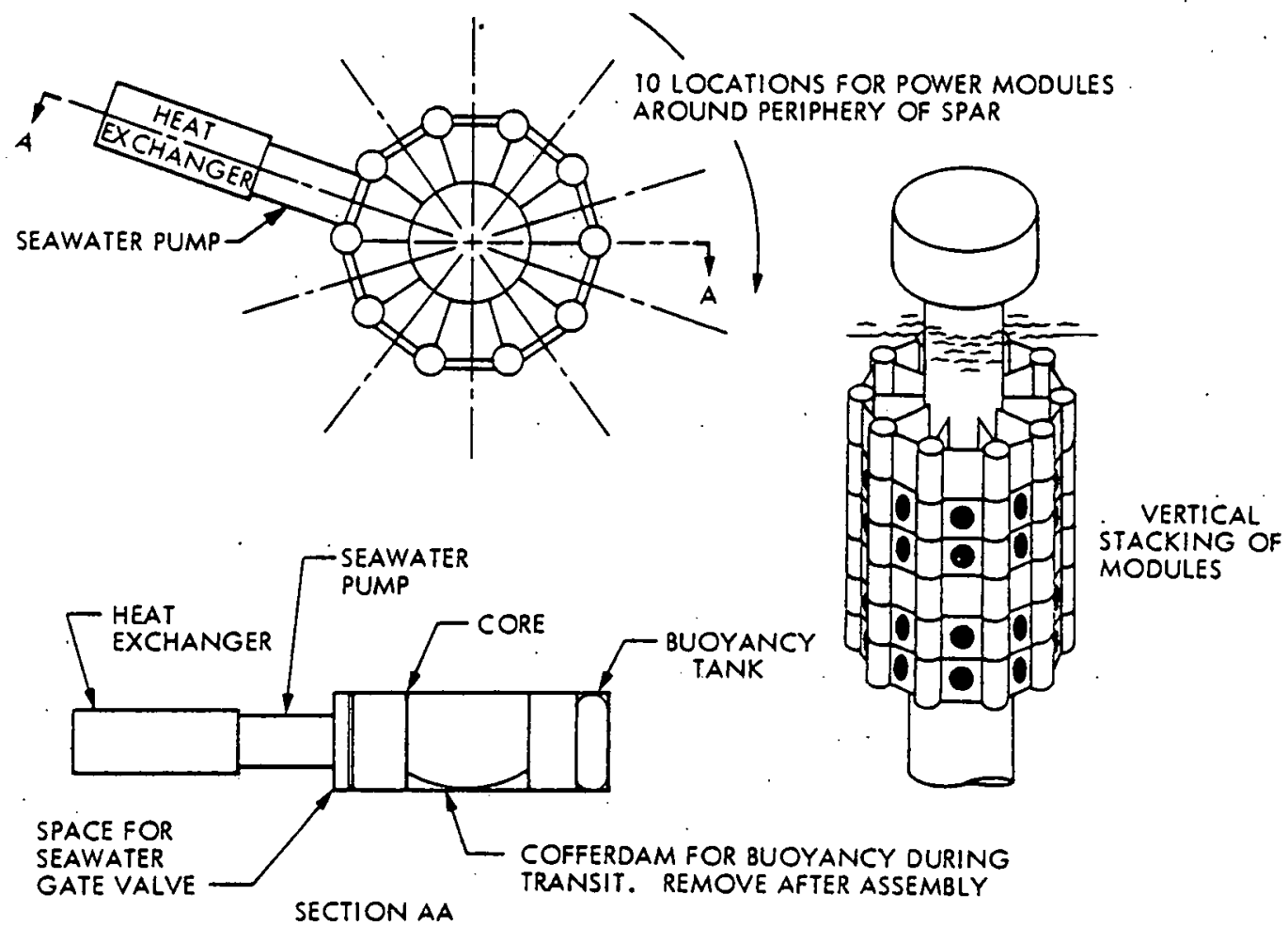

Fig. 2-11 500-MW(e) Spar With External Power Modules Modular Construction

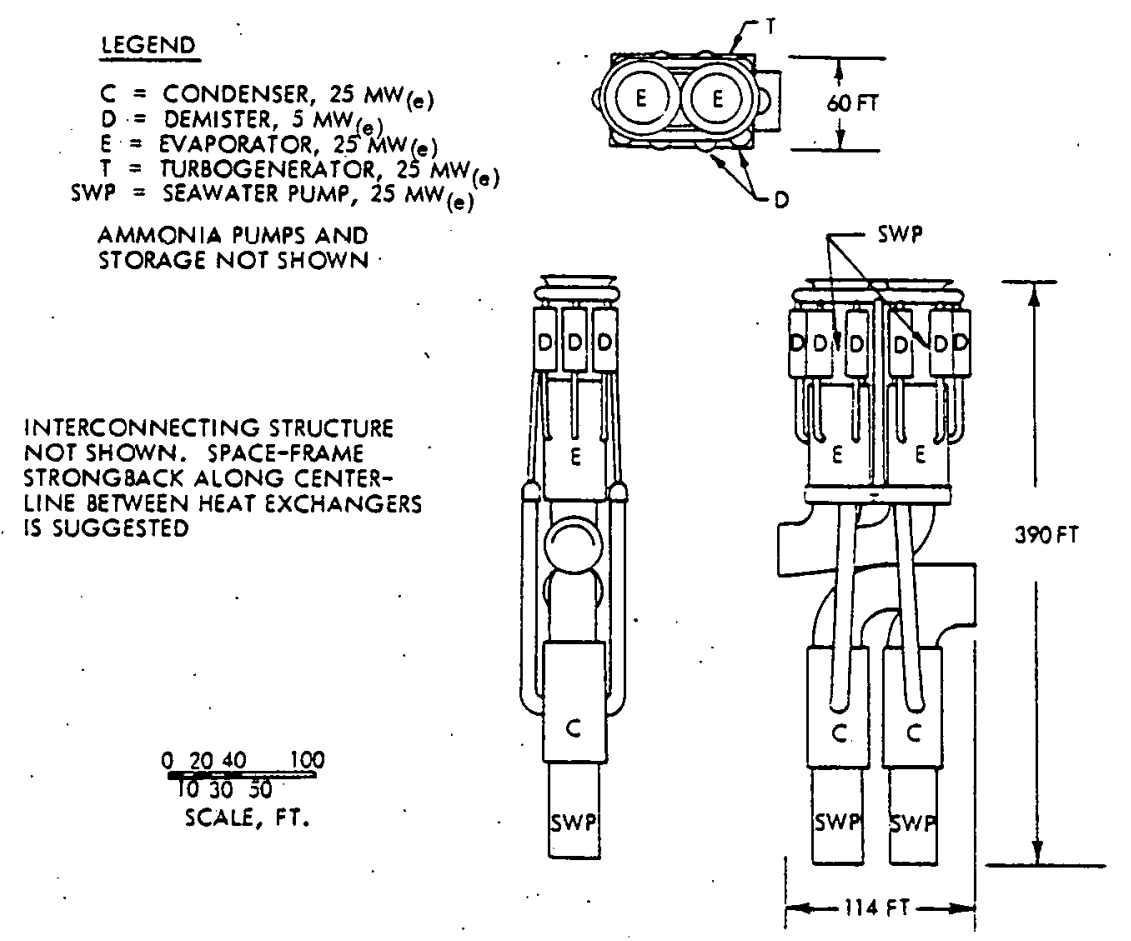

Fig. 2-12 50-MW(e) Net External Power System Module. Units are $25-\mathrm{MWW}(\mathrm{c})$ (net) vertical 
(b) 100 MW(e) Plant Configuration

The design concepts described in the previous sections have been applied to layout of 25-MW(e) power modules, of which four are attached to a central core to form a 100MW(e) plant. The arrangements shown may have horizontal cylindrical, vertical cylindrical, or vertical spherical heat exchanges. The horizontal cylindrical and spherical vertical power modules (Fig. 2-13) are shown with monocoque shell interconnecting structure, while a space-frame structure is suggested for the vertical cylindrical module (Fig. 2-14). In general, the comments on the power module configurations for the 500-MW(e) plant apply to the similar designs presesented here.

HORIZONTAL CYLINDRICAL HEAT EXCHANGERS

BASED ON GOVERNMENT FURNISHED DATA

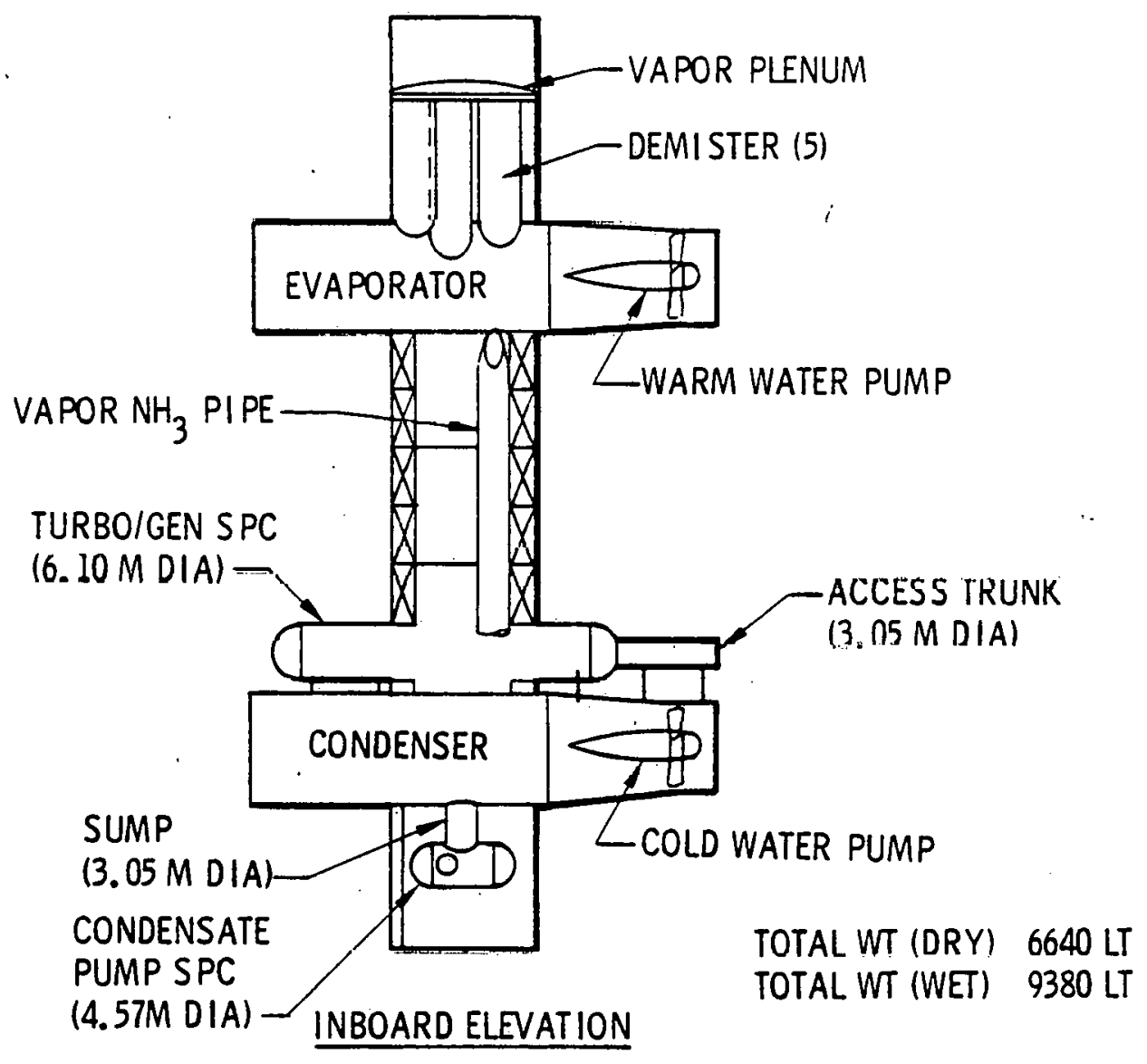

Fig. 2-13 25-MW(e) Detachable Power Module 

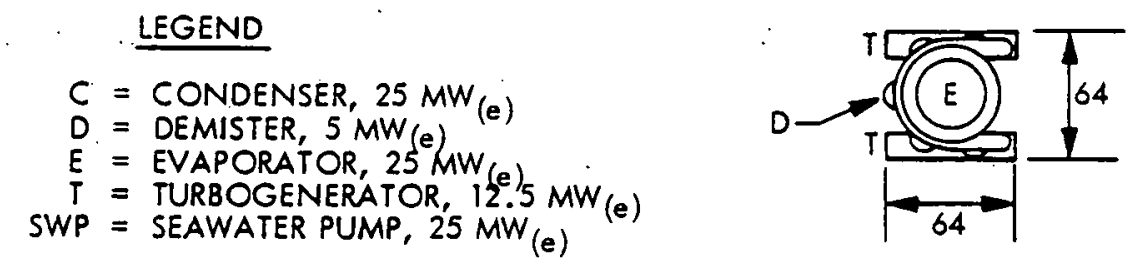

AMMONIA PUMPS AND STORAGE NOT SHOWN

$$
\begin{aligned}
& 02040 \quad 100 \\
& \hline 03050 \\
& \text { SCALE, FT }
\end{aligned}
$$

INTERCONNECTING STRUCTURE NOT SHOWN. SPACE FRAME WITH FOUR EQUALLY SPACED MAIN VERTICAL MEMBERS IS SUGGESTED.
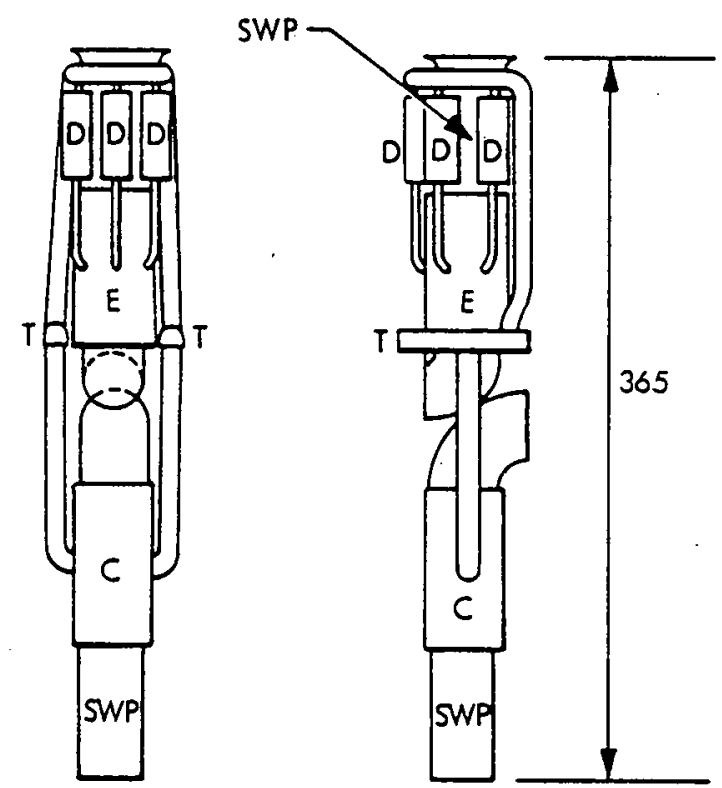

Fig. 2-14 25-MW(e) Net External Power System Module 


\section{References}

1. Letter, Mr. D. Price (GTR) to Mr. R. Waid (LMSC Proj. Mgr.) "Transmittal of OTEC Power Requirements as Generated by Gilbert Associates, "File No. EG-77-C-01-4063, 16 Aug 1977.

2. Memorandum, Mr. R. Berg (Gilbert Assoc.) to Mr. D. Price (GTR) "Transmittal of Heat Exchanger Design Information", 23 August 1977 


\subsubsection{Energy Transfer System}

Consideration of the Energy Transfer System provides criteria for selection of the preferred configurations and plant size (generating capacity). These are:

- Minimum cost, evaluated for the case of an OTEC park of $3000 \mathrm{MW}(\mathrm{e})$ total capacity

- Adequate space for chemical conversion equipment

The approach for electrical transmission is to postulate various arrangements of plants throughout the park resource area, and various plant sizes, determining the cost in each case. The observable trends then give guidance to the selection process. The requirements imposed by chemical conversion equipment are considered separately.

The arrangements considered are three:

- Plants uniformly distributed throughout an approximately circular resource area

- Plants clustered throughout the approximately circular resources area

- Plants in a line across a unidirectional current

Plant sizes considered range from 50 to $500 \mathrm{MW}(\mathrm{e})$. Net powers actually assumed for computation purposes were $50,80,160$, and $500 \mathrm{MW}(\mathrm{e})$.

System cost is calculated for each arrangement and plant size. For the distributed and clustered arrangement, this also involves optimizing the plant spacing. The cost does not include the step-up transformer or AC-DC conversion equipment which prepares the power for transmission to shore, nor does it include the shore cable cost, these items being the same for all examples. The method is discussed and the. results summarized below.

2.3.2: 1 Spacing Optimization Analysis. At a particular site location, given the size of each plant and the total capacity of all the plants to be emplaced, plant spacing is determined by a tradeoff between two factors: 
- Plant cost - larger spacing results in less reduction of seawater surface temperature due to withdrawal of thermal energy, maintaining a larger temperature differential and more efficient power cycle operation, thereby reducing plant cost of fixed power output

- Cable cost - smaller spacing results in shorter cables, thereby reducing the cost of the electrical power collection network connecting the array of plants

The optimization procedure is to minimize total system cost as a function of plant spacing, expressed in terms of the ocean area throughout which the plants are distributed.

Plant Cost as a Function of Spacing. Determination of plant cost as a function of spacing is a three-step process :

(1) Formulation of a model describing the processes of energy withdrawal from the warm sea surface layer

(2) Determination of the depression of sea surface layer temperature as a function of the rate of energy withdrawal

(3) Evaluation of the increase in plant cost as a function of the depression of sea surface layer temperature

This analysis assumes that the cold water resource is not affected by the operation of the plants.

The energy withdrawal model represents the OTEC plant as a sink for warm ocean surface water. This sink imposes a load on the existing thermal resource. Analysis of the load includes determination of the depth and horizontal extent of the sea volume from which water is drawn, the amount of recirculation of seawater from heat exchanger outlets back to inlets, and the mixing of cooler subsurface waters into the surface layer, all as a funotion of plant size, local ocean currents, and temperature profiles.

In this section we have assumed that recirculation in the neighborhood of the plant is negligible, and that the plant draws warm water uniformly from a region of radius (or half-width in the case of ocean currents) equal to half the plant spacing. The evaporator seawater discharge is below the mixed layer and flows outward to "infinity" without short-circuiting into the inward flow. 
This assumption is based on the presence of the thermocline which strongly inhibits vertical transport phenomena. However, the thermocline is not a perfect barrier, so the plant-induced flow field will actually decay with distance away from the plant. Additional analysis is required to determine whether this decay distance is large when compared to the plant spacings, as assumed here.

Further, we have assumed that the entire evaporator heat flow is withdrawn from the surface layer and deposited below the mixed layer. Therefore, for an OTEC park of $\mathrm{P}_{\mathrm{e}}$ total capacity, made up of plants operating at $\eta_{t}$ thermal-to-electrical conversion efficiency, the total thermal load is $\mathrm{P}_{\mathrm{e}} / \eta_{\mathrm{t}}$.

In the case where the OTEC park consists of plants distributed uniformly throughout resource area $A_{r}$, the thermal flux $\phi_{t}$ drawn out of the warm surface layer is, on the average

$$
\phi_{t}=\frac{P_{e}}{\eta_{t} A_{r}}
$$

The effect of withdrawing this thermal flux $\phi_{t}$ is to perturb the thermal equilibrium of the warm surface layer, causing its temperature $T_{S}$ to drop to a lower value. The magnitude of the temperature drop is calculated by methods described by Fry (Ref: 1) and Blathen (Ref. 2). The calculation determines the heat balance of a control volume consisting of a unit area of the mixed layer. Heat transfer across the boundaries of lhe cunlivil volume uccurs by:

- Radiation at the water-air interface

- Evaporation at the water-air interface

- Conduction/convection at the air-water interface

- Advection (currents) laterally within the mixed layer

The heat flux is calculated as a function of surface temperature $T_{S}$ for each of the heat transfer mechanisms listed; and then the terms are summed to give the total flux $\phi$. The unperturbed surface temperature is the one for which $\phi$ equals zero. 
The effect of the OTEC park is determined by first calculating $d \phi / \mathrm{dT}_{\mathrm{S}}$, then computing

$$
\Delta T_{s}=\frac{\phi_{t}}{d \phi / d T_{s}}
$$

The references give values of $\mathrm{d} \phi / \mathrm{dT}_{\mathrm{S}}$, as tabulated in Table 2-16 for particular sites, assuming that the plants are distributed uniformly throughout the resource area.

Table 2-16

VALUES OF $\mathrm{d} \phi / \mathrm{dT}_{\mathrm{S}}$ FOR PARTICULAR SITES

\begin{tabular}{|l|c|l|}
\hline \multicolumn{1}{|c|}{ Site } & Reference & \multicolumn{1}{|c|}{$\mathrm{d} \phi / \mathrm{dT}_{\mathrm{s}}$} \\
\hline $\begin{array}{l}\text { Caribbean Ocean, Excluding } \\
\text { Current Contribution }\end{array}$ & $(1)$ & $\begin{array}{l}-18.7 \mathrm{MW}_{\mathrm{t}} / \mathrm{mi}^{2} \circ \mathrm{F} \\
-13.7 \mathrm{MW}_{\mathrm{t}} / \mathrm{Km}^{2} \circ \mathrm{C}\end{array}$ \\
\hline Caribbean Ocean, Including & $(1)$ & $\begin{array}{l}-48 \mathrm{MW}_{\mathrm{t}} / \mathrm{mi}^{2} \circ \mathrm{F} \\
-35.2 \mathrm{MW}_{\mathrm{t}} / \mathrm{Km}^{2} \circ \mathrm{C}\end{array}$ \\
\hline Currents & & $-39 \mathrm{MW}_{\mathrm{t}} / \mathrm{mi}^{2} \circ \mathrm{F}$ \\
Keahole Point, Hawaii & $(2)$ & $-28.7 \mathrm{MW}_{\mathrm{t}} / \mathrm{Km}^{2} \circ \mathrm{C}$ \\
\hline
\end{tabular}

The effect of the depression of $T_{S}$ by OTEC park operation is to increase the cost of the plant required to generate a given net output. For small perturbations in $T_{S}$, the cost relationship is linear,

$$
C_{p}=C_{p o}\left(I-K_{c} \Delta T_{s}\right)
$$

where $C_{p}$ is plant cost, $C_{p o}$ is plant cost at zero $\Delta T_{S}$, and $K_{c}$ is the costtemperature coetiicient. It can be shown that $K_{c}$ has the same value as the slope of the curves of plant output vs. temperature, such as those shown in Fig. 2-15, based on computer calculated performance. 


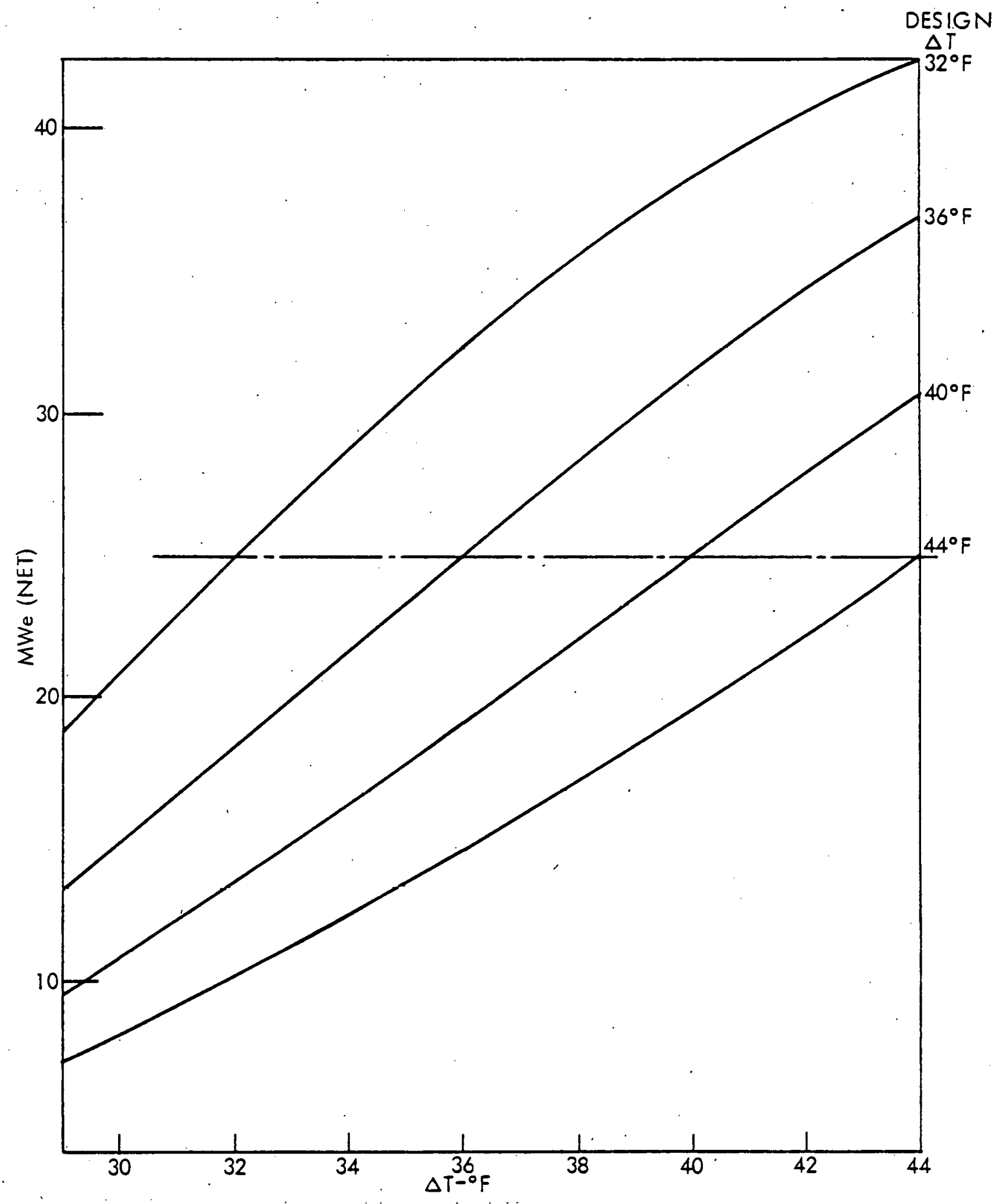

Fig. 2-15 Off-Design Performance of 25-MW(e) (Net) Module $2-43$ 
From an average of these data we determine the value

$$
\mathrm{K}_{\mathrm{C}}=0.0668\left({ }^{\circ} \mathrm{F}\right)^{-1} \text { or } 0.127\left({ }^{\circ} \mathrm{C}\right)^{-1}
$$

We can now express the change in plant cost as a function of the parameters defined above.

$$
\Delta C_{p}=-\frac{K_{o} P_{o} C_{p o}}{\eta_{t} A_{I} d \phi / d T_{s}}
$$

This relationship is valid for plants distributed uniformly throughout a resource area $A_{I}$ and drawing warm water uniformly from the whole area.

When a steady, unidirectional current exists, it may be advantageous to arrange the OTEC park plants in a line perpendicular to the current flow. In this case, the plant spacing necessary for safety, i.e., collision avoidance in rough weather, is usually much greater than the width of the stream tube which is drawn into the evaporators. As a result, the plants do not interact in their effect on the resource (provided that plants are not placed such that their wakes impinge on others downstream).

However, the size of the plant determines its effect on the resource. A larger plant, with greater seawater flow, draws its warm water inflow from a greater depth. As a result, the average inflow temperature $\bar{T}_{S}$ is lower. This effect is evaluated by Fry (Ref. 1) for Caribbean Ocean conditions. In general, the depression $\Delta \bar{T}_{S}$ of average surface temperature is a function of plant net power $P_{p}^{\prime}$, efficiency $\eta_{t}$, and site dependent variables

$$
\Delta \overline{\mathrm{T}}_{\mathrm{s}}=\left(\mathrm{P}_{\mathrm{p}} / \eta_{\mathrm{t}} \text {, site dependent variables }\right)
$$

The resultant change in plant cost is, as before

$$
\Delta C_{p}=C_{p o} K_{c} \Delta \bar{T}_{s}
$$


This relation is valid for a line of OTEC plants arrayed perpendicularly across a unidirectional current.

Cable Cost as a Function of Spacing. The cost $\mathrm{C}_{c}$ of the interconnecting cables is simply the product of the average cable length $\overline{\mathrm{L}}_{c}$, the number of cables per plant $\mathrm{N}_{c}$, the number of plants in the park $\mathrm{N}_{p}$, and the installed cable cost per unit length $\mathrm{F}_{\mathrm{C}}$,

$$
\mathrm{C}_{\mathrm{c}}=\overline{\mathrm{L}}_{\mathrm{c}} \mathrm{N}_{\mathrm{c}} \mathrm{N}_{\mathrm{p}} \mathrm{F}_{\mathrm{c}}
$$

The average cable length will be expressed as the product of average plant spacing $S$ and a constant $\mathrm{K}_{\mathrm{S}}$, which account for the site factors which prevent cables from being laid along the most direct paths; and variations in plant locations from a geometrically uniform grid. For this study we assume $\mathrm{K}_{\mathrm{S}}=1.2$.

Plant spacing is determined by assuming that each plant occupies a hexagonal area of dimension $S$ between opposite sides, having six equidistant nearest neighbors. The resource area $A_{r}$ occupied by $\mathrm{N}_{p}$ plants is, therefore

$$
A_{r}=N_{p} s^{2} \frac{\sqrt{3}}{2}
$$

Solving for spacing $S$,

$$
S=\sqrt{\frac{2 A_{r}}{\sqrt{3} N_{p}}}=1.075 \sqrt{\frac{A_{r}}{N_{p}}}
$$

and the cable cost is

$$
C_{c}=1.075 \mathrm{~K}_{\mathrm{S}} \sqrt{\mathrm{A}_{\mathrm{r}} \mathrm{N}_{\mathrm{p}}} \mathrm{N}_{\mathrm{c}} \mathrm{F}_{\mathrm{c}}
$$


Riser and Cable Junction Costs. Cable risers and junctions are necessary to complete the power collection network.

The riser is a special cable, designed to withstand the varying tension and bending loads, and the abuse of being dragged across the bottom, resulting from plant motions. Its cost per unit length $F_{r}$ is therefore two to five times the material cost of the bottom cables. For purposes of this study, we as sume the riser takes a catenary form from plant to bottom approximated by a quarter circle. The riser length $L_{r}$, in terms of ocean depth $D$, is

$$
L_{L}=\frac{\pi}{2} \mathrm{D}
$$

and the cost of the riser, $C_{r}$, is

$$
C_{r}=F_{r} L_{L}=\frac{\pi}{2} F_{r} D
$$

A cable junction is required at every node in the power collection network where power from two or more plants is merged. The equipment types which might be included in the junction are

- Cable terminal - the mechanical and electrical connection of a single cable into the power circuit. Cable replacement takes place by physically disconnecting the cable at the terminal

- Disconnect switch - makes or breaks the circuit between a cable terminal and the rest of the circuit. Can be operated only when the circuit is not energized

- Circuit breaker - capable of interrupting the circuit while energized, particularly for fault isolation

- Line compensation - discrete reactive elements placed across an AC transmission line to compensate for the cable capacitance

- Power converters - used here to include both transformers for changing the voltage of AC circuits, and AC-DC converters 
The simplest junction would contain only cable terminals. This would require shutting down the entire system for the duration of the maintenance period should cable repair or replacement be required.

The next simplest junction would include disconnect switches. This would require the system to shut down only for the moment required to actuate the switches which isolate the cable requiring work.

It is conceivable that junctions containing either of these equipment types could be placed on the sea bottom and be operated remotely for an extended period. The more complex equipment is, however, not adequately qualified at present for such service, although it is technically feasible to qualify this equipment for such service if the need is demonstrated.

The resulting tradeoff is between use of subsurface junctions which do not require risers for their connecting cables but require the entire park to shut down if repairs are needed, versus surface junctions which do require additional risers but can instantly isolate a section of cable requiring attention without interrupting operation of the rest of the park. In this report, the surface junction alternative is chosen.

The cost of a junction component is proportional to its power rating. Thus the cost of all the junctions in the system is proportional to the cumulative sum of all the power handled by the system, i.e., the contribution of a single plant to the cumulative power sum is the capacity of that plant times the number of junctions through which the plant's power passes. With specific cost $F_{j}$ per unit of capacity, and cumulative power $P_{j}$, the cost $C_{j}$ of junction equipment is

$$
C_{j}=F_{j} P_{j}
$$

This report assumes that all junctions are housed aboard plant platforms. This ignores the one exception, which is the park consisting of a few plants, or clusters of plants, which has a central power collection junction site where no plant is located. The 
justification for ignoring this cost element is (1) it is a small contribution to the total cost of the park, (2) it is independent of plant size or spacing, and (3) generating an accurate estimate of its cost requires effort exceeding its present usefulness.

In summary, the cost of risers and junctions is

$$
N_{r} C_{r}+C_{j}=\frac{\pi}{2} N_{r} F_{r} D+F_{j} P_{j}
$$

where $\mathrm{N}_{r}$ is the number of risers in the system. $\mathrm{N}_{r}$ depends on system layout, an rather than presenting a general expression in terms of the number of plante and a layout-dependent parameter, it is expedient to simply count the risers for the specific cases considered.

OTEC Park Cost. Combining all the cost terms, the total OTEC park cost is

$$
C=C_{p o}\left(1-\frac{K_{c} P_{e}}{\eta_{t} A_{r} d \phi / d T_{s}}\right)+1.075 K_{s} \sqrt{A_{r} N_{p}} N_{c} F_{c}+\frac{\pi}{2} N_{r} F_{r} D+F_{j} P_{j}
$$

for a park with plants distributed throughout an area. $A_{r}$. For the linear cross-ourrent arrangement, the cost is computed employing a modified relation. The plant cost term is computed using $\overline{\mathrm{T}}_{\mathrm{S}}$ based on ingestion of warm water from the current flowing around the plant. The length of cable between each plant is the plant spacing, subtracting the horizontal extension of the risers from plant to cable. Assuming the junctions are made on the plants, cable length $L_{c}$ is

$$
L_{c}=s-2 D
$$

The riser and junction costs are calculated as before. Therefore system cost is 


$$
C=C_{p o}\left(1-K_{c} \Delta \bar{T}_{s}\right)+\left(N_{p}-1\right)(S-2 D) N_{c} F_{c}+\frac{\pi}{2} N_{r} F_{r} D+F_{j} P_{j}
$$

If the plants are closely spaced so that $S$ is less than $2 D$, then no bottom cable is used and the plants are connected by catenary risers. In this case the cost is

$$
C=C_{p o}\left(1-K_{c} \Delta \bar{T}_{s}\right)+\frac{\pi}{2} N_{r} F_{r} D^{\prime}+F_{j} P_{j}
$$

where $\mathrm{D}^{\prime}$ is the depth at the bottom of the catenary, assuming the catenary to be approximated by a semicircle.

Spacing Optimization. The optimum plant spacing for a park with plants distributed uniformly throughout area $A_{r}$ is found by setting $d C / d_{r}=.0$ and calculating the corresponding value of $S$.

$$
A_{r}=\left(-\frac{1.860 c_{p o} K_{c} P_{e}}{\eta_{t} K_{s} N_{c} F_{c} \sqrt{N_{p}} d \phi / d T_{s}}\right)^{2 / 3}
$$

Note: $\mathrm{d} \phi / \mathrm{dT}_{\mathrm{S}}$ is intrinsically negative so the term in brackets is positive.

2.3.2.2 OTEC Park Arrangements. To determine the trends of OTEC park cost with plant size and spacing, cases having several arrangements and numbers of plants are calculated. The arrangements are:

- Plants uniformly distributed throughout the resource area

- Plants clustered about six locations in the resourrce area

- Linear cross-current layout 
For each arrangement, four different plant sizes as indicated earlier are used, always adding up to a nominal capacity of $3000 \mathrm{MW}(\mathrm{e})$ for the park. The number of plants in each case and the supporting rational are:

- Uniformly distributed

- 6 plants (500 MW(e) each) - hexagonal arrangement

- 19 plants (160 MW(e) each) - one in center and two hexagonal tiers

- 37 plants (80 MW(e) each) - one in center and three hexagonal tiers

- 61 plants (50 MW(e) e3ch) - one -in oentcr and four hexagonal tiers

- Clustered

- 6 plants -hexagonal arrangement

- 18 plants - six elusters of three

- 36 plants - six clusters of six

- 60 plants - six clusters of ten

- Linear

- 6, 18, 36, 60 plants

Junctions in the uniformly distributed park are located to maximize the number of plants feeding each junction. In the clustered arrangement, there are 7 junctions, one in the center of each cluster and one in the center of the park. In the linear arrangements, there is a junction on each plant except the most remote.

The clustered arrangement is treated as a six-plant park in determining its impact on the thermal resource. The only variable is the number of risers.

Evaluation, Distributed and Clustered Plants. Values used in Eq. 21 are as follows:

$$
\begin{array}{ll}
\mathrm{C}_{\mathrm{po}} & =6 \times 10^{9} \$(2000 \$ / \mathrm{KW}(\mathrm{e})) \\
\mathrm{K}_{\mathrm{c}} & =0.0668 \\
\mathrm{P}_{\mathrm{e}} & =3000 \mathrm{MW}(\mathrm{e}) \\
\eta_{\mathrm{t}} & =0.025 \\
\mathrm{~K}_{\mathrm{S}} & =1.2 \\
\mathrm{~N}_{\mathrm{c}} & =4 \text { (DC sÿstem, singly redundant) }
\end{array}
$$




$$
\begin{array}{ll}
\mathrm{d} \phi / \mathrm{dT}_{\mathrm{S}} & =-18.7 \mathrm{MW}_{\mathrm{t}} / \mathrm{mi}^{2} \circ \mathrm{F},-13.7 \mathrm{MW}_{\mathrm{t}} / \mathrm{Km}^{2} \circ \mathrm{C} \\
F_{\mathrm{r}} & =160 \$ / \mathrm{ft}, 525 \$ / \mathrm{m} \\
\mathrm{D} & =4,000 \mathrm{ft}, 1220 \mathrm{~m} \\
F_{\mathrm{j}} & =10,000 \$ / \mathrm{MW}(\mathrm{e})
\end{array}
$$

Two values of $F_{c}$ are used. One, supplied by DOE, assumes cable cost is independent of capacity. The other assumes the cable cost varies by a factor of two over a capacity range of 10 , being equal to the DOE-supplied number at a capacity of $100 \mathrm{MTW}(\mathrm{e})$ : These values are:

$$
\begin{array}{ll}
\text { (Constant) } \quad F_{c}= & 422 \times 10^{3} \$ / \mathrm{mi}, 680 \times 10^{3} \$ / \mathrm{Km} \\
\text { (Variable) } \quad F_{c}= & 106 \times 10^{3}\left(\mathrm{P}_{\mathrm{p}}\right)^{3} \$ / \mathrm{mi} \\
& 171 \times 10^{3}\left(\mathrm{P}_{\mathrm{p}}\right)^{3} \$ / \mathrm{Km}
\end{array}
$$

The number of junctions and the value of $P_{j}$ depends on the particular park arrangement. Results are tabulated for three situations:

(1) Uniformly distributed plants, constant cable cost, Table 2-17

(2) Uniformly distributed plants, variable cable cost, Table 2-18

(3) Clustered plants, Table 2-19

2.3.2.3 Evaluation, Linear Arrangement. The cost of the linear arrangement park, for the four plant sizes chosen, is calculated using the same parameter values as listed above. In addition, $\Delta \overline{\mathrm{T}}_{\mathrm{E}}$ is determined from the relations given by Fry (Ref. 1) using a current velocity of $2 \mathrm{kt}$. Under these conditions $\Delta \bar{T}_{S}$ is essentially zero and there is no performance change as a function of plant size. The plants are assumed to be closely spaced, and $D^{\prime}$ is taken to be the same as $D$. System cost as a function of plant size is presented in Table 2-20.

\subsubsection{Electrical Transmission Summary. The cost of the $3000 \mathrm{MW}(\mathrm{e})$ OTEC park} as a function of plant size is plotted in Fig. 2-16 for the four arrangements discussed above. The cost increment over baseline plant cost represents the cost of the power collection network (cables, risers, and junction equipment), and the increase in plant cost to compensate for the depression of surface temperature $T_{S}$ resulting from plant operation. 
TABLE $2-17$

SYSTEM COST VS. PLANT SIZE

- Plants Uniformly Spaced Throughout Resource Area

- Constant Cable Cost

\begin{tabular}{|c|c|c|c|c|c|c|c|c|c|c|c|c|}
\hline \multirow[b]{2}{*}{$N_{p}$} & \multirow[b]{2}{*}{$\mathrm{N}_{\mathrm{r}}$} & \multirow[b]{2}{*}{${ }^{N} \mathbf{j}$} & \multirow[b]{2}{*}{$\begin{array}{l}\text { Plant } \\
\text { Power } \\
\text { (MWe) }\end{array}$} & \multirow[b]{2}{*}{$\begin{array}{c}F= \\
(S / M i) \\
(S: S m)\end{array}$} & \multirow[b]{2}{*}{$\begin{array}{c}\mathrm{H}_{\mathrm{r}} \\
\left(\mathrm{Mi}^{2}\right) \\
\left(\mathrm{Km}^{2}\right)\end{array}$} & \multirow[b]{2}{*}{$\begin{array}{c}S \\
(M i) \\
\text { (kim) }\end{array}$} & \multirow[b]{2}{*}{$\begin{array}{l}\Delta \mathrm{T}_{\mathrm{S}} \\
\left({ }^{\circ} \mathrm{F}\right) \\
\left({ }^{\circ} \mathrm{C}\right)\end{array}$} & \multicolumn{5}{|c|}{$\cos \mathrm{T}$ (normalized to $3000 \mathrm{MW}(\mathrm{e})$ park) } \\
\hline & & & & & & & & $\begin{array}{l}\text { Plants } \\
(\$ M)\end{array}$ & $\begin{array}{c}\text { Catiles } \\
(\mathrm{S} M)\end{array}$ & $\begin{array}{c}\text { Risers } \\
(\$ M)\end{array}$ & $\begin{array}{c}\text { Junctions } \\
\text { (SM) }\end{array}$ & $\begin{array}{l}\text { Total } \\
(\$ M)\end{array}$ \\
\hline 6 & 48 & 1 & 500 & $\begin{array}{l}422 \times 10^{3} \\
262 \times 10^{3}\end{array}$ & $\begin{array}{r}9761 \\
25281\end{array}$ & $\begin{array}{l}45.4 \\
65.8\end{array}$ & $\begin{array}{l}0.66 \\
0.37\end{array}$ & 6265 & 527 & 48 & 30 & 6870 \\
\hline 19 & 144 & 7 & 160 & $\begin{array}{l}422 \times 10^{3} \\
262 \times 10^{3}\end{array}$ & $\begin{array}{r}6653 \\
17231\end{array}$ & $\begin{array}{l}2 \mathrm{C} .1 \\
32.3\end{array}$ & $\begin{array}{l}0.96 \\
0.53\end{array}$ & 6385 & 733 & 144 & 67 & 7329 \\
\hline 37 & 288 & 13 & 80 & $\begin{array}{l}422 \times 10^{3} \\
262 \times 10^{3}\end{array}$ & $\begin{array}{r}5437 \\
14082\end{array}$ & $\begin{array}{l}13.1 \\
21.1\end{array}$ & $\begin{array}{l}1.18 \\
0.66\end{array}$ & 6473 & 955 & 288 & 98 & 7814 \\
\hline 61 & 480 & 21 & 50 & $\begin{array}{l}422=10^{3} \\
262=10^{3}\end{array}$ & $\begin{array}{r}4504 \\
11665\end{array}$ & $\begin{array}{r}9.2 \\
14.8\end{array}$ & $\begin{array}{l}1.43 \\
0.79\end{array}$ & 6573 & 1118 & 480 & 140 & 8311 \\
\hline
\end{tabular}


TABLE 2-18

SYSTEM COST VS. PLANT SIZE

- Plants Uniformly Spaced Throughout Resource Area

- Cable Cost Depends on Capacity

\begin{tabular}{|c|c|c|c|c|c|c|c|c|c|c|c|c|}
\hline \multirow[b]{2}{*}{$\mathbf{N}_{\mathbf{p}}$} & \multirow[b]{2}{*}{$\mathbf{N}_{r}$} & \multirow[b]{2}{*}{$\mathbf{N}_{j}$} & \multirow[b]{2}{*}{$\begin{array}{l}\text { Plant } \\
\text { Power } \\
\text { (MWe) }\end{array}$} & \multirow[b]{2}{*}{$\begin{array}{c}F_{c} \\
(\$ / M i) \\
(\$ K m)\end{array}$} & \multirow[b]{2}{*}{$\begin{array}{c}\mathrm{A}_{\mathrm{r}} \\
\left(\mathrm{Mi}^{2}\right) \\
\left(\mathrm{Km}^{2}\right)\end{array}$} & \multirow[b]{2}{*}{$\begin{array}{l}S \\
(M i) \\
(\mathrm{Km})\end{array}$} & \multirow[b]{2}{*}{$\begin{array}{l}\Delta \mathrm{T} \\
\because \mathrm{s} \\
\left({ }^{\circ} \mathrm{F}\right) \\
\left({ }^{\circ} \mathrm{C}\right)\end{array}$} & \multicolumn{5}{|c|}{ CosT (normalized to $3000 \mathrm{MW}$ (e) park) } \\
\hline & & & & & & & & $\begin{array}{l}\text { Plants } \\
\text { (\$M) }\end{array}$ & $\begin{array}{l}\text { Cables } \\
\text { (\$M) }\end{array}$ & $\begin{array}{l}\text { Risers } \\
(\$ M)\end{array}$ & $\begin{array}{l}\text { Junctions } \\
(\$ M)\end{array}$ & $\begin{array}{c}\text { Tota } 1 \\
\text { (\$M) }\end{array}$ \\
\hline 6 & 48 & 1 & 500 & $\begin{array}{l}684 \times 10^{3} \\
425 \times 10^{3}\end{array}$ & $\begin{array}{r}7073 \\
18319\end{array}$ & $\begin{array}{l}36.9 \\
59.4\end{array}$ & $\begin{array}{l}0.91 \\
0.51\end{array}$ & 6365 & 727 & 48 & 30 & 7170 \\
\hline 19 & 144 & 7 & 160 & $\begin{array}{l}486 \times 10^{3} \\
302 \times 10^{3}\end{array}$ & $\begin{array}{r}6049 \\
15667\end{array}$ & $\begin{array}{l}19.2 \\
30.9\end{array}$ & $\begin{array}{l}1.06 \\
0.59\end{array}$ & 6425 & 776 & 144 & 67 & $\begin{array}{l}7412 \\
-\end{array}$ \\
\hline 37 & 288 & 13 & 80 & $\begin{array}{l}395 \times 10^{3} \\
245 \times 10^{3}\end{array}$ & $\begin{array}{r}5562 \\
14406\end{array}$ & $\begin{array}{l}13.2 \\
21.2\end{array}$ & $\begin{array}{l}1.15 \\
0.64\end{array}$ & 6461 & 901 & 288 & 98 & 7748 \\
\hline 61 & 480 & 21 & 50 & $\mid \begin{array}{lll}343 \times 10^{3} \\
213 \times 10^{3}\end{array}$ & $\begin{array}{r}5173 \\
13398\end{array}$ & $\begin{array}{r}9.9 \\
15.9\end{array}$ & $\begin{array}{l}1.24 \\
0.69\end{array}$ & 6497 & 978 & 480 & 140 & 8094 \\
\hline
\end{tabular}


TABLE 2-19

SYSTEM COST VS. PLANT SIZE

- Clustered Plants

- Constant Cable Cost

\begin{tabular}{|c|c|c|c|c|c|c|c|c|c|c|c|c|}
\hline \multirow[b]{2}{*}{$N_{p}$} & \multirow[b]{2}{*}{$\mathrm{N}_{\mathbf{r}}$} & \multirow[b]{2}{*}{$\mathrm{N}_{\mathbf{j}}$} & \multirow[b]{2}{*}{$\begin{array}{l}\text { Plant } \\
\text { Power } \\
\text { (MWe) }\end{array}$} & \multirow[b]{2}{*}{$\begin{array}{c}F_{c} \\
(\$ / M i) \\
(\$ K m)\end{array}$} & \multirow[b]{2}{*}{$\begin{array}{c}\mathrm{A} r \\
\left(\mathrm{Mi}^{2}\right) \\
\left(\mathrm{Km}^{2}\right)\end{array}$} & \multirow[b]{2}{*}{$\begin{array}{c}S \\
(\mathrm{Mi}) \\
(\mathrm{Km})\end{array}$} & \multirow[b]{2}{*}{$\begin{array}{l}\Delta \mathrm{T}_{\mathrm{S}} \\
\left({ }^{\circ} \mathrm{F}\right) \\
\left({ }^{\circ} \mathrm{C}\right)\end{array}$} & \multicolumn{5}{|c|}{$\operatorname{cosT}$ (normalized to $3000 \mathrm{MW}_{(\mathrm{e})}$ park) } \\
\hline & & & & & & & & $\begin{array}{l}\text { Plants } \\
(\$ M)\end{array}$ & $\begin{array}{c}\text { Cables } \\
\text { (\$H) }\end{array}$ & $\begin{array}{l}\text { Risers } \\
(\$ M)\end{array}$ & $\begin{array}{c}\text { Junctions } \\
(\$ M)\end{array}$ & $\begin{array}{l}\text { Toța } 1 \\
\text { (\$M) }\end{array}$ \\
\hline 6 & 48 & 1 & 500 & $\begin{array}{l}422 \times 10^{3} \\
262 \times 10^{3}\end{array}$ & $\begin{array}{r}9761 \\
25281\end{array}$ & $\begin{array}{l}43.4 \\
69.8\end{array}$ & $\begin{array}{l}0.66 \\
0.37\end{array}$ & 6265 & $52 ?$ & 48 & 30 & 6870 \\
\hline 18 & 192 & 7 & 1500 & $\begin{array}{l}422 \times 10^{3} \\
262 \times 10^{3}\end{array}$ & $\begin{array}{r}9761 \\
25: 281\end{array}$ & $\begin{array}{l}4.3 .4 \\
69.8\end{array}$ & $\begin{array}{l}0.66 \\
0.37\end{array}$ & 6265 & $5: 2 ?$ & 192 & 60 & 7044 \\
\hline 36 & 336 & 7 & 80 & $\begin{array}{l}422 \times 10^{3} \\
262 \times 10^{3}\end{array}$ & $\begin{array}{r}9761 \\
25281\end{array}$ & $\begin{array}{l}43.4 \\
69.8\end{array}$ & $\begin{array}{l}0.66 \\
0.37\end{array}$ & 6265 & 527 & 336 & 60 & 7188 \\
\hline 60 & 528 & 7 & 50 & $\begin{array}{l}422 \times 10^{3} \\
262 \times 10^{3}\end{array}$ & $\begin{array}{r}9761 \\
25281\end{array}$ & $\begin{array}{l}43.4 \\
69.8\end{array}$ & $\begin{array}{l}0.66 \\
0.37\end{array}$ & 6265 & 527 & 528 & 60 & 7380 \\
\hline
\end{tabular}


TABLE $2-20$

SYSTEM COST VS. PLANT SIZE

- Linear OTEC Park Arrangement

\begin{tabular}{|c|c|c|c|c|c|c|c|c|}
\hline & \multicolumn{4}{|c|}{$\operatorname{cosT}$ (normalized to $3000 \mathrm{MW}(\mathrm{e})$ park) } \\
\hline $\mathrm{N}_{\mathrm{p}}$ & $\mathrm{N}_{\mathrm{r}}$ & $\mathrm{N}_{\mathbf{j}}$ & $\begin{array}{l}\text { Power } \\
\text { Plant }\end{array}$ & $\Delta \mathrm{T}_{\mathrm{s}}$ & Plants & Risers & Junctions & Total \\
\hline & & & (MWe) & $\begin{array}{l}\left({ }^{\circ} \mathrm{F}\right) \\
\left({ }^{\circ} \mathrm{C}\right)\end{array}$ & $(\$ M)$ & $(\$ M)$ & $(\$ M)$ & $(\$ M)$ \\
\hline 6 & 40 & 5 & 500 & $\begin{array}{l}0.0 \\
0.0\end{array}$ & 6000 & 40 & 70 & 6110 \\
\hline 18 & 136 & 17 & 160 & $\begin{array}{l}0.0 \\
0.0\end{array}$ & 6000 & 136 & 243 & 6379 \\
\hline 36 & 280 & 3.5 & 80 & $\begin{array}{l}0.0 \\
0.0\end{array}$ & 6000 & 280 & 504 & 6784 \\
\hline 60 & 472 & 59 & 50 & $\begin{array}{l}0.0 \\
0.0\end{array}$ & 6000 & 472 & 885 & 7357 \\
\hline
\end{tabular}




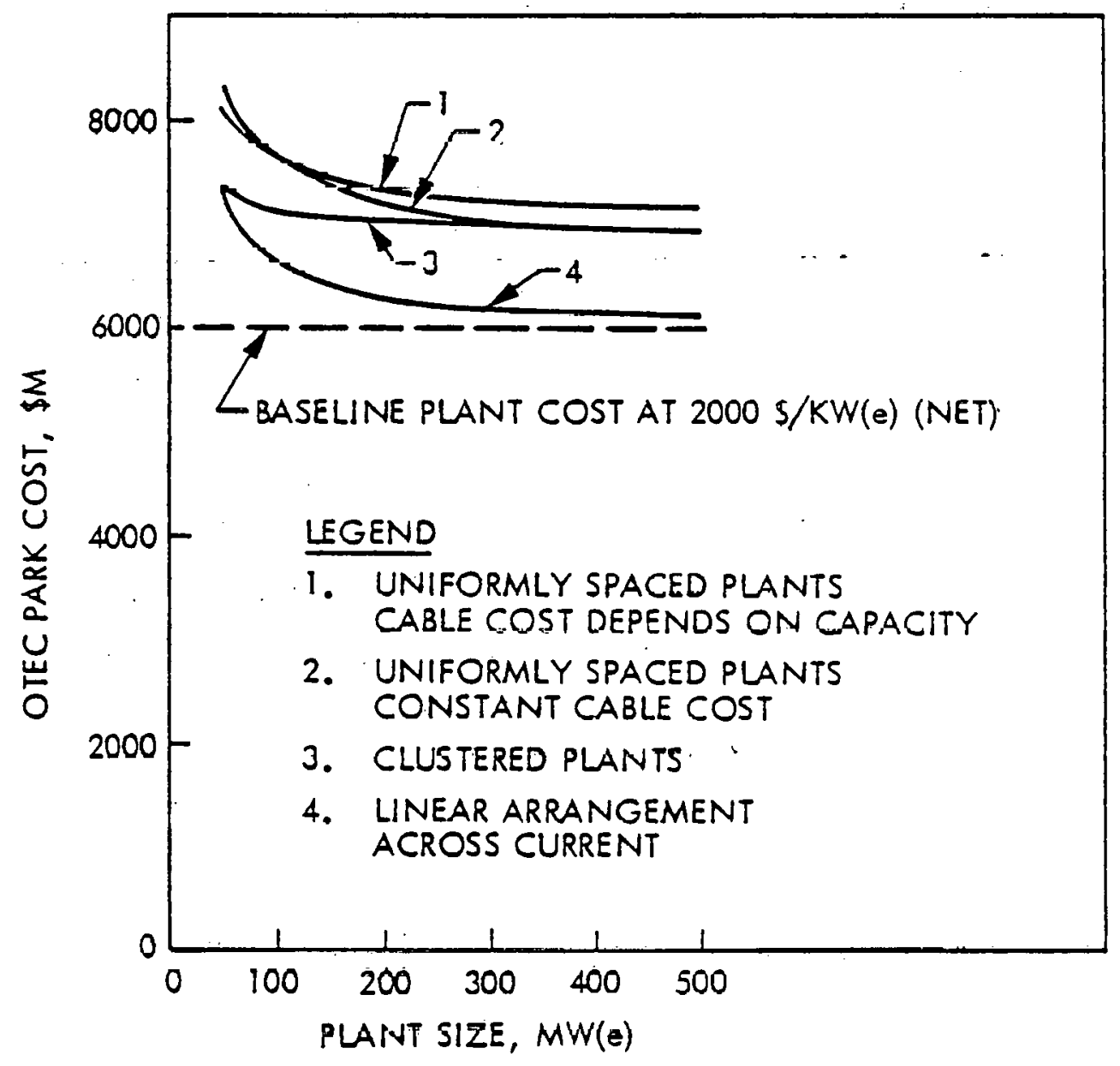

Fig. 2-16 OTEC Park Cost as a Function of Plant Size 
It is evident that a plant size of 150 to $200 \mathrm{MW}(\mathrm{e})$ is sufficient to provide most of the benefit of scale with regard to the electrical energy transfer system. The final selection of the preferred plant size range must, of course, also include the effect of plant construction and position keeping costs as functions of plant size.

Some comparison of the four arrangements is in order. The linear arrangement which takes advantage of a unidirectional current has the lowest cost because it has no bottom cables. In the presence of any appreciable current (say 1/2 kt or greater) the plants can be closely spaced, connected by a series of catenary risers. System costs increase for small plant size because the number of plants in the park increases inversely as plant size, with proportional increase in number of risers and geometric increase in required junction equipment capacity.

The clustered arrangement has the next lowest cost. The cost is relatively independent of plant size because the bottom cable and junction arrangement, and depression of ocean surface temperature, are èssentially the same in all cases. The dependence of cost on plant size reflects mainly the increase in the number of risers with the smaller, more numerous plants.

The comparison of the two highest cost curves; for arrangements of plants uniformly spaced throughout the park area, illustrates the effect of the two assumed cable cost relations (constant cost and cost dependent on cable capacity). As expected, the assumption that cable cost depends on capacity, in this case capacity to the 0.3 power, tends to flatten the curve of cost versus plant size.

\subsubsection{Impact of Chemical Conversion Energy Transfer. The impact of chemical} conversion energy transfer on configuration selection is considered in terms of

- Adequiacy of plant. layouts to contain conversion equipment or their suitability to be modified for such purposes.

- Adaptability of plants to the "grazing" mode, in which they would cruise about slowly, following the location of the highest thermal gradients. 
The procedure is to compile requirements on deck area, volume, and weight for a typical chemical conversion plant, tabulate the equipment containment characteristics of the current configuration layouts, assess adequacy for equipment containment and grazing, and recommend modifications where necessary.

Requirements. A 100-MW(e) liquid ammonia plant is selected as typical of the equipment which would be contained in an OTEC plant for chemical conversion. The deck area, volume, and weight of this equipment, using current state of the art, is presented in Table 2-21.

Table 2-21

EQUIP:MENT SIZE AND WEIGHT FOR 100 MW(e) AMMONIA PLANT (REF. 3)

\begin{tabular}{|l|r|r|r|}
\hline \multicolumn{1}{|c|}{ Item } & $\begin{array}{r}\text { Deck Area } \\
\left(\mathrm{ft}^{2}\right) \\
\left(\mathrm{m}^{2}\right)\end{array}$ & $\begin{array}{c}\text { Volume } \\
\left(\mathrm{ft}^{3}\right) \\
\left(\mathrm{m}^{3}\right)\end{array}$ & $\begin{array}{c}\text { Weight } \\
\text { (Ton) } \\
\text { (metric ton) }\end{array}$ \\
\hline Power Conditioning & 1,200 & 21,600 & 132 \\
Desalination & 111 & 612 & 60 \\
Electrolyzers & 936 & 13,104 & 50 \\
(Lurgi type) & 87 & 371 & 23 \\
Air Separation & 1,702 & 193,292 & 2,945 \\
Unit* & 1,926 & 5,473 & 1,339 \\
Ammonia & 179 & 54,606 & 130 \\
Synthesis Loop* & 3,880 & 21,874 & 59 \\
Total & 360 & 619 & 418 \\
& 27,044 & 304,176 & 3,676 \\
& 2,512 & 8,622 & 1,670 \\
\hline
\end{tabular}

* Includes work-around space for installation and maintenance equal to $50 \%$ of number quoted.

Platform Characteristics. The characteristics relative to chemical conversion plant containment, for the six configurations as currently defined, are presented in Table $2-22$. 
Table 2-22

PLATFORM EQUIPMENT CONTAINMENT CHARACTERISTICS

\begin{tabular}{|c|c|c|c|}
\hline Configuration & $\begin{array}{l}\text { Available } \\
\text { Deck Area } \\
\quad\left(\mathrm{ft}^{2}\right) \\
\left(\mathrm{m}^{2}\right)\end{array}$ & $\begin{array}{l}\text { Available } \\
\text { Height } \\
\text { (ft) } \\
\text { (m) }\end{array}$ & Comment \\
\hline Ship & $\begin{array}{r}91,978 \\
8,545\end{array}$ & $\begin{array}{l}\text { Equipment placed on } \\
\text { present weather deck, } \\
\text { height restricted by } \\
\text { crane and helicopter } \\
\text { landing clearances. }\end{array}$ & $\begin{array}{l}\text { Ammonia vapor piping } \\
\text { intrudes into above-deck } \\
\text { space. Remaining space } \\
\text { is adequate. }\end{array}$ \\
\hline $\begin{array}{l}\text { Circular } \\
\text { Barge }\end{array}$ & $\begin{array}{r}28,923 \\
2,687\end{array}$ & $\begin{array}{l}\text { Equipment placed on } \\
\text { present weather deck, } \\
\text { height restricted by } \\
\text { crane and helicopter } \\
\text { landing clearances. }\end{array}$ & $\begin{array}{l}\text { Locating plant in unused. } \\
\text { area on existing layout. }\end{array}$ \\
\hline $\begin{array}{l}\text { Semi- } \\
\text { Submersible }\end{array}$ & $\begin{array}{r}143,440 \\
13,326\end{array}$ & $\begin{array}{l}\text { Equipment placed on } \\
\text { present weather deck, } \\
\text { height restricted by } \\
\text { crane and helicopter } \\
\text { landing clearances. }\end{array}$ & $\begin{array}{l}\text { Requires decking in } \\
\text { present open trusswork } \\
\text { area. }\end{array}$ \\
\hline $\begin{array}{l}\text { Tuned } \\
\text { Sphere }\end{array}$ & - & - & $\begin{array}{l}\text { Above-water deck area } \\
\text { not detailed on layout. }\end{array}$ \\
\hline Submersible & - & - & $\begin{array}{l}\text { Present layout shows } 9 \mathrm{~m} \\
\text { diam. column at waterline } \\
\text { topped by four decks } 25 \mathrm{~m} \\
\text { diam. } \times 3.21 \text { interdeck } \\
\text { height, with space for } \\
\text { accommodations and plant } \\
\text { machinery only. }\end{array}$ \\
\hline Spar & - & - & $\begin{array}{l}\text { Present layout shows } 30 \mathrm{~m} \\
\text { diam. column above water- } \\
\text { line with space for accom- } \\
\text { modations and plant } \\
\text { machinery only. }\end{array}$ \\
\hline
\end{tabular}

Assessment. In all cases, the weight of equipment is small compared to platform weight, so can be included without penalty to capacity or stability. In some cases the added weight of chemical conversion equipment is an advantage since it reduces the need for inert ballast. 
The ship, circular barge, and semi-submersible are all adequate as configured, having sufficient available deck area and volume. The other three configurations will require addition of space for the chemical conversion plant.

Minimum motions in seas is an asset in chemical conversion plant operation. Motions may interfere with the functioning of equipment where liquid levels or orientation are important, or may impede transfer of product to a pipeline or barge. However, no quantitative requirements have as yet not been defined in this area. As a result, smaller motions can be used as a factor in selecting the best of two configurations which are otherwise equal, but no broader judgements can be made.

The suitability for grazing operation is evaluated in terms of the percentage of plant net output consumed in cruising at a speed of $1 \mathrm{kt}$ in still water. The power requirements are scaled down from the $3 \mathrm{kt}$ and assume a thruster motor efficiency of $90 \%$. The results are plotted in Fig. 2-17. They show that the ship, circular barge, and semi-submersible are about equivalent, with the submersible, sphere, and spar requiring higher power. The cost penalty associated with grazing can also be calculated as the product of total plant cost times the percentage plotted in Fig. 2-17.

Recommended Modifications. The chemical conversion plant, for safety reasons, must be contained in a non-submerged compartment or on an open deck. The ship, circular barge, and semi-submersible are adequate in this regard as currently configured. It is suggested that the containment can be within a disk-shaped structure, as shown in Fig. 2-18a, which can be appended to each of the other three configurations as shown in Fig. 2-18b. The tuned sphere and spar as now configured have adequately stout structures to support the added load. The submersible, however, has a waterline column of $9 \mathrm{~m}$ diameter, which is probably too slender to support the superstructure. It is suggested that this column be divided into four columns of $4.5 \mathrm{~m}$ diameter at a centerline spacing of $11.0 \mathrm{~m}$, providing added structural strength while keeping the same waterline area. 


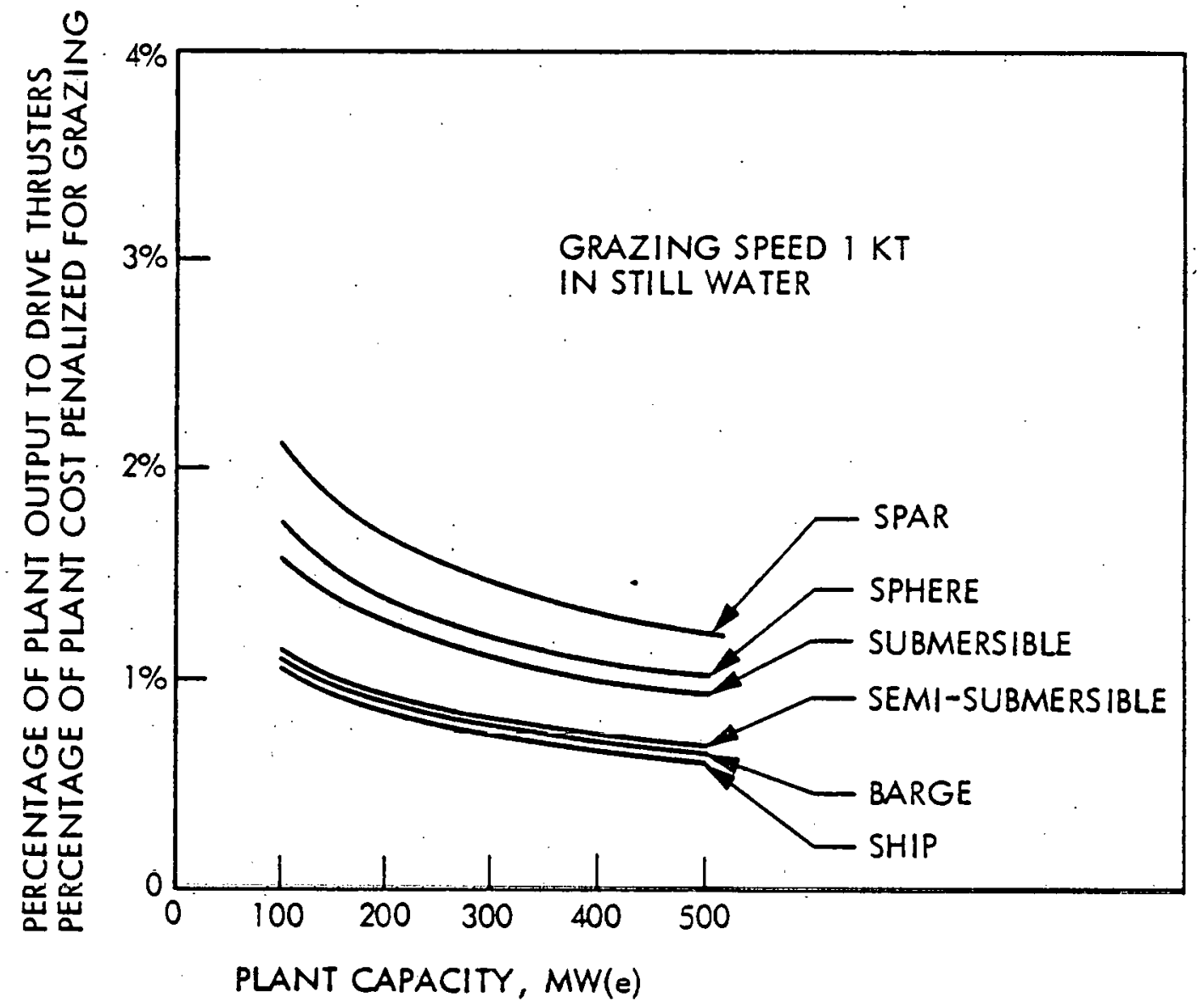

Fig. 2-17 Power and Cost' Penalty for Grazing 


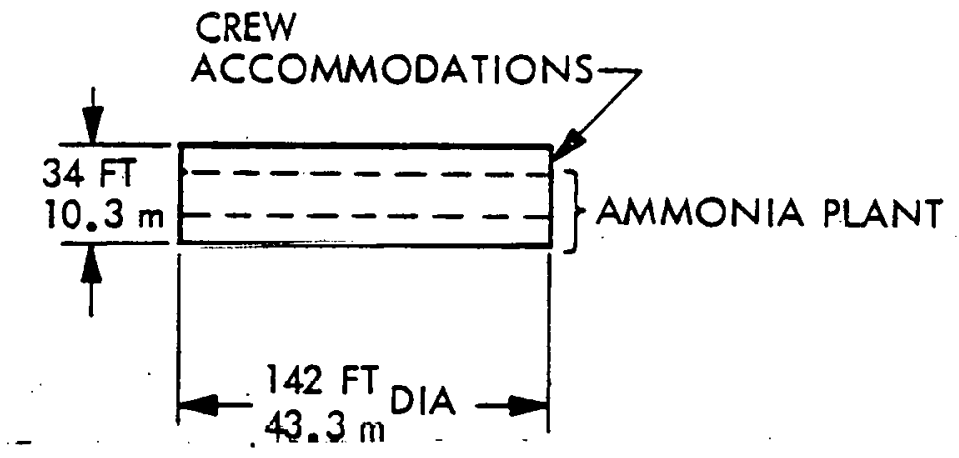

(a) Dimensions of Containment Space

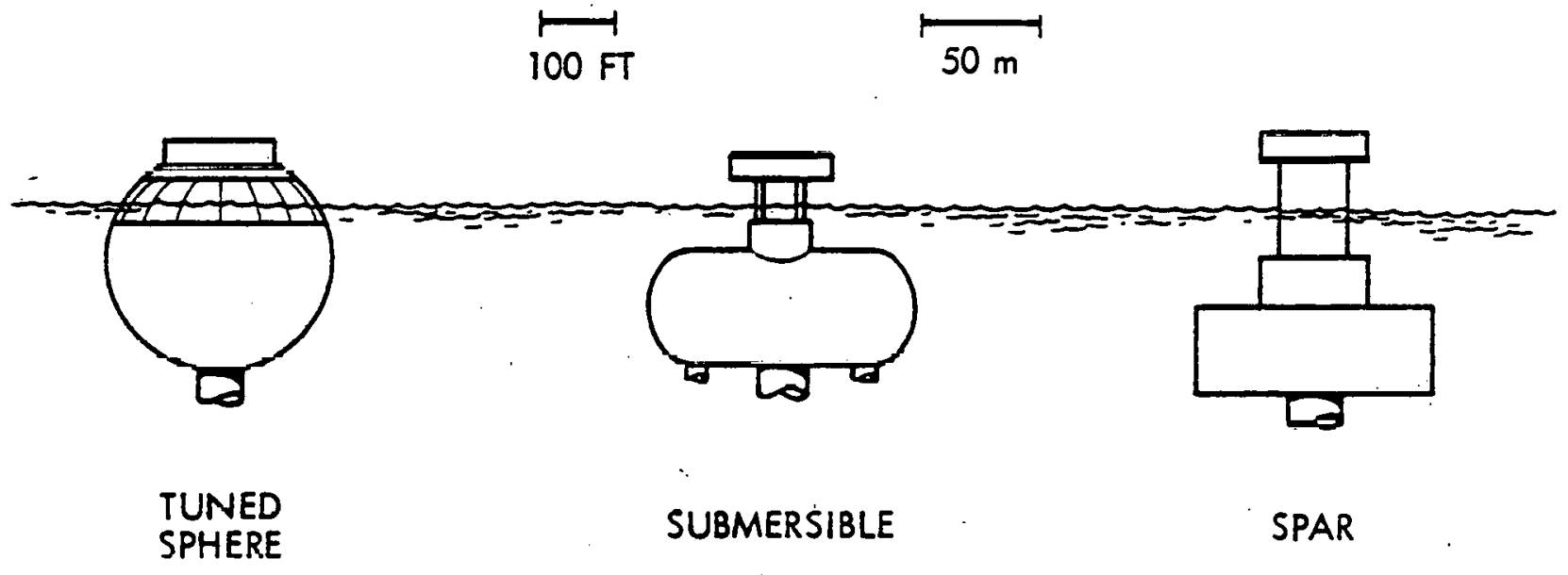

(b) Installation on Platform Configurations

Fig. 2-18 Suggested Chemical Conversion Plant Containment 
2.3.2.6 Evaluation of the APL Plant Ship Concept. The John Hopkins University applied Physics Laboratory (APL) has designed a $100 \mathrm{MW}(\mathrm{e})$ ammonia manufacturing plant ship around twenty of their five MW(e) power modules, which use the "trombone" type heat exchanger. This design is evaluated in comparison with the ship configuration prepared for this study. The main characteristics of the two concepts are listed in Table 2-23.

Table 2-23

COMPARISON OF APL PLANT SHIP DESIGN WITH STUDY SHIP CONFIGURATION

\begin{tabular}{|l|r|r|r|}
\hline \multirow{2}{*}{ Hull Material } & APL Design & \multicolumn{2}{|c|}{ Study Configuration } \\
\cline { 4 - 4 } & $\begin{array}{c}\text { Reinforced } \\
\text { Concrete }\end{array}$ & Mild Steel & $\begin{array}{c}\text { Reinforced } \\
\text { Concrete }\end{array}$ \\
\hline Length (m) & 145 & 165 & 171 \\
Beam (m) & 60 & 66 & 71 \\
Draft (m) & 26 & 25 & 27 \\
Weight (MT) & & & 153,400 \\
Hull and Structure & 36,800 & 40,000 & 56,000 \\
Cold Water Pipe & 12,200 & 56,800 & 329,900 \\
Displacement (MT) & 128,800 & 274,000 & 107 \\
Cost (\$M) & & & 174 \\
Platform(a) & 29 & 6.3 & 10 (b) \\
Cold Water Pipe & & $(\mathrm{b})$ \\
\hline
\end{tabular}

(a) Includes all items except power system and ammonia.

(b) Designed for sea states at Brazil site.

The API platform is smaller than the study configuration. This is the result of using the "trombone" type heat exchanger which lends itself to compact packaging and short, direct seawater flow paths. The heat exchangers are contained in trunks, open at top and bottom, which are integrated into the platform structure. Water-tight compartments comprise a relatively small portion of the total hull volume. The site is relatively benign, with a maximum expected sea state of six. As a result, the concrete 
weight of the APL design is considerably less than that of the study concept, which is a generalized design suitable for various heat exchanger types and sites.

The APL platform appears structurally sound. It is compartmented to give good strength and rigidity, and can be assembled from modules, avoiding the need for extraordinary construction facilities. The assumptions made in the static stability analysis appear valid, and presumably the analysis was done correctly. However, for the dynamic analysis a rigid cold'water pipe attachment was assumed and elasticity in the cold water pipe was ignored. As a result the analysis is questionable in two areas.

- The bending moments and shear at the platform/cold water pipe interface may not be properly estimated.

- The effects of cold water pipe elasticity on platform stability are not included. Excitation of elastic nodes in the cold water pipe can greatly amplify loads and motions for both platform and pipe.

Thus, the cold water pipe design may be inadequate both structurally and in provision for deployment and attachment.

The APL cost estimates for the platform are comparable, on a weight-for-weight basis, with costs used for concrete in this study. However, the $\$ 6.3 M$ estimate for the cold water pipe is in the range of recent estimates for the 1-MTW(e) OTEC-1 cold water pipe, so certainly must be low for a 100-MW(e) capacity pipe, considering even the cost advantages of concrete over other materials.

In summary, the APL design is a good integration of the platform with their particular power system, and is sound from the structural, stability, and producibility standpoint. However, the analysis and design of the cold water pipe may be inadequate and its cost estimate appears to be unrealistically low.

2.3.2.7 Summary. All of the configurations are suitable as platforms for chemical conversion energy transfer, either as presented or with the suggested modification to add containment space. All other things being equal, the platform with the least motion 
in seas is the most desirable. Existing requirements on motions are not well enough defined to provide a more definitive criterion. In grazing operation, the ship, circular barge, and semi-submersible have the smallest thruster power requiremént, with the others requiring up to twice the power.

\subsubsection{References.}

1. Carnegie-Mellon University, Department of Civil Engineering, Effects of Oceanic Flow Patterns on the Thermal Efficiency of Ocean Thermal Energy Conversion (OTEC), by D. J. Fry, C00/2895-3, Pittsburgh, Pa. , Apr 1976

2. University of Hawaii, Department of Ocean Engineering, A Further Evaluation of the Oceanographic Conditions Found Off Keahole Point, Hawaii, and the Environmental Impact of Nearshore Ocean Thermal Energy Conversion Plants on Subtropical Hawaiian Waters, by Karl H. Bathen, Nov 1975

3. Institute of Gas Technology, IIT Center, Optimization Study of OTEC Delivery Systems Based on Chemical-Energy Carriers, by Alex J. Konopka, Abu Talib, Bernard Yudow, and Nicholas Biederman, ERDA/NSF/00033-76/T1, Chicago, III., Dec 1976 


\subsubsection{Seawater System}

The seawater system is the second most significant subsystem of the platform in cost, size, and impact on the net power output of the plant. The following five subsystems have been analyzed and design guidelines have been developed for incorporating them in the platform.
(1) Cold water pipe
(2) Seawater pumns
(3) Platform/CWT transition
(4) Water ducts
(5) Biofouling/corrosion control

The optimum plant integrates these components with each other and with the hull and power systems within the constraints of the platform. Because of the large portion of the platform devoted to the seawater system, it is necessary to optimize the size, cost, and performance of all elements of the system. This section identifies the characteristics of the most satisfactory design of the major elements of the seawater system. 
2.3.3.1 Cold Water Pipe. The cold water pipe (CWP) conducts cold seawater to the cold water plenum in the OTEC platform and is therefore an essential element of the Seawater System. The pipe extends from a depth dependent on the site temperature profile to the platform/CWP transition depth, which varies with platform type.

A baseline design concept and alternative approaches are presented in this section. Design features, including size, material, loads, structure, construction, and deployment are presented to (1) demonstrate concept feasibility and (2) to illustrate design variability between candidate platforms and sites. CWP variability is incorporated in the evaluation process, thereby allowing discrimination between platforms.

Cold Water Pipe Size. The diameter is the sum of inside diameter based on required seawater flow rate and structural wall thickness, while the length is the difference between inlet depth based on seawater temperature difference requirement and depth of hull/CWP transition.

A review of the temperature difference profiles for the five candidate sites (Ref. 1) reveals a wide variation with site and season. The fraction of time during which delta temperature is below a minimum of $16.7^{\circ} \mathrm{C}$ and above a desired operating level of $22.2^{\circ} \mathrm{C}$ at depths of $600 \mathrm{~m}$ and $1000 \mathrm{~m}$ is reviewed. At $1000 \mathrm{~m}$ depth the desired delta temperature is available at least half time at three sites, and quarter time at two sites. Further, the minimum temperature is exceeded all year at all sites except New Orleans. The desired delta temperature is not available at $600 \mathrm{~m}$ depth except at the Brazil site where it is available quarter time. Therefore, $1000 \mathrm{~m}$ depth is selected as the requirement for cold water inlet depth. This requirement is assumed to be independent of platform net power output.

\begin{tabular}{|l|c|c|c|c|}
\hline \multirow{2}{*}{ Site } & \multicolumn{2}{|c|}{$\begin{array}{c}\text { Percent of Time } \\
\text { Below 16.7 } \mathrm{C} \Delta \mathrm{T}\end{array}$} & \multicolumn{2}{c|}{$\begin{array}{c}\text { Percent of Time } \\
\text { Abovc } 22.2^{\circ} \mathrm{C} \Delta \mathrm{T}\end{array}$} \\
\cline { 2 - 5 } & $600 \mathrm{~m}$ & $1000 \mathrm{~m}$ & $600 \mathrm{~m}$ & $1000 \mathrm{~m}$ \\
\hline Hawaii & 0 & 0 & 0 & 25 \\
New Orleans & 38 & 17 & 8 & 29 \\
Puerto Rico & 21 & 0 & 0 & 58 \\
Key West & 31 & 0 & 0 & 45 \\
Brazil & 0 & 0 & 25 & 53 \\
\hline
\end{tabular}

$2-67$ 
The inside diameter, determined by required flow rate, is obtained by an optimization program which seeks minimum life-cycle costs for seawater pumps, pipe, and power. The optimum inside diameters for 100, 200, and 500-MW(e) (net) output are 16.4, 22.7 , and $34.9 \mathrm{~m}$, respectively. The flow rates associated with these sizes are $5.7 \times 10^{3}, 11.4 \times 10^{3}$, and $28.4 \times 10^{3} \mathrm{~m}^{3} / \mathrm{sec}$, respectively. The wall thickness is dependent on CWP material and loading. Based on results of analytical studies for concrete pipe, a wall of $0.61 \mathrm{~m}$ was selected to provide sufficient bending strength under dynamic loading in severe seaways. The resultant thickness-to-diameter ratio of 0.037 held constant, yields outside diameter of $17.6,24.4$, and $37.5 \mathrm{~m}$.

Cold Water Pipe Material. Several candidate materials presently under investigation in various OTEC studies are concrete, glass reinforced plastic, steel, aluminum, and rubber. Steel reinforced precast concrete is selected for its high weight, large outside diameter of pipe, low maintenance, and potentially low cost (Ref. 2). The first two features cause concrete CWP to have a greater impact on platform requirements (greater buoyancy, large diameter of CWP/hull interface) than lighter pipes of alternate materials. Consequently, greater data range is provided for platform discrimination.

Material properties include modulus of elasticity equal to $3 \times 10^{6} \mathrm{psi}$, density of 150 $\mathrm{lb} / \mathrm{ft}^{3}$, and maximum compressive strength of 5000 psi for reinforced concrete.

Cold Water Pipe Loads. The CWP is loaded statically by its own weight, by the seawater moving inside, externally by the current, at the upper end by the platform, and by wave action. The primary loading is shown to be loads induced on the CWP by wave foroes on the platform. These dynamic loads are dependent on platform motion response; heading; wave severity; depth of pipe attachment; pipe material, size, and stiffness; and of the platform/CWP interface. The sensitivity and trend of these loads to parameter variations is summarized in this section. A linear superposition of stresses for a specified loading case indicates the significance of dynamic bending stress with respect to resultant stress. 
The maximum bending moment occurs on the CWP at different depths depending on pipe material, platform, and other parameters. This moment characterizes the CWP dynamic loading condition and is used to illustrate the influence of pipe material and wave height (Fig. 2-19). The amplitude of peak moment is approximately two to three times the significant values; while the significant value is four times the rms moment. Moment is seen to increase with wave height from the sea state 6 condition to the 100-yr storms at the candidate operational sites by a factor of 10 in one case. The moment on the aluminum case exceeds that on the GRP and concrete pipe with segments. The concrete pipe without joints experiences the largest moment, five times the segmented pipe moment. With exceptions moment is lowered by reducing material modulus.

Bending stress is seen to be lowest for the segmented concrete CWP and highest for aluminum (Fig. 2-20). However, allowable stress levels are higher for aluminum. The segmentation reduces stress levels by a factor of 4 . The range of stresses in CWP attached to the six different platform types is $0.9 \times 10^{\mathrm{J}} \mathrm{psi}$ to $1.47 \times 10^{3} \mathrm{psi}$, with the semi-submersible producing the lowest stress and the circular barge the highest for a segmented concrete pipe of 2-ft wall thickness for a significant wave height of $45.8 \mathrm{ft}$. The spar with a high attachment point $(60 \mathrm{~m}$ depth vs. $115 \mathrm{~m}$ ) has a $45 \%$ lower bending stress. This indicates the desirability of optimizing the height of the attach point. Heading of the ship, semi, and submersible platforms also affects dynamic bending stress in the 100-year storm conditions. Therefore, heading control in extreme condition. is one approach to minimizing stresses and pipe wall thickness.

Maximum significant shear force increases with wave height and varies with CWP material in a manner similar to the variation of bending moment (Fig. 2-21). The effect of increasing pipe wall thickness generally decreases maximum stress if the thickness is increased significantly, otherwise the stress may actually be higher for a CWP with larger wall thickness. This may be attributed to higher pipe stiffness and resonance with a lower modal period with increasing thickness. 


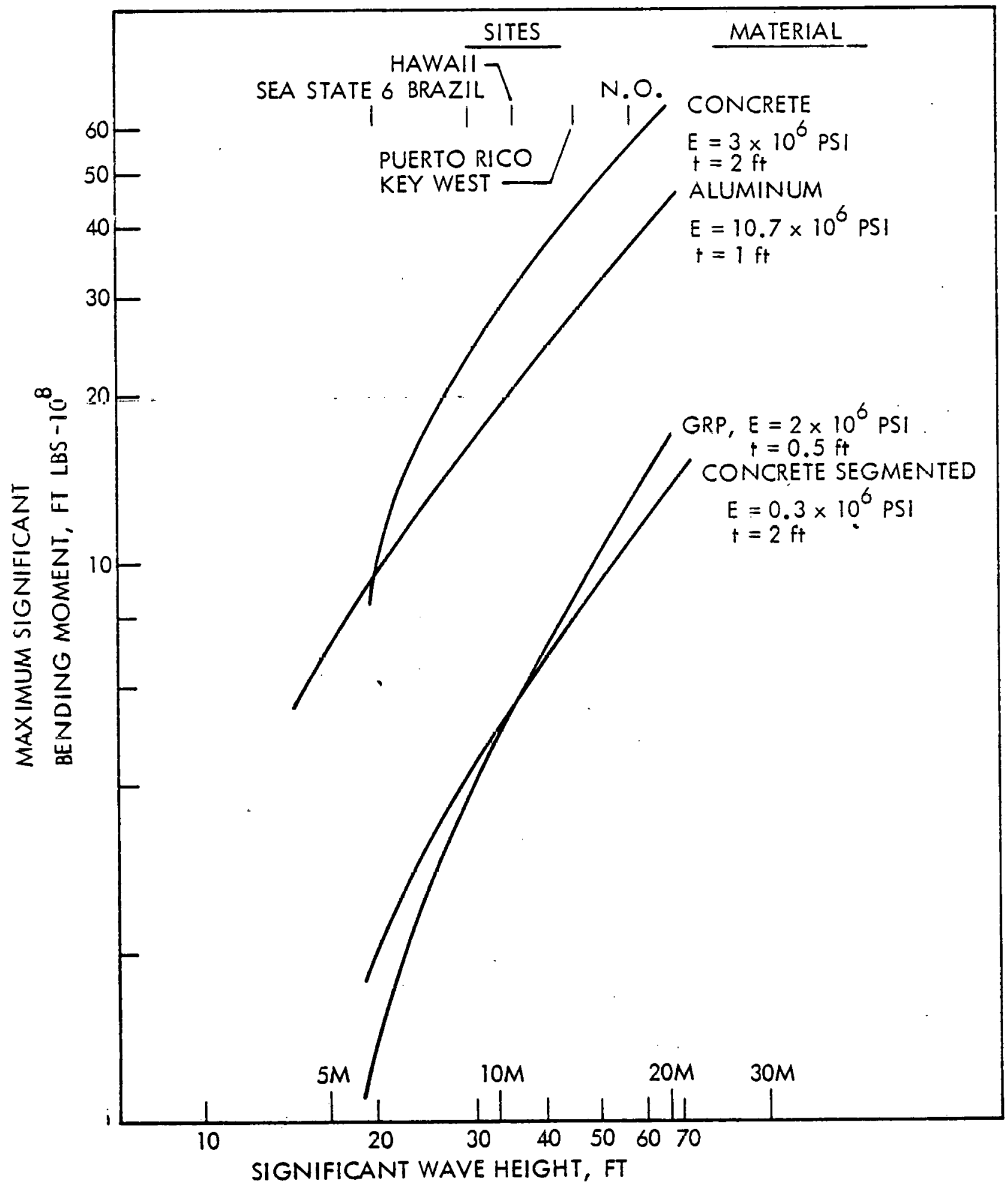

Fig. 2-19 Influence of CWP Material on Maximum Significant Dynamic Bending Moment - 100-MW(e) Net Spar 


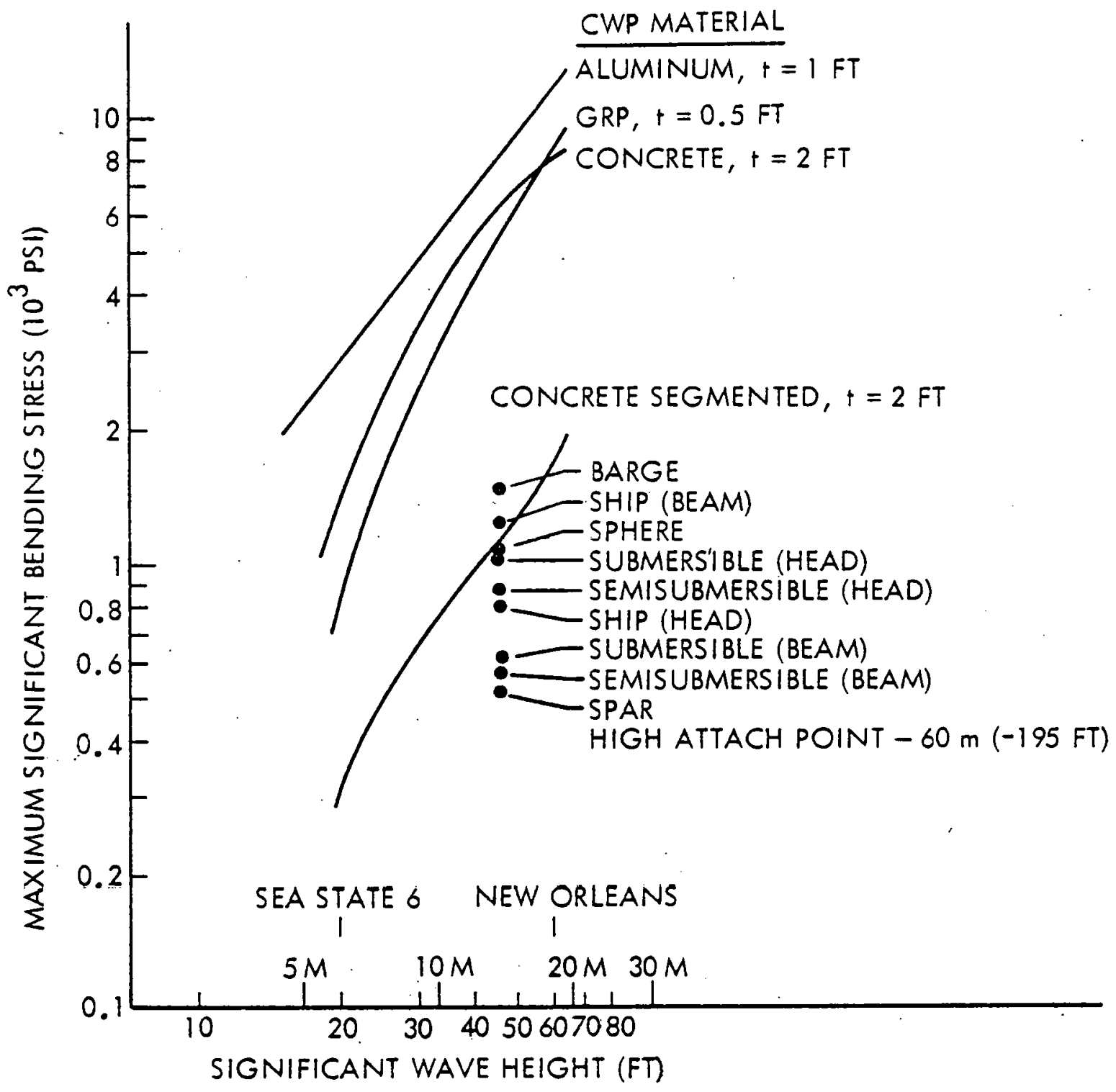

Fig. 2-20 Influence on CWP Material on Naximum Significant Dynamic Bending Stress - 100-NWW(e) Spar

$$
2-71 \text {. }
$$




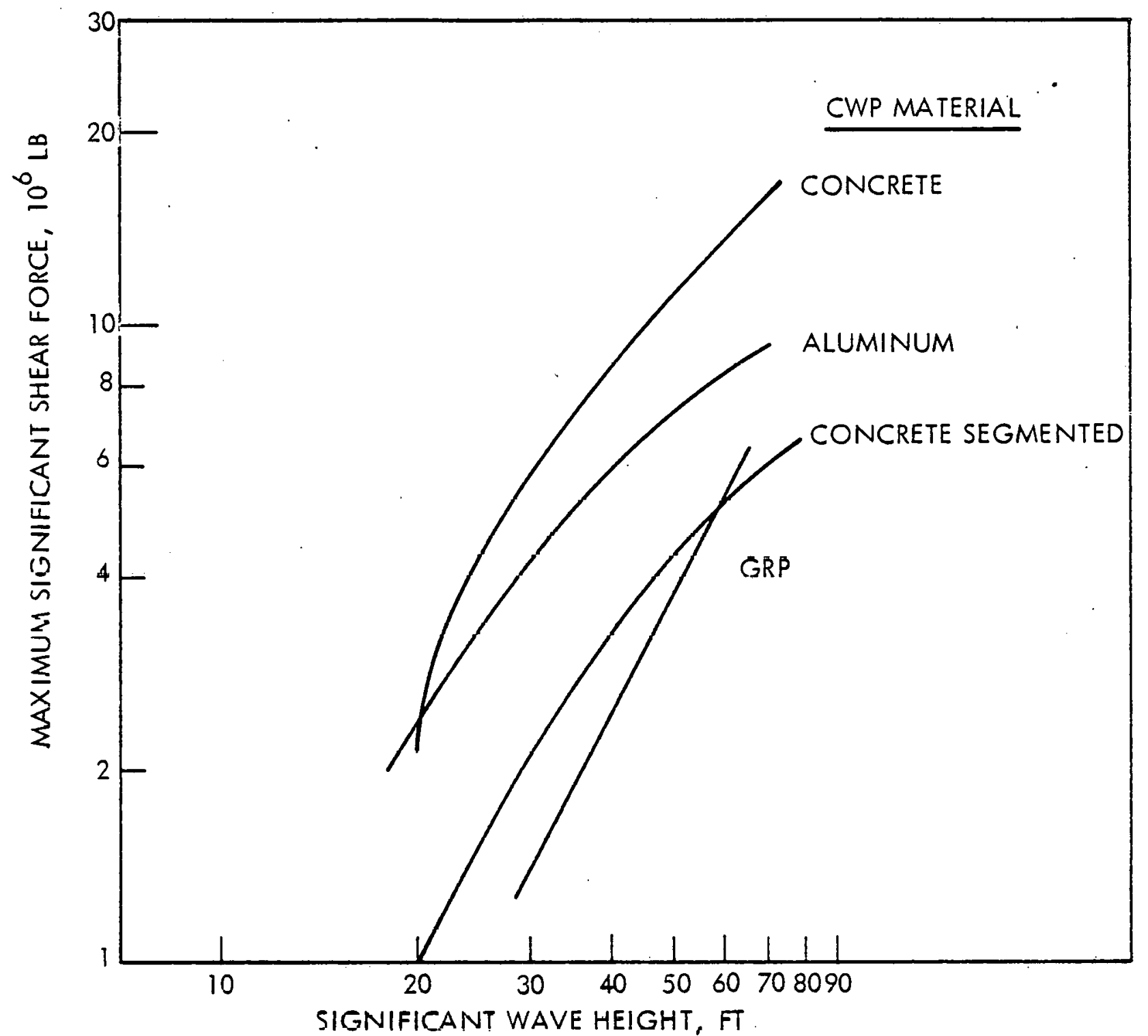

Fig. 2-21 Variation of Maximum Significant Shear in CWP With Wave Height and Pipe Material-100-MW(e) Spar

A stress analysis of the baseline $100 \mathrm{MW}(\mathrm{e})$ (net) CWP concept including both static and dynamic loads reveals the variation of resultant stresses. Loads include static weight, current shear and moment, dynamic shear, moment and axial force diue to platform and wave forces, and pressure differential. Stresses at three depths where CWP dynamic moments are high were computed for the ship iil a six knot current, quartering seas, 100 year storm in New Orleans. The results are summarized in Table 2-24. At the attachment depth of $13.6 \mathrm{~m}$ the dominant stress component is axial tension due to pipe weight, while at $121 \mathrm{~m}$ depth the dynamic bending stress is 57 percent of the resultant stress. 
Table 2-24

STRESS ANALYSIS OF CWP

100-MW(e) Ship, New Orleans, 6-Knot Current, Concrete $\mathrm{CWP}, 0.3 \times 10^{6} \mathrm{psi}$

Stiffness of attachment to platform $=10^{9}$ in roll \& pitch, ${ }_{s}=17.7 \mathrm{~m}(58.1 \mathrm{ft})$

\begin{tabular}{|c|c|c|c|c|c|c|c|c|c|}
\hline \multirow{2}{*}{ Depth (m) } & \multicolumn{4}{|c|}{ Static Stress (psi) } & \multicolumn{3}{|c|}{ Dynamic Stress (psi) } & \multirow{2}{*}{ Resultant (psi) } & \multirow{2}{*}{$\begin{array}{c}\text { Safety } \\
\text { Factor on } \\
\text { Ultimate }\end{array}$} \\
\hline & Axial & Shear & Bending & Hoop & Axial & Bending & Shear & & \\
\hline 13.7 & 1105 & 33.5 & 238.4 & 21.0 & 121.5 & 191.7 & 70 & 1663 & 3 \\
\hline 122.0 & 967 & 5.7 & 0.5 & 18.0 & 106.0 & 1453.0 & 31.6 & 2527 & 2 \\
\hline 867.0 & 145 & 0.1 & 0 & 2.8 & 16.0 & 1500.0 & 20.5 & 1651 & 3 \\
\hline
\end{tabular}

The necessary thickness of the wall of the pipe has been estimated for two platforns (barge and spar) to meet the requirements for the dynamic bending stress with an approximate consideration for the other pipe stresses.

The estimated wall thickness increases rapidly with significant wave height. The lower limit for wall thickness in low sea conditions is dictated by buckling criteria for the CWP (Ref. 2) for both stiffened and unstiffened pipe structures, Fig. 2-22. The glass reinforced plastic (GRP) pipe requires the smallest wall with the flexible joint, segmented concrete requiring the thickest. There has been extensive extrapolation of the principal data to derive these results. However, the trends are reasonable and the magnitudes are certainly representative of the needed wall thicknesses. Refinements to the CWP design solution, as illustrated by the two foot thinner wall resulting from the raised attachment of the concrete pipe to the spar, are needed in the final optimizing of the pipe, platform and power systems. At this point, it is sufficient to note that the cost of material for the cold water pipe is highly variable. It changes with site since survival in the extreme local storm is the design criteria for the CWP. 


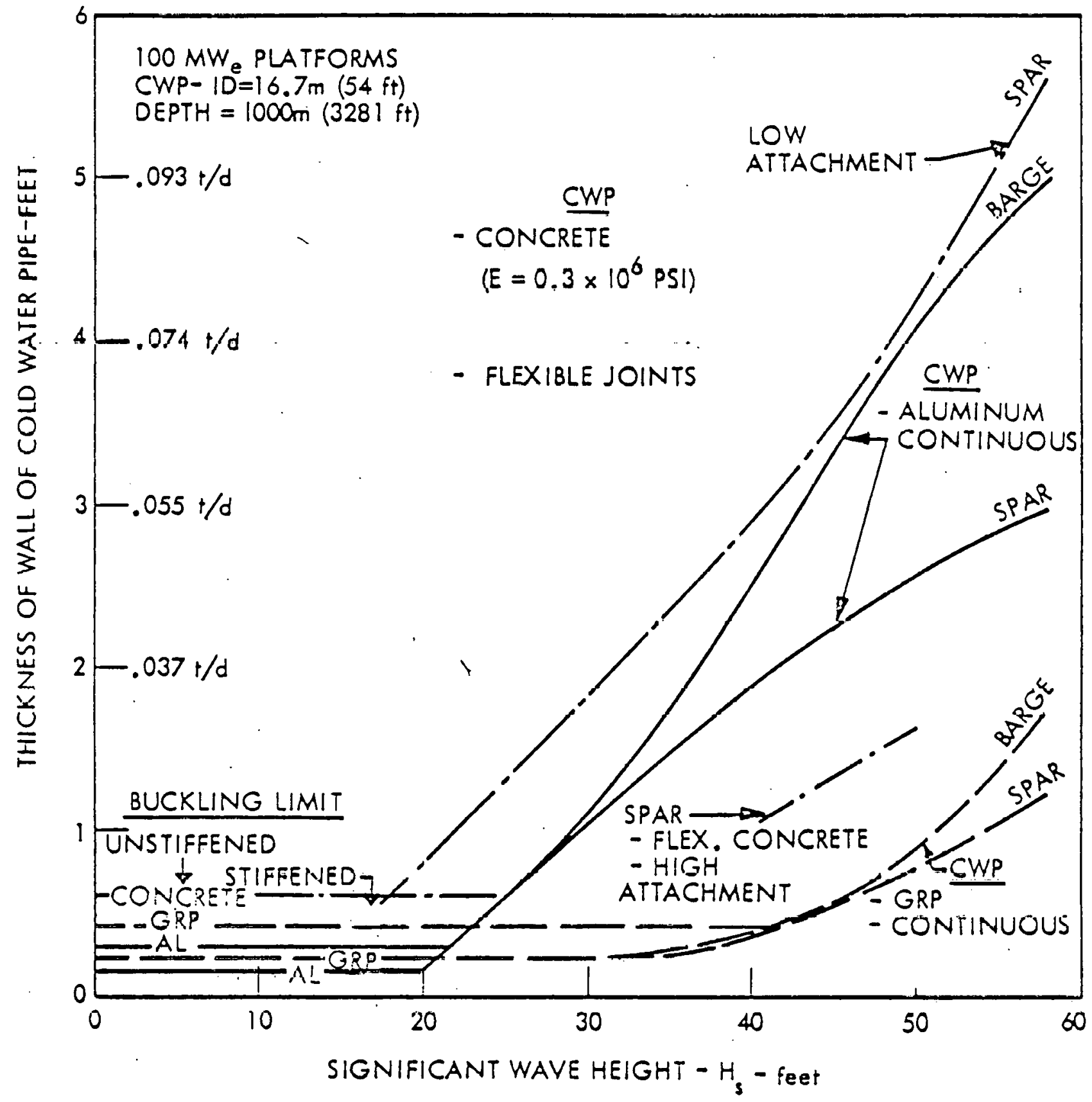

Fig. 2-22 Wall Thickness of CWP for 100-MW(e) Platforms as Functions of Significant Wave Height 
The effects of platform on the CWP are evident as these two example platforms require widely differing wall thickness $(3 \mathrm{ft}$ vs $5 \mathrm{ft}$ for two platforms with aluminim pipe). Other platforms cause smaller dynamic bending stresses and require an even wider range of wall thickness.

Costs have been derived for steel reinforced concrete pipe and these have been extended to estimate costs of these pipes of varying wall thickness, Table 2-25. The importance of platform induced loads on the cost of this subsystem is emphasized by the 2.4 to 1 range in costs for each site and a 2 to 1 range in cost among these four sites. Those platforms having high costs for this design would be modified downward by an optimization with the power system loading to a smaller diameter pipe and/or a shorter length pipe. It should be observed that the estimated cost for the CWP on the barge at New Orleans is 85 percent as costly as the concrete structure of this barge.

Cold Water Pipe Structure. The cold water pipe is a thin-walled shell of reinforced concrete material. Characteristics of the baseline design concept are identified in Table 2-26 for a 100 MW(e) (Net) plant output.

Table $2-25$

ESTIMATED COSTS FOR FLEXIBLE JOINTED CONCRETE COLD

WATER PIPE, BOTTOM AT $1000 \mathrm{METER}(3,281 \mathrm{FT})$,

$\mathrm{E}=0.3 \times 10^{6} \mathrm{PSI}, 100 \mathrm{MW}(\mathrm{e})(\mathrm{NET}) \mathrm{CAPACITY}$

\begin{tabular}{|l|c|c|c|}
\hline \multicolumn{1}{|c|}{ Site } & Hawaii (\$M) & $\begin{array}{c}\text { Key West, } \\
\text { Puerto Rico (\$M) }\end{array}$ & New Orleans (\$M) \\
\hline Significant Wave Height & 35.9 & 45.8 & 58.1 \\
\hline Platform Trpe & & & \\
Ship (Beam) & 23.3 & 33.5 & 47.0 \\
Barge & 16.3 & 24.1 & 37.3 \\
Semi & 16.5 & 23.1 & 31.6 \\
Tuned Sphere & 21.3 & 24.3 & 39.2 \\
Submersible & 20.3 & 27.6 & 36.8 \\
Spar - high attachment & 9.4 & 13.2 & 19.6 \\
& & & \\
\hline
\end{tabular}


Table 2-26

COLD WATER PIPE BASELINE DESIGN

\begin{tabular}{|c|c|c|c|}
\hline \multirow{2}{*}{ Characteristic } & \multicolumn{3}{|c|}{ Net Power Output (MW (e)) } \\
\hline & 100 & 200 & 500 \\
\hline Depth of Lower End (m) & 1000 & 1000 & 1000 \\
\hline Depth of Upper End (m) & $25-120$ & $25-120$ & $42-133$ \\
\hline Length (m) & $880-975$ & $880-975$ & $867-958$ \\
\hline Inside Diam. (m) & 16.4 & 22.7 & 34.9 \\
\hline Length/D & 60 & 43 & 27 \\
\hline Thickness/ID & 0.037 & 0.037 & U. U.' \\
\hline Wall Thickness (m) & 0.61 & 0.84 & 1.29 \\
\hline Outside Diam. (m) & 17.6 & 24.4 & 37.5 \\
\hline Weight/Unit Length (LT/Ft) & 17.67 & & \\
\hline Weight/Unit Length in Water ( $\mathrm{LT} / \mathrm{Ft}$ ) & 7.62 & & \\
\hline Concrete Volume, $\mathrm{Yd}^{3} / \mathrm{Ft}$ & 9.77 & 19.0 & 44.7 \\
\hline Concrete Pipe Cost, $\$ M$ & & & \\
\hline Spar with High Attachment & & & \\
\hline Designed for $\mathrm{N} . \mathrm{O} \cdot\left(\mathrm{H}_{\mathrm{g}}=58.1 \mathrm{ft}\right)$ & 19.7 & 41.2 & 95 \\
\hline
\end{tabular}


The pipe consists of a series of sections joined with structurally continuous bearings such as neoprene rubber. The top of the upper section is flanged to distribute the CWP weight onto the hull/CWP interface bearing (Section 2.3.3.3). To reduce the weight, the wall of each section has 25-percent void spaces. The inner and outer surfaces are unobstructed by stiffeners. Steel reinforcing tendons provide axial and circumferential prestressing. Subsections are precast in a shore facility in $15-m$ lengths. This is accomplished by slip-forming vertically oriented subsections. Three subsections are then assembled by gluing the ends together and post-tensioning the now completed 45-m-long section in the horizontal position. Each section (2650 tons) is then lifted by overhead crane aboard a barge for towing to the operational site where final assembly of the CWP is completed.

The joint connects each $45-\mathrm{m}$ section together to form a continuous pipe. The joint provides a method of CWP installation and a means to reduce seaway-induced peak bending stresses in the pipe. Based on the analytical prediction of bending stresses, a preliminary estimate of joint rotational stiffness is $1 \times 10^{9} \mathrm{ft}-\mathrm{lb} / \mathrm{radian}$. Ongoing analytical effort will provide further guidelines on the significance of segment length and joint axial and rotational stiffnesses in reducing CWP stresses.

The joint design concept shown in Fig. 2-23 will provide stiffnesses in the range required. The joint consists of an elastomeric element of 17.7-m OD, 16.5-m $\mathrm{ID}$ and 1.5-m length. The steel ring assembly is prefabricated and installed on each pipe section.

An element of 40 Shore hardness will experience a 40 -psi shear stress at the upper section of the CWP under static conditions and will rotate a maximum of 2 deg as shown. This level of rotation adds an average of 25 psi stress to the extending side. The angular stiffness of this design is approximately $4 \times 10^{9} \mathrm{ft}-\mathrm{lb} / \mathrm{radian}$, and axial stiffness is $7 \times 10^{7}$. The rubber in the upper pipe sections is stressed to 1000 psi tension. Alternate materials for these sections will be sought. The equivalent modulus of a non-segmented CWP having equal deflection is $0.3 \times 10^{6} \mathrm{psi}$. 


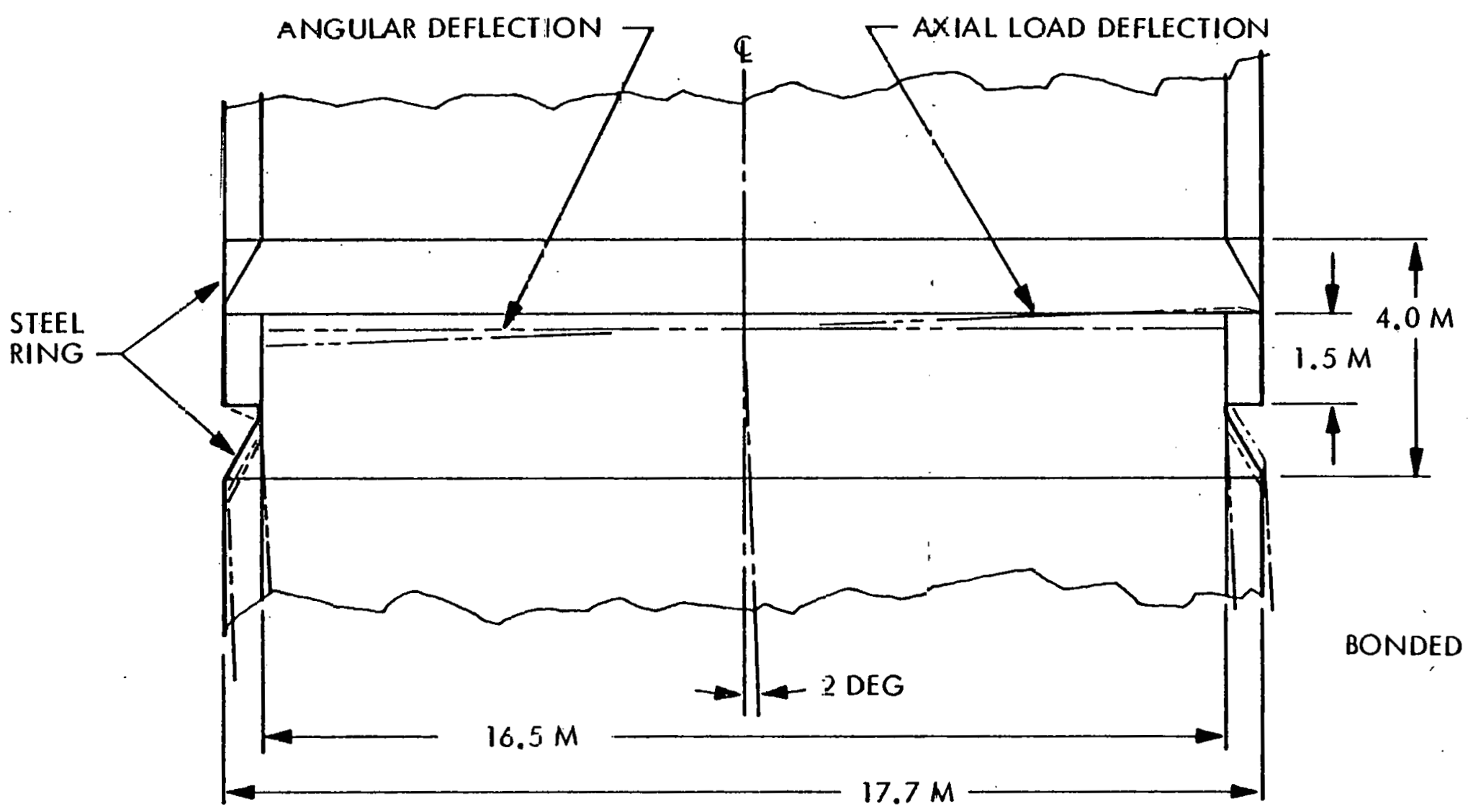

Fig. 2-23 Cold Water Pipe Joint Concept 
Cold Water Pipe Assembly and Installation. The CWP installation sequence is presented in this section. Features of the pipe, equipment required, sequence of steps, and duration of process are presented. Costs for deployment and installation of the CWP including the effect of platform size, type, and site are treated.

The pipe sections are towed on a barge to the moored platform at the operational site. The barge is rafted to a crane vessel which in turn is rafted to the OTEC platform (see Fig. 2-24). A ring structure consisting of hydraulic jacking equipment is assembled in the platform center well on a temporary spacer structure. The conceptual design of this system is based on data (provided by Earl and Wright) which is indicative of state-of-practice in offshore oil jackup rigs. The largest of these rigs is approximately 25,000 mt. There are twelve hydraulic cylinders of 2-m diam. and

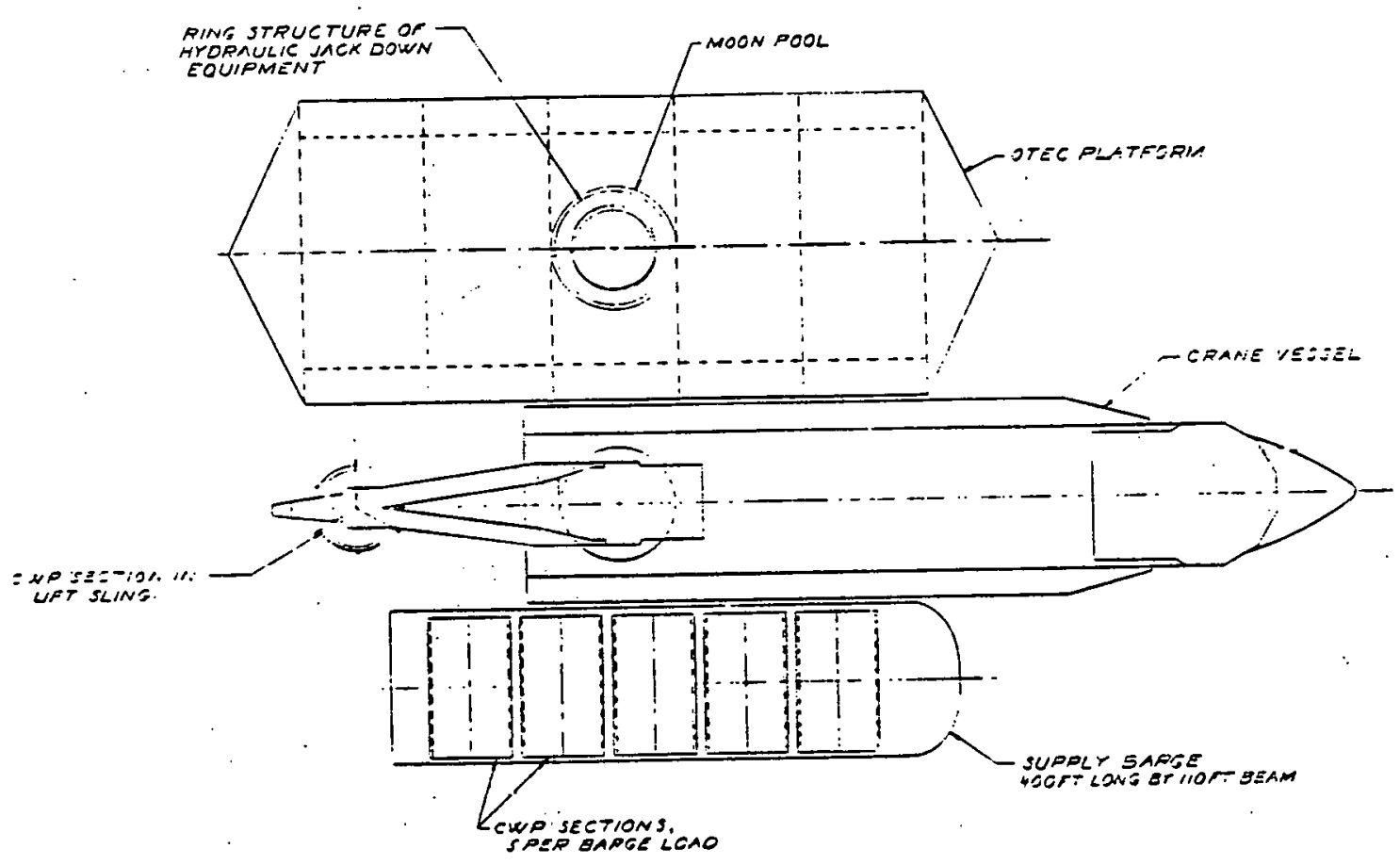

Fig. 2-24 CWP Section Supply and Handling Arrangement 
3.6-m stroke. Each cylinder connects an upper and lower segmented ring and each ring contains 24 gripping shoes. A control system providing semi-automatic operations yields equal, continuous hydraulic operation.

The assembly and installation sequence for the CWP on a 100-MW(e) (net) ship platform is illustrated in section views in Fig. 2-25. All platform designs feature a center well for CWP installation following this procedure. The first CWP section is hoisted and levered into the center well by the crane with a 3-point sling assembly with the jacking cylinders extended (Step 2). Depending on platform type and size, as well as site, an unboard overhead crane may be required in addition to the crane on the crane vessel rafted to the platform. With the first section supported by the lower ring, the second pipe section is positioned above the first, using the upper ring for position control (3), and the elastomeric joint is bonded onto the lower section (4). The bonding takes place above the waterline. Upon completion of curing, the two-section assembly is lowered, the lower ring assembly holds the pipe, and sequences (3) and (4) are repeated until the required assembled CWP length, less one section, is completed.

At this stage a ring of sabot blocks is installed on the upper deck on the center well rim. The final CWP section, with upper flange, is lowered onto these blocks and the joint completed. The jacking structure is removed from the well and relocated onto supporting structure on the main deck. The elastnmeric hearing blocks oomprieing the platform/CWP interfaces are positioned below the waterline.

The lower ring shoes hold the CWP while the upper ring is extended to receive a section of CWP. This section serves as a lowering fixture and is bolted to the upper end of the CWP (6). The final lowering operation is completed by alternate gripping by the upper and lower rings until the flange is seated on the elastomeric bearing. The fixture joint is de-bolted, removed and reaction rings are installed above the upper bearing columns to preload these blocks. The CWP is thereby assembled and installed (7).

To accomplish the lowering operation using the hydraulic grip shoes, lifting grooves are required in the CWP outer wall (see Fig. 2-26). This groove pattern is formed during the pre-casting operation of section segments. 


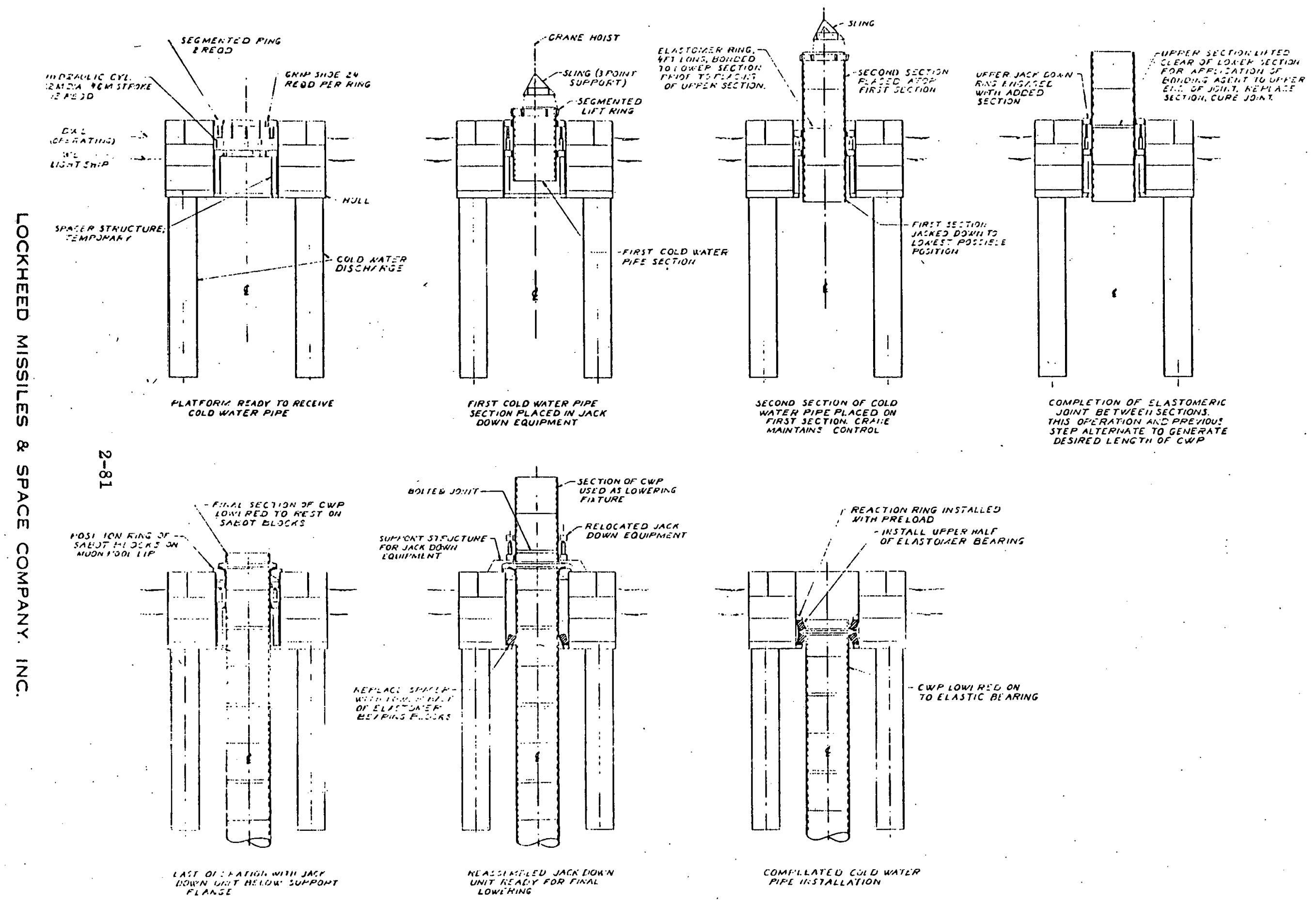

Fig. 2-25 Assembly and Installation Sequence for 100 Megawatt Cold Water Pipe 

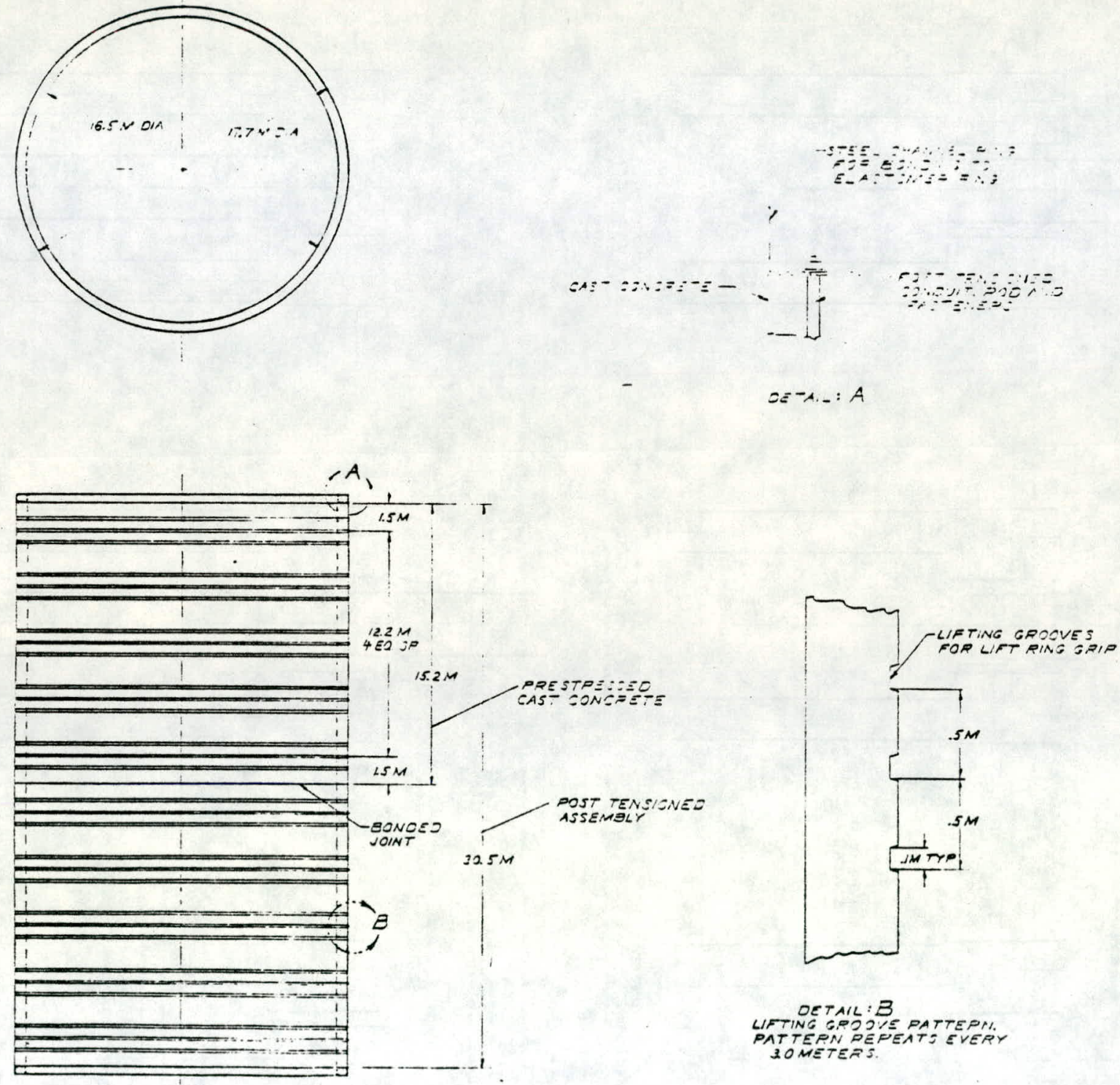

Fig. 2-26 Detail of Cold Water Pipe Section 
The assembly and sequence described represents a major offshore operation. An estimate of time to complete this operation using $30 \mathrm{~m}$ long sections is 98 days on the following basis:

Hydraulic cylinder capacity $-4 \mathrm{ft} \times 15 \mathrm{ft} \times 12=2262 \mathrm{ft}^{3}$ oil (16,919 gal.) Complete $1 / 2$ cycle, $16919 \mathrm{gal} . / 150 \mathrm{gpm}=112.79 \mathrm{~min}$.

Seven full cycles required/section, or $26.32 \mathrm{hr} / \mathrm{section}$

Install section, make and cure joint -36 hrs

Time per section -62 hrs (2.6 days)

Total for 30 sections -78 days

Down time $-25 \%$

Time to completion - 98 days

Time to completion for $45 \mathrm{~m}$ sections is 75 days. The estimated cost for CWP deployment is $\$ 23 \mathrm{M}$ to $\$ 28 \mathrm{M}$.

Alternatives to this approach to CWP installation involve completion of CWP assembly on shore followed by towing to site, upending and floating CWP into position in the platform. The latter step may be completed by attaching the CWP to the side of the platform either structually or through a flexible hose to carry the cold seawater from a floating spar pipe separately moored or tied to the platform. The pipe may be floated into an open well between the outer hulls of a catamaran-like platform. Another option is to flood the CWP down under the surface followed by pipe positioning below the platform keel under the pipe transition, deballasting the pipe and attaching it to the bearing. In any case, these alternatives require a major ballasting system and buoyancy collar to float the 25,000 ton structure after the upending stage. A twin-hulled shape is limited to surface platforms so that for the submerged platforms structural completion at the operations site is required. The selected approach is within the state of practice in offshore technology and is considered to be the most feasible in applicability to all platforms under investigation.

A crane temporarily installed on the OTEC platform to handle the CWP segments would avoid relative motion problems between the crane barge and the jacking ring on the platform. 
2.3.3.2 Sea Water Pumps. The seawater pumps are a critical element in the OTEC plant since the major parasitic power consumption is in these pumps providing the necessary water flow to the heat exchangers and primarily overcoming the flow losses in the heat exchanger. Because of the necessary size of the pumps and a desire for redundancy/serviceability multiple pumps are generally considered. LMSC has extended the analysis of Westinghouse (Ref. 3), with additional data obtained in the Test Facilities Study, and for ongoing power system development efforts. The results of this analysis differ primarily in that the economy of scale is predicted to he much less than reported by WEC.

The pump outer casing radius was determined to he well represented by $r_{0}-0.316 Q^{1 / 2}$ (meters), where $r_{0}$ is the outer casing radius and $Q$ is the flow rate through the pump in $\mathrm{m}^{3} / \mathrm{s}$. This corresponds to a specific speed of approximately 5000 . The average axial velocity through the runner is $4.54 \mathrm{~m} / \mathrm{s}$, which is a good conservative value for cavitation concerns. WEC proposed a higher velocity $(8.27 \mathrm{~m} / \mathrm{s})$ for two candidate designs of pumps. These may be achievable, and may be necessary if they are to be fabricated in existing facilities which appear to be limited at about a $3 \mathrm{~m}$ radius. One large pump per circuit per 25 MWe net module would be pressing the fabrication limit. Multiple pumps in the circuit would require much smaller sizes $(2 \mathrm{~m})$ which are more readily accommodated by existing facilities.

Cost data for a series of pumps in the range of interest from the same vendor are well represented by the following:

$$
\text { Cost }(\$ K)=121(\mathrm{D})^{1.68}
$$

where $D$ is the diameter of the outer casing $\left(=2 r_{0}\right)$, and 121 is an empirical fit to one representative set of date.

The trend with size, represented by the exponent on the diameter of 1.68 , is a straight line fairing through the slopes of several data sets in this range of size. There is a 
small concave upward curvature to the data which is not fully reflected by the exponential fitting. However, in the range of current interest for OTEC flow rates per pump, 10 to $100 \mathrm{~m}^{3} / \mathrm{s}$, the trend is well represented up to about $50 \mathrm{~m}^{3} / \mathrm{s}$. Greater comparative costs than this trend are likely for pumps with greater than $50 \mathrm{~m}^{3} / \mathrm{s}$ capacity.

These two functional relations result in seawater pump costs as a function of the required flow rate as follows:

$$
\frac{\text { Cost }}{\mathrm{Q}}=55.8 \frac{1}{\mathrm{Q}^{.16}}
$$

This function compares with that reported by WEC (Ref. 3)

$$
\frac{\operatorname{Cost}^{\text {(WEC })}}{Q}=239 \frac{1}{Q^{.616}}
$$

These two functions give the same cost for a pump capacity of approximately $25 \mathrm{~m}^{3} / \mathrm{s}$, while the LMSC function predicts twice the cost as predicted by WEC for $100 \mathrm{~m}^{3} / \mathrm{s}$. Figure 2-27 presents these cost data and the two cost models.

It is important to note that while this new LMISC cost model presents a good fit for this sizing up of pumps, the magnitude of estimates of pump costs from various vendors vary by a factor of $2-1 / 2$ for the similar requirements. This variability emphasizes the problem of utilizing random data in developing cost trends. It is believed that the new LMSC function is a good scaling model and that it represents a potentially good price in a competitive market.

Costs have been developed for four pump capacities which in multiples total $100 \mathrm{~m}^{3} / \mathrm{s}$ flow rate (approximately that required for one circuit of a 25 MWe net power modules). In addition to the estimated cost of purchasing the pumps the cost of volume occupied in the hull by the pumps was computed using a rate of $\$ 662 / \mathrm{m}^{3}$ or $\$ 18.75 / \mathrm{ft}^{3}$ for the 


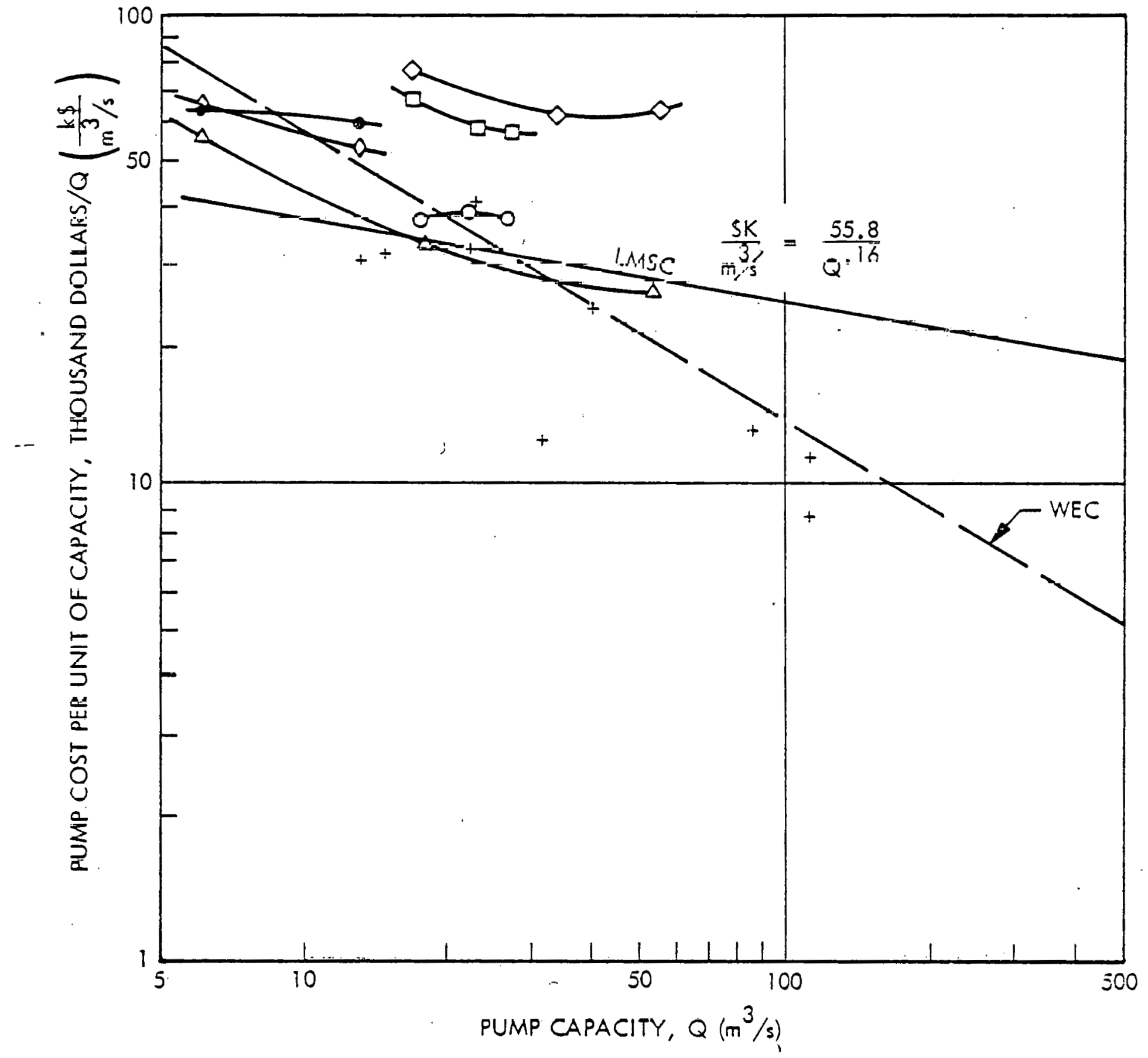

Fig. 2-27 Costs for Seawater Pumps 
value of volume in a typical hull. The total actual cost for pumps of larger capacity is less than for several smaller capacity pumps, as is evident from the cost function. The value of volume in the hull tends to reduce this economy of scale. Assuming a 1.375 packing factor for the pump assembly, the total cost is essentially independent of the rated capacity of the pumps.

The considerations for serviceability, replacement, sealoff, etc., now become the ones to dictate the number of pump units to package, since there is no clear cost advantage one way or the other (at this stage). If the pump costs are double those used in the current model, the results would tend to favor the larger (or one) pump. If the platform costs per occupied volume increase, then more smaller pumps would be indicated. If the scaling trend does rise beyond $50 \mathrm{~m}^{3} / \mathrm{s}$ capacity, or U.S. facilities are unable to fabricate the large single pump economically, then multiple units would be indicated. At this point, there is no clear driver in the selection of the seawater pump capacity or number per module.

Covering all reasonable outcomes has resulted in the specification of a seawater pump envelope for use in all design studies and a cost of $\$ 3.5 \mathrm{M}$ per circuit for the pump (s) which will be used in later design maturity. This envelope is $9 \mathrm{~m} \times 9 \mathrm{~m} \times 18 \mathrm{~m}$ with the long axis inline with the flow through the heat exchangers. In this volume the following combination of pumps can be accommodated.

1 - short $(\eta \sim 68 \%)$ pump rated for 25 MWe net

3 -pumps $(\eta>76 \%)$ rated for $81 / 3$ MWe net

or 4 -pumps $(\eta>76 \%)$ rated for $61 / 4$ MrWe net

Note that 2 pumps of 12.5 MWe radius would be slightly wider and much less high than this envelope, and should be able to be fitted into any arrangement developed with this envelope.

The total actual cost of the seawater pumps for a $100 \mathrm{MWe}$ net plant is $\$ 3.5 \mathrm{M} \times 2 \times$ $4=\$ 28 \mathrm{M}$. This is on the order of 10 percent at the platform cost. It is evident that 
a size, cost, producibility, efficiency optimization is needed of the pump in conjunction with the platform (arrangements, volumes, and flow losses) and the power system (flow rate requirements, head losses, enhancement). While some cost reduction is probable, the general conclusion will still stand, that the number of pumps per circuit will probably be determined by factors of redundancy, operational convenience, and serviceability. In this regard, 3 or 4 smaller rated pumps would be recommended. 
2.3.3.3 Platform - Cold Water Pipe Transition. The transition structure transfers the supporting loads between the suspended cold water pipe (CWP) and the cold water pipe major foundation. Interface requirements therefore include static and dynamic load distribution, axial, torsional, and rotational bearing stiffnesses, low wear rate, 40-yr life in seawater environment, and compatability with CWP installation method. Concept options include gimbal, ball joint, heave-compensated cable, and CWP flange on clastomeric bearing. The latter approach is selected as the baseline concept and applied to all platforms.

Analysis of motions and loads for the six platforms indicates that the bending stiffness of the transition influences the extent of CWP bending stress. Results indicate that an infinite stiffness results in maximum bending and that stiffnesses of $10^{9} \mathrm{ft} \mathrm{lb} / \mathrm{radian}$ and below result in lower bending stress. The selected stiffness requirement is therefore $10^{9} \mathrm{ft} /$ radian. Axial stiffness of $10^{7} \mathrm{lb} / \mathrm{ft}$ is selected to limit relative vertical motion between CWP and platform. Lateral bearing stiffness is chosen to be $10^{4} \mathrm{lb} / \mathrm{ft}$.

The concept depicted in Fig. 2-28 will support the CWP on the foundation with the required levels of fixity. The bearing consists of a set of 22 rubber columns, $3.5 \mathrm{~m}$ diam., of $9.1 \mathrm{~m}$ height above and below an annular flange fixed to the outside wall of the CWP. The foundation for these columns are extensions of the platform structure and internal to the center well. The upper foundation provides for pre-compression of the rubber columns. The dimensions shown allow for a 10 -deg relative rotation between the platform and CWP. The minimum well diameter is $25 \mathrm{~m}$ to allow for insertion of the CWP upper section with flange. Further, volume is required to allow for lateral displacement of the rubber. The bearing proportions allow for 30 percent compression. This is the maximum allowable compression for continuous flexure of 40 Shore Durometer hardness rubber (Ref. 4). With this maximum rubber compression, the required rubber column height is $9.1 \mathrm{~m}$. A form factor of 1.0 allows for appropriate area for rubber expansion under compression. 


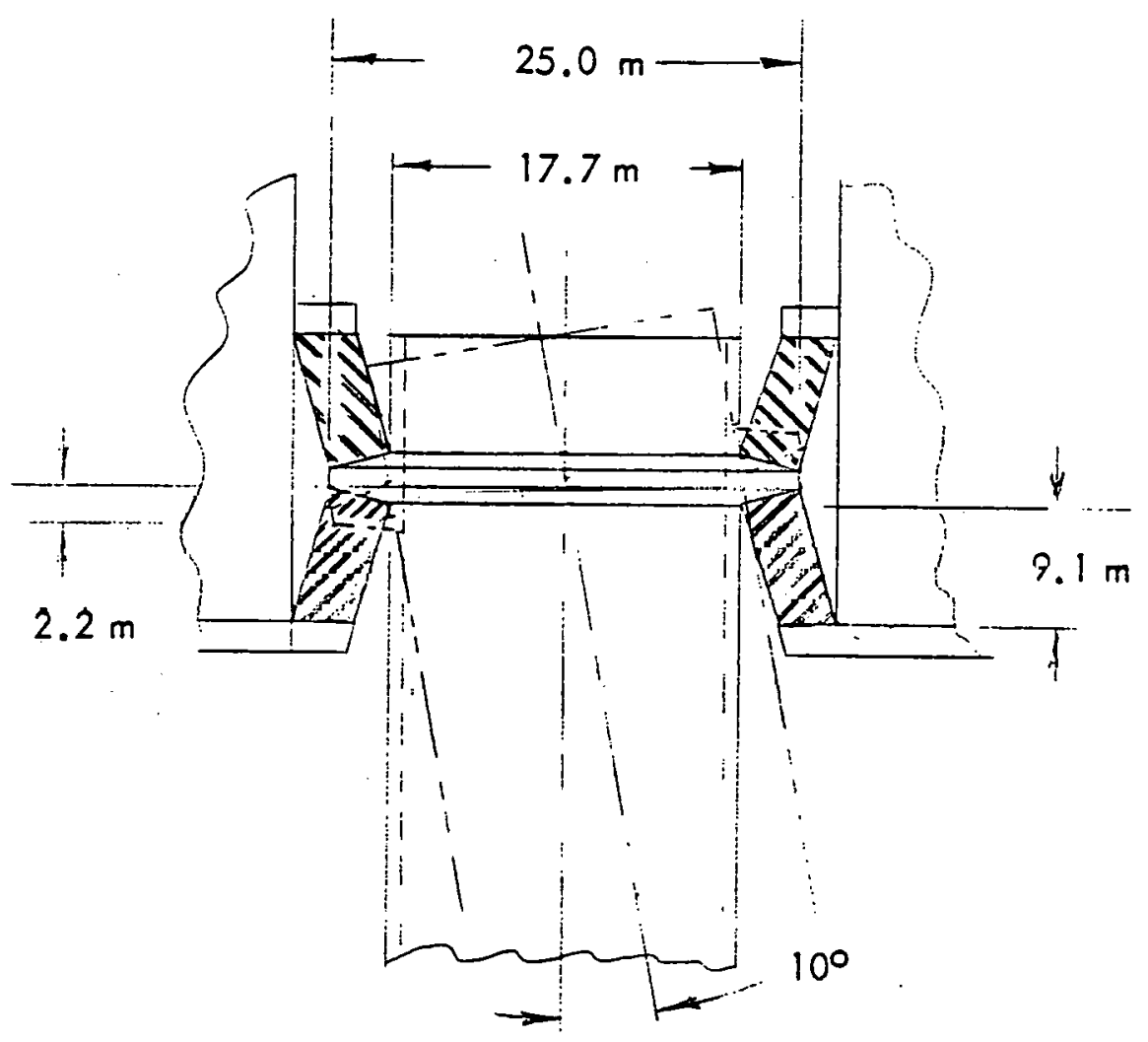

Fig. 2-28 Elastomeric Bearing for Cold Water Fipe/ Platform Interface
Angular Stiffness
$3.6 \times 10^{10}$
$\mathrm{ft}-\mathrm{lb} / \mathrm{radian}$
Axial Stiffness
$1.2 \times 10^{7} \mathrm{lb} / \mathrm{ft}$

shows that this particular design exceeds the required stiffness. Further analysis will consider a lower angular motion requirement, lnwer hardness mbber, and alternative bearing materials. In addition, data on the behavior of rubber in the seawater environment will be investigated.

The size of the rubber columns, the clearance with the platform, and the cost of the attachment are dependent upon the actual platform configuration, the environmental conditions for the site, and the design considerations of the cold water pipe. This baseline design concept indicates capability to satisfy all these requirements within a nominal space and for a nominal weight. The baseline transition section is used throughout this phase with refinements anticipated in conceptual design. 
2.3.3.4 Water Ducts. The baseline power system specified for this study included warm and cold water circulating piping as shown in the following table:

\begin{tabular}{|c|c|c|c|c|c|}
\hline \multirow{2}{*}{$\begin{array}{l}\text { Module } \\
\text { Output } \\
\text { MWe } \\
\text { (gross) }\end{array}$} & \multirow{2}{*}{$\begin{array}{l}\text { Outside } \\
\text { Diameter } \\
\text { of Pipe } \\
\text { (feet) }\end{array}$} & \multicolumn{4}{|c|}{ For a total 25 MWe (combined modules) } \\
\hline & & $\begin{array}{c}\text { No of } \\
\text { Modules }\end{array}$ & $\begin{array}{l}\text { Length of } \\
\text { Piping } \\
\text { (feet) }\end{array}$ & $\begin{array}{l}\text { Dry Weight } \\
\text { of Piping } \\
\text { (short tons) }\end{array}$ & $\begin{array}{l}\text { Cost of } \\
\text { Piping } \\
\text { (\$M) }\end{array}$ \\
\hline 25 & 25 & 1 & 600 & 1,800 & 1.77 \\
\hline 12.5 & 18 & 2 & 1,200 & 1,500 & 1.45 \\
\hline 8 & 15 & 3. & 1,800 & 1,300 & 1.80 \\
\hline 5 & 12 & 5 & 3,000 & 1,800 & 1.83 \\
\hline
\end{tabular}

These pipe diameters were used in the comparison design of the six platforms. The length of the circulating piping was minimized in each platform design to be consistent with the design guidelines. The length of piping is considered only as that length which is within the hull boundary. The cold water discharge extensions utilized by the surface platforms to provide discharge below 100 meters is not included as internal piping.

The average lengths of internal ducting for the six $100 \mathrm{MWWe}$ net platform designs discussed in Section 2.4 are generally less than that specified above. These duct lengths are not flow lengths, since components having seawater (heat exchangers, pumps) are not included. Duct lengths for $100 \mathrm{MW}(\mathrm{e})$ platforms are shown in Table 2-27.

Three platforms have significantly shorter lengths of total ducting than the others (spar, circular barge, and submersible). The semi and the ship have complex flow paths for distributing the cold water requiring up to 6.7 times the duct length required by the submersible. The most satisfactory duct length would be the most cost effective. For the same duct diameter the shortest length duct would be the best cost solution for a duct alone. The dual purpose duct/wing tank arrangement for the ship requires consideration of the overall cost of the duct and hull system. The comparison of platforms for the specified internally-mounted power system used these arrangements and ducting lengths and diameters as the most consistent basis for comparison. 
Table 2-27

INTERNAL LENGTH OF SEAWA?ER DUCTING FOR 100-MW(e) NET PLANT

\begin{tabular}{|l|rc|rr|rr|r|}
\hline \multirow{2}{*}{ TYPE OF PLATFORM } & \multicolumn{2}{|c|}{ COLD WATER } & \multicolumn{2}{|c|}{ WARM WATER } & \multicolumn{2}{|c|}{ TOTAL } & l/ $\ell_{\text {SPAR }}$ \\
& $M$ & $(F T)$ & $M$ & $(F T)$ & $M$ & (FT) & \\
\hline SHIP & 147 & $(481)$ & 25 & $(83)$ & 172 & $(564)$ & 2.26 \\
CIRCULAR BARGE & 38 & $(125)$ & 48 & $(158)$ & 36 & $(283)$ & 1.13 \\
SEMISUBMERSIBLF & 155 & $(510)$ & 41 & $(135)$ & 196 & $(645)$ & 2.58 \\
TUNED SPHERE & 101 & $(332)$ & 39 & $(128)$ & 170 & $(460)$ & 1.84 \\
SUBMERSIBLE & 23 & $(75)$ & 70 & $(229)$ & 93 & $(304)$ & 1.22 \\
SPAR & 29 & $(94)$ & 47 & $(154)$ & 76 & $(248)$ & 1.0 \\
\hline
\end{tabular}


Optimization of the seawater ducting design must account for several very critical features of the seawater system and interfaces with the hull, seawater pumps, and the power system. The importance of optimizing the seawater ducting is shown by the cost of the system. The total cost of seawater ducting consists of at least the following elements:

1. Cost of material for the duct

2. Cost of erecting the duct in the hull

3. Cost of a foundation to support the duct and the water contained in the duct and to distribute the load into the hull structure. The foundation may be estimated to weigh 10 percent of the supported weight.

4. Cost of biofouling/corrosion control.

5. In addition to these costs, the duct occupies a volume in the hull which could be used for other purposes. Hence a volume cost evaluation must be added in deriving the effective cost of duct. This volume cost should be based on the cost per unit volume for the hull and position control system. This rate varies between $\$ 500 / \mathrm{m}^{3}$ and $\$ 700 / \mathrm{m}^{3}$ for the $100-\mathrm{MWe}$ net platforms described in Section 2.4.

An estimate of these cost elements per unit length of ducting is in Table 2-28.

The effective value of the sea water ducting in the comparative platform designs for 100 MWe net is presented in Table 2-29.

The large cost values for the seawater ducting are evident as it is as much as 48 percent of the total platform cost for the ship and 46 percent for the submersible. The smallest cost percentage is for the spar with 19 percent of the platform cost devoted to the duct system. As a result of these large duct costs, it is apparent that this is an area for cost refinement, if not major reduction. As one avenue to provide cost reduction, the costs of the ducting has been developed as a function of inside diameter of the duct. The premise is that a smaller diameter duct would have lower actual costs (material, erection, and foundation) and lower costs for use of volume. The cost of additional power to pump the water at higher velocities in the smaller diameter duct must then be weighed against the savings in the cost of the duct. 
Table 2-28

UNIT COST OF SEAWATER DUCTING

\begin{tabular}{|c|c|c|c|}
\hline $\left.\begin{array}{ll}\text { 1. } & \text { MATERIAL } \\
\text { 2. } & \text { ERECTION }\end{array}\right\}$ & $\$ 3100 / T O N N E$ (STEEL) & $=\$ 30,512 / \mathrm{M}$ & $(\$ 9300 / F T)$ \\
\hline - FOUNDATION & & $\$ 15,194 / M$ & $(\$ 4631 / F T)$ \\
\hline CORROSION & & SMALL & \\
\hline & TOTAL ACTUAL COST & $=\$ 45,706 / \mathrm{M}$ & $(\$ 14,931 / \mathrm{FT})$ \\
\hline VOLUME COST & @ $\$ 500 / \mathrm{M}^{3}$ & $=\$ 22,772 / M$ & $(\$ 6941 / F T)$ \\
\hline & @ $\$ 700 / \mathrm{M}^{3}$ & $=\$ 31,877 / \mathrm{M}$ & $(\$ 9716 / F T)$ \\
\hline TIVE C & DUCTING & $\$ 68,478 / M$ & $(\$ 21,872 / F T)$ \\
\hline ER UN & & $\$ 77,583 / \mathrm{M}$ & $(\$ 24,647 / \mathrm{FT})$ \\
\hline
\end{tabular}

Table 2-29

COMPARATIVE COST VALUE OF SEAWATER DUCTS FOR 100-MW(e) NET

100 MWe NET

EFFECTIVE COST VALUE OF

PERCENT OF

SEA WATER DUCTING

PLATFORM COSTS

\section{SHIP}

$\$ 94 M$

48

CIRCULAR'BARGE

47 .

25

SEMISUBMERSIBLE

107

46

TUNED SPHERE

77

34

SUBMERSIBLE

.51

27

SPAR

42

19 
The results of this evaluation of duct diameter indicate that a duct nominally sized for $7 \mathrm{fps}$ water velocity is 2.73 times as costly as the optimum sized duct (Fig. 2-29). The nominal $7.6 \mathrm{~m}$ (25 ft) diameter duct becomes optimal at $4.4 \mathrm{~m}(14.5 \mathrm{ft})$ with a resultant velocity of $20 \mathrm{fps}$. A system designed for such high velocities will require great care to avoid large flow losses as the flow turns, diffuses into the heat exchangers and is diffused into the sea. Hence, a total flow system optimization is required, including power system performance (and even optimization), to assure that the least cost duct system is designed. It is conceivable to realize a 50 percent improvement in the cost of the internal duct systems.

There are several features which suggest further savings could be realized by placement of the duct exterior to the hull or as a part of the side of the hull. This latter approach has been employed in the design of the ship configuration, Section 2.4.1. It seems unecessary to have a platform which has a double hull (for collision safety) and carries a pipe inside which is full of water. This requires three (3) barriers to be built having room pressure to hydrostatic pressure as a design requirement between the barriers. If the seawater ducts were placed exterior to the hull there would need to be only one (1) barrier and that one would have a design differential pressure which is very small (accounting only for density gradients, pumping head, and oscillatory pressure loads). The foundation structure would probably cost as much as for the internally-mounted duct. There might be a need to insulate the cold water portions of an external duct, but this might be less costly than the insulation/air conditioning for the internally mounted ducts. The external duct could be part of the hull structure and could thereby provide some collision protection. The resultant platform would be smaller by at least the volume of the extracted ducts resulting in a small structural cost for the hull.

These considerations could be expected to provide some additional refinement and reduction in the cost of the seawater duct system. Overall integrated platforms reflecting these concepts are expected to be not much changed in comparison with each other. They will all have the same potential for some improvement. The seawater duct diameter specified in the baseline power system appears to be an adequate 


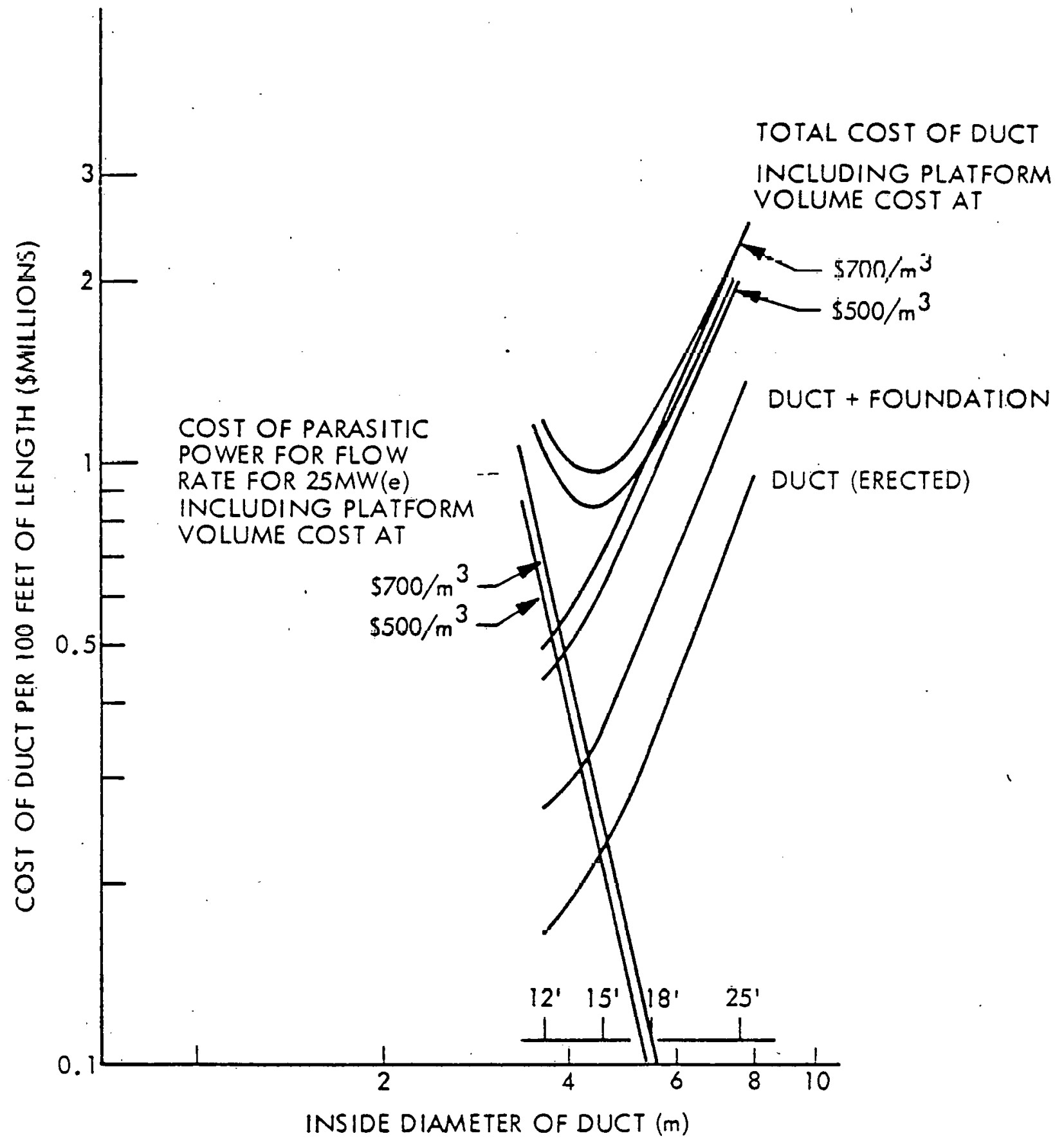

Fig. 2-29 Cost of Seawater Ducts 
indicator of the arrangements and first order costs for the integrated OTEC plants developed for comparison of hull types. Some cost reductions could be anticipated in this subsystem during conceptual design.

The following Section, 2.3.3.5, discusses the materials compatibility problems between upstream components, such as the seawater ducting, and the heat exchanger materials. There appear to be several material and protection systems that will meet the needs of most candidate heat exchanger materials. This is an area which requires continuing coordination and optimization with the power system.

\subsubsection{Biofouling/Corrosion Control. Biofouling and corrosion control methods} must consider the entire seawater system. These considerations include materials galvanic compatibility, reliability and life of coatings and cathodic protection systems, and maintenance costs for each system. An example of galvanic incompatibility would be a steel cold water pipe and steel ducting with an aluminum heat exchanger. A potential solution to this combination of materials is a high quality paint coating system and cathodic protection or cathodic protection alone to prevent corrosion of the steel.

The experience with coatings and cathodic protection systems used on offshore platforms has demonstrated that there are corrosion protection coatings that will survive more than 10-yrs with only minor maintenance. The cathodic protection system experience indicates 20-yr life systems can be readily achieved. A similar problem of galvanic incompatibility would occur if a copper-nickel alloy were used for upstream screens if the heat exchangers were aluminum. Table 2-30 provides a listing of candidate systems materials and their compatibility or incompatibility. The application of biofouling control measures should consider the entire seawater system. An example is that should no biofouling control measures be applied to the platform it would act as a large breeding area for biofouling that would continuously release micro-organisms into the seawater flow into the heat exchangers. The result would be a high cost of maintaining clean heat exchangers. The use of anti-fouling paints on the platform and cold water pipe must also consider the heat exchanger materials. Those anti-foulant coatings that use cuprous oxide as a toxic agent increase the pitting attack on aluminum and on steel alloys that are downstream. 
Table 2-30.

HEAT EXCHANGER/PLATFORM MATERIALS COMPATIBILITY

HEAT EXCHANGER MATERIALS

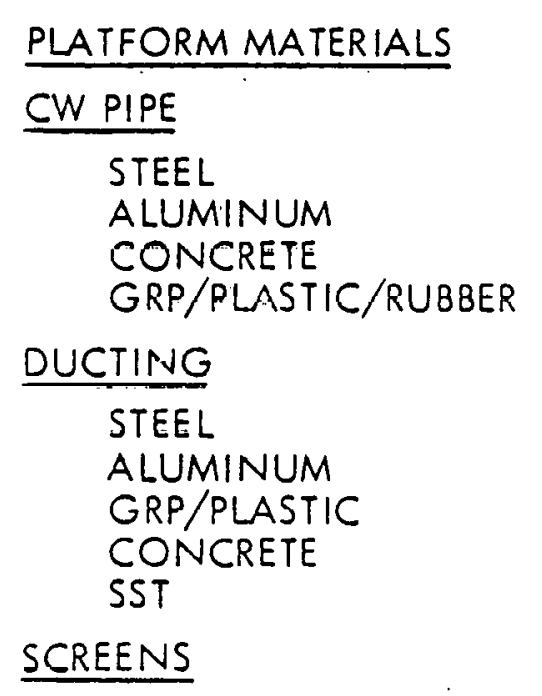

\begin{tabular}{|c|c|c|}
\hline $\begin{array}{l}\text { ALUMINUM } \\
\text { ALLOYS } \\
\end{array}$ & $\begin{array}{c}A 1-6 x \\
\text { SST } \\
\end{array}$ & $\begin{array}{l}\text { C.P. } \\
\mathrm{Ti}_{\mathrm{i}} \\
\end{array}$ \\
\hline $\begin{array}{c}N C \\
C \\
C \\
C\end{array}$ & $\begin{array}{l}c \\
c \\
c \\
c\end{array}$ & $\begin{array}{l}c \\
c \\
c \\
c\end{array}$ \\
\hline
\end{tabular}

Cu-Ni (90-10)

STEEL-GALVANIZED

STEEL-COATED W/A.F. SST

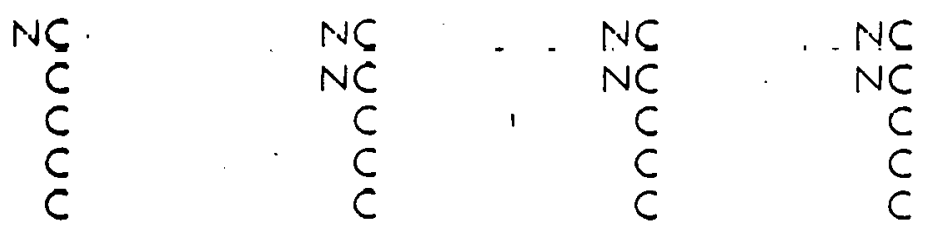

CW PIPE TRANSITION

STFEL

ALIJMINIUM

BRONZE

GRAPHITE

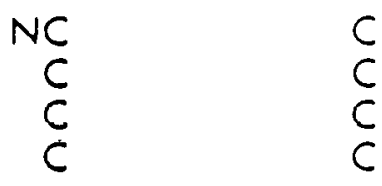

$\begin{array}{ll}c & c \\ c & c \\ c & c\end{array}$

$\frac{c}{c}$

PUMPS

STEEL

SST

BRONZE

NI CAST IRON

$\begin{array}{cc}N C & C \\ C & C \\ N C & C \\ C(?) & -C\end{array}$

$\begin{array}{ll}c & c \\ c & c \\ c & c \\ c & c\end{array}$

NE
NC
NC

$\frac{c}{c}$

$c$

$\frac{c}{c}$

NC = NOT COMPATIBLE 
There are several systems which can be used in combination to provide both biofouling control and corrosion protection. These are long life antifouling coatings, such as "No Foul", impregnation of anti-foulants in concrete mix, mechanical cleaners, and sonic vibrations. These systems all involve reasonably large costs. The risks in their use are mainly because of the short experience that has been obtained with them and with possible degradation of mechanical properties.

A recommended platform material selection and corrosion and biofouling control measures for those materials are as follows. The hull structural material should be concrete with galvanized re-bar, cathodic protection, and anti-foulants should be impregnated in the concrete. Galvanized re-bar in combination with cathodic protection can assure 40 year life. Anti-foulants impregnated in concrete have demonstrated "hard" fouling control for more than $7 \mathrm{yrs}$ (total experience to date). These recommendations lead to a minimum life cost of less than $\$ 100 \mathrm{~K}$ for the cathodic protection system for the concrete and approximately $\$ 350 \mathrm{~K}$ for the biofouling control for a 10-yr period with the spar platform.

The spar configuration should have the least cost for biofouling control since the major hull surface is located at greater depth than for other configurations where the growth of biofouling is known to be significantly reduced. 
2.3.3.5 References.

1. Department of Energy, OTEC Demonstration Plant Environmental Package, 14 Jul 1977

2. Westinghouse Electric Company, Ocean Thermal Power Plants Cold Water Pipe, Seawater Pumps, and Platform Station Keeping, by T. Little and H. Davison, 27 Sep 1977

3. ----, Deep Water Pipe, Pump and Mooring Study, Ocean Thermal Energy Conversion Program, by J. E. Little, J. D. Marks, and K. H. Wellwan, Annapolis Report No. COO-2642-3, Jun 1976

4. Military Handbook 149A, 30 Jun 1965, pp. 22-31 


\subsubsection{Position-Control System}

Position control is required at all sites, with grazing of a production plant at the Brazil site. The two principal options are mooring and dynamic positioning. System requirements include:

(1) Orient platform to minimize aero-hydro drag, recirculation of seawater, and platform seaway response.

(2) Mooring effective from $955 \mathrm{~m}$ at Keahole Pt. to $5455 \mathrm{~m}$ at Brazil site.

(3) Allowable line load is $20 \%$ of breaking strength for operation and $50 \%$ for extreme conditions.

(4) Assume wind, current, and wave drag are colinear and normal to maximum projected platform area.

(5) Watch circle to be $5 \%$ of water depth with electrical transmission.

(6) Various seafloor conditions - terrigeneous and clayey silt at Gulf of Mexico site, for example.

(7) Variable thrust and vectoring for dynamic positioning system, if required.

This section begins with an analysis of the horizontal loads on the platform to establish the holding power required for position-keeping in the extreme condition. This condition consists of 100-yr storm wind, wave, and current acting in the same heading normal to the platform maximum projected area. Hence, it is assumed that the azimuthing control capability is not operational in this condition. Following this is a treatment of the mooring system and dynamic positioning system, including cost comparisons for the combinations of platform type (6), operational site (5) and net plant output (50 to $500 \mathrm{MW}(\mathrm{e}))$.

2.3.4.1 Environmental Loads. The horizontal force on the plant in the extreme conditions is obtained as

$$
\begin{aligned}
F_{T}= & \frac{1}{2} \rho A V_{S}^{2} C_{D}+\frac{1}{2} \rho_{a} A_{W} V_{W}^{2} C_{D W}+F_{C W P}\left(V_{S}, D_{T}, T_{T}\right) \\
& +F_{\text {WAVE }}+F_{\text {LIVE }}\left(V_{S}, D, L\right)+F_{D I S C H}\left(N, V_{S}, I, D\right)
\end{aligned}
$$


where

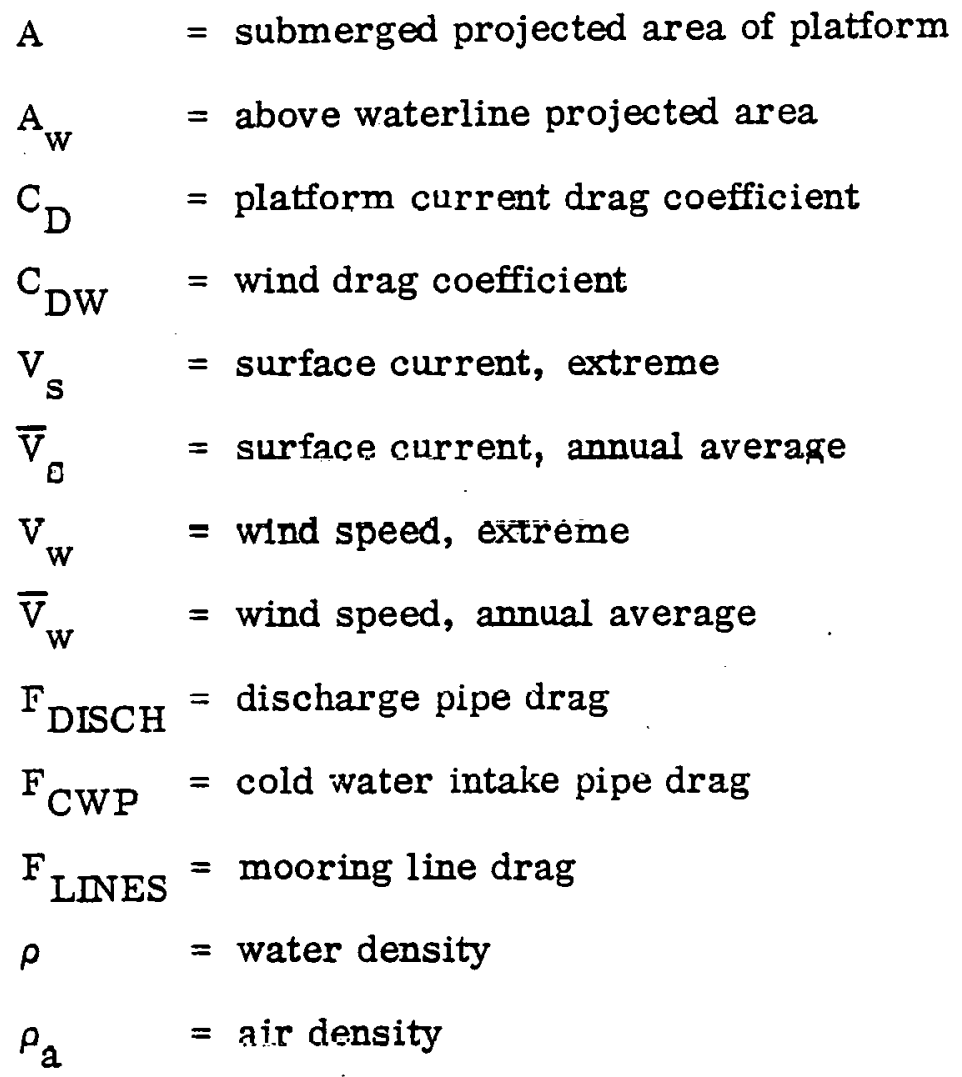

Data on site conditions listed in Table 2-31 indicate the extreme case (100-yr storm), operational current, and assumed annual average wind speed. The latter two are criteria for determining annual fuel requirements for thrusters. The extreme current profile is given in Fig. 2-30. Areas and drag coefficients for each platform type are shown in Table 2-32. These coefficients, comparable to those reporter in Ref. 1, are based on the submerged shape of each 100-MW(e) (net) platform design. Since the platform proportions do not vary significantly for the 200 and $500 \mathrm{MW}$ (e) (net) designs, it is assumed that the coefficients are independent of platform size. The mooring line drag and seawater discharge pipe drag were neglected in the analysis as these components are less significant than platform and cold water pipe (CWP) drag.

The dependence of CWP drag on Reynolds number is included in the typical results shown in Table 2-33. The dependence of drag on surface current and pipe diameter is illustrated in Fig. 2-31, while the significant dependence of drag on CWP upper end depth is shown in Fig. 2-32. The following expression for CWP drag in the extreme current profile is based on these results. 
Table 2-31

SITE ENVIRONMENTAL CHARACTERISTICS

\begin{tabular}{|c|c|c|c|c|c|c|}
\hline Criteria & Porameter. & Hawaii & New Orleans & Brazil & Puerto Rico & Key West \\
\hline \multirow{4}{*}{$\begin{array}{l}100-Y_{r} \\
\text { Storm }\end{array}$} & $\begin{array}{l}\text { Max Wind (kts) } \\
\text { Gust (kts) }\end{array}$ & $\begin{array}{l}65.7 \\
95.2\end{array}$ & $\begin{array}{l}100.3 \\
145.4\end{array}$ & 61 & $\begin{array}{l}92.8 \\
134.6\end{array}$ & $\begin{array}{l}113.8 \\
165.0\end{array}$ \\
\hline & $H_{1 / 3^{(f t)}}$ & 35.9 & 58.1 & 29.0 & 44.2 & 45.8 \\
\hline & $T_{\left.1 / 3^{(s e c}\right)}$ & 12.72 & 15.91 & 18.0 & 13.8 & 13.67 \\
\hline & Current (kts) & 2.18 & 2.49 & 3.2 & 2.76 & 6.4 \\
\hline \multirow{8}{*}{ Typical } & Wind, $k$ ts & $20-44$ & $20-56$ & $20-40$ & $20-40$ & $20-56$ \\
\hline & Annual Average W/ind (kts) & 5 & 5 & 5 & 5 & 5 \\
\hline & $H_{1 / 3}(\mathrm{ft})$ & 20 & 20 & 20 & 20 & 20 \\
\hline & $T_{0}(\mathrm{Sec})$ & 10.3 & 10.3 & 10.3 & 10.3 & 10.3 \\
\hline & Current (kts) & 1.13 & 1.17 & 0.5 & $1.21^{\circ}$ & 4.73 \\
\hline & Depth & 3,150 & 3,950 & 18,000 & 4,000 & 4,850 \\
\hline & Depth of $30^{\circ} \mathrm{F} \Delta \mathrm{T}$ & $1,089-1,419$ & $891-2,442$ & 1,155 & $1,568-2,045$ & $1,353-2,145$ \\
\hline & Depth of $36^{\circ} \mathrm{F} \Delta T$ & $1,568-3,300$ & $1,320-4,125$ (7 mos) & $1,188-2,013$ & $2,079-2,805$ & $1,881-4,125$ \\
\hline
\end{tabular}

Table 2-32

OTEC PLATFORM CHARACTERISTICS

\begin{tabular}{|c|c|c|c|c|c|c|c|c|c|c|c|}
\hline \multirow[b]{2}{*}{ PLATFORM } & \multirow[b]{2}{*}{$\begin{array}{c}\text { NET } \\
\text { OUTPUT } \\
\text { [(MW(o)] }\end{array}$} & \multirow[b]{2}{*}{$\begin{array}{c}\operatorname{MAX} \\
\text { BEAM } \\
(m)\end{array}$} & \multirow[b]{2}{*}{$\begin{array}{l}\text { LENGTH } \\
(m)\end{array}$} & \multirow[b]{2}{*}{$\underset{(\mathrm{m})}{\text { ORAFT }}$} & \multicolumn{2}{|c|}{ CURRENT } & \multirow{2}{*}{$\begin{array}{c}\text { CURRENT } \\
\text { DRAG } \\
\text { COEFF } \\
\left(C_{0}\right)\end{array}$} & \multicolumn{2}{|c|}{ WIND } & \multirow{2}{*}{$\begin{array}{l}\text { WIND } \\
\text { DRAG } \\
\text { COEFF } \\
\left(W_{D}\right)\end{array}$} & \multirow{2}{*}{$\begin{array}{l}\text { DEPTH } \\
\text { OF CWP } \\
\text { ATTACH, } \\
\text { (m) }\end{array}$} \\
\hline & & & & & $\begin{array}{c}\text { FRONTAL } \\
\text { AREA } \\
\left(\mathrm{m}^{2}\right)\end{array}$ & $\begin{array}{c}\text { LATERAL } \\
\text { AREA } \\
\left(\mathrm{m}^{2}\right)\end{array}$ & & $\begin{array}{c}\text { FRONTAL } \\
\text { AREA } \\
\left(\mathrm{m}^{2}\right)\end{array}$ & $\begin{array}{c}\text { LATERAL } \\
\text { AREA } \\
\left(\mathrm{m}^{2}\right)\end{array}$ & & \\
\hline SHIP & $\begin{array}{l}100 \\
200 \\
500\end{array}$ & $\begin{array}{l}66 \\
82 \\
82\end{array}$ & $\begin{array}{l}165 \\
305 \\
356\end{array}$ & $\begin{array}{l}25 \\
25 \\
42\end{array}$ & $\begin{array}{l}1,650 \\
2,050 \\
3,444\end{array}$ & $\begin{array}{r}4,125 \\
7,625 \\
14,952\end{array}$ & $\begin{array}{l}0.5 \\
0.5 \\
0.5\end{array}$ & $\begin{array}{r}462 \\
574 \\
1,476\end{array}$ & $\begin{array}{l}1,155 \\
2,135 \\
6,408\end{array}$ & $\begin{array}{l}0.6 \\
0.6 \\
0.6\end{array}$ & $\begin{array}{l}25 \\
25 \\
42\end{array}$ \\
\hline BARGE & $\begin{array}{l}100 \\
200 \\
500\end{array}$ & $\begin{array}{r}98 \\
105 \\
149\end{array}$ & $\begin{array}{l}98 \\
105 \\
149\end{array}$ & $\begin{array}{l}31 \\
38 \\
61\end{array}$ & $\begin{array}{l}3,038 \\
3,990 \\
9,089\end{array}$ & $\begin{array}{l}3,038 \\
3,990 \\
9,089\end{array}$ & $\begin{array}{l}0.7 \\
0.7 \\
0.7\end{array}$ & $\begin{array}{l}1,1.94 \\
1,260 \\
6,556\end{array}$ & $\begin{array}{l}1,194 \\
1,260 \\
6,556\end{array}$ & $\begin{array}{l}0.6 \\
0.6 \\
0.6\end{array}$ & $\begin{array}{l}31 \\
38 \\
61\end{array}$ \\
\hline SPHERE & $\begin{array}{l}100 \\
200 \\
500\end{array}$ & $\begin{array}{r}91 \\
115 \\
175\end{array}$ & $\begin{array}{c}91 \\
115 \\
175\end{array}$ & $\begin{array}{c}73 \\
92 \\
140\end{array}$ & $\begin{array}{r}5,682 \\
9,387 \\
20,649\end{array}$ & $\begin{array}{r}5,682 \\
9,387 \\
20,649\end{array}$ & $\begin{array}{l}0.6 \\
0.6 \\
0.6\end{array}$ & $\begin{array}{r}1,862 \\
2,625 \\
4,163\end{array}$ & $\begin{array}{l}1,862 \\
2,625 \\
4,163\end{array}$ & $\begin{array}{l}1.0 \\
1.0 \\
1.0\end{array}$ & $\begin{array}{r}73 \\
92 \\
140\end{array}$ \\
\hline $\begin{array}{l}\text { SEMI- } \\
\text { SUBMERSIBLE }\end{array}$ & $\begin{array}{l}100 \\
200 \\
500\end{array}$ & $\begin{array}{l}120 \\
142 \\
162\end{array}$ & $\begin{array}{l}132 \\
144 \\
216\end{array}$ & $\begin{array}{l}40 \\
48 \\
80\end{array}$ & $\begin{array}{r}3,200 \\
4,776 \\
10,336\end{array}$ & $\begin{array}{r}3,700 \\
5,352 \\
11,872\end{array}$ & $\begin{array}{l}0.6 \\
0.8 \\
0.6\end{array}$ & $\begin{array}{l}1,000 \\
1,120 \\
1,600\end{array}$ & $\begin{array}{l}1,325 \\
1,848 \\
2,600\end{array}$ & $\begin{array}{l}1.0 \\
1.0 \\
1.0\end{array}$ & $\begin{array}{l}40 \\
40 \\
80\end{array}$ \\
\hline SURMERSIBLE & $\begin{array}{l}100 \\
200 \\
500\end{array}$ & $\begin{array}{r}49 \\
49 \\
119\end{array}$ & $\begin{array}{l}116 \\
195 \\
335\end{array}$ & $\begin{array}{l}69 \\
69 \\
69\end{array}$ & $\begin{array}{r}2,351 \\
1,886 \\
11,122\end{array}$ & $\begin{array}{r}0,150 \\
9,555 \\
16,415\end{array}$ & $\begin{array}{l}0.5 \\
0.5 \\
0.5\end{array}$ & $\begin{array}{r}347 \\
347 \\
1,000\end{array}$ & $\begin{array}{r}347 \\
347 \\
1,000\end{array}$ & $\begin{array}{l}1.0 \\
1.0 \\
1.0\end{array}$ & $\begin{array}{l}49 \\
69 \\
69\end{array}$ \\
\hline ŚPAR & $\begin{array}{l}100 \\
200 \\
500\end{array}$ & $\begin{array}{l}100 \\
118 \\
156\end{array}$ & $\begin{array}{l}100 \\
118 \\
156 .\end{array}$ & $\begin{array}{l}115 \\
121 \\
153\end{array}$ & $\begin{array}{r}5,900 \\
8,117 \\
16,218\end{array}$ & $\begin{array}{r}5,900 \\
8,117 \\
16,218\end{array}$ & $\begin{array}{l}0.7 \\
0.7 \\
0.7\end{array}$ & $\begin{array}{r}750 \\
920 \\
1,320\end{array}$ & $\begin{array}{r}750 \\
920 \\
-1,320\end{array}$ & $\begin{array}{l}1.0 \\
1.0 \\
1.0\end{array}$ & $\begin{array}{l}120 \\
121 \\
133\end{array}$ \\
\hline
\end{tabular}




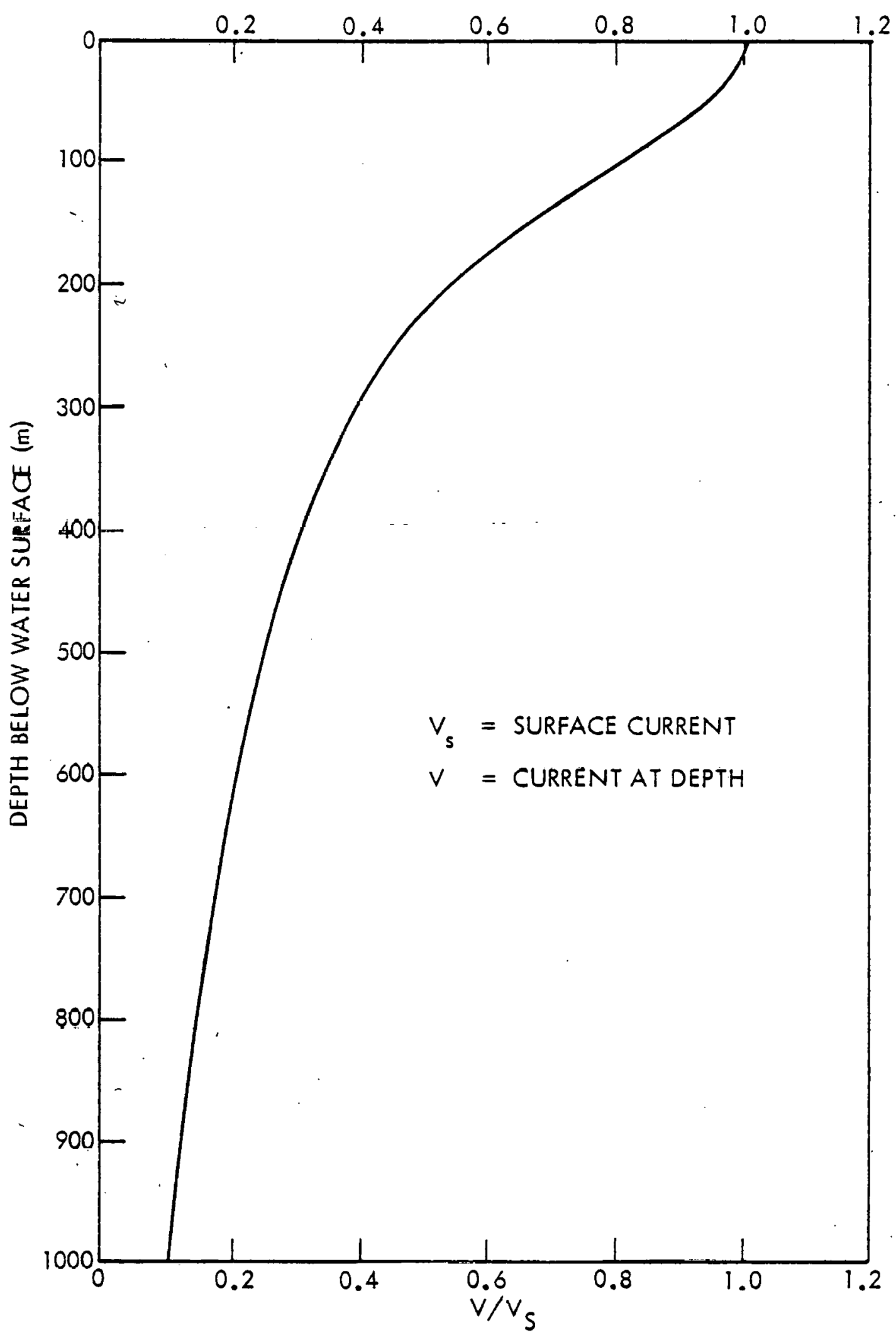

Fig. 2-30 Normal for Key West and Extreme-Current Profile for all Sites (Ref. 6)

$$
2-104
$$


Table 2-33

COLD WATER PIPE HYDRODYNAMICS

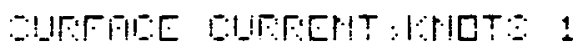

PIBMEE OF FIFE EEONEHTS1

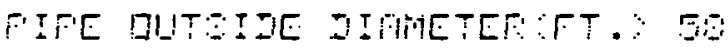

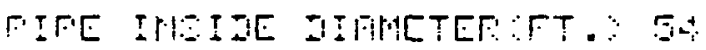

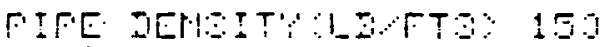

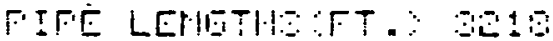

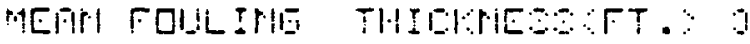

IEFTH OF EUTERIOR FOILIHE:FT.

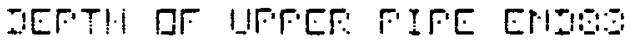

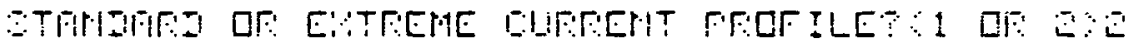

'UII FEFEEHTAEE IH HILL

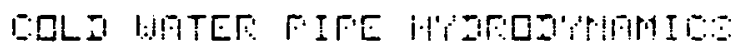

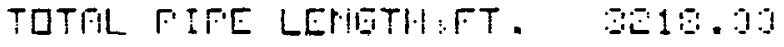

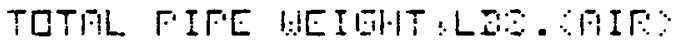
UIPTCF:
127019101.90

5401504019

\begin{tabular}{|c|c|c|c|c|c|c|c|c|}
\hline 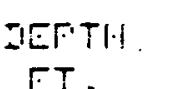 & $\begin{array}{l}\text { EUREEHT } \\
\text { TT }\end{array}$ & FENHILIS & $\therefore$ & $E L$ & $\operatorname{Ien}$ & U1ma & $\because$ TRDLIHAL & $\begin{array}{l}\text { BHEDITHE } \\
\text { FET OHT }\end{array}$ \\
\hline$P T=0$ & 1.15 & HUMEF: & .45 & 19 & Loge. & Lo & PHDAEE: & FHEQ \\
\hline 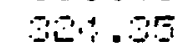 & 1.5 & 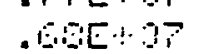 & .64 & 3.19 & 7815. & $17 \div 10$ & 0 & 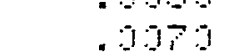 \\
\hline 15. & 1.15 & $.5 E+17$ &.$\therefore t$ & 9.90 & $5+94$. & 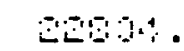 & 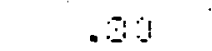 & $\therefore 00$ \\
\hline $6+6.15$ & .97 & $.450+97$ & .4 & 9.91 & 3030 & Font & 10 & 99 \\
\hline 97.95 & $.8:$ & ד &. & 9.90 & EF: & . & .00 & .90 \\
\hline 967.95 & .9 & $.04[4 \cdot 97$ & .0 & 10 & 1703 & 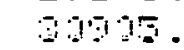 & 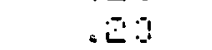 & 90 \\
\hline 125.5 & .57 & . & .0 & 1010 & $11+x^{4}$ & 15: & 80 & 10 \\
\hline 100.75 & .65 & 7T. & 18 & 9.91 & 11. & G01. & 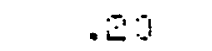 & 911 \\
\hline \pm 40.65 & $\therefore \therefore$ & . $80 \mathrm{~A}$ & .5 & 9.90 & Ba. & 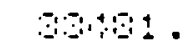 & . & 195 \\
\hline $16 \pm 2.55$ & $. \therefore:$ & . & 85 & 9.91 & 515 & 8095 & . & 115 \\
\hline 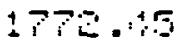 & .89 & .296477 & 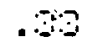 & 9.11 & 450 & $3+4+5$. & 10 & 11 \\
\hline 403 & $\therefore 7$ & . $18 E+17$ & ים & 9.90 & $\therefore 3+4$ & $8+5+5$. & 10 & 90 \\
\hline تح. & .95 & $.17 E \cdot 17$ & $\therefore 1$ & 9.91 & 50 & 95016 & . & $9:-$ \\
\hline 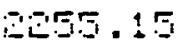 & : & . $18 E+97$ & $\therefore 0$ & 9.79 & 897. & . & . & 121 \\
\hline & . & . 19 & 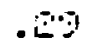 & 9.91 & 25 & $\because 979$ & ل0 & 1 \\
\hline 2576 . & تS & . $15[-17$ & .27 & 9.81 & $15 \pm$ & 9070 . & 00 & 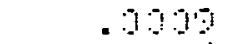 \\
\hline 5 & 9 & 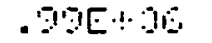 & : & 9.90 & 80 & 9597. & . & $1:$ \\
\hline 7 & 11 & .78E. & 5 & 9.91 & & 80015 & I & \\
\hline 5069 & .1 & . BEE J6 & I. & 9.99 & $\ldots$ & 30040 & .0 & \\
\hline
\end{tabular}




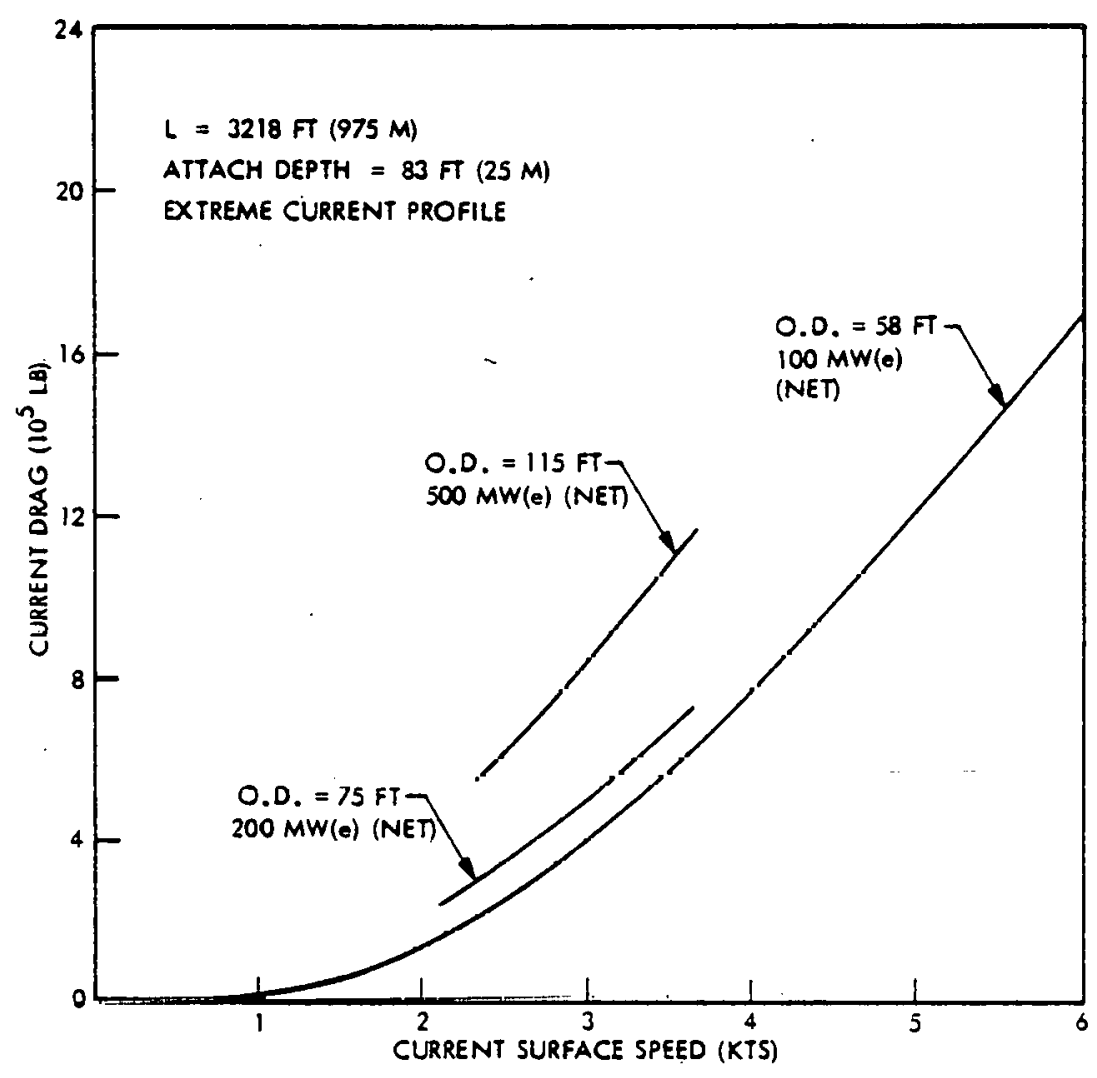

Fig. 2-31 Cold Water Pipe Current Drag vs. Current Surface Speed.

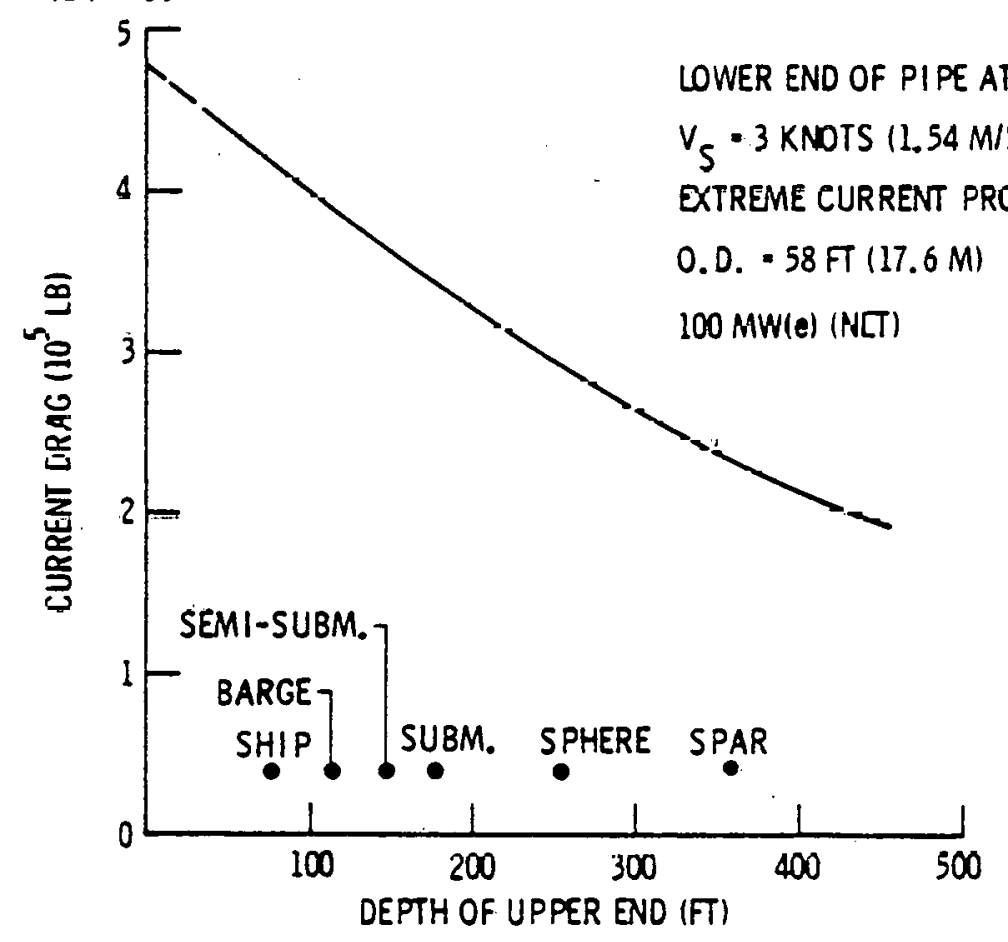

Fig. 2-32 Cold Water Pipe Current Drag vs. Depth of Attachment 


$$
\mathrm{F}_{\mathrm{CWP}}=\frac{1}{2} \rho \overline{\mathrm{C}}_{\mathrm{D}} \mathrm{V}_{\mathrm{S}}^{2} \mathrm{dL}-\mathrm{K}\left(\frac{\mathrm{V}_{\mathrm{S}}}{5}\right)^{2}\left(\mathrm{Z}_{\mathrm{A}}-\mathrm{Z}_{\mathrm{o}}\right)
$$

where

$$
\begin{aligned}
& \bar{C}_{D}=\text { equivalent drag coefficient, } 0.091 \\
& d=C W P \text { OD } \\
& L=C W P \text { length } \\
& Z_{A}=\text { depth of CWP upper end, ft } \\
& Z_{O}=83 \mathrm{ft} \\
& K=\frac{d F}{d Z_{A}}, 667 \mathrm{lb} / \mathrm{ft}
\end{aligned}
$$

The seaway induces a slow drift oscillatory force on the moored platform. An estimate of this force is based on the theory of Maruo as verified by Remery and Hermans (Ref. 3).

$$
\mathrm{F}_{\mathrm{WAVE}}=\frac{1}{2} \rho \mathrm{g}(\mathrm{Ra})^{2} \mathrm{~L}
$$

where

$$
\begin{aligned}
& g=\text { acceleration of gravity } \\
& R=\text { wave reflection coefficient } \\
& d=\text { rms wave amplitude }\left(=\frac{1}{3} \mathrm{H}_{1 / 3}\right) \\
& L=\text { platform length }
\end{aligned}
$$

The variation of platform size with net power output in the determination of platform drag is treated by scaling platform length and area as follows,

$$
\left(\frac{L_{1}}{L_{2}}\right)=\left(\frac{P_{1}}{P_{2}}\right)^{0.33},\left(\frac{A_{1}}{A_{2}}\right)=\left(\frac{P_{1}}{P_{2}}\right)^{0.67}
$$


where $P$ is the net plant output. These scaling factors are good first approximations to the design data given in Table 2-32.

A sample of results obtained for six platform types at five sites is shown in Figs. 2-33 through 2-35. For the extreme condition (100-yr storm, colinear drag components, and unfavorable heading) the first figure illustrates the relative cumulative contribution of wind, wave, and current for the ship in the Key West site. The range of proportions in this case varies with platform size as follows:

\begin{tabular}{|l|c|c|}
\hline \multirow{2}{*}{ Drag Component } & \multicolumn{2}{|c|}{ Peroent of Totol Dras } \\
\cline { 2 - 3 } & 100 MW (e) NET & 500 NTW(e) NET \\
\hline Platform Current & 42 & 57 \\
Platform Wind & 6 & 11 \\
Platform Wave & 32 & 20 \\
CWP Current & 20 & 12 \\
\hline
\end{tabular}

These proportions vary with platform type depending on frontal area relative to the ship. The variation of ship total drag with site (Fig. 2-34) clearly indicates that Hawaii produces the lowest and Key West the highest drag, higher by a factor of five. Total drag force for the $100 \mathrm{MW}-(e)$ (net) platform increases from $1.2 \times 10^{6} \mathrm{lb}$ in Hawaii to $6 \times 10^{6}$ in Key. West. This conclusion applies to the other platforms as well, although the factor is dependent on platform type.

Total drag for platform in the Gulf of Mexico and high current Key, West sites increases with operating displacement (Fig. 2-35). The spar has the lowest and the semisubmersible the highest drag in the Gulf, while in Key West the spar drag exceeds the drag of the semi-submersible. Drag of the other three platforms is within the drag of these platforms.

2.3.4.2 Mooring System. The mooring system consists of multipoint spread mooring lines attached to the platform and to deadweight anchors on the seafloor. High strength chain at the anchor attachment prevents line wear due to chafing. Tensioning vinches mounted on the platform provide line length and tension control for platform azimuthing 


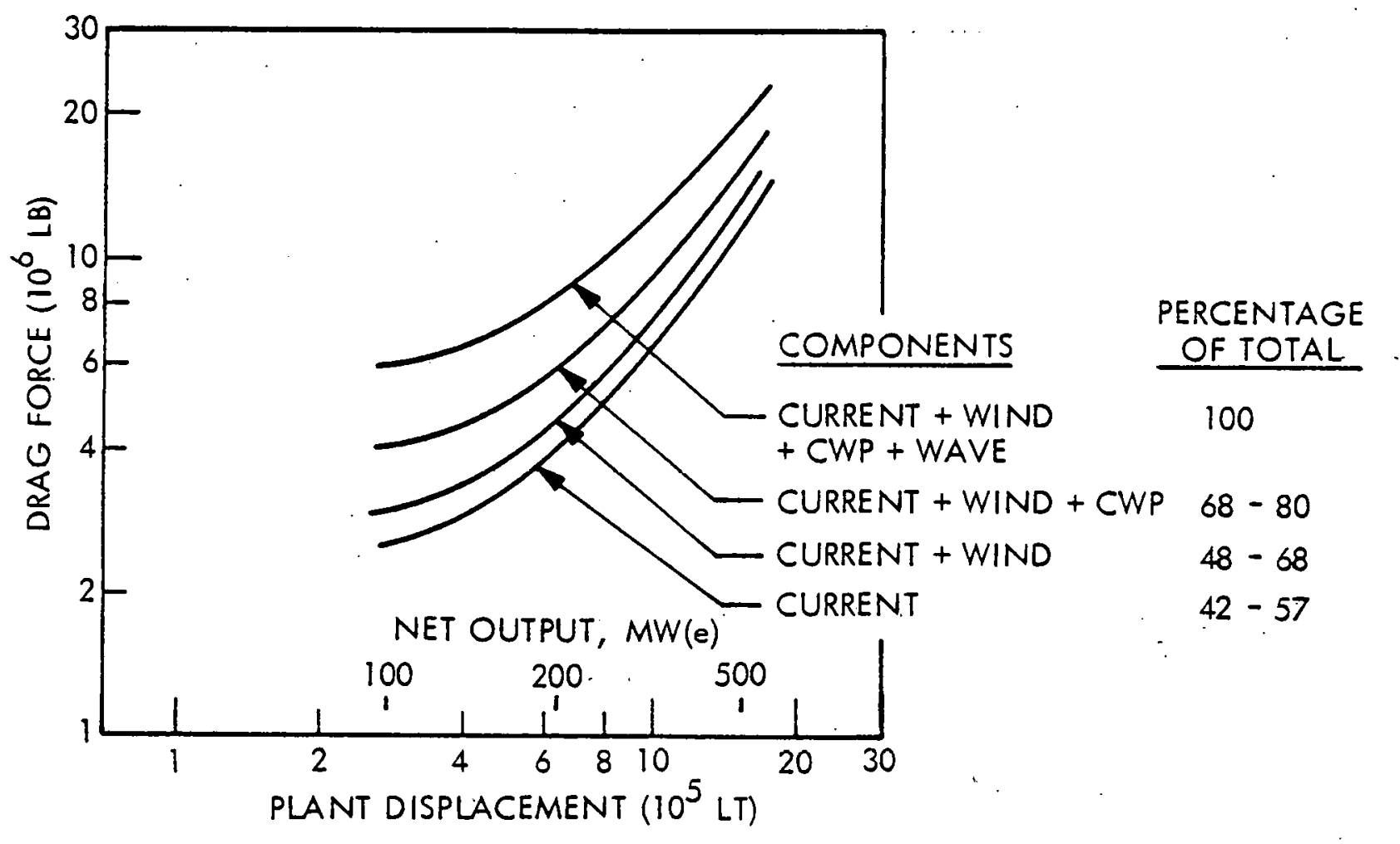

Fig. 2-33 Ship Drag vs. Size at Key West Extreme Conditions

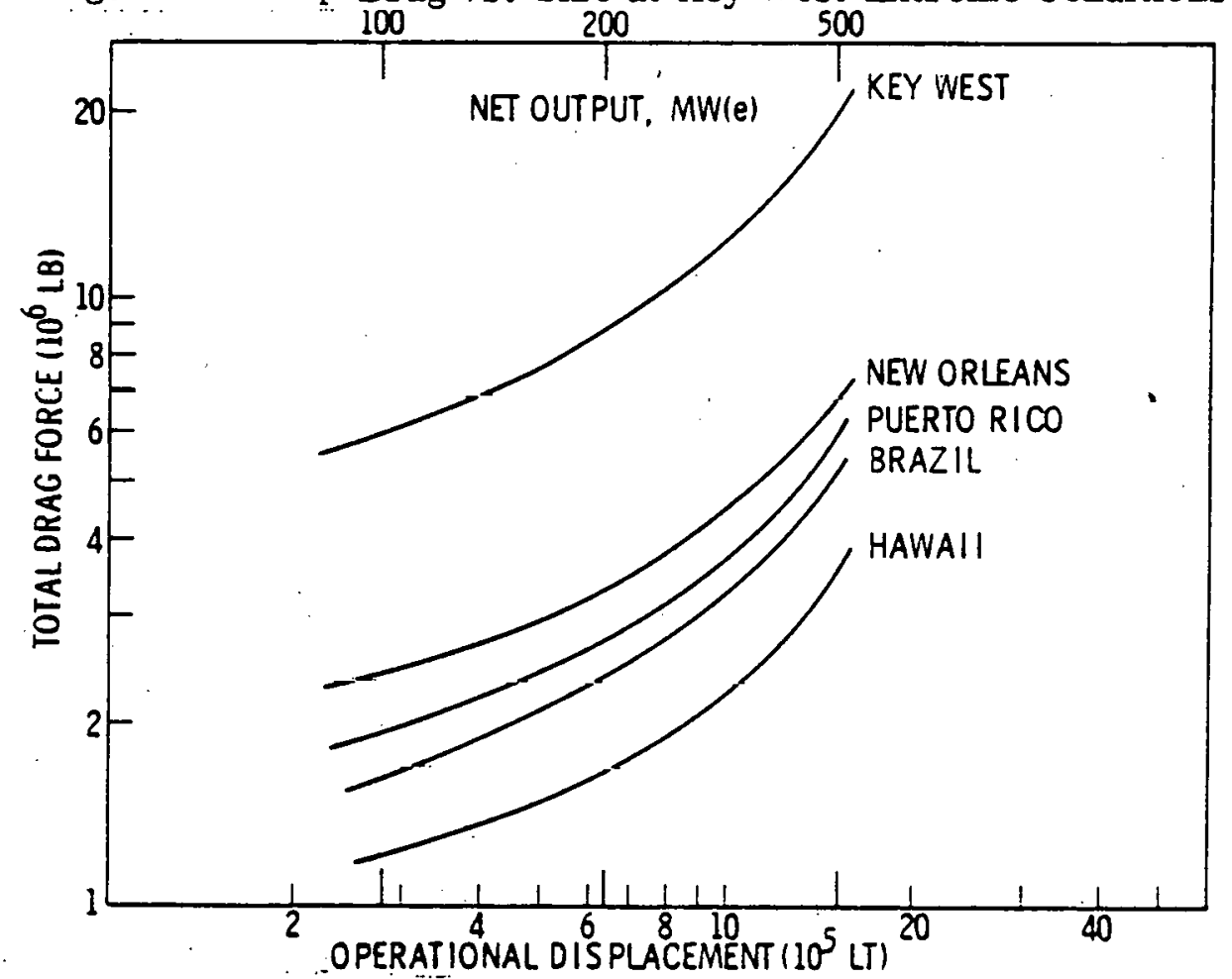

Fig. 2-34 Ship Drag vs. Size and Site 


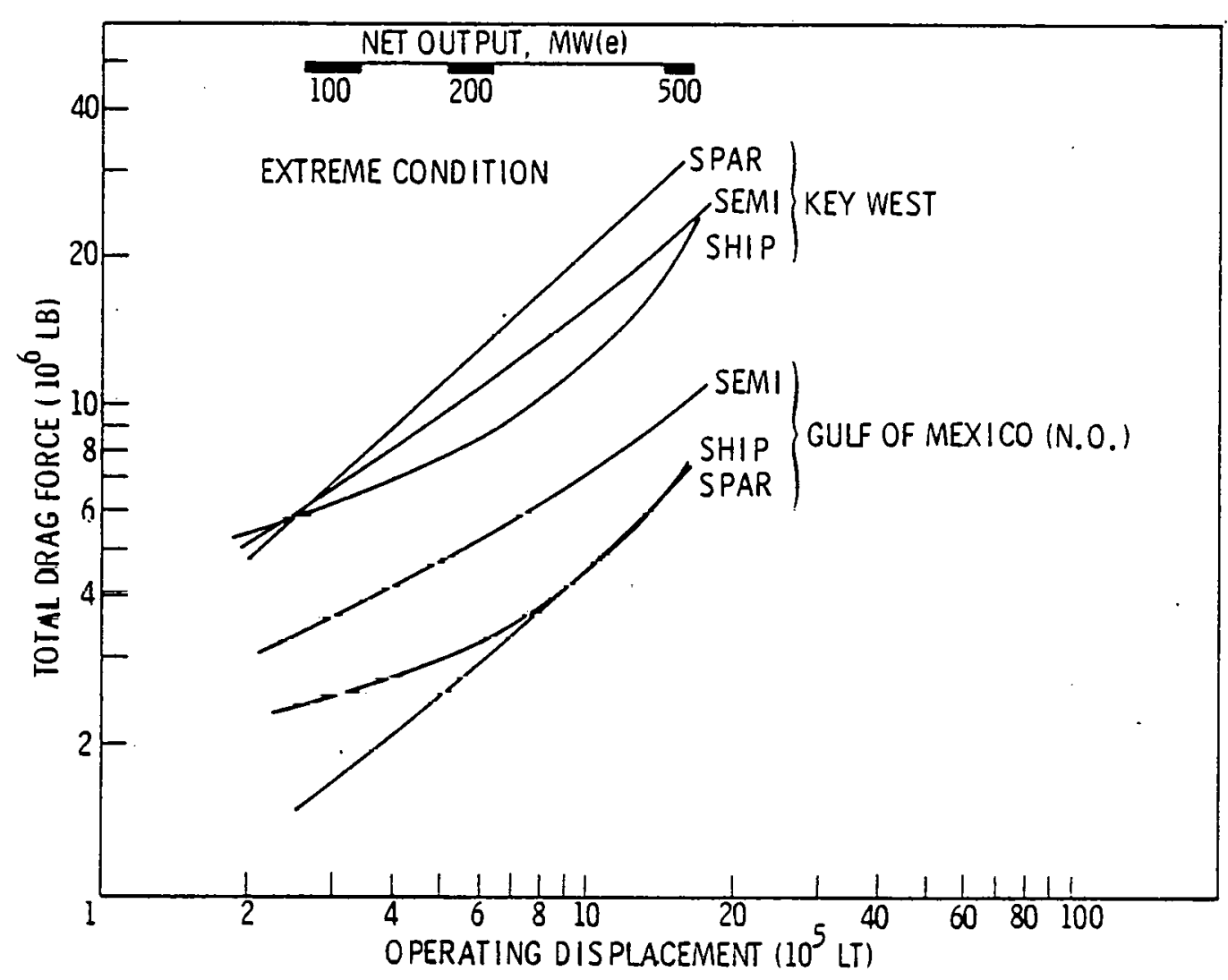

Fig. 2-35 Platform Drag vs. Platform Size, Type, and Site

and positioning in changing environmental conditions.

The concrete deadweight anchor is selected, based on its "simplicity, reliability, and holding capacity" (Ref. 4). Alternatives include free-fall concrete deadweight, pile, plate, and drag embedment anchors. The strongest commercially available line, 10-in.-diam. nylon braid, has a breaking strength of $2.1 \times 10^{6} \mathrm{lb}$. Anchor chain is high strength size four with a breaking strength of $1.9 \times 10^{6} \mathrm{lb}$. Deployment of the mooring system consists of floating each anchor to site, ballasting, and lowering the anchor on the mooring line with the assistance of a crane barge and tugs.

A functional model for the mooring system provides a method of establishing a set of parametric cost data for the various platforms and sites. In addition, a baseline design mooring system is analyzed to demonstrate the technical feasibility of this approach to position-keeping . 
The cost functional model is summarized in Table 2-34. The anchor function is based on two concrete deadweight anchor designs for deep ocean and high current sites (Ref. 4). The costs are based on engineering estimates or quotations and include forty percent for contingency, engineering, and profit. Replacement costs for the mooring lines only are included in these results.

Table 2-34

SUMMMARY OF MOORING SYSTEM FUNCTIONAL MODEL

\begin{tabular}{|c|c|c|c|}
\hline \multicolumn{2}{|r|}{ Component } & Unit Cost & Cost Function \\
\hline 1. & $\begin{array}{l}\text { Line } \\
10 \mathrm{in} . \\
2.1 \times 10^{6} \mathrm{lb} \\
26.5 \mathrm{lb} / \mathrm{ft} \\
\text { Specific gravity } 1.14\end{array}$ & $\$ 142 / \mathrm{ft}$ & $142.3 \times \mathrm{N}_{L} \times \mathrm{L}_{L} \times \mathrm{N}_{\mathrm{LL}}$ \\
\hline 2. & $\begin{array}{l}\text { Present Worth Factor for } \\
6 \text { Replacements \& Original }\end{array}$ & - & $2.6 \overline{\times} \mathrm{N}_{L} \times \mathrm{L}_{\mathrm{L}} \times \mathrm{N}_{\mathrm{LL}}$ \\
\hline 3. & Chain (Size 4) & $\$ 91.7 / \mathrm{ft}$ & $91.7 \times \mathrm{N}_{L} \times 200 \times \mathrm{N}_{L I}$ \\
\hline 4. & Anchor (Concrete Deadweight) & $\$ 293 / \mathrm{LT}$ & $293\left(8790+3.31 \mathrm{~F}_{\mathrm{H}}\right) \times \mathrm{N}_{\mathrm{L}}$ \\
\hline 5. & Traction Winch & - & $1553 \times \mathrm{T} \times \mathrm{N}_{\mathrm{L}}$ \\
\hline & \multicolumn{3}{|c|}{$\begin{array}{l}\mathrm{L}_{\mathrm{L}}=\text { line length, } \mathrm{ft} \\
\mathrm{N}_{\mathrm{L}}=\text { number of legs, } 3 \\
\mathrm{~N}_{\mathrm{LL}}=\text { number of lines per leg, }=\mathrm{T} \times 10^{-6} \mathrm{lb} \\
\mathrm{F}_{\mathrm{H}}=\text { total platform drag, } \mathrm{LT}\end{array}$} \\
\hline
\end{tabular}

Deployment costs, less than two percent of the total mooring system cost, are excluded from this summary. System costs shown in Fig. 2-36 vary between $\$ 32 \mathrm{MI}$ and $\$ 120 \mathrm{MI}$ for a 100-MW(e), (net) platform and between $\$ 100 \mathrm{MI}$ and $\$ 320 \mathrm{M}$ for a 500-iVW (e) (net) platform. The lowest cost mooring system is that for the submersible in Hawaii (not shown). These results generally follow the total drag data variation between size, site, and platform type. 


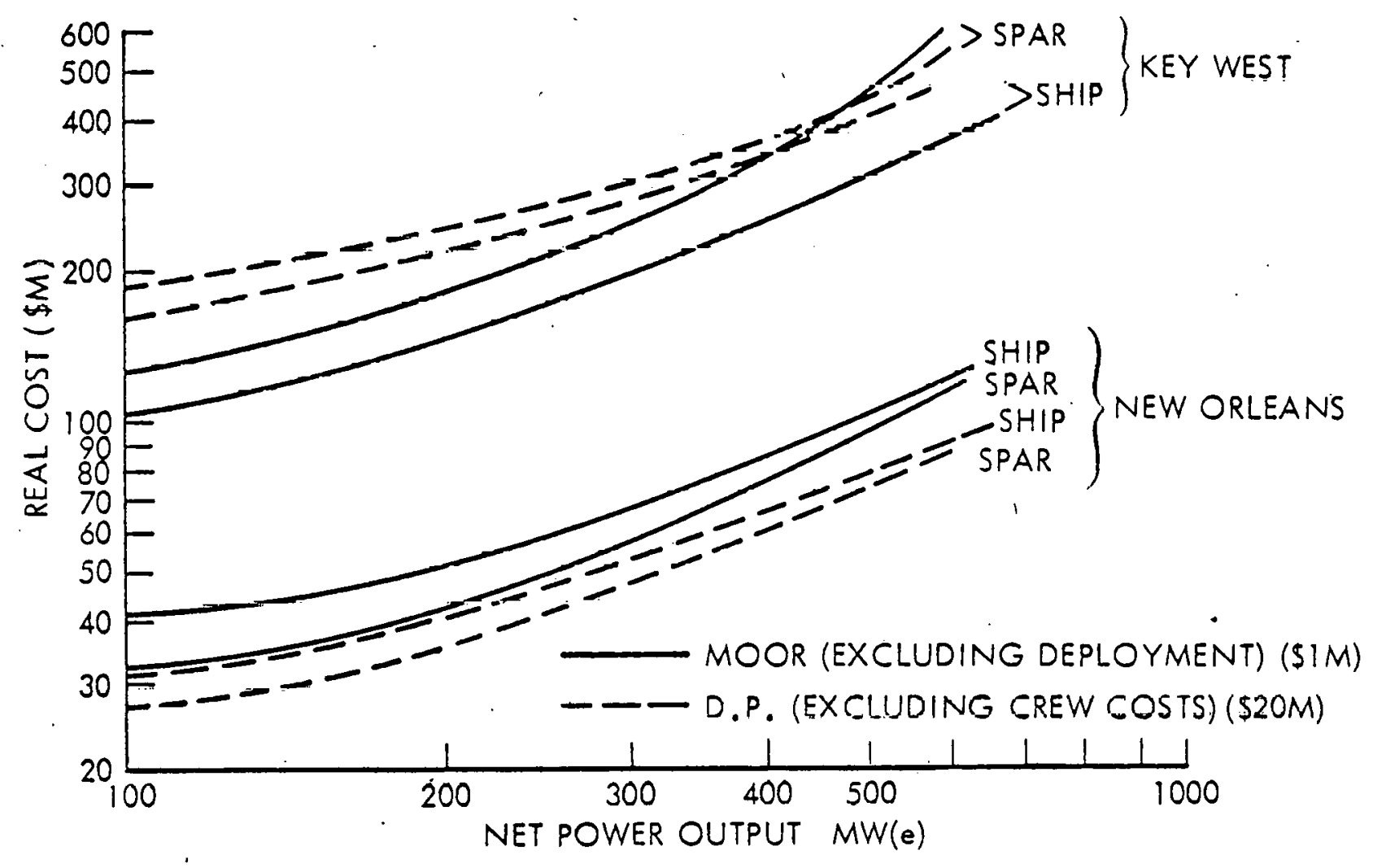

Fig. 2-36 Real Cost of Position-Keeping System 
Table 2-35

DYNAMIC POSITIONING FUNCTIONAL COST MODEL

\begin{tabular}{|c|c|c|}
\hline Component & Unit Cost & Cost Function \\
\hline $\begin{array}{l}\text { 1. Thrusters } \\
4000 \mathrm{HP} \text { Units } \\
25 \mathrm{Lb} / \mathrm{HP} \\
\text { 2. Annual Fuel Cost } \\
\text { OTEC Power } \\
\text { Present Worth Factor (40 Yr) } \\
\text { 3. Controls System }\end{array}$ & $\begin{array}{l}\$ 892,000 \\
\$ 0.03 / \mathrm{KWHR} \\
11.925 \\
\$ 2 \times 10^{6}\end{array}$ & $\begin{array}{l}8.92 \times 10^{5} \times \mathrm{N}_{\mathrm{TH}} \\
11.925 \times 196 \times \overline{\mathrm{P}} \\
\$ 2 \times 10^{6}\end{array}$ \\
\hline $\begin{array}{l}\mathrm{P} \quad=\text { Maximum Power, }=\mathrm{F}_{\mathrm{H}} / 25 \\
\overline{\mathrm{P}}=\text { Average Annual Power, }=\overline{\mathrm{F}} \\
\mathrm{N}_{\mathrm{TH}}=\text { Number of Thrusters, }=\mathrm{P} / 4\end{array}$ & $\begin{array}{l}/ 25 \\
00+1\end{array}$ & -. \\
\hline
\end{tabular}

The number of thrusters required varies between 10 for the $100 \mathrm{MW}(\mathrm{e})$ spar in Hawaii to 216 for the $500 \mathrm{MW}(\mathrm{e})$ barge in Key West. Total system costs are found to be less than (by $\$ 6 \mathrm{M}$ at $100 \mathrm{MW}(\mathrm{e})$ ) the cost of a mooring system for the Gulf of Mexico and greater than (by $\$ 60 \mathrm{M}$ at $100 \mathrm{MW}(\mathrm{e})$ ) the mooring system cost for Key West. The variation of dynamic positioning system costs with platform type is observed to be $\$ 26 \mathrm{M}$ to $\$ 31 \mathrm{M}$ for $100-\mathrm{MW}(\mathrm{e})$ (net) platforms in New Orleans and $\$ 400 \mathrm{M}$ to $\$ 450 \mathrm{M}$ for 500-MW(e) (net) platform in Key West. The power requirements for the thrusters are assumed to be provided by the OTEC power system under all conditions. In the extreme, or 100-year environmental loads, the number of thrusters that can be powered is $100 \times$ $1000 /(4000 \times 0.7457)$, or 33 thrusters, assuming $100 \mathrm{MW}(e)$ (net) output in this.condition. There is insufficient power to position any platform in Key West, so that dynamic positioning is not feasible for this site. It is noted that disruption of the thermal resource accompanies extreme sea conditions indicating that full plant output may not be available when required. Auxiliary power supplies would therefore be required. 
The cost models do not include crew costs required for maintenance and occasional manual operation of the thrusters or of the tensioning winches on the mooring system. Although these costs are significant over the life of the plant (estimate of $\$ 20 \mathrm{M}$ for the D.P. system), they are assumed to be included in operational costs.

\subsubsection{References.}

1. Westinghouse Electric Corporation Oceanic Division, Ocean Thermal Power Plants, Cold Water Pipe, Seawater Pumps; and Platform Station Keeping, ERDA Contract No. $E(11-1) 4071$, dtd 27 Sep 1977, pp. 4-6

2. Science Applications, Inc., OTEC Cold Water Pipe Hydrodynamic Loads, by D. T. Hove and W.C.I. Shik, SAI-76-548-LA, 8 Dec 1976

3. G. F.M. Remery and A. J. Hermans, "The Slow Drift Oscillations of a Moored Object in Random Seas", Offshore Technology Conference Paper No. 1500, Dallas, Texas, 1971

4. Civil Engineering Laboratory, Preliminary Selection of Anchor Systems for OTEC, by T. M. Atturio, P. J.- Valent, and R. J. Taylor, Port Hueneme, California, TM No. 42-76-2, Oct 1976

5. Lockheed Missiles \& Space Co., Inc., OTEC Platform Configuration and Integration Technology Review, LMSC-D564896A, Oct 1977

6. OTEC Platform Configuration and Integration, Environmental Data Package, Jul 14, 1977, (Rev. 1 Aug. 2) 


\subsection{PLATFORM OPTIOINS}

OTEC commercial plants have been arranged in six-types of hulls utilizing the specified, baseline internally-mounted, power system as defined and discussed in Section 2.3.1. Arrangements with the baseline power system were made for plants with net output of 100, 200, and $500 \mathrm{MW}(\mathrm{e})$. These eighteen platform arrangements provide the basis for functional models representing the commercial plants. These models are used to define the cost and the size of similar platforms for the purposes of this study.

The costs for the platforms include all major subsystems including the cost of deployment of the platform and the cold water pipe. These costs are considered valid for comparative purposes among the six platform types and as a function of platform size since they are all based on the same specified internallymounted power system.

Lower platform costs are expected for platforms which fully optimize the platform subsystems in conjunction with the power system and the electrical transmission system. Areas of potential cost optinizations are discussed for each of these platforms and in Sections 3 and 4 . One new candidate arrangement (detachable module spar) has been examined because of its potential for producing a lower cost platform than for an internally mounted power system. The other platforms were surveyed and were determined to be unlikely of significant improvement by utilization of a detachable module.

The characteristics of the seven platforms in steel and in concrete for OTEC commercial plants are summarized in this section. 


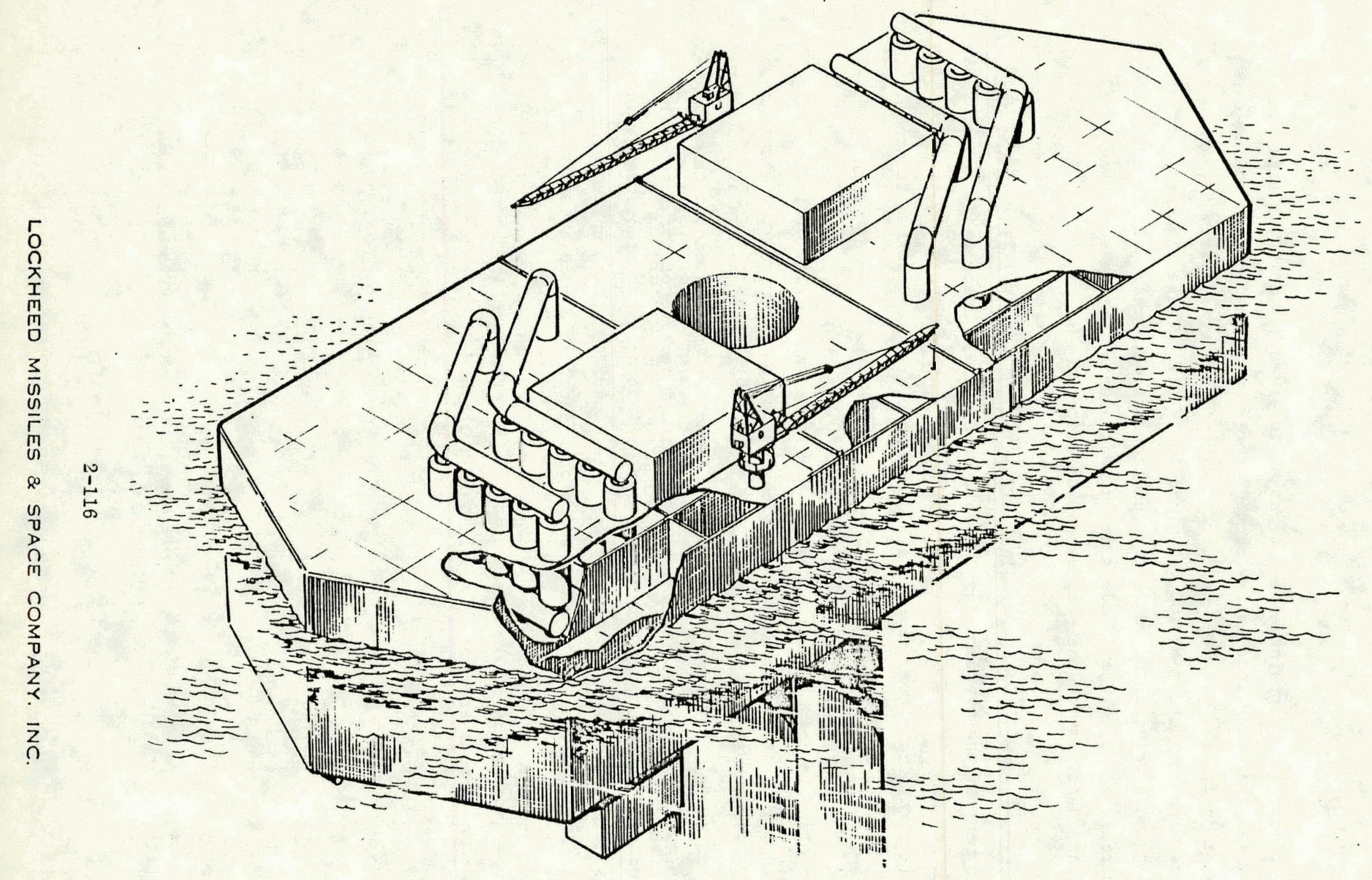

Fig. 2-37 OTEC Ship Configuration for 100-MW(e) (Net) Commercial Plant 


\subsubsection{Ship Configuration}

2.4.1.1 General Description. The 100-MW(e) ship configuration is presented in Fig. 2-38; 200-MW(e) and 500-MWW(e) configurations are represented in Table 2-36. Major sizing data and general arrangements are shown in keeping with the preconceptual nature of the present phase of the OTEC Study. A summary of the key sizing data for the three platforms is presented in Table $2-36$.

The proposed 100-MW(e) OTEC Ship is essentially a hollow rectangular box with a water distribution system around the perimeter. The simplicity of the arrangement allows easy modifications of the basic geometry of the ship to accommodate component growth or changes to the power plant module from 25-MW(e) to any other combination prior to construction. Previous studies by Lockheed indicate that smaller module size will mean larger required total volume for the net power output. Therefore, smaller modules and/or component growth would mean a larger ship would be required, although the same concept could be retained. Reorientation of the heat exchangers to a fore-aft direction, or use of vertical heat exchangers, would radically change the seawater system. The Ship concept would have to be redesigned to accommodate these changes.

The 200-MW(e) OTEC Ship is identical in arrangement to the 100-MW(e) ship except that the length has been increased to accommodate the larger CWP and the extra 100MW(e) of equipment, and the width of the wing tanks has been doubled to allow for twice the water flow. 


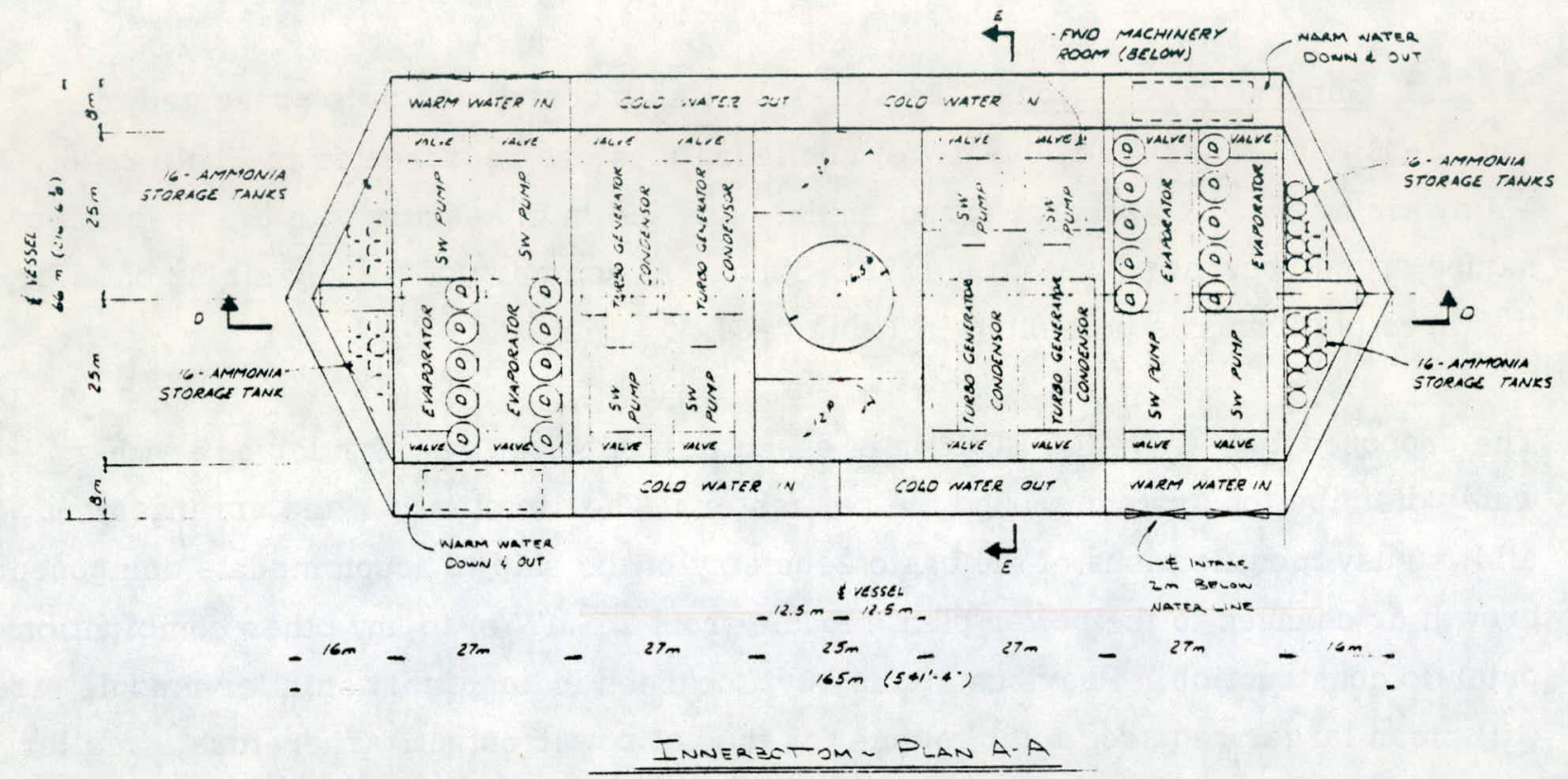

E vessel

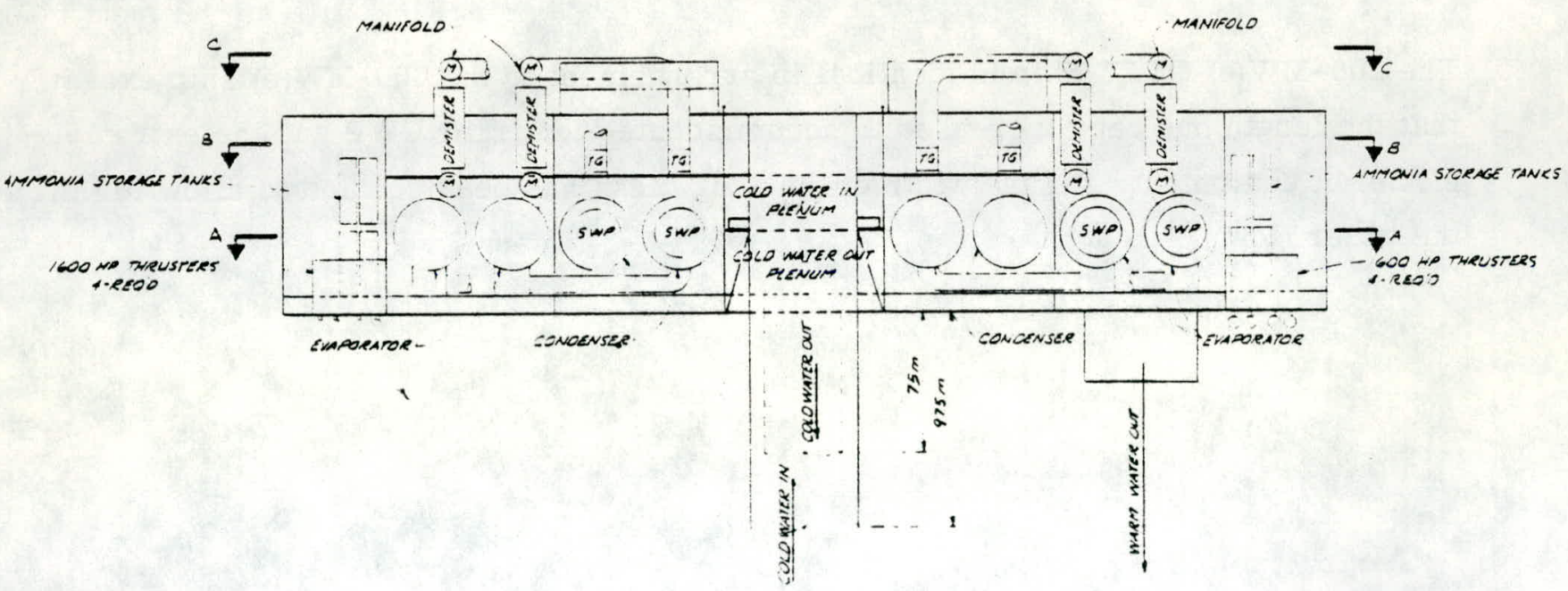

Fig. 2-38 Ship-100 MW(e) (Net) Steel 
Table 2-36

PRINCIPAL CHARACTERISTICS OF 100, 200 AND 500 MW(e) (NET) SHIP

\begin{tabular}{|l|r|r|r|}
\hline \multirow{2}{*}{ Item } & \multicolumn{3}{|c|}{ SHIP } \\
\cline { 2 - 4 } & $100 \mathrm{MW}(\mathrm{e})$ & $200 \mathrm{MW}(\mathrm{e})$ & $500 \mathrm{MW}(\mathrm{e})$ \\
\hline Length (Width) (m) & 165 & 305 & 356 \\
Breadth (m) & 66 & 82 & 82 \\
Height (m) & 32 & 32 & 56 \\
Draft (m) & 25 & 25 & 48 \\
Displacement (MT) & 274,000 & 630,000 & $1,500,000$ \\
Cost (x 10 & $\$ 233$ & $\$ 482$ & $\$ 194$ \\
Cost/KWe & $\$ 2,330$ & $\$ 2,410$ & $\$ 1,970$ \\
\hline
\end{tabular}


The 500-MW (e) Ship is similar to the 100-MW(e) Ship in operating concept. However, in this arrangement, the heat exchangers are stacked two high. Stacking the heat exchangers causes a significant increase in operating draft, but allows the geometry of the Ship to maintain conventional shipshape proportions.

Hydrostatic properties for the $100-\mathrm{MW}(\mathrm{e})$ platform were computed for the vessel with and without the CWP attached. The curves of form are produced on Fig. 2-39. All values plotted reflect the molded volume of the vessel. The 100-MW(e) OTEC Ship weight summary is presented in Table 2-37.

2.4.1.2 Design Features. The ship is wall-sided throughout finr ease of construction and flexibility in equipment placement. The departure from a normal streamlined hull shape will not be a significant disadvantage, since the vessel will never be under way after initial deployment, and the mooring system design is predicated on survival at the worst possible heading to the environment. This last requirement results from the assumption of power loss of the heading control system in the survival condition.

The scantlings have been sized using steel throughout. When the OTEC Ship is actually designed, weight might be minimized to allow for shallow draft construction; however, since additional weight must be added to the vessel to reach operating draft, mild steel was selected over the higher strength steels available for ship construction. With an adequate cathodic protection system, and proper detailed design, the OTEC Ship can be designed and constructed of steel to meet a 40 -yr life.

The hull is enclosed by non-tight structural cofferdams on all sides. The bottom of the ship and the forward and aft ends are enclosed by watertight cofferdams. The main deck and the inner bottom are similarly framed. Main frames opnnning the full width or depth of cofferdams are oriented transversely to the ship. These are crossed by intermittent longitudinal members of full cofferdam width or depth. Between the full depth longitudinals, the spaces are divided by longitudinal stiffeners on each face of cofferdam. The interior space is partitioned by transverse walls and truss framing which support the main deck. 


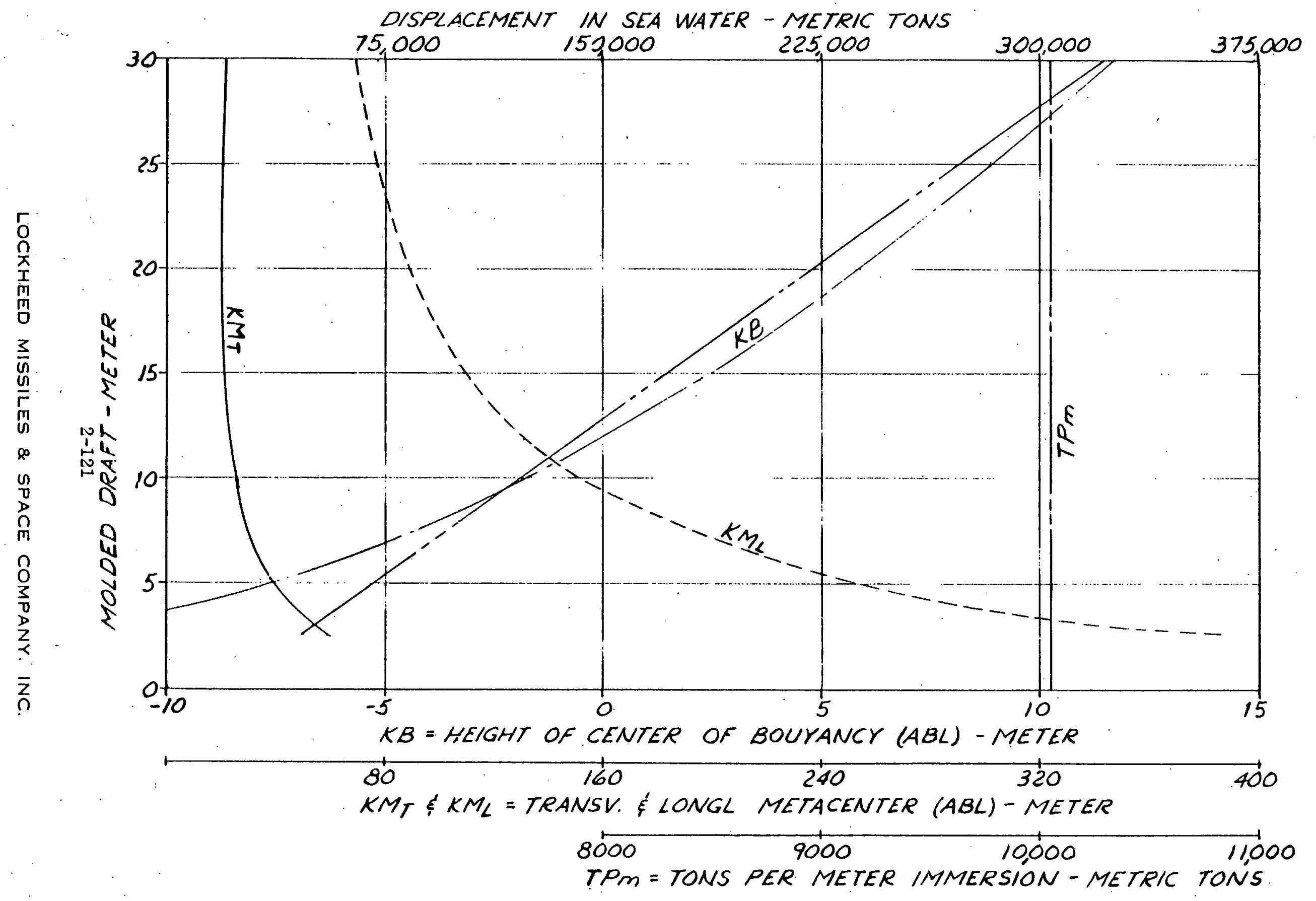

Fig. 2-39 OTEC Ship $100 \mathrm{MW}(\mathrm{e})(\mathrm{Net})$ Curves of Form 
Table 2-37

OTEC SHIP WEIGHT SUMMARY

\begin{tabular}{cc} 
LIGHTSHIP & OPERATING \\
WEIGHT & WEIGHT \\
METRIC & METRIC \\
TONS & TONS \\
\hline
\end{tabular}

0.1 OTEC PLATFORM

1.0 HULL AND STTRUCTURE
1.1 Shell
1.2
Bulkhead
17,400
17,400
1.3
Decks
1.4
Platforms
8,300
8,300
1.5
Deck House
4,600
4,600
1.6
Not Used
1.7
Not Used
1.8 Foundations
1.8.1 Cold Water Pipe
2,000
2,000
500
500
1.8 .2 Equipment
2,500
2,500
4,700
4,700

1.9 Misc. Weights

1.9.1 Fixed Baliast

1.9.2 Free Flooding seawater

$45,000 \quad 45,000$

TOTAI

96,000

$85,000 \quad 181,000$

2.0 SEAWATER SYSTEM

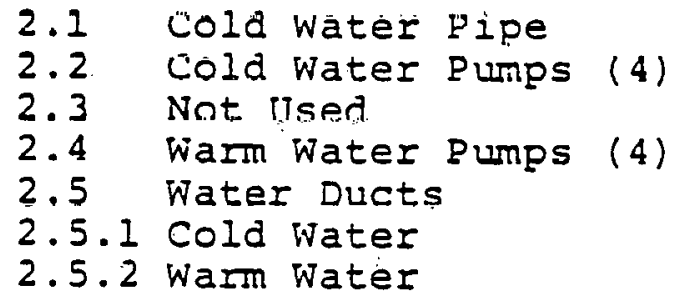

TOTAL

\begin{tabular}{cc}
56,800 & 24,400 \\
700 & 700 \\
700 & 700 \\
3.000 & $\begin{array}{c}2,000 \\
0\end{array}$ \\
\hline 01,200 & 27,800
\end{tabular}


Table 2-37 (Continued)

3.0 POSITION CONTROL SYSTEM

\subsection{Mooring \\ 3.2 Thrusters}

4.0 SUPPORT SOBSYSTEMS

5.0 OUTFIT AND FURNISHINGS

TOTAL PLATFORM WEIGHTS

0.2

0.3

1.0

HEAT EXCRANGERS

$(8)$

2.0

TURBO-GENERATORS

(4)

3.0 DEMISTÉRS (20)

4. 0 AMMONIA SYSTEM

4.1
4.2
4.3
4.4
4.5
10.6
4.7

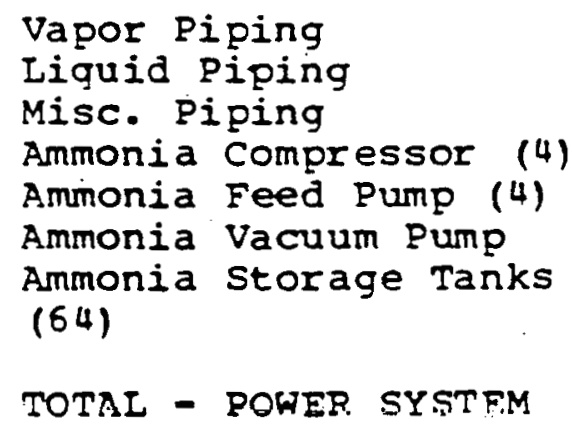

TOTAL - POWER SYSTFM

\begin{tabular}{rr}
500 & 500 \\
\hline 500 & 500 \\
3,500 & 3,500 \\
1,500 & 1,000 \\
\hline 151,200 & 213,900 \\
200 & 200
\end{tabular}

$\begin{array}{rr}16.500 & 27.390 \\ 820 & 820 \\ 830 & 860\end{array}$

140

150

$90 \quad 300$

$20 \quad 20$

$40 \quad 40$

100

100

10

10

$\frac{1.050}{19.600 \mathrm{MT} \quad 32.610}$

0.4

\section{MISCELIANEOOS}

1.0 SEAFATER BALLAST

20.000

2.0 CONSUMABLES

3.0. CWP INSTALLATION CRANE

$\begin{array}{r}5,000 \\ 3,000 \quad 3,000 \\ \hline\end{array}$

TOTAL MISCELLANEOOS

$3,000 \quad 28,000$

TOTAL WEIGHT WITH CWP

$174,000 \mathrm{MT} \quad 274,000 \mathrm{MT}$

TOTAI WEIGHT WITHOUT CWP $117,200 \mathrm{MT} 249,600 \mathrm{MT}$ 
The seawater system consists of the cold water intake pipe (CWP), cold water discharge pipe, warm water intake and discharge systems, seawater plenums, piping, pumps and valves. The CWP conducts water up from a depth of $1,000 \mathrm{~m}$ to the cold water intake plenum, located in the center of the vessel and extends transversely between the wing walls. The cold water flows from this vented plenum to wing tanks, and then through butterfly valves into the saltwater pumps. After passing through the pumps and condensers, the cold water exits through another valve into the opposite wing tank. It then flows into the cold water discharge plenum, located directly below the intake plenum, and out through two cold water discharge pipes which extend $75 \mathrm{~m}$ below the hull to a depth of $100 \mathrm{~m}$.

The warm water intake is provided through the side of the hull into wing tanks forward and aft of the cold water system. The warm water pumps pump the water through the evaporators and out into the opposite wing tanks. From here the warm water is discharged down through two 8-m-diam. pipes extending $20 \mathrm{~m}$ below the hull to a depth of $45 \mathrm{~m}$. The use of wing tanks for the seawater distribution system eliminates the need for internal seawater pipes and provides damage protection without further penaity on hull displacement. It is anticipated that transvorso mounting of the pumps and heat exchangers will be acceptable, since roll will be minimized by the vessel's large beam and its ability to orient into the prevailing seas.

The ship will be held on location by a fixed mooring system. This system will limit excursion to acceptable limits as dictated by the electrical transmisssion cable requirements. Heading control will be accomplished by use of the thrusters located below the ends of the hull possibly combined with selective manipulation of mooring line lengths. The goals of heading control will be to minimize environmental forces, minimize adverse motions, and provide warm water intake from an optimum direction with respect to current flow.

The electrical power transmission equipment is located on the Second Decls at the center of the ship above the cold water plenum. The power cables will transit through the hull from a common junction box. 
The heat exchanges for the closed loop ammonia power system are on the inner. bottom of the ship. The ammonia vaporized in the evaporator passes through the demisters which are mounted on top of the evaporator and penetrate the main deck of the ship. The dry vapor from the demisters are manifolded together and the routed above the main deck directly over the turbine generators. The vapor piping then penetrates the main deck and passes through the turbine generator and into the condenser. The condensed ammonia is then pumped back to the evaporator to complete the cycle. The OTEC Ship has a total of $440 \mathrm{~m}$ of ammonia vapor piping and $180 \mathrm{~m}$ of ammonia liquid piping. The main power system auxiliaries are located within the hull of the ship. The ammonia storage tanks are located in the forepeak and after peak sections of the ship. They are segregated from the rest of the vessel by watertight bulkheads. The inert gas system is located below the aft port seawater pump on the lower deck level.

\subsubsection{Constructability.}

(a) Facility Requirements

Due to the wide beam of the ship, $66 \mathrm{~m}$ (217 ft), none of the facilities surveyed is of sufficient size in which to construct the ship as a single unit. The General Dynamics, Quincy Division, yard has two graving docks adjacent to each other, separated by a wall. If this wall is removed the resulting dock is $267 \mathrm{~m} \times 92 \mathrm{~m}(874.5 \times 300 \mathrm{ft})$ wide and $6.7 \mathrm{~m}(22 \mathrm{ft}) \mathrm{draft}$. This is of sufficient size in which to build either the shell only or the hull plus machinery. After launch a protected water site with $22 \mathrm{~m}$ (72 ft) water depth is required for adding permanent ballast.

Numerous existing facilities could be used if the construction was started on barges at a shore site adjacent to the shipyard. A barge platform capable of supporting the hull until the watertight shell could be built would have dimensions of $183 \mathrm{~m} \times 76 \mathrm{~m}(600 \mathrm{ft} \times 250 \mathrm{ft})$. Since barges can be moved to deeper water and deballasted to float the ship, 
and the ship then towed back for completion of the construction, a minimum shore site draft of $6.6 \mathrm{~m}(21.5 \mathrm{ft})$ would be required for the barge construction option.

If a new facility were built it should have the following dimensions:

$\begin{array}{lr}\text { Width: } & 76 \mathrm{~m}(250 \mathrm{ft}) \\ \text { Length: } & 183 \mathrm{~m}(600 \mathrm{ft}) \\ \text { Depth: } & 9 \mathrm{~m}(30 \mathrm{ft})\end{array}$

This would allow the Ship to be oompleted except for the installation of the permanent ballast.

A summary of required facilities is presented in Table 2-38.

(b) Construction Methods

Four construction options were considered applicable for the OTEC Ship. These methods are described below. Option I is shown pictorially on Figure 2-40. A summary of the percent of construction completed in each phase is shown in Table 2-39.

(1) Optiun I - Graving dock construction.

By removing the separating wall at the General Dynamics Quincy Division, $22 \mathrm{ft}$ graving docks that are 149.33 and $150.33 \mathrm{ft}$ wide by $874.5 \mathrm{ft}$ long, a single dock $874.5 \times 300 \times 22 \mathrm{ft}$ results. The ship can be constructed in this dock, including structure, equipment (dry), and auxiliary machinery. Seawater ducts and tanks are used to reduce draft. Launch draft is $6.6 \mathrm{~m}(21.5 \mathrm{ft})$. At an adjacent sheltered water site, the ship outfitting is completed exoept for installation of the pcrmanent ballast, and the draft of the ship is $22 \mathrm{~m}(72 \mathrm{ft})$. Seawater ducts are opened and tanks flooded. In deep water, the CWP is installed. 
Table 2-38

SUMMARY - REQUIRED FACILITIES

Shel tered

Size Draft Facility Water Depth

Drydock -

Bull shell $165 \times 66 \mathrm{~m}$ only

$3.9 m$

GD, Quincy
or New

$22 m$

Bull and

Machinery

$165 \times 66 \mathrm{~m}$

GD. Qunicy

or New

$22 m$

Barge

$183 \times 76 \mathrm{~m}$

$6.6 m$

Many yards

$22 \mathrm{~m}$ 


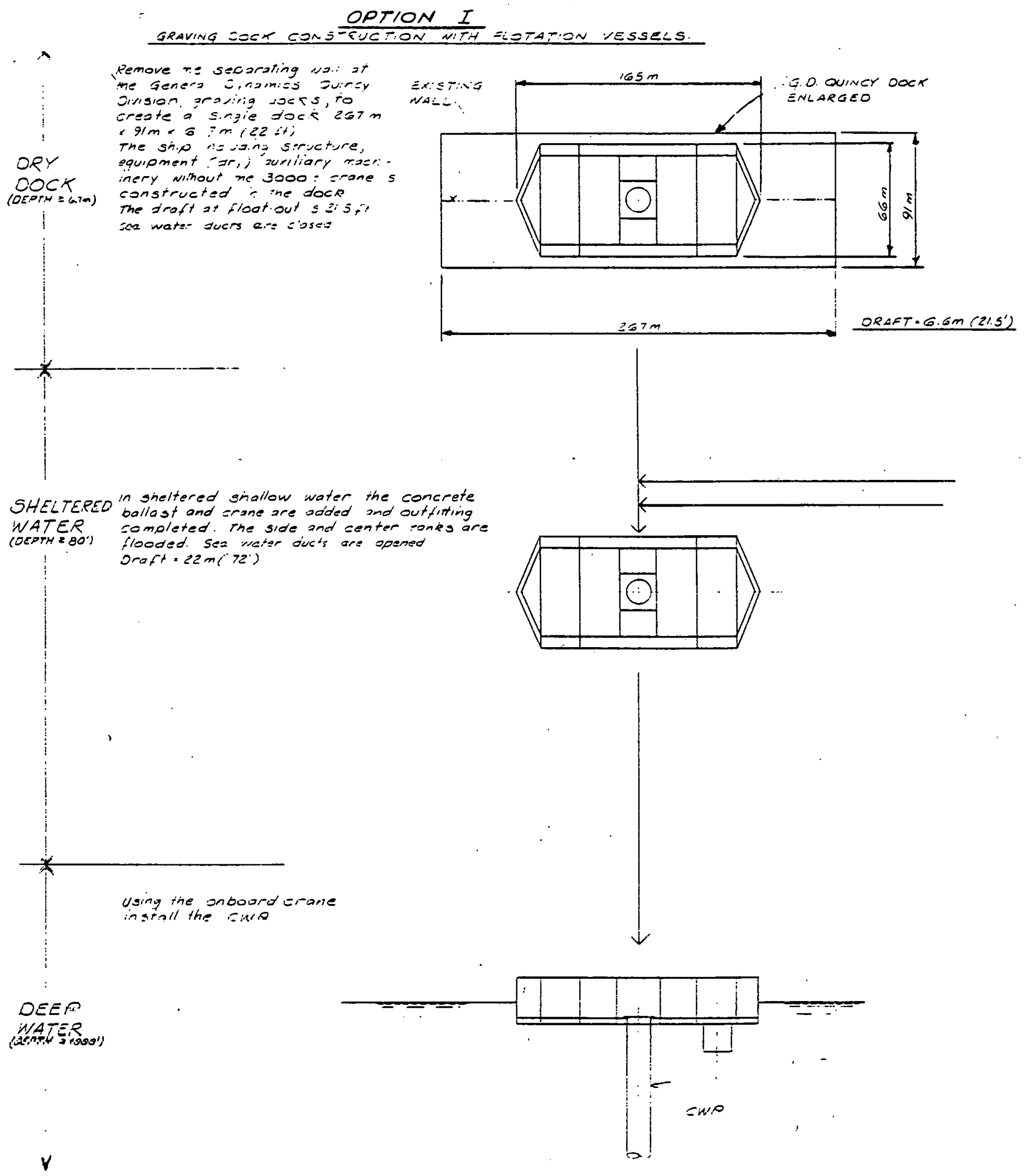

Fig. 2-40 Ship-100 MWV(e) (Net) Steel 
Table 2-39

SUMMARY OF CONSTRUCTION METHODS

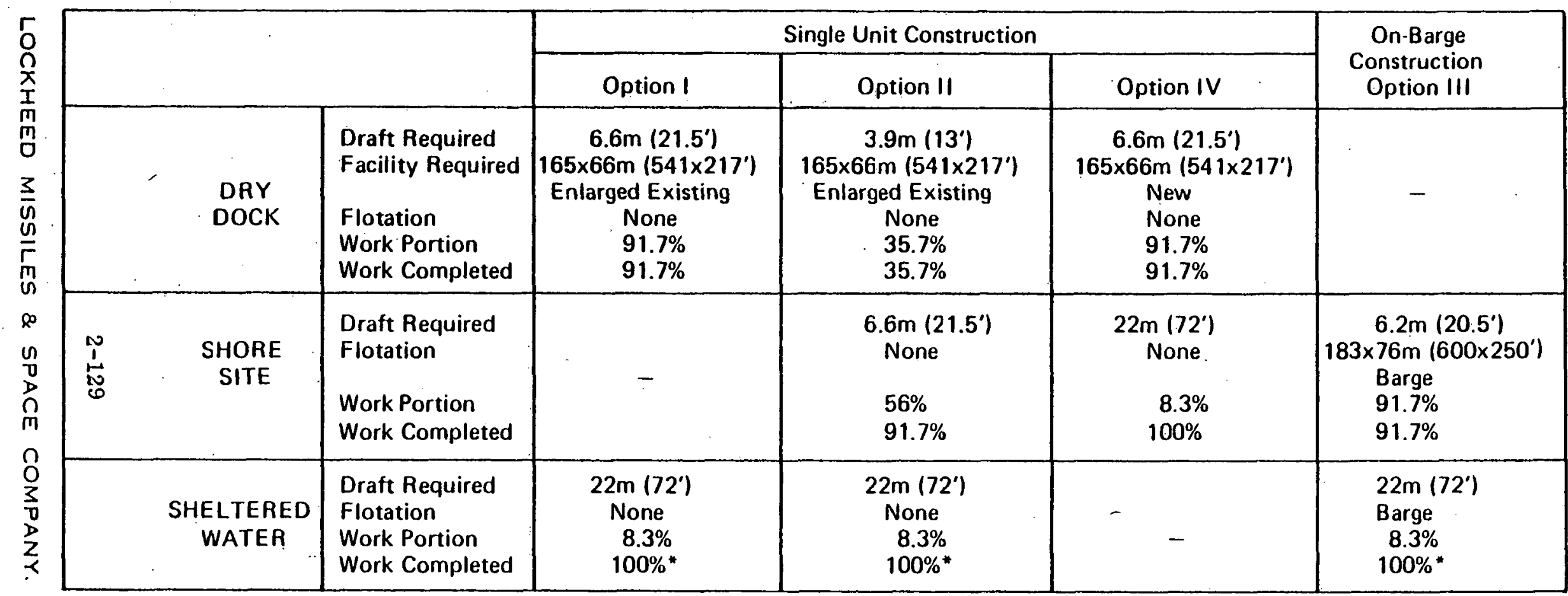

* Excluding mobilization - CWP installation, crane installation and removal, towing. 
(2) Option II - Dock construction of empty hull.

Within the enlarged dock described in Option I, the Ship's hull alone is constructed without upper deck leaving the ship's compartments accessible from above. The vessel draft is $3.9 \mathrm{~m}$ $(13 \mathrm{ft})$. After float-out into an adjacent shore-site facility the power plant and auxiliary machinery, and upper deck are installed, followed by outfitting and crane installation. The draft at this time is $6.6 \mathrm{~m}(21.5 \mathrm{ft})$. The vessel is towed to a protected deep water site where the permanent ballast is installed and tanks flooded. This method would allow existing floating cranes to install the large seawater and power system components and could possibly save considerable time in construction over Option I unless heavy lift cranes were available at the graving dock.

(3) Option III - On-barge construction.

Barge modules are assembled in shallow water to form a $183 \times 76 \mathrm{~m}$ $(600 \times 250 \mathrm{ft})$ floating platform on which the Ship's shell is sonstructed. When the watertight shell is completed, the barges are sunk adid the ship Muated. Installation of the power system, seawater system, and auxiliary equipment is completed with the vessel at a $10.4 \mathrm{~m}$ draft (34 ft). The vessel is then towed to a protected water site where the permanent ballast is added burying the vessel draft to $22 \mathrm{~m}(72 \mathrm{ft})$. The CWP is installed at the OTẼC site.

(4) Option IV - Construction in new 30-ft drydock.

A $183 \times 76 \mathrm{~m}(600 \times 250 \mathrm{ft}), 30-\mathrm{ft}$-deep drydnck is constructed. The ship is built in this dock, including structure, power plant, and accessories and crane. Draft is $10.4 \mathrm{~m}$ (34 ft) after flooding of the dock. In sheitered water, the outfitting is completed and concrete added to a draft of $22 \mathrm{~m}(72 \mathrm{ft})$. The CWP is installed in deep water. 


\subsubsection{Operability.}

\section{(a) Maintenance}

The OTEC Ship's internal geometry and equipment arrangement will make on-site maintenance and repair relatively easy. All power system, seawater system, electrical transmission system, and vessel, service systems are accessible from within the hull of the Ship. Onboard workshops will handle all minor repair items, and there is sufficient room near all the equipment to allow major overhaul work to be performed on board the vessel.

- If the ship is part of an OTEC farm, it is possible that all major repair work will be done on a mobile support vessel which is equipped with extensive machine shops and repair facilities. In this case all major components on the Ship except for the heat exchangers can be removed without major impact to the plant operation.

Periodically, the heat exchanges will have to be retubed. The present arrangement allows enough room for the retubing to be done in place. If the heat exchanges must be removed, a gantry crane can be temporarily installed to lift the heat exchanger onto the Main Deck of the vessel. A barge crane could then remove the unit from the ship for retubing. The heat exchangers would be reinstalled in a similar manner.

\section{(b) Operation}

Once the Ship is moored in position, the OTEC plant will be similar in operation to an offshore oil and gas production facility except on a larger scale. Manning requirements and schedules, equipment monitoring and maintenance, and the continual checking for dangerous gas or vapor leaks will be similar in both types of facilities. Startup, shutdown, and emergency evacuation procedures for both offshore oil production and OTEC plants will also be of similar complexity and importance. 
The operation of the OTEC Ship should not present any significant deviation from procedures which have already proven to be acceptable in numerous offshore installation.

\section{(c) Performance}

The Ship platform is designed to satisfy the requirements of the American Bureau of Shipping. ABS measures intact stability by the ability of the vessel to withstand the overturning forces of a severe wind and accompanying waves.

A measure of the stability of the intact vessel is a comparison between the overturning energy created by wind and waves and the righting energy created by the heeled vessel. The amount by which the righting energy exceeds the overturning energy up to the limiting angle is a measure of the ve ssel's ability to resist capsizing or downflooding. The ABS rules require that the area under the righting moment curve by at least $40 \%$ greater than the area under the heeling mornent curve up to some limiting angle. The heeling moment curve used is that of a $51.5 \mathrm{~m} / \mathrm{sec}(100$ knots) beam wind which decreases as cosine of the heel angle. The limiting angle is that corresponding to eitlier the secund intersection of the two curves, beyond which the overturning moment exceeds the righting moment, or the occurence of downflooding, whichever is less.

The intant stability of the vessel has been evaluatod for throo conditions:

จ. Light draft (in transit)

- Operating draft (25 m)

- Operating mode: CWP breaks off 
For each case, the KG value was calculated. In each case, the area ratio between the righting moment and the heeling moment curves was greater than 1.4. The vessel has sufficient stability in the intact condition to withstand anticipated environmental loads to a degree established as acceptable by ABS.

The amplitude of the significant motions of the 100-iNW(e) ship and the attached cold water pipe are presented in Table $2-40$.

2.4.1.5 Risks. A potential risk area which may have a bearing on power availability is due to the possible adverse affect of the ship's sensitivity to wave motion on heat exchanger performance, habitability, fatigue loading on the CWP, and application of large bending moment at the pipe-hull interface. 
Table 2-40

CALCULATED SEAWAY RESPONSE FOR SHIP PLATFORM

IN HEAD AND BEAM SEAS, CONCRETE CWP,

$\mathrm{E}=0.3 \times 10^{6}$ PSI, $10^{9} \mathrm{LB}-\mathrm{FT} / \mathrm{RADIAN}$

CWP ATTACHMENT STIFFNESS

\begin{tabular}{|c|c|c|c|c|c|}
\hline \multirow[t]{2}{*}{ Response } & \multirow[t]{2}{*}{ Units } & \multicolumn{4}{|c|}{$\begin{array}{l}\text { Significant Amplitude for } \\
\text { Significant Wave Height }\end{array}$} \\
\hline & & $20 \mathrm{ft}$ & $35.9 \mathrm{ft}$ & $45.8 \mathrm{ft}$ & $58.1 \mathrm{ft}$ \\
\hline \multicolumn{6}{|c|}{ HFADSFAS } \\
\hline Surge & $\mathrm{ft}$ & 1.6 & 5.7 & 8.7 & 14.6 \\
\hline Heave & $\mathrm{ft}$ & 1.4 & 7.4 & 11.7 & 20.1 \\
\hline Pitch & $\operatorname{deg}$ & 0.6 & 2.6 & 4.0 & 6.2 \\
\hline Max. Acceleration & $\mathrm{ft} / \sec ^{2}$ & 0.7 & 2.9 & 4.2 & 6.1 \\
\hline CWP Rotation & deg & 0.6 & 2.6 & 3.9 & 6.4 \\
\hline Max. Bending Moment & $\mathrm{lb}-\mathrm{ft}$ & $9.91 \times 10^{7}$ & $3.88 \times 10^{8}$ & $5.83 \times 10^{8}$ & $8.57 \times 10^{8}$ \\
\hline Max. Bending Stress & psi & $1.45 \times 10^{2}$ & $5.66 \times 10^{2}$ & $8.5 \times 10^{2}$ & $1.25 \times 10^{3}$ \\
\hline Max. Shear Force & $\mathrm{lb}$ & $6.11 \times 10^{5}$ & $1.62 \times 10^{6}$ & $2.39 \times 10^{6}$ & $3.53 \times 10^{6}$ \\
\hline \multicolumn{6}{|c|}{ BEAM SEAS } \\
\hline Sway & ft & 2.6 & 6.8 & 9.7 & 15.3 \\
\hline Heave & $\mathrm{ft}$ & 3.7 & 14.5 & 21.4 & 32.2 \\
\hline Roll & deg & 2.2 & 7.8 & 11.0 & 14.8 \\
\hline Max. Acceleration & $\mathrm{ft} / \mathrm{sec}^{2}$ & 1.9 & 5.7 & 7.9 & 10.2 \\
\hline UWP Rotation & dèg & 2.1 & 7.9 & 11.3 & 15.5 \\
\hline Max. Bending Moment & $1 b-f t$ & $2.41 \times 10^{8}$ & $6.0 \times 10^{8}$ & $8.62 \times 10^{8}$ & $1.21 \times 10^{9}$ \\
\hline Max. Bending Stress & psi & $3.51 \times 10^{2}$ & $8.75 \times 10^{2}$ & $1.26 \times 10^{3}$ & $1.77 \times 10^{3}$ \\
\hline Max. Shear Force & lb & $1.32 \times 10^{6}$ & $2.95 \times 10^{6}$ & $4.07 \times 1.0^{6}$ & $5.54 \times 10^{6}$ \\
\hline
\end{tabular}




\subsubsection{Costs.}

(a) Construction Cost - SHIP

The estimated costs to construct the OTEC ship in an existing facility assuming no draft, width, or length limitations are shown in Table 2-41. This is the basic cost to build a 100-MW(e) Ship. To this basic cost must be added a cost based on the construction method employed in building the Ship.

The following cost factors have been used:

Construction Facility

Graving Dock

Shore Site (at Shipyard)

Protected Water

Unprotected Waters

On Site (Mobilization Cost)

\section{Cost Factor}

1.0

1.25

2.0

3.0

Using weighting factors based on the percentage of construction at each phase of construction from Table 2-41, a construction cost for each construction option was developed. A summary of these costs is shown in Table 2-42.

(b) Mobilization Costs - General

Mobilization includes the following: installation of the $3000 \mathrm{~T}$ crane for on-site installation of the CWP, towing to the site, installation of the CWP, and completion of platform construction if required. Mobilization costs are largely affected by down time caused by weather and sea states. Assuming a crane barge can operate in six foot significant seas while performing maximum capacity lifts, downtime can vary from $20 \%$ in a Gulf of Mexico environment to $70 \%$ in a North Sea environment. Mobilization costs have been estimated over the range between these two extremes. 
Table 2-41

PLATFORM CONSTRUCTION COST - SHIP

1.0 HULL AND STRUCTURE

\begin{tabular}{rrc}
$\$ / M T$ & $M T$ & $C O S T(\times 106)$ \\
3100 & 17370 & 53.9 \\
3100 & 8330 & 25.8 \\
3100 & 4600 & 14.3 \\
2600 & 2000 & 5.2 \\
2600 & 500 & 1.3 \\
& & \\
3100 & 7200 & 22.3 \\
115 & 45000 & 5.2 \\
\hline & 85000 & 128.0
\end{tabular}

2.0 NOT USED

3.0 POSITION CONTROL SYSTEM

3.1 Thrusters

TOTAL $\frac{7.0}{7.0}$

4.0 SUPPORT SUBSYSTEMS

4.1 Cathodic Protection/Coating 7.4

4.2 Machinery 3.0

- Elevatore

- Deck cranes

- Dlesel Generators (quarters)

- Emergenry Generagore (Quafters)

- Hoists, tuggers, forklifts 
Table 2-41 (Contimued)

4.3 Hull Piping Systems/w Machinery 11.0

- Ballast

- Bilge

- De-Ballast Vent

- Sounding

- Engine Cooling

- Compressed Air

- Lube OiI

- Fuel Oil

- Fresh Water

4.4 HVAC

8.2

4.5 Safety Equipment

1.0

- Fire Protection

- Lifeboats

- Life Rafts

4.6 Electrical Work (Misc.) 1.5

$\begin{array}{lll}4.7 & \text { Vessel Management } & 3.6\end{array}$

4.8 Accomodation 2.5

4.9 Misc. Workshops 1.0

4.10 Radio and Communications 0.2

TOTAL 39.4

5.0 Installation of OFE $500 \quad 26,000 \quad 13.0$

-. DACS

- Sea Water System

- Mooring system

- 3000m Gantry Crane

- Energy Transfer System

- Power system

Total $\$ 187,400,000$ 
Table 2-42

CONSTRUCTION METHOD COSTS - SHミP

\begin{tabular}{|c|c|c|c|c|c|c|c|c|c|c|c|c|c|}
\hline \multirow{2}{*}{$\begin{array}{l}\text { Construction } \\
\text { Location }\end{array}$} & \multirow{2}{*}{$\begin{array}{c}\text { Work } \\
\text { Description }\end{array}$} & \multicolumn{3}{|c|}{ Option I } & \multicolumn{3}{|c|}{ Option II } & \multicolumn{3}{|c|}{ Option III } & \multicolumn{3}{|c|}{ Option IV } \\
\hline & & Weight & $\begin{array}{l}\text { Unit } \\
\text { Cost } \\
\end{array}$ & Cost & Weight & $\begin{array}{l}\text { Unit } \\
\text { Cost }\end{array}$ & Cost & Weight & $\begin{array}{l}\text { Unit } \\
\text { Sost }\end{array}$ & Cost & Weight & $\begin{array}{l}\text { Unit } \\
\text { Cost }\end{array}$ & Cost \\
\hline $\begin{array}{c}\text { DAY } \\
\text { DOCK } \\
\text { (Cost Factor) } \\
=1 \\
\end{array}$ & $\begin{array}{l}\text { Structure } \\
\text { Equip. Instil. }\end{array}$ & $\begin{array}{l}10,000 \\
26,000\end{array}$ & $\begin{array}{r}3,070 \\
500\end{array}$ & $\begin{array}{c}122.8 \\
13\end{array}$ & 25,700 & 3,070 & 78.9 & & & & $\begin{array}{l}40,000 \\
26,000\end{array}$ & $\begin{array}{r}3,070 \\
500\end{array}$ & $\begin{array}{c}122.8 \\
13\end{array}$ \\
\hline $\begin{array}{c}\text { SHORE } \\
\text { SITE } \\
\text { (Cost Factor) } \\
=1.25\end{array}$ & $\begin{array}{l}\text { Structure } \\
\text { Equip. InstI. }\end{array}$ & & & & $\begin{array}{l}14,300 \\
26,000\end{array}$ & $\begin{array}{r}3.070 \\
500\end{array}$ & $\begin{array}{l}54.9 \\
16.3\end{array}$ & $\begin{array}{l}40,000 \\
26,000\end{array}$ & $\begin{array}{r}3,070 \\
500\end{array}$ & $\begin{array}{r}153.5 \\
16.3\end{array}$ & & & \\
\hline $\begin{array}{l}\text { SHALLOW } \\
\text { WATER } \\
\text { (Cost Factor) } \\
=2\end{array}$ & $\begin{array}{l}\text { Structure } \\
\text { Equip. Instl. } \\
\text { Concrete } \\
\text { Ballast }\end{array}$ & 45,000 & 115 & 10.4 & 45,000 & 115 & 10.4 & 45,000 & 115 & 10.4 & 45,000 & 115 & 10.4 \\
\hline $\begin{array}{c}\text { ON-SITE } \\
\text { (Cost Factor) } \\
=3\end{array}$ & $\begin{array}{l}\text { Structure } \\
\text { Equip. Instl. } \\
\text { Concrete } \\
\text { Ballast } \\
\end{array}$ & & & & & & & & & & & & \\
\hline Subtotal & & & & 146.2 & & & 160.5 & & & 180.2 & & & 146.2 \\
\hline $\begin{array}{l}\text { Support } \\
\text { Subsystem } \\
\text { and DP } \\
\text { System }\end{array}$ & & & & 46.4 & & & 46.4 & & & 46.4 & & & 46.4 \\
\hline Total & & & & 192.6 & & & 206.9 & & & 226.6 & & & 192.6 \\
\hline & Units & ant & $\$ / \mathrm{mt}$ & $\begin{array}{c}\$ \\
\text { million }\end{array}$ & $\mathrm{mt}$ & $\$ / m t$ & $\begin{array}{c}\$ \\
\text { million }\end{array}$ & $\mathrm{mt}$ & $\$ / m t$ & $\begin{array}{c}\$ \\
\text { million }\end{array}$ & $\mathrm{mt}$ & $\$ / \mathrm{mt}$ & $\begin{array}{c}\$ \\
\text { million }\end{array}$ \\
\hline
\end{tabular}


Assuming costs of $\$ 300,000$ day for the installation equipment, assembly crews, and supply/support vessels, and the maximum construction period of 320 days (see Section 2.4.1.7) the basic cost range for mobilizing the OTEC platform will be:

$$
\begin{aligned}
& \text { Minimum Cost }=\$ 39,900,000 \\
& \text { Maximum Cost }=\$ 96,000,000
\end{aligned}
$$

Since all construction of the OTEC ship is planned to be completed within shipyard and shallow water areas no additional mobilization costs above those mentioned need be considered.

Mobilization costs - ship: $\$ 40$ to 96 million. 
2.4.1.7 Schedule. The CWP is expected to weigh 60,000 MT dry and have a length of $1,000 \mathrm{~m}$. If a crane of $200 \mathrm{MT}$ lifting capacity is available there will be 30 lifts, assuming CWP installation is done segment by segment. The procedure envisioned is that a 2,000 MT CWP module will be lifted on board from a supply ship, using a crane on the supply ship or other attendant vessel. The OTEC gantry crane will lift this module and lower it down to the point where the joint can be made up; and then the pipe is lowered, after the joint is made. The following time period estimates are assumed:

$\begin{array}{ll}\text { Lift Module into Position } & 1 \text { day } \\ \text { Make Up Joint } & 1 \text { day } \\ \text { Lower CWP Assembly } & 1 \text { day }\end{array}$

Therefore, with 30 joints at 3 days per joint, the minimum assembly time for the CWP will be 90 days. Applying downtime factors and allowing for transit time of 10 days both ways for the installation support vessels, the minimum and maximum assembly time is as follows:

Minimum Worktime

- Basic CWP Installation 90 days

- Downtime $(30 / 0.8-90) 23$ days

- Transit Time $(10+10) \underline{20 \text { days }}$

Minimum Time $=133$ days

Maximum Worktime

- Basic CWP Installation 90 days

- Downtime (90/0.3-90) 210 days

- Transit Time 20 days

Maximum Time $=320$ days

2.4.1.8 Summary. The ship platform should provide an adequate platform for an OTEC commercial plant if the sensitivity of the power system (principally the heat exchangers) to platform motions does not significantly affect the availability of power from the plant. The use of the wing tank area for sea water ducting is a step in the direction to optimization among the platform systems. Extension of this approach to include the power system and the cold water pipe in an optimization of the plant should lead to further refinements in the hull arrangement and in reduction of the costs of the ship-type platform. 


\subsubsection{Circular Barge Configuration}

2.4.2.1 General Description. The 100-iVW(e) circular barge configuration is presented in Fig. 2-41. The 200-MW(e) and 500-MW(e) configurations are presented in numerical form. Major sizing data and general arrangements are shown in keeping with the preconceptual nature of the present phase of the OTEC Study. Significant properties for the three configurations are shown in Table 2-43. Tables 2-44 through 2-46 present weight estimates and preliminary characteristics.

The OTEC plant components, their size and proper relative orientation, was the overriding consideration in determining the arrangements and the principal dimensions of the platform. The principal dimensions were minimized to reduce construction, maintenance, and operation costs. In this preliminary stage of the design, the results of naval architecture calculations have not required that changes be made in the OTEC arrangements or platform principal dimensions. Double shell or approximate location of watertight one-compartment subdivision bulkheads were considered in the design of arrangements.

Table $2-43$

PRINCIPAL CHARACTERISTICS OF 100-, 200-, AND 500-MW(e) (NET) BARGES

\begin{tabular}{|c|c|c|c|}
\hline \multirow{2}{*}{ Item } & \multicolumn{3}{|c|}{ Barge } \\
\hline & $100 \mathrm{MWe}$ & $200 \mathrm{MWe}$ & $500 \mathrm{MWe}$ \\
\hline Length (Width) (m) & 98 & 105 & 149 \\
\hline Breadth $(\mathrm{m})$ & 98 & $10 \mathrm{~s}$ & 149 \\
\hline Height $(m)$ & 43 & 50 & 105 \\
\hline Draft (m) & 31 & 38 & 91 \\
\hline Displacement (MT) & 284,000 & 416,000 & $1,660,000$ \\
\hline $\operatorname{Cost}\left(\times 10^{-6}\right)$ & $\$ 210$ & $\$ 419$ & $\$ 1,363$ \\
\hline Cost $/ K W e$ & $\$ 2,100$ & $\$ 2,095$ & $\$ 2,730$ \\
\hline
\end{tabular}




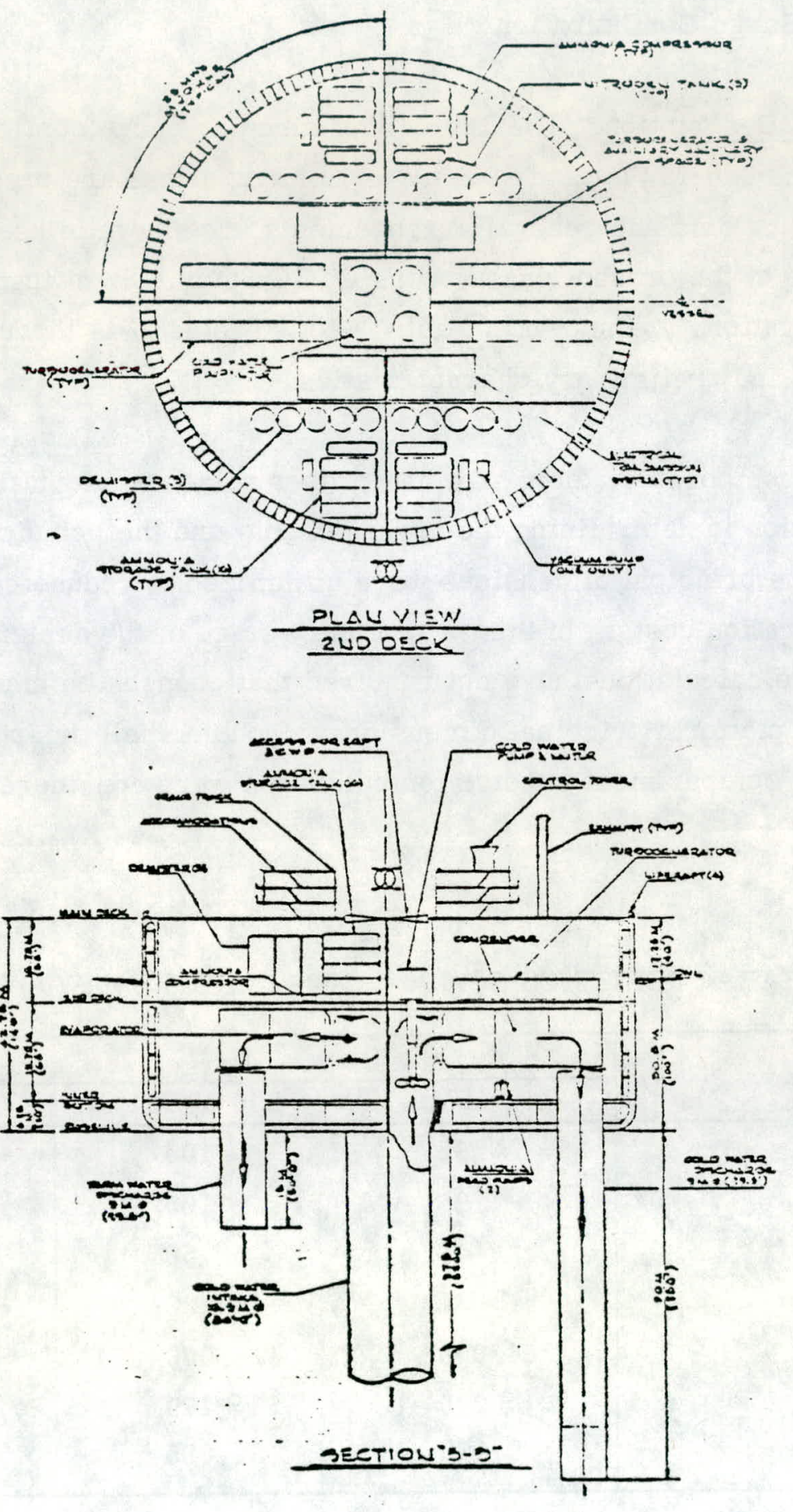

Fig. 2-41 Circular Barge $100 \mathrm{MIW}(\mathrm{e})$ (Net) Steel 
Table 2-44

MASS PROPERTIES FOR $100 \mathrm{MW}$ (e) CIRCULAR BARGE

O.D. 97.5 M. (320'); I.D. 91.5 M. (300'); Depth 42.7 M. (140'.) Approximate weight estimate and preliminary characteristics:

METRIC TONNES LONG TONS

Hull Structure:

Shell

Decks

Bulkheads

Superstructure

Hull Structure

$\begin{array}{r}26,417 \\ 8,128 \\ 5,080 \\ \quad 1,016 \\ \hline\end{array}$

$\begin{array}{r}26,000 \\ 8,000 \\ 5,000 \\ 1,000 \\ \hline\end{array}$

Foundations

40,641

40,000

Power System Cold Water Pipe (Dry)

12,193

12,000

Sea Water Piping

55,883

55,000

Fixed Ballast

6,096

6,000

Power System (Dry)

33,530

33,000

32,514

32,000

Light Ship (Dry)

Power System Water (Internal)

180,857

178,000

Power System Water (Extermal)

15,241

15,000

20,321

20,000

Power System Water (Exchangers)

Variable Ballast

7,112

7,000

60,963

60,000

TOTAL WEIGHT (OPERATING)

284,494

280,000

Tonnes per cm. or Tons per inch

.72 .08

186

Tonnes per metre or tons per foot

7,208

2,232 


\section{Table 2-44 (Cont.)}

\begin{tabular}{|c|c|c|c|}
\hline & METRE & FEET \\
\hline \multicolumn{2}{|l|}{ Ful1 load mean draft } & 30.48 & 100.0 \\
\hline \multicolumn{2}{|l|}{ K.G. Without Ballast and CWP } & 13.72 & 45.0 \\
\hline \multicolumn{2}{|l|}{ K.G. With Ballast and CWP } & -46.03 & -151.0 \\
\hline \multicolumn{2}{|l|}{ K.B. } & 14.81 & 48.6 \\
\hline \multicolumn{2}{|l|}{ B.M. } & 20.67 & 67.8 \\
\hline \multicolumn{2}{|l|}{ R.M. } & 35.48 & 116.4 \\
\hline \multicolumn{2}{|l|}{ G.M. Without Ballast \& CNP } & 21.76 & 71.4 \\
\hline \multirow{4}{*}{$\begin{array}{l}\text { G.M. With Ballast and CWP } \\
\text { Raddi of gyration without } \\
\text { CWP or Ballast }\end{array}$} & & 81.51 & 267.4 \\
\hline & $R_{x \times x}$ & 31.10 & 102.0 \\
\hline & $R_{y y}$ & 36.00 & 118.0 \\
\hline & $\mathrm{R}_{\mathbf{z z}}$ & 33.53 & 110.0 \\
\hline
\end{tabular}

$2-144$ 
Table 2-45

$200 \mathrm{MW}(\mathrm{e})$ (NET) OFF-BASELINE DESIGN

3.1 Mass Properties for 200 MWe Circular Barge:

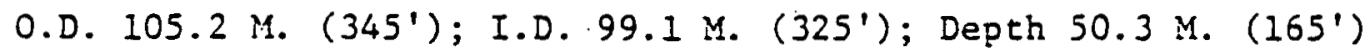

Approximate weight estimate and preliminary characteristics:

METRIC TONNES

LONG TONS

Hull Structure:

Shell

39,626

39,000

Decks

Bulkheads

12,193

12,000

Superstructure

8,128

8,000

Hull Structure

Power System Foundations

1,016

1,000

Cold Water Pipe (Dry)

60,963

60,000

20,321

20,000

Sea Water Piping

79,252

78,000

10,160

10,000

Fixed Ballast

- 0 -

- 0 -

OTEC Plant (Dry)

65,027

64,000

Iight Ship (Dry)

235,723

232,000

OTEC Nater (Intemal)

28,449

28,000

OTEC Water (External)

34,546

34,000

OTEC Water (Exchangers)

14,225

14,000

Variable Ballast

103,637

102,000

TOTAL WEIGHT (OPERAIING)

416,579

410,000

Tonnes per cm. or tons per inch

89.03

223

Tonnes per metre or tons per foot

8,903

2,676

Full load mean draft

$38.1 \mathrm{M}$.

... $125 \mathrm{ft}$. 
Table 2-46

$500 \mathrm{MW}(\mathrm{e})$ CIRCULAR BARGE OFF-BASELINE DESIGN

\section{Mass Properties for 500 MWe Circular Barge:}

O.D. 149.4 M. (490 ft.); I.D. 140.21 M. (460 ft.); Depth $105.16 \mathrm{M}$.

(345 ft.)

Approximate weight estimate and preliminary characteristics:

METRIC TONNES LONG TONS

Hull Structura:

She11

Decks

Bulkheads

Superstructure

HulI Structure

Power System Foundations

Cold Water Pipe (Dry)

Sea Water Piping

Fixed Ballast

Power System (Dry)

152,407

150,000

49,786

49,000

30,481

30,000

2,032

2,000

\section{,}


2.4.2.2 Design Features: The main hull envelope will be constructed of ordinary strength steels, welded throughout. A double shell will be provided on the sides and bottom. Higher strength steels will be used as required at the hull/CWP interface and any other critical areas. The side and bottom shell will be framed circumferentially and will have radial webs at selected intervals.

Main watertight bulkheads will be located as shown on the general arrangement drawing. Bulkhead scantlings will be designed with the Main Deck as the bulkhead deck. Details of continuity and tightness of the bulkheads will be developed to provide necessary strength and watertight subdivision.

Strength decks will be located on the Main Deck, 2nd Deck and Innerbottom levels as shown on the general arrangement drawing. Deck penetrations will be compensated by insert plates of extra thickness. Platforms and flats will be provided as required to suit auxiliary machinery arrangements.

A deck house will be provided above the main deck that will contain all accommodations, store spaces, communications and navigation spaces, and miscellaneous service areas. Bulkheads and decks will be steel, and all boundaries will be watertight. The house structures. will be supported by the house boundaries; bulkheads, trunks and casings, and by a system of pillars, beams and girders.

Masts and kingposts will be provided as shown on the general arrangement drawing to support the required antenna arrays, aids to navigation, and ventilation systems. 
Service platforms, decks and gratings will be included as required to provide access to all equipment for operation and maintenance.

Foundations for the heat exhangers, pumps, tanks, turbogenerators and other heavy equipment will be welded steel construction throughout. Foundation girders and webs will be integrated with the basic hull structure and will have long tapers in reducing to primary structure. Adequate access will be provided in all foundations for cleaning, maintenance and proper operation of equipment. Foundation structures will be designed to act as complete supports for all static and dynamic loads.

2.4.2.3 Constructability. Existing domestic construction facilities include graving docks that will accommodate lengths up to $1200 \mathrm{ft}$, breadths up to $200 \mathrm{ft}$ and drafts up to $40 \mathrm{ft}$. The circular barge beam (diameter) is the one critical dimension that will have a major impact on selection of existing facilities. The number of hulls to be constructed would also be of major importance in determining whether tu alupt construction methods to existing facilities or incur the cost of a specially built construction yard.

Restricting constructability concepts to existing facilities, it is entirely within the state-of-the-art to build the hull in halves (or in more sections at the option of the contractor) and join the sections afloat. This method of construction has been successfully employed for several years in both domestic and foreign yards for large tankers and floating structures utilized in the offshore oil industry. Shipyards with existing facilities for this type of construction include the Bethlehem-Sparrows Point Yard in Baltimore, Maryland; Sun Shipbuilding and Drydock Co. in Chester, Pa.; Ingalls Shipbuilding Corp. in Pascagoula, Miss.; and National Steel and Shipbuilaing Co. in San Diego, Ca.

The construction sequence would provide for bottom shell, double bottom, side shell, and interior decks and bulkheads to be erected in a graving dock up to a depth to be determined by the contractor. Major power system and seawater system components would be installed in timely sequence as the hull is erected. This would continue until the drydock weight limitations or float-out draft limitations were reached. 
After float-out, the hull sections wo uld be joined afloat and construction would continue at an outfitting pier or in sheltered waters, depending upon draft limitations. Preliminary weight estimates indicate that the entire hull (excluding the cold and warm water pipe projections) could be completed in this manner within the limits of domestic facilities.

Installation of the cold water intake pipe and the warm and cold water discharge pipes would have to be carried out afloat on-site. Center well access and crane facilities could be provided on-board the barge for installation of the cold water intake pipe in sections. The shorter discharge pipes could be installed from below the hull or by telescoping down from within the hull.

2.4.2.4 Operability. A permanent mooring system will be used to keep the platform on station and minimize loads on the power transmission systems risers. A positioning system of rotatable thrusters will be used to orient the platform so that sea currents at the surface are perpendicular to the intakes for warm water. The positioning system will also orient the platform to minimize loads on the transmission cable and cold water pipe and weather effects on crew comfort.

Because of the size of this platform and the cold water pipe, hull maintenance can not be performed in a normal shipyard. For steel hulls periodic maintenance will be required at 4-yr intervals at the platform moored site. This will require cleaning, sandblasting and painting in artificial dry environment. Underwater vehicles with devices which can scrape off large growth will be required to precede vehicles which move over the surface of the huil and form a large sealed dry space for sandblasting and painting. This will be a continual hull maintenance program so that each area of the submerged hull will be cleaned and painted every 4 yrs. At these periods ultrasonic gaugings will be taken to check for any deterioration of hull material. Cold water and warm water discharges will be made of low-maintenance concrete and should not require maintenance to preserve material. 
For periodic maintenance of the OTEC plant components, overhead cranes will be installed from the overhead of each deck to assist in removal, disassembly, reassembly, and reinstallation of large items. The arrangem ent of each deck allows for removal of major components. Retubing the heat exchanger can be performed in place for one or more power modules while allowing full capacity operation of the remaining power modules. Heat exchangers can be removed and replaced with direct vertical lift access while other power modules are allowed full operating capacity. Servicing of the sea water pump motor is convenient.

The amplitude of sigulficant motions of the 100 WWe circular barge and the loads in the cold water pipe are summarized in Table $2-47$.

2.4.2.5 Risks. The primary risk for the circular barge is related to the effect of the platform motions on the cold water pipe and the pipe of hull transition. The barge has the largest heave, surge, sway, and pitch motions of the several platforms and is only exceeded in roll angle by the ship in a beam sea. These motions are reflected in the largest dynamic bending moments being imposed by the barge on the cold water pipe. While some refinements and tuning of the platform/CWP interface can be expected to reduce the currently predicted loads, the trend will still remain. Extensive analysis and design will be required to get a good definition of a CWP that will have long life on the circular barge. The uncertainty in cost, schedule, and technical options for this problem leads to this as a major risk area. The related prohlem of potential power output degradation with platform motions also reflects the inherent motion characteristics of a surface platform. 
Table 2-47

CALCULATED SEAWAY RESPONSE FOR CIRCULAR BARGE PLATFORM IN HEAD AND BEAM SEAS, CONERETE CWP, $t=2 \mathrm{FT}$ $E=0.3 \times 10^{6}$ PSI, $10^{9}$ LB-FT/RADIAN

CWP ATTACHMENT. STIFFNESS

\begin{tabular}{|c|c|c|c|c|c|}
\hline \multirow[t]{2}{*}{ Response } & \multirow[t]{2}{*}{ Units } & \multicolumn{4}{|c|}{$\begin{array}{l}\text { Significant Amplitude for } \\
\text { Significant Wave Height }\end{array}$} \\
\hline & & $20 \mathrm{ft}$ & $35.9 \mathrm{ft}$ & $45.8 \mathrm{ft}$ & $58.1 \mathrm{ft}$ \\
\hline \multicolumn{6}{|c|}{$\mathrm{HEAD} S \mathrm{SAS}$} \\
\hline Surge & ft & 2.3 & 6.4 & 9.3 & 15.3 \\
\hline Heave & ft & 3.4 & 17.1 & 26.1 & 40.2 \\
\hline Pitch & deg & 1.1 & 4.7 & 7.3 & 12.0 \\
\hline Max. Acceleration & $\mathrm{ft} / \mathrm{sec}^{2}$ & 1.1 & 3.1 & 4.6 & 6.6 \\
\hline CWP Rotation & $\operatorname{deg}$ & 0.8 & 3.7 & 6.5 & 11.2 \\
\hline Max. Bending Moment & $1 b-f t$ & $1.58 \times 10^{8}$ & $4.20 \times 10^{8}$ & $6.20 \times 10^{8}$ & $9.6 \times 10^{8}$ \\
\hline Max. Bending Stress & psi & $2.30 \times 10^{2}$ & $6.12 \times 10^{2}$ & $3.04 \times 10^{2}$ & $1.40 \times 10^{3}$ \\
\hline Max. Shear Force & $1 b$ & $7.52 \times 10^{5}$ & $2.13 \times 10^{6}$ & $3.20 \times 10^{6}$ & $4.92 \times 10^{6}$. \\
\hline \multicolumn{6}{|c|}{ BEAM SEAS } \\
\hline Sway & ft & \multirow{8}{*}{\multicolumn{4}{|c|}{ Essentially the same as Head Seas }} \\
\hline Heave & ft & & & & \\
\hline Roll & deg & & & & \\
\hline Max. Acceleration & $\mathrm{ft} / \mathrm{sec}^{2}$ & & & & \\
\hline CWP Rotation & deg & & & & \\
\hline Max. Bending Moment & $\mathrm{lb}-\mathrm{ft}$ & & & & \\
\hline Max. Bending Stress & psf & & & & \\
\hline Max. Shear Force & $\mathrm{Ib}$ & & & & \\
\hline
\end{tabular}


2.4.2.6 Costs. Cost estimates for the 100-MW(e), 200-MW(e), and 500-MW(e) platforms are presented in Tables $2-48,2-49$, and $2-50$, respectively.

2.4.2.7 Schedule. The estimated span required for construction of the circular barge is 42 months. A further span of 5 months is estimated for deployment of the bargetype commercial plant.

2.4.2.8 Summary. The barge will provide an adequate platform for an OTEC power system if the output is not sensitive to platform motions. The arrangements presented in this comparison study represent a nearly optimum for use of the barge for horizontal heat exchangers. There is ample room for servicing the power system components chiefly because of the arrangement problem encountered with linear elements in a circular envelope. Integration and optimization of the power system, seawater system, and the hull should provide for some small reduction in cost of the platform. 
Table 2-48

$100 \mathrm{MW}(\mathrm{e})$ (NET) CIRCULAR BARGE COST ESTIMATE

ITEM $\quad$ WT. $\quad \underline{\text { STM }} \quad$ ECF $^{1}$ TOTAL COST

1. Shell Plating \&

Stiffeners

26,400

$\$ 3100$

1.25

$102,300 \times 10^{3}$

2. Bulkheads \&

Stanchions

5,100

3100

1.00

$15,810 \times 10^{3}$

3. Decks, Platforms,

Flats, Misc.Outfit.

$8,100 \quad 3100$

1.00

$25,100 \times 10^{3}$

4. Superstructure

1,000

2600

2.00

$5,200 \times 10^{3}$

5. Power System Foundations

12,200

3100

1.00

$37,820 \times 10^{3}$

6. Warm and Cold

Water Pipes

2,286

3100

3.00

$21,260 \times 10^{3}$

7. Accomodations

$-$

TOTAL $\frac{2,450 \times 10^{3}}{\$ 209,940,000}$

WOTE: 1. Erection Complexity. Factor is used to correct $\$ / M T$ values for varying construction conditions. We have assigned a factor of 1.0 for erection in graving dock, 2.0 for collpletion afloat in sheltered water, and 3.0 for all construction required on-site.

2. Total Cost Estimate does not include Power System Cost, Sea Water System costs or Electrical Transmission System Costs. 
Table 2-49

$200 \mathrm{MW}(\mathrm{e})$ CIRCULAR BARGE COST ESTIMATE

\begin{tabular}{|c|c|c|c|c|c|c|}
\hline & ITEM & WT. & $\$ / M T$ & $\underline{E C E^{1}}$ & \multicolumn{2}{|c|}{ IOTAL COST } \\
\hline 1. & Huli Shell & 39,600 & $\$ 3,100$ & 1.5 & $\$$ & $184,100 \times 10^{3}$ \\
\hline 2. & Huld Decks & 12,200 & $1,1 \cup 0$ & 1.5 & & $50,700 \times 10^{3}$ \\
\hline 3. & Bull Bulkheads & 8,100 & 3,100 & 1.5 & & $37,700 \times 10^{3}$ \\
\hline 4. & Superstructure & 1,000 & 2,600 & 2.0 & & $5,200 \times 10^{3}$ \\
\hline 5. & Power System Fndn. & 20,300 & 3,100 & 1.5 & & $94,400 \times 10^{3}$ \\
\hline 6. & Discharge Pipes & 4,075 & 3,100 & 3.0 & & $37,900 \times 10^{3}$ \\
\hline 7. & Accommodations & - & - & - & & $2,900 \times 10^{3}$ \\
\hline & & & & TOTAI & S & $418,900,000$ \\
\hline
\end{tabular}

NOTE: 1. Erection Complexity Factor is used to correct \$/MT values for varying construction conditions. We have assigned a factor of 1.0 for erection in graving dock, 2.0 for completion afloat in sheltered water, and 3.0 for all construction, required on-site.

2. Total Cost Estimate does not include Power System cost, Sea Water System costs or Electrical Transmission System costs. 
Table 2-50

$500 \mathrm{MW}(\mathrm{e})$ CIRCULAR BARGE COST ESTIMATES

IIEM

1. Hull

2. Superstructure

3. Power System Fndn

4. Discharge Pipes

5. Accomodations
WT.

$$
234,700
$$$$
2,000
$$$$
44,700
$$$$
5,300
$$$$
-
$$

S/MT $\quad$ ECF

1.5

2.0

1.5

3.0

$-$

TOTAL:
TOTAL $\cos T$

$$
\begin{array}{r}
1,091,400 \times 10^{3} \\
10,400 \times 10^{3} \\
207,900 \times 10^{3} \\
49,400 \times 10^{3} \\
3,500 \times 10^{3} \\
\hline
\end{array}
$$

$\$ 1,362,600,000$

NOTE: 1. Erection Complexity Factor is used to correct $\$ / M T$ values for varying construction conditions. We have assigned a factor of 1.0 for erection in graving dock, 2.0 for completion afloat in sheltered water, and 3.0 for all construction required on-site.

2. Total Cost Estimate does not include Power System rost, Sea Water System costs or electrical Transmission System costs. 


\subsubsection{Semisubmersible Configuration}

2.4.3.1 General Description. The 100-MW(e) semisubmersible configuration is presented in Fig. 2-42; $200 \mathrm{MW}(\mathrm{e})$ and $500 \mathrm{MW}(\mathrm{e})$ configurations are presented in numerical form. Major sizing and general arrangements are shown in keeping with the pre-conceptual nature of this phase of the OTEC study. A summary of the key sizing data for the three platforms is presented in Table 2-51.

The size and configuration of the OTEC Beiui is detcrminod by the size of the heat exchangers and seawater pumps. Growth of these components would require an equivalent increase in the Semi dimensions. Reortentallum of the major components, stleh as using vertical heat exchangers, could not be accommodated without major redesign of the Semi-Submersible.

The 200-MW(e) Semi is an enlarged version of the 100-MW(e) Semi. The arrangement and operation of the 200-MW(e) Semi are described in Section 2.4.3.2.

The arrangement of the seawater intakes, discharge, and heat exchangers have been changed on the 500-MW(e) Semi. The heat exchangers are stacked two high with the evaporators above the condensers. The demisters are stored in a raised area which spans the entire widtb of the hull.

The cost of upgrading an existing facility, or building a new facility, is not included in cost estimates. In the construction option, which builds the platform on floating barges, the cost of the barges are not included in the estimate.

The hydrostatic characteristics of the vessel were calculated manually. The two side pontoons and the center pontoon were taken as lower hull and the free-flooding tanks assumed part of intact hull. The effect of water in free-flooding tanks takes as weight on the vessel. The weight of CWP in water was included in obtaining the total displacement. The hydrostatic properties were computed for the vessel with and without the CWP attached. 
Table 2-51

PRINCIPAL CHARACTERISTICS OF 100, 200 AND 500 MW(e) (NET) SEMIS

\begin{tabular}{|c|c|c|c|}
\hline \multirow{2}{*}{ Item } & \multicolumn{3}{|c|}{ SEMI } \\
\hline & $100 \mathrm{MW}(\mathrm{e})$ & $200 \mathrm{MW}(\mathrm{e})$ & $500 \mathrm{MW}(\mathrm{c})$ \\
\hline Length (Width) (m) & 132 & 144 & 216 \\
\hline Breadth (m) & 120 & 142 & 162 \\
\hline Height (m) & 65 & 65 & 105 \\
\hline Draft $(\mathrm{m})$ & 40 & 40 & 40 \\
\hline Displacement (MT) & 350,000 & 590,000 & $1,690,000$ \\
\hline Cost $\left(\times 10^{-6}\right)$ & $\$ 337$ & $\$ 562$ & $\$ 1,265$ \\
\hline Cost/KW & $\$ 3,370$ & $\$ 2,810$ & $\$ 2,530$ \\
\hline
\end{tabular}


The curves of form are produced on Fig. 2-43. All values plotted reflect the molded volume of the vessel.

The 100-MW(e) Semi weight summary is presented in Table 2-52.

\subsubsection{Design Features. The Semi platform consists of:}

- A central submerged hull, $90 \mathrm{~m} \times 80 \mathrm{~m} \times 28 \mathrm{~m}$, containing the cold water system and condensers

- Two "pontoons" each $20 \mathrm{~m} \times 20 \mathrm{~m} \times 152 \mathrm{~m}$ attached to the sides of the control hulls and housing the warm water system and evaporators

- Four 20-m-diam. stability columns extending up from the ends of the pontoons

- Two 13-m-diam. columns at the pontoon centers, providing warm water intake

- A single 20-m central column providing venting for the cold water system

- A deck structure supporting deck houses and crane facilities

The scantlings have been sized for mild steel throughout. Unlike the Ship, the Semi will require special through-thickness quality steel at the major hull-to-hull and hullto-column connections to ensure an adequate life for these connections. This special steel will also be used at the main deck to column connections. The Semi, like the Ship and the Spar, can be designed to meet a 40-yr operating life.

The hull structure is enclosed by structural cofferdams on all exterior surfaces. The hull top and bottom are similarly framed. Main frames spanning the full width or depth of cofferdams form a grid which supports plate stiffeners on both faces of the cofferdam. Main frames are oriented transversely in the hull top and bottom of the mid hull and pontoons. They continue up the side shell, forming ring frames encircling the mid-hull and pontoons. These frames are crossed by intermittent longitudinal members of full cofferdam width or depth. Where they continue up the fore and aft shell cofferdams, they are crossed by horizontals the full width of the cofferdam. Between these longitudinals, the spaces are divided by longitudinal plate stiffeners on each face of the cofferdams. In the fore and aft cofferdams, these stiffeners are located vertically. 

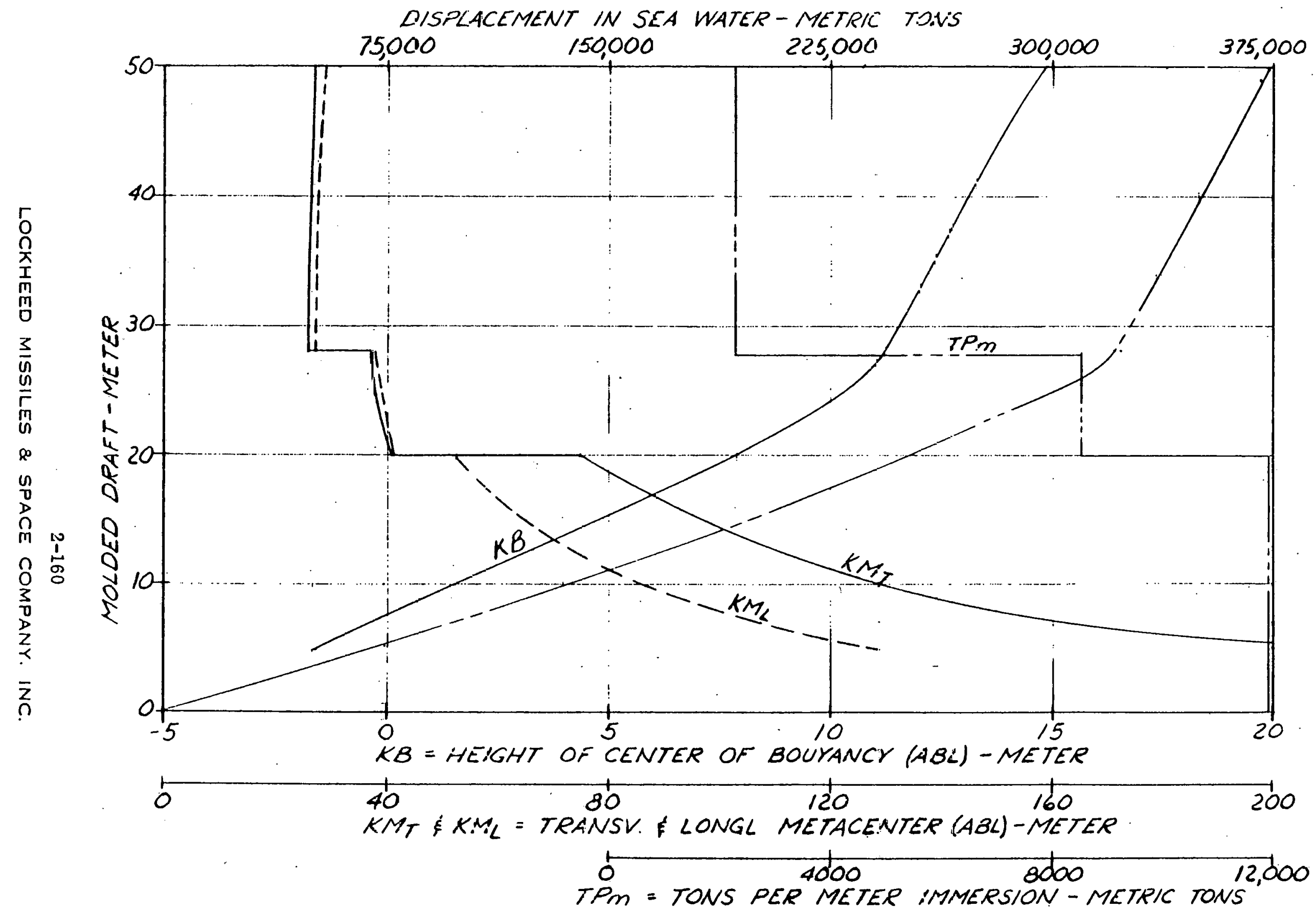

Fig. 2-43 OTEC Semi-Submer-:Lle $100 \mathrm{MW}(\mathrm{e})$ (Nei) Curves of Form 
Table 2-52

OTEC SEMI-WEIGHT SUMMMARY

\section{LSMC}

WBS

0.1 OTEC PLATFORM

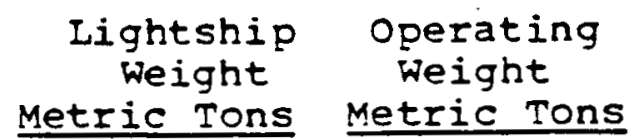

1.0 HUIL AND STRUCTURE

1.1 Shell

1.1.1 Pontoons

1.1.2. Mid Hull

18,400

16,100

98.400

1.1.3 Columns

10.700

16,100

1.2 Bulkhead

1.2.1 Pontoons

$1.2 .2 \mathrm{Mid}$ Hull

2,880

520

10.700

1.3 Decks

3.600

3.600

1.4 Platforms

5,900

5.900

1.5 Deck House

800

2,880

520

1.6 Not Used

1.7 Not Used

1.8 Foundations

1.8.1 Cold Water Pipe

1.8.2 Equipment

2.500

4.700

2.500

1.9

1.9.1 Fixed Ballast

1.9.2 Free Flooding Ballast

\begin{tabular}{rr}
$50,000 \quad \begin{array}{l}50,000 \\
97,000\end{array}$ \\
\hline $116,100 \quad 213,000$
\end{tabular}


Table 2-52 (Cont.)

2.0 SEA WATER SYSTEM

2.1 Cold Water Pipe

2.2 Cold water Pumps (4)

$55,700 \quad 24.000$

$700 \quad 700$

2.3 Not Used

2, 4 Wasm Water Fumps (4)

$700 \quad 700$

2.5 Water Ducts

2.5.1 Cold Water

2.5 .2 Warm Water

\begin{tabular}{ll}
$2,900 \quad 2,000$ \\
\hline $60,000 \quad 27,400$
\end{tabular}

3.0 POSITION CONTROI SYSTEM

3.1 Mooring

3.2 Thrusters

4. 0 SOPPORT SUBSYSTEMS

5.0 OUTFIT AND FURNISHINGS

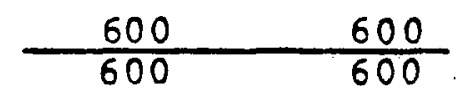

ENERGY TRANSFER SYSTEM

200

$\begin{array}{ll}3.500 & 3.500 \\ 1.000 & 1.000\end{array}$

0.2

POWER SYSTEM (see Table 3-1)

19,600

200

0.3

MISCELLANEOUS

1.0 IIQUID BALLAST

64,000

2.0. CONSUMABLES

5,000

3.0 CWP INSTALIATION CRANE

\begin{tabular}{|c|c|c|}
\hline & 2,000 & 3,000 \\
\hline Total & 3,000 & 71.000 \\
\hline
\end{tabular}

TOTAL W/CWP $204.000 \quad 350,000$

TOTAL WITHOUT CWP

$148,300 \mathrm{MT} \quad 326,000 \mathrm{MT}$ 
The seawater system consists of the cold water intake pipe (CWP), cold water discharge pipe, warm water intake and discharge systems, salt water plenums, piping, pumps, and valves.

The CWP conducts water up from 1,000 $\mathrm{m}$ depth to the cold water intake plenum, located in the center of the vessel and extending across between the wing wall in the central hull. The cold water flows from this amply vented plenum to wing tanks, and then through butterfly valves into the saltwater pumps. After passing through the pumps and condensers, the cold water exits through another valve into the opposite wing tank. It then flows into the cold water discharge plenum, located directly below the intake plenum, and out through the cold water discharge pipe. The discharge pipe.consists of a 24-m sleeve extending to a depth of $100 \mathrm{~m}$ around the cold water inlet pipe. This sleeve can. be structurally integrated with the inlet pipe, and provides insulation between the cold inlet water and the surrounding warm surface water.

The warm water intake is provided through the sides of the 13-in. columns into plenums located centrally in the pontoons. The warm water pumps take suction from these plenums, pump the water through the evaporators and down through the ends of the pontoons. The warm water discharges from the hull at a depth of 40 meters. This distribution system eliminates the need for internal saltwater pipes.

The Semisubmersible will be held on location by a fixed mooring system. This system will limit excursion to acceptable limits as dictated by the electrical transmission cable requirements. Heading control will be accomplished by use of the thrusters located at the ends of the pontoons, possibly combined with selective manipulation of mooring line lengths. The goals of heading control will be to minimize environmental forces, minimize adverse motions, and provide warm water intake from an optimum direction with respent to current flow.

The electrical power transmission equipment is located on the upper level of the mid hull fivd of the CWP well and above the SW pumps. The power cables will transit through the hull from. a common junction box. The headroom in the space is limited; however, it can be increased with a resultant penalty in hull displacement. 
The power system arrangement in the OTEC Semi results in long ammonia piping runs. The ammonia is vaporized in the evaporators located in the pontoons of the vessel. The vapor passes up through the demisters which are in the corner columns, and then down the columns and into the upper level of the mid hull where the turbo-generators are located. The turbogenerators are mounted directly above the condenser, and the liquid ammonia is piped out the bottom of the condenser back to the evaporators. The Semi has $530 \mathrm{~m}$ of ammonia vapor piping and $530 \mathrm{~m}$ of ammonia liquid piping. The ammonia storage tanks are located in the pontoon adjacent to the evaporators, and the inert gas storage tanks are on the lower level of the mid hull below the aft condensers.

\subsubsection{Sunstructability.}

(a) Facility Requirements

A single drydock $267 \times 92 \mathrm{~m}(874.5 \times 300 \mathrm{ft})$ can he constructed from the two $22-\mathrm{ft}$ draft docks at General Dynamics, Quincy Division, shipyard. This is of sufficient size in which to build the central $80 \times 80 \mathrm{~m}$ hull section.

The hull pontoons, $152 \times 20 \mathrm{~m}(433 \times 66 \mathrm{ft})$ each, can be built within numerous U.S. facilities. For modular assembly of the complete lower hill, a shoreside watcr depth of $5.5 \mathrm{~m}(18 \mathrm{ft})$ is required.

A new drydock capable of containing the $132 \times 120 \mathrm{~m}$ Semi would require a draft of $7.8 \mathrm{~m}(25.5 \mathrm{ft})$.

A barge platform capable of supporting the Semi, including equipment and outfitting, would be $168 \times 137 \mathrm{~m}(550 \times 450 \mathrm{ft})$ with a draft of $21 \mathrm{ft}$ at launch. The Semi draft after sinking the barges is $25.5 \mathrm{ft}$. Barge height is $25 \mathrm{ft}$. So a total shoreside water depth of $50.5 \mathrm{ft}$ is required.

(b) Construction Methods

There are three construction methods presented for the Semi. These methods are described below. Option I is illustrated in Fig. 2-44. A summary of the percent of construction completed in each phase is presented in Table 2-53. 


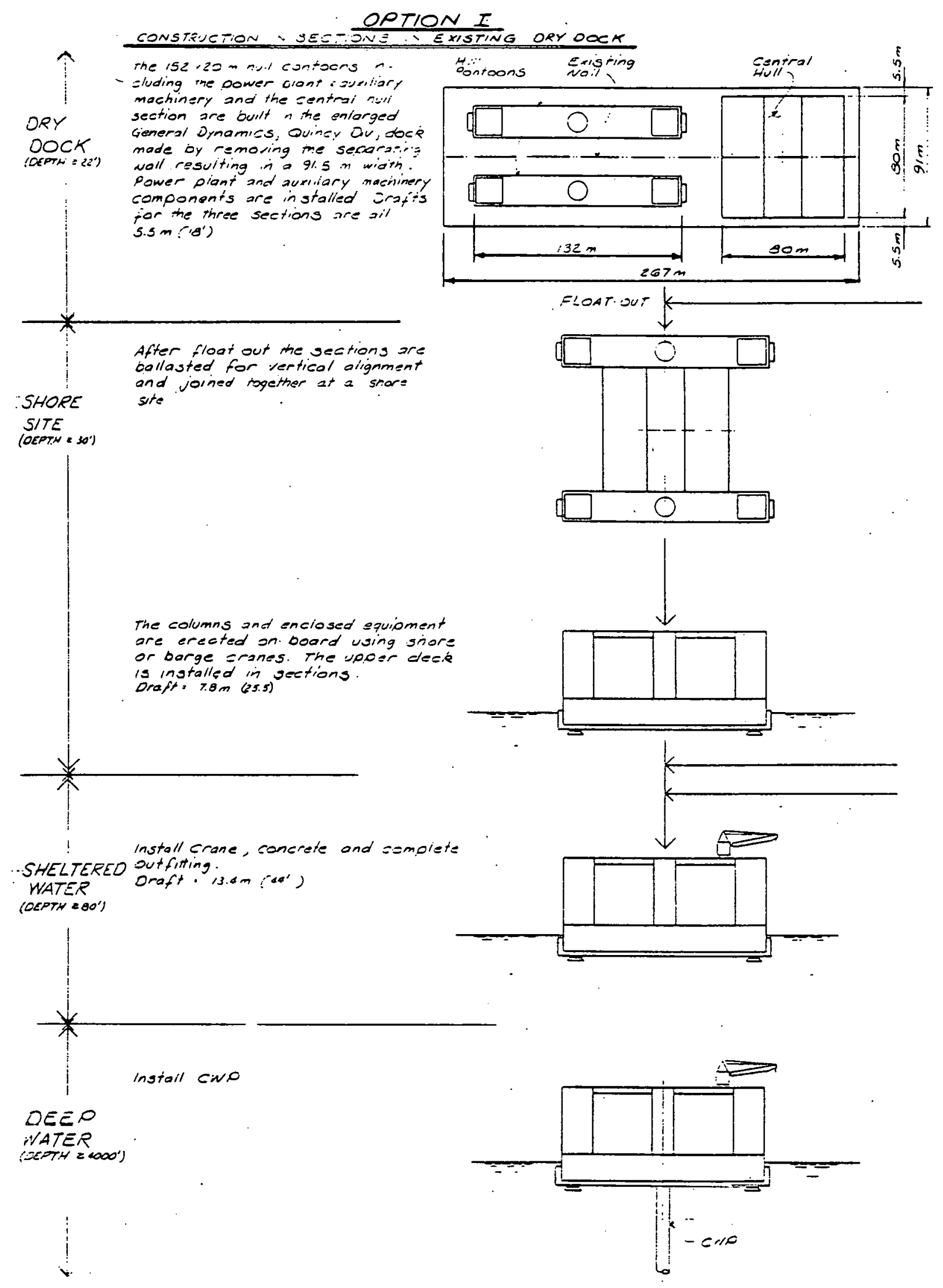

Fig. 2-44 Semisubmersible 100-MMV(e) Net) Steel 
Table 2-53

SUMMARY OF CONSTRUCTION,METHODS - SEMI

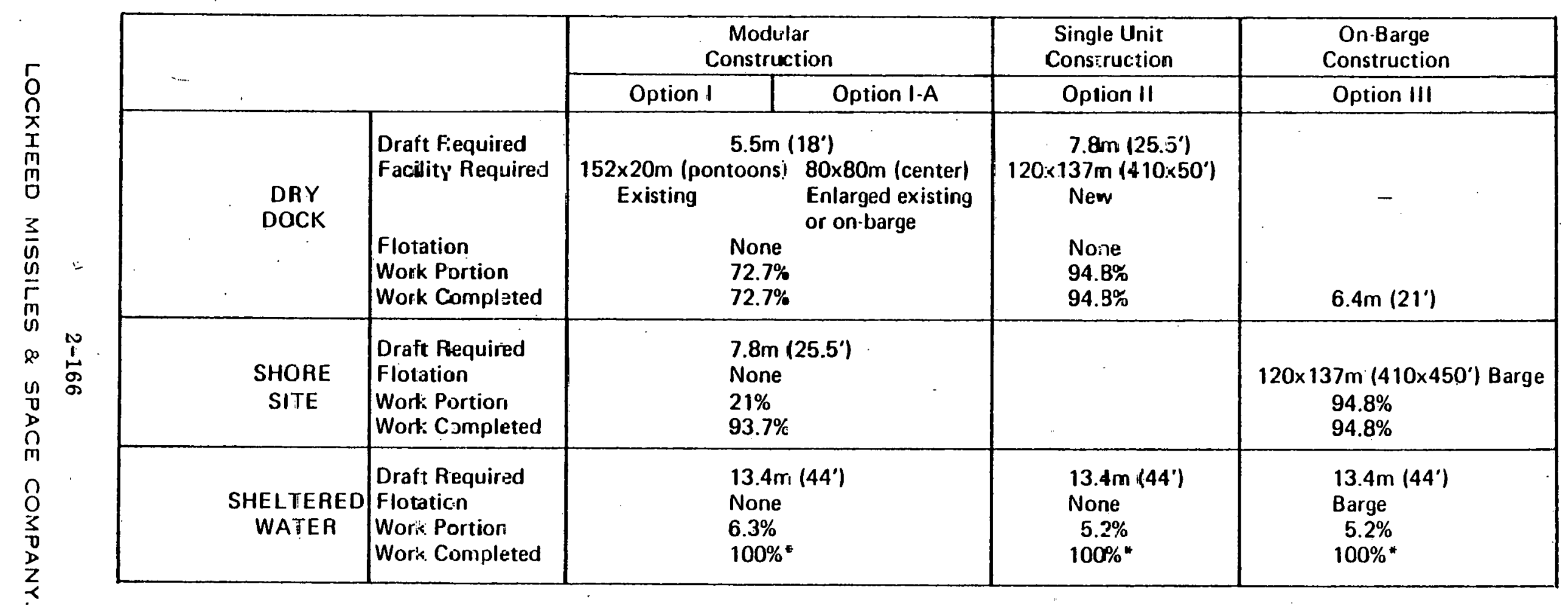

* Excluding mobilization - CWP installation, crane installation and removal, Iowing. 
(1) Option I - Construction in sections in existing drydocks.

The $152 \times 20 \mathrm{~m}$ hull pontoons are built in existing docks of $22 \mathrm{ft}$ depth, including the power plant and auxiliary machinery. The $80 \times 80$ central hull section is built in the enlarged General Dynamics, Quincy Div., dock made by removing the separating wall resulting in a $91.5-\mathrm{m}$ width. Power plant and auxiliary machinery components are installed. Drafts for the three sections are all $18 \mathrm{ft}$. After floatout, the sections are ballasted for vertical alignment and joined together in shallow sheltered water. The columns and enclosed equipment are erected on-board using shore or barge cranes and the upper deck installed in sections. The crane is installed and outfitting completed. Draft is $44 \mathrm{ft}$. In deep water, the CWP is installed.

(2) Option I-A - Center section constructed on a barge.

This varies from option $I$ in that the center hull section is constructed on a $84 x$ $84 \mathrm{~m}$ barge which is sunk to launch the hull. This eliminates the need to construct or enlarge docking facilities.

(3) Option II - Construction in a new dock.

A new dock $125 \times 137 \mathrm{~m}(410 \times 450 \mathrm{ft}) 30 \mathrm{ft}$ deep is built in which to construct the entire Semi. The structure, power plant, and auxiliary machinery are installed. The draft is $25.5 \mathrm{ft}$. After float-out, in shallow water, the outfitting is completed and crane installed.

In deep water the CWP is installed.

(4) Option III - Construction on barge.

A large barge platform $125 \times 137 \mathrm{~m}(440 \times 450 \mathrm{ft})$ is assembled from sections and the entire Semi is constructed on top. The barge draft is $6.4 \mathrm{~m}(21 \mathrm{ft})$ with a Semi weight of 95,000 MT and barge weight of 20,000 MT at launch. The Semi is launched by sinking the barge. 


\subsubsection{Operability.}

\section{(a) Maintenance}

All power system, seawater system, electrical transmission equipment, and vessel service systems are accessible from within the hull of the Semi making on-site maintenance and repair relatively easy. On-board, workshops will handle minor repair items, and there is sufficient space to perform major equipment overhauls in the mid hult. Equipment removal while at operating draft, is limited to access through the corner columns or through the $4 \mathrm{~m}$-diam. elevator shafts within the CWP well. The heat exchangers can be retubed in place. If removal is required, the Semi must deballast to expose mid-hull to remove the condenser. The evaporators can be removed through the corner columns without surfacing, allowing operation of the other modules.

(b) Operation

The Semi is similar to the Ship and Spar when in operation. All the work spaces are within a pressure hull like the Spar, but access from the workspaces to the main deck is much better on the Semi than the Spar though not as convenient as the ship. The ammonia storage tanks are not isolated on the Semi which makes the gas detection and safety precautions related to ammonia leaks much more important on the Semi than cither the Spar ur Sh1p. The accommodations on the Semi should provide the best separation from machinery operation noise and vibration among the three vessels.

(c) Performance

\section{(1) Intact Stability}

The vessel is designed to satisfy the requirements of the American Bureau of Shipping. ABS measures intact stability by the ability of the vessel to withstand the overturning forces of a severe wind and accompanying waves. 
A measure of the stability of the intact vessel is a comparison between the overturning energy created by wind and waves and the righting energy created by the heeled vessel. The amount by which the righting energy exceeds the overturning energy up to the limiting angle is a measure of the vessel's ability to resist capsizing or downflooding. The ABS rules require that the area under the righting moment curve be at least $30 \%$ greater than the area under the heeling moment curve up to some limiting angle. The heeling moment curve used is that of a $51.5 \mathrm{~m} / \mathrm{sec}$ (100 knots) wind. The limiting angle is that corresponding to either the second intersection of the two curves, beyond which the overturning moment exceeds the righting moment, or the occurence of downflooding, whichever is less.

The intact stability of the vessel has been evaluated for three conditions:

- Light draft (in transit)

- Operating draft $(40 \mathrm{~m})$

- Operating mode and CWP breaks off

For each case the $\mathrm{KG}$ value was calculated, and for each case the area ratio between the righting moment and the heeling moment curves was greater than 1.3. The vessel has sufficient stability in the intact condition to withstand anticipated envrionmental loads to a degree established as acceptable by ABS.

(2)

Damaged Stability

Damaged stability calculations are performed to assure that the vessel will survive flooding of certain spaces due to damage without capsizing or sinking or flooding into additional spaces. The extent of damage which a vessel should be able to tolerate and the environment loads which it should be able to resist are established in the ABS Rules. This assumes that damage can occur at exposed positions of column located on the periphery of the vessel. The vertical range in which 
damage may occur extends from $1.5 \mathrm{~m}$ above the waterline to $1.5 \mathrm{~m}$ below. The vertical extent of damage is assumed to be $3.0 \mathrm{~m}$, occuring anywhere within the assumed vertical range. The horizontal extent is assumed to be $45 \mathrm{deg}$ and the assumed depth of penetration is $1.5 \mathrm{~m}$. Therefore, if a horizontal flat is within the vertical range of damage, it must be assumed damaged. Also, interior bulkheads must be located inboard of the assumed depth of damage if they are to be assumed intact. The overturning energy of wind and wave is assumed to act upon the damaged vessel, adding a heeling moment to that oaused by the fluoding water. The wind heeling moment,computed in the same manner as for the intact stability, is that created by a $25.8 \mathrm{~m} / \mathrm{sec}(50$ knots) wind. The ABS Rules require that the flooded vessel have sufficient stability to sustain the heeling energy of the wind without capsizing or heeling over to an angle at which down flooding can occur.

The Semi-submersible configuration in this study is such that the inner columns are $2 \mathrm{~m}$ away from the outer column shell at operating draft, and the double skin on lower hull are at least $2 \mathrm{~m}$ spaced. The amuint of flooded water would not cause severe heeling moment. The vessel has sufficicnt stability ii the damaged condition to withstand anticipaled environmental loads to a degree established as acceptable by ABS.

(3) The amplitudes of the significant motions of the $100 \mathrm{MW}(\mathrm{e})$ semi-submersible and the loads in the cold water pipe are presented in Table $2-54$.

2.4.3.5 Risks. Cost and schedule assoniated with eemi-submersible construction is probably the only serinus platform risk. Even the $100 \mathrm{NW}(e)$ plant cannot be constructed without modularization in the GD Quincy graving dock. This implies the employment of construction techniques not presently completely predictable al though feasibility appears highly probable. 
Table $\cdot 2-54$

CALC.ULATED SEAWAY RESPONSE FOR SEMI PLATFORM IN HEAD AND BEAM SEAS, CONCRETE CWP,

$E=0.3 \times 10^{6}$ PSI, $10^{9}$ LB-FT/RADIAN

CWP ATTACHMENT STIFFNESS

\begin{tabular}{|c|c|c|c|c|c|}
\hline \multirow[t]{2}{*}{ Response } & \multirow[t]{2}{*}{ Units } & \multicolumn{4}{|c|}{$\begin{array}{l}\text { Significant Amplitude for } \\
\text { Significant Wave Height }\end{array}$} \\
\hline & & $20 \mathrm{ft}$ & $35.9 \mathrm{ft}$ & $45.8 \mathrm{ft}$ & $58.1 \mathrm{ft}$ \\
\hline \multicolumn{6}{|c|}{ HEAD SEAS } \\
\hline Surge & $\mathrm{ft}$ & 1.2 & 4.4 & 6.6 & 11.4 \\
\hline Heave & $\mathrm{ft}$ & 1.0 & 3.9 & 6.2 & 11.5 \\
\hline Pitch & $\operatorname{deg}$ & 0.8 & 1.9 & 2.6 & 3.7 \\
\hline Max. Acceleration & $\mathrm{ft} / \mathrm{sec}^{2}$ & 1.1 & 2.3 & 2.9 & 3.6 \\
\hline CWP Rotation & deg & 1.0 & 2.7 & 3.7 & 5.2 \\
\hline Max. Bending Moment & $\mathrm{lb}-\mathrm{ft}$ & $1.38 \times 10^{8}$ & $4.26 \times 10^{8}$ & $5.96 \times 10^{8}$ & $8.13 \times 10^{8}$ \\
\hline Max. Bending Stress. & psi & $2.01 \times 10^{2}$ & $6.21 \times 10^{2}$ & $8.69 \times 10^{2}$ & $1.19 \times 10^{3}$ \\
\hline Max. Shear Force & $\mathrm{lb}$ & $6.02 \times 10^{5}$ & $1.73 \times 10^{6}$ & $2.44 \times 10^{6}$ & $3.35 \times 10^{6}$ \\
\hline \multicolumn{6}{|c|}{ BEAM SEAS } \\
\hline Sway & $\mathrm{ft}$ & 0.8 & 2.8 & 4.4 & 8.1 \\
\hline Heave & $\mathrm{ft}$ & 1.0 & 4.5 & 7.1 & 12.9 \\
\hline Roll & $\operatorname{deg}$ & 0.7 & 1.9 & 2.6 & 3.5 \\
\hline Max. Acceleration & $\mathrm{ft} / \mathrm{sec}^{2}$ & 0.8 & 1.7 & 2.3 & 2.9 \\
\hline CWP Rotation & $\operatorname{deg}$ & 1.0 & 2.4 & 3.3 & 4.6 \\
\hline Max. Bending Moment & $\mathrm{lb}-\mathrm{ft}$ & $9.11 \times 10^{7}$ & $2.67 \times 10^{8}$ & $3.76 \times 10^{8}$ & $5.16 \times 10^{8}$ \\
\hline Max. Bending Stress & psi & $1.33 \times 10^{2}$ & $3.90 \times 10^{2}$ & $5.48 \times 10^{2}$ & $7.53 \times 10^{2}$ \\
\hline Max. Shear Force & $\mathrm{lb}$ & $5.28 \times 10^{5}$ & $1.29 \times 10^{6}$ & $1.75 \times 10^{6}$ & $2.30 \times 10^{6}$ \\
\hline
\end{tabular}




\subsubsection{Costs.}

\section{Construction Cost - Semisubmersible}

The estimated costs to construct the OTEC semisubmersible in an existing facility, assuming no draft, width, or length limitations are shown in Table 2-55. The total cost, $\$ 51 \mathrm{M}$, is the base cost used in estimating the cost to build the Semi when considering construction facility limitations.

Using cost factors discussed in Section 2.4.1 and the percent of construction completed for each phase as shown in Table 2-53, a cost for each construction option was developed. A summary of these costs is shown in Table 2-j6.

Mobilization Costs - Semisubmersible

Since all construction of the OTEC Semi is planned to be completed within shipyard and shallow water areas, no additional mobilization costs above those mentioned in Section 2.4. 1 need be considered.

Mobilization costs - Semi: $\$ 40$ to 96 million

The construction sequence from then follows that of Option $I$. 
Table 2-55

PLATFORM CONSTRUCTION COSTS - SEMI

S/MT MT COST

1.0 HOLL AND STRUCTURE

$\times 106$

\subsection{Shell}

1.1.1 Pontoon

1. 1.2 Mid Full

1. 1.3 Columns

3,100

3,100

$1.8,400$

57.0

$4,3.00$

16,100

49.9

1. 2 Bulkheads

1.2. 1 Pontoons

1.2.2 Mid kull

3.100

10,700

46.0

1. 3 Deck

3.100

$2.880 \quad 8.9$

$520 \quad 1.6$

3,100

$3.600 \quad 11.2$

1. 4 Platform

2.600

$5,900 \quad 15.3$

1.5 Deck House

2.600

800

2.1

1.6 Not Used

1.7 Not Used

1.8 Foundations

1.8.1 CWP

1.8.2 Equipment

$$
3.100
$$

3,100

$$
2.500 \quad 7.7
$$

$4,700 \quad 14.6$

1.9 Permanent Ballast

$\frac{115 \quad 50,000 \quad 5.7}{116,100220.0}$

2.0 NOT OSED

3.0 Position Control System

3.1 Not Used

3.2 Dynamic - Azimuthing Thrusters 7.0

4.0 Support Subsystem

4.1 Cathodic Protectors/Coating 9.9

4. 2 Machinery and related piping 3.0

- Elevators

- Deck Cranes

- Diesel Generators (Quarters) 
Table 2-55 (Cont.)

- Emergency Generators (Quarters)

- Hoists, Tuggers, Forklifts

- Compressed air system

4.3 Hull Piping Systems/w Machinery

17.0

- Ballast

- Bilge

- De-Ballast Vent

- Sonndry

- Engine rooling

- Compressed Air

- Lube Oil

- Fuel oil

- Fresh Water

4. 4 FVAC

19.7

4.5 Safety Equipment

1.0

- Fire Protection

- Life Boats

- Iife Rafts

4.6 Electrioal Work (Misc.) 1.2

4.7 Vessel Management 3.6

4.8 Accomodation 2.5

4.9 Workshops (Misc.) 1.0

4. 10 Radio and Communications 0.2

TOTAL $\quad 51.1$

5.0 INSTALIATION OF OWNER

FURNISHED EQUIPMENT $500 \quad 26,000 \quad 12.0$

- DACS

- Energy Transfer System

- Power System

- Seawater System

- Mooring System

- 3000MT Gantry crane

TOTAL PLATFORM COST

$\$ 291,100.000$

$2-174$ 
Table 2-56

CONSTRUC'TION METHOD COSTS - SEMISUBMERSIBLE

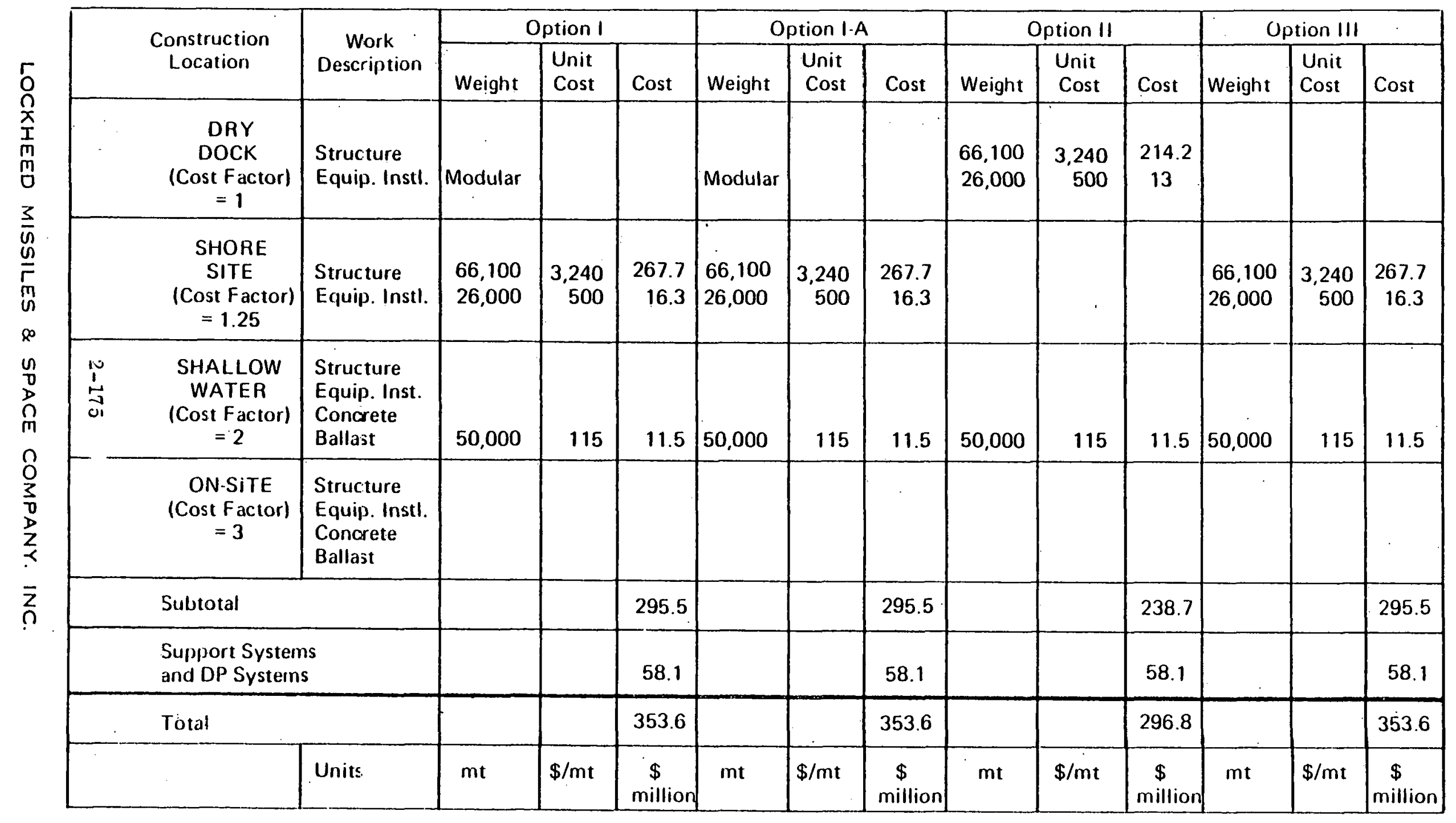




\subsubsection{Tuned Sphere Configuration}

2.4.4.1 General Description. The 100-MW(e) Tuned Sphere configuration is presented in Fig. 2-45; 200-MW(e) and 500-MW(e) configurations are presented in numerical form. Major sizing and cost data (see Table 2-57) and general arrangements are shown in keeping with the preconceptual nature of the present phase of the Study.

Reference to Fig. 2-45 reveals that cold water is drawn into each onndenser from an individualized cold water trunk (canal or plenum) of relatively large cross section leading radially from the cold water pipe well. This trunk is thermally insulated from the warm water by the warm water gallery deck $(0.6-\mathrm{m}$ thick concrete) which forms the top clusre of the cold water trunk. Note also that turning vanes are assumed in each heat exchanger to effect flow to and from tube bundles. The 500-MW(e) plant configures cold water plumbing differently from the 100 and $200 \mathrm{MW}(e)$ plants in that each condenser draws cold water from the cold water pipe well for direct axial flow through the condenser. Cold water discharge is vectored down $10 \mathrm{deg}$ below the horizontal in each platform; discharge depths are 42,48 , and $52 \mathrm{~m}$, respectively, for the baseline 100-MW(e), 200-MW(e), and 500-MW(e) platforms. Warm water exhaust is in each instance vertically down, exiting the vessel near the keel.

Cold water discharge on the baseline configures platforms (horizontally mounted heat exchangers) differs markedly from the off-baseline configurations. In the latter instances, all cold water discharge is vertically down in the vicinity of the cold water pipe entry to the vessel, radially inboard of the vertically discharged warm water exhaust. Plumbing runs in the latter instance are shorter and without significant "turn" loses. Less posential for thermal "fouling" is presented when considered vis a vis the baseline platforms. Off-baseline configurations for which Tuned Sphere arrangement drawings were prepared include:

- $100 \mathrm{MW}(\mathrm{e})$ (vertical shell/tube heat exchangers) as comprised by four 25-MW(e) (net) modules of these characteristics:

a. One 25-MW(c) (nct) module

b. Two 12.5-MW(e) (net) submodules

c. Three 8-MW(e) (net) submodules

d. Five 5.0-MW(e) (net) submodules 


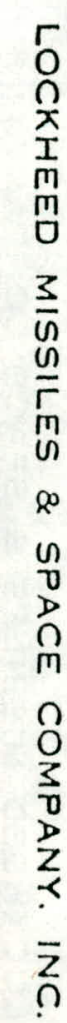

HEAT EX CHANGER LIFTIWG GEAR

SPALE. DECK AREA WITH:

COFFERDAM REMOVABLE:
COFERRDM PORTADLE

FITTEDAS REG'D

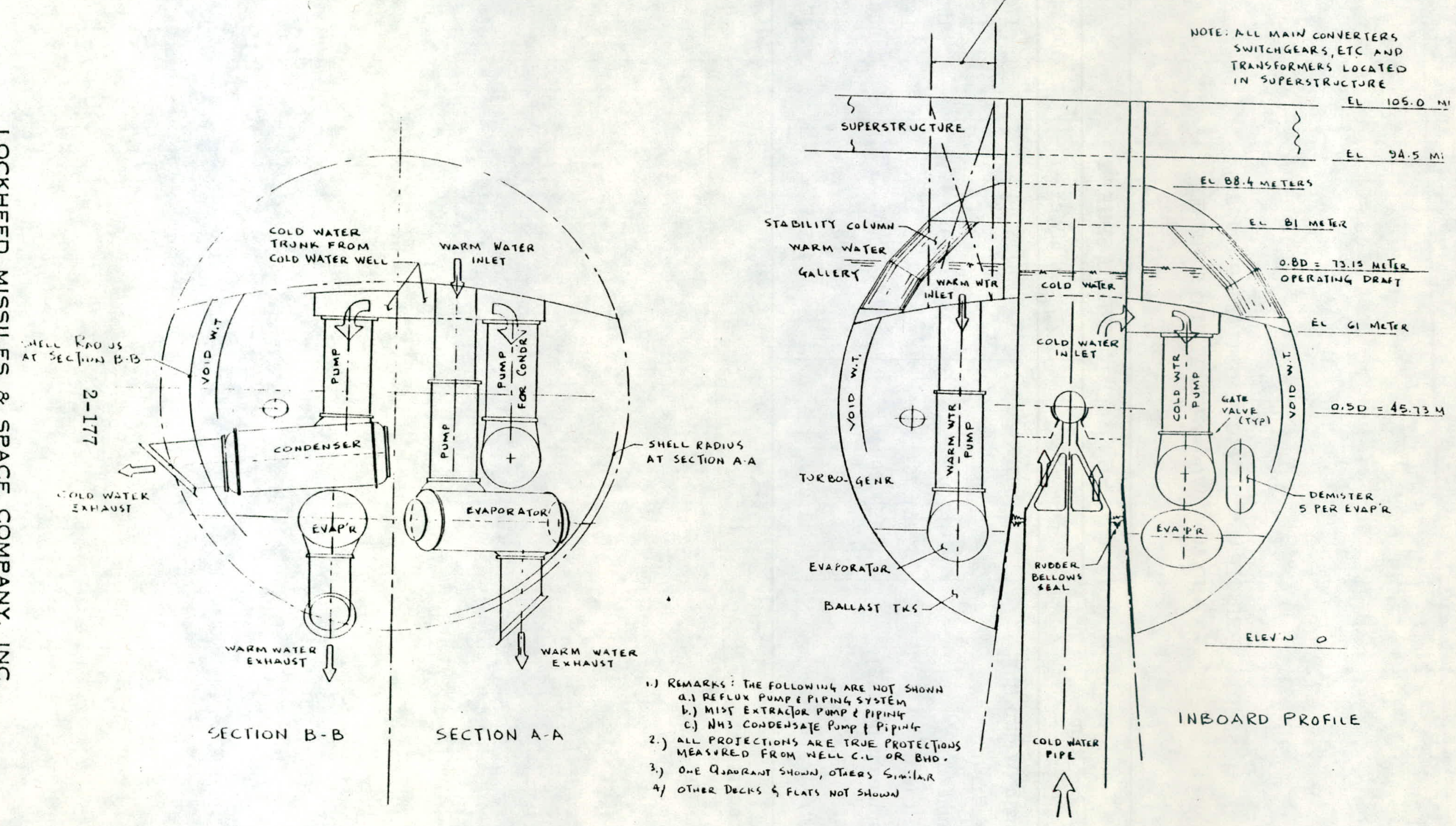

Fig. 2-45 100-MW(e) Baseline Tuned Sphere OTEC Platform 
Table 2-57

PRINCIPAL CHARACTERISTICS OF 100, 200

AND $500 \mathrm{MW}(\mathrm{e})$ (NET) TUNED SPHERES

\begin{tabular}{|l|c|c|c|}
\hline \multirow{2}{*}{\multicolumn{1}{c|}{ Item }} & \multicolumn{3}{|c|}{ TUNED SPHERE } \\
\cline { 2 - 4 } & $100 \mathrm{MWe}$ & $200 \mathrm{MWe}$ & $500 \mathrm{MWe}^{*}$ \\
\hline Length (Width) (m) & 91 & 115 & 175 \\
Breadth (m) & 91 & 115 & 175 \\
Height (m) & 105 & 129 & 185 \\
Diufl (m) & 73 & 92 & 140 \\
Displacement (MT) & 129,000 & 249,000 & $1,000,000$ \\
Cost ( $\times 10^{-6}$ ) & $\$-129$ & $\$ 93$ & $\$ 435$ \\
Cost/KWe & 1,290 & $\$ 465$ & $\$ 870$ \\
\hline
\end{tabular}

*Concrete 
The following comments appear pertinent. The smallest baseline configuration analyzed was the 100-MW(e), horizontal shell/tube heat exchanger, four 25-MW(e) net power module, design. The smallest Tuned Sphere platform into which this could be configures was of $91.44 \mathrm{~m}$ diam and is consistent with the off-baseline designs. Evidence is given that the 100-MW(e) baseline platform will also house a 125-MW(e) power plant provided use is made of vertically mounted heat exchangers rather than horizontally mounted ones.

In the Tuned Sphere platform this makes a strong argument for use of a power plant characterized by vertically mounted heat exchangers. An attempt to house six 25-MW(e) modules in a 91.44-m hull failed. It is inferred from 125-MW(e) and 150-MW(e) off baseline studies that the smallest Tuned Sphere hull that will accommodate an off baseline 100-MW(e) power plant is of $84 \mathrm{~m}$ diam. The cost savings which would be realized have not been computed. Much versatility associated with the $91.44-\mathrm{m}$ hull, however, would be sacrificed in adoption of an 84-m hull design.

Table 2-58 presents derived hydrostatics data for 100, 200, and 500-MW(e) platforms at operating draft.

Table 2-58

HYDROSTATICS DATA

\begin{tabular}{|c|c|c|c|c|c|c|c|}
\hline \multirow{2}{*}{ Platform } & \multicolumn{7}{|c|}{ Meters } \\
\cline { 3 - 8 } & $\begin{array}{c}\text { Displacement } \\
(\mathrm{LT})\end{array}$ & Draft & $\mathrm{KB}$ & $\mathrm{BM}$ & $\mathrm{KM}$ & $\mathrm{KG}$ & $\mathrm{GM}$ \\
\hline $100 \mathrm{MW}(\mathrm{e})$ & 282,161 & 73.2 & 37.1 & 1.31 & 38.4 & 36.3 & 2.13 \\
$200 \mathrm{MW}(\mathrm{e})$. & 580,429 & 92 & 50.2 & 3.17 & 53.3 & 51.2 & 2.13 \\
$500 \mathrm{MW}(\mathrm{e})$ & $1,933,130$ & 14.0 & 72.1 & 1.92 & 24.0 & 71.9 & 2.13 \\
\hline
\end{tabular}

A summary of the sizing data for the $100-\mathrm{MW}(\mathrm{e})$ configuration is furnished in Table 2-59. 
Table $2-59$

PRINCIPAL FEATURES - TUNED SPHERE

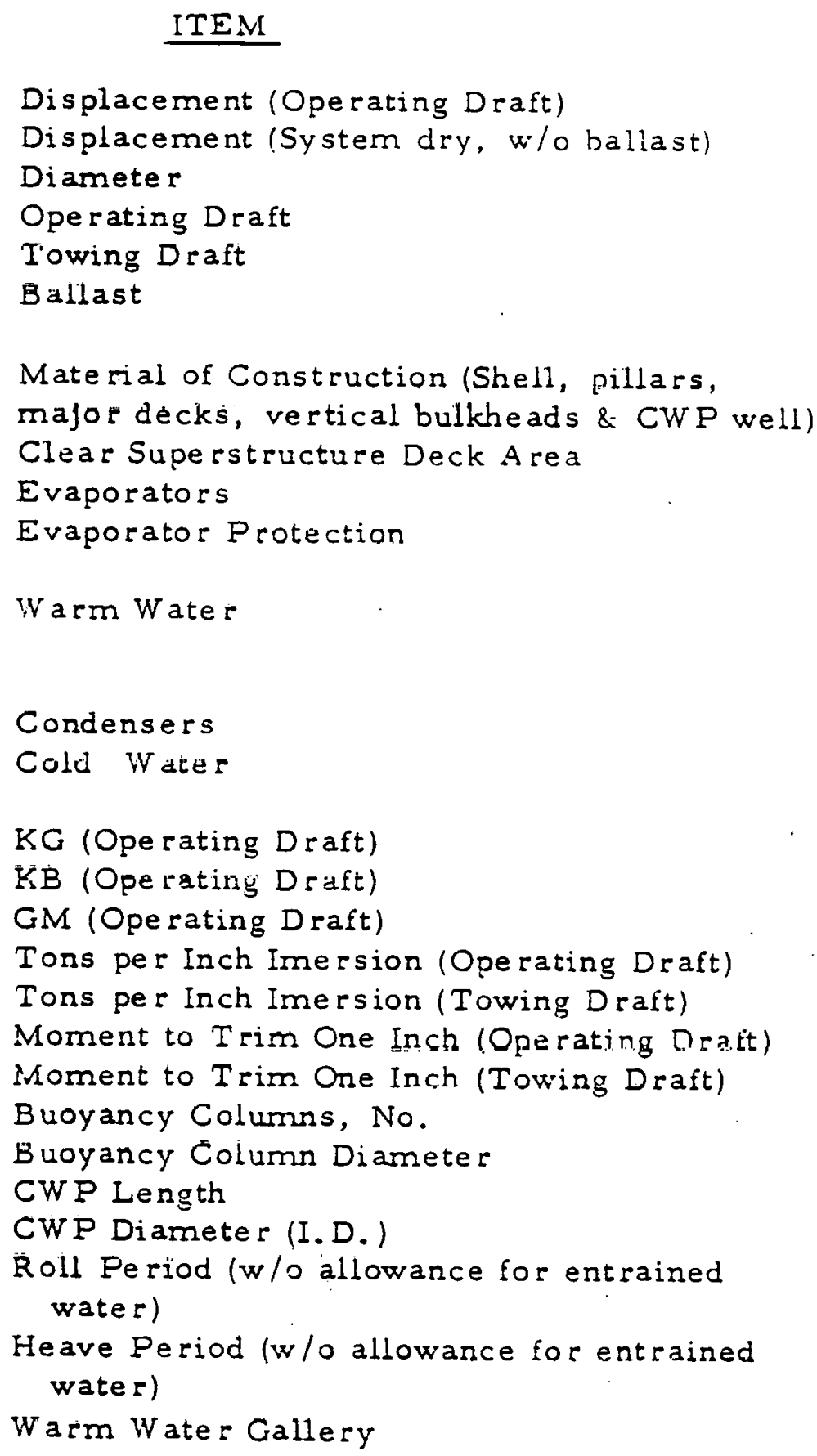

DESCRIPTION

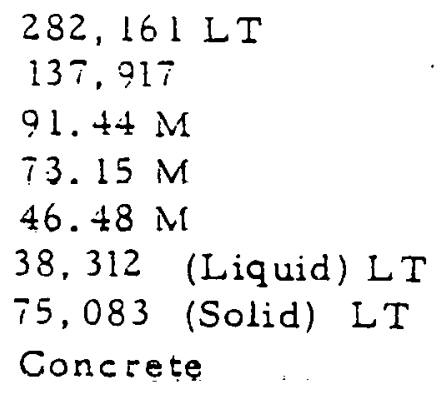
ation) 


\subsubsection{Design Features.}

The following comments refer to Fig. 2-45. Depicted is a $91.44 \mathrm{~m}$-diam. platform housing four 25-MW(e) power plant modules. The platform operates at a keel depth of $73.2 \mathrm{~m}$ (draft/diameter ratio $=0.8$ ). Sixteen $7.6-\mathrm{m}$-diam. columns plus a cofferdamed CWP vent at the vessel centerline define the waterplane area. The 16 columns and the deck at the 61-m level define the warm water gallery; vertical betweencolumn trash racks and screens over the warm water inlets at the 61-m level are the means for preventing evaporator fouling by marine life. The warm water gallery is shown here as $12 \mathrm{~m}$ deep; this will accommodate a $25-\mathrm{m}$ wave without uncovering the warm water inlet (refined motion analyses may well show the Tuned Sphere platform operable in 25-m waves). To operate by skimming warm water from only the warmest water layer, the platform would off-load ballast to reach the desired gallery water 
depth (277 ton/ft for draft change in the operating range). Alternatively, it is conceivable that the warm water inlet diffuser would be extensible and adjusted mechanically vertical ly to draw water at the preferred layer depth; platform draft would in this instance remain constant.

The 61-m-level deck is provided soft patches for access to heat exchangers and other major equipments. It is anticipated the soft patch area would be cofferdamed to avoid ingestion of seas when the soft patches are penetrated; this would provide access when only a portion of the power plant is shut down. Controlled off-center do-ballasting would maintain trim when major components are removed for reconditioning at an offcenter localion. The CWP is shown suspended at the platform c.g.; it is provided a 7-deg deflection range before it will contact the platform hull. Damage control measures are taken which will limit listing to that degree, thereby avoiding loading of the CWP from collision flooding, etc. Motion excursions in pitch/roll and surge are such on this platform that these also will not cause contact. (The ball joint suspension has not been designed; the platform is believed to accommodate readily other CWP suspension configurations.)

A concrete hull is the basis of design, hydrostatic pressure on this hull form assuring a compression structure ideal for this structural material. Construction in an excavated pit cofferdamed from adjacent deep water is expected; subsequent construction stages would occur in near offshore regions: Inspection and maintenance of the spherical shaped hull will be facilitated by its shape. It will prove feasible to construct a hlister type auxiliary compartment whose curvature adapts to that of the hull and makes a pneumatic seal therewith; this could be manned and drawn over the hull providing shirtsleeve environment access for the closest of inspections or the most complex of large aroa ropair operations.

Platform list stiffness readily accommodates lifting of 200 LT loads over the side at operating draft; this will satisfy all routine servicing requirements. To replace a 2031 LT dry weight horizontal evaporator or condenser the platform would be deballasted to maintain trim, and the heavy duty crane placed in operation: To install. 
the CWP, the platform would deballast to the $61-\mathrm{m}$ waterline where a list stiffness of $2490 \mathrm{LT} / \mathrm{in}$. is obtained. This means off-loading $11,500 \mathrm{LT}$ of $44,557 \mathrm{LT}$ of liquid ballast.

To limit flooding due to collision, a collision bulkhead is provided to the $39.6-\mathrm{m}$ level; at platform operating draft of $73.2 \mathrm{~m}$ this protects the platform against vessels having drafts to $110 \mathrm{ft}$. Damage to two buoyancy columns (of 16) results in a draft increase of only $1.2 \mathrm{~m}$ and developing of a 5-deg list.

Emergency power, startup, standby, and normal service electrical equipments and watch stations require a total of $2718 \mathrm{cu} \mathrm{m}$ (6 m height by $453 \mathrm{sq} \mathrm{m}$ deck area). A total of $1575 \mathrm{cu} \mathrm{m}$ of this is made available in the 'tween decks volume at the $81 \mathrm{~m}$ to $88 \mathrm{cu} \mathrm{m}$ level. The balance is considered more appropriately positioned $286 \mathrm{cu} \mathrm{m}$ on platform decks in each power module quadrant.

The simplest mooring system would be a single-point mooring with a scope of 1.5 to 2 . However, it becomes obvious that a current direction change or a wind change would very soon tangle (foul) the mooring line and cold water pipe; consideration of multiple leg moors followed. A two-leg system provides the necessary restraint to prevent the fouling of the cold water pipe and a mooring leg. However, each leg must be as "strong" as a single point moor, since current and wind may be in line with the two anchors. There is no redundancy; hence the failure of one moor will permit the cold water pipe to foul, either with the failed moor or the good moor. A similar analysis may be made for a three-leg moor, only it is $1 / 3$ more expensive than a two-leg moor in materials and emplacement. A four-leg moor does offer advantages; each leg need carry only half the mooring load and in event of a failed moor the cold water pipe will not foul with a good leg. After consideration of the actual mooring loads to be encountered, a twoleg moor was tentatively selected for the Tuned Sphere configuration studies.

Examination of 100-yr return cycle storms at each candidate site revealed the Puerto Rico site as potentially developing the greatest mooring loads; these were 662 IT (162 wind, 503 current with wave drift force not computer) as compared to the New Orleans site total of 599 LT. An L. Jusne oil quality rig 4-3/4-in. chain designed with a 1.89 
safety factor, was selected. Mooring in $4000 \mathrm{ft}$ of water with a 2:1 scope results in vertical loads on the anchor and platform of 56 LT and 755 LT, respectively. Chain slope at the sea bed is $5 \mathrm{deg}$. As noted, a two-leg moor was assumed.

\subsubsection{Constructability.}

(a) Facility Requirements

Construction site studies have focused on the requirement for deep water relatively close to shore, with a sloping underwater contour that facilitates a two to four stage construction/outfitting process. Two potential sites are in the Gulf Coast/Caribbean area. 'The first of these in in the region at the head of the DeSoto Canyon i.e., along the Florida coast, from Pensacola east to Freeport. The 10-fathom line is frequently within $1 \mathrm{mi}$ of the coast, the 30 fathom line at 15 to $18 \mathrm{mi}$. Three-hundred $\mathrm{ft}$ of water can be reached at $20 \mathrm{mi}$. Bottom conditions would appear to facilitate necessary local dredging.

The western end of Puerto Rico, in the vicinity of Mayaguez (population proper in excess of 70,000), also appears attractive. Evidence of considerable dredging would indicate bottom conditions not unfavorable to this. Seventy $\mathrm{ft}$ of water is found readily within $1 \mathrm{mi}$. of the shoreline, $200 \mathrm{ft}$ within $2 \mathrm{mi}$. As will be seen; the candiate operating site off Puerto Rico is significantly the most tolerant of the state-of-the-art in CWP technology, i.e., reliable long-life CWPs can be forecasted here with the highest confidence factor. Life-cycle costs will be reduced by selection of the Puerto Rico operating site; mobilization costs may be similarly affected by selection of a Puerto Rican sonstruction site.

\section{(b) Construction Methods}

The methods investigated for the construction of the OTEC Tuned Sphere were based on the previous data obtained for the construction of Tuned Sphere concrete drilling platforms, and not any one of the methods, except as shown below, was considered 
to be suitable and economical for use in construction of all section of the sphere. The construction method recommended in this report is, therefore, a staged construction method utilizing several of the methods investigated. The methods investigated were:

- Conventional Cast-In-Place Construction

- Precasting of Components for Later Assembly

- Cast-In-Place Slipforming of the Vertical Bulkheads, the Cylindrical Surfaces, and Spherical Components of Sphere

- Ground Forming of the Spherical Surfaces

- Composite Steel-Concrete Construction Methods

The basic construction procedures are summarized below for the purpose of presenting an overall perspective of one of the ways in which the construction could be economically performed.

The construction method appearing to be most feasible, as a result of this study and as summarized here, was selected only after conferences with several large contracting firms capable of doing the actual construction on the sphere. These firms provided CHENCO with a very positive reaction that the specific method proposed here was practical, economical, and could be done with existing and available equipment. The method proposed basically utilizes four construction stages or phases with Phase I being completed on land adjacent to the channel used in Phase II. After completion of Phase I; the Tuned Sphere would then be moved to the channel selected. Phase III could be accomplished in the same location as Phase II, if the channel used was deep enough or could be dredged deep enough to complete Phase III. After this, the Tuned Sphere would then be towed to deep water for completion during State $I V$.

The sequences of construction are very similar to the sequences used on various European concrete drilling platforms and production platforms for the North Sea oil production operations. Examples of these structures are the CONDEEP types such as used in the Beryl, Brent, Frigg, and Statfjord fields; the Philips Petroleum platform used in the Ekofisk field, the ANDOC platform used in the Dunlin Field, and the SEATANK Company designs built by Sir Thomas McAlpine in Scotland. 
Phase I consists of pouring a ground formed disc pad on plug, which will be used as foundation for the erection crane and which will remain in place until the Cold Water Pipe (CWP) is being placed in Phase $I V$. This pad will provide a large extra ballast chamber, during subsequent construction and transport, between the three const ruction locations. The spherical shell (up to the $70-\mathrm{ft}$ level) is then formed using the crane mounted interior face horizintal slip-form and a prepared ground surface as the outside of the sphere. The cylindrical centerwell is then slip-formed, and after this, the remainder of the sphere is formed using the form inside and a new outside hanging form, which is progressively moved around the perimeter. This is similar to the slip-forming used in California and Texas for irrigation ditches. The centerwell and upper deck for Phase I are then poured, the earth cofferdam removed, and the Tuned Sphere moved out to the adjacent channel for Phase II construction.

Phase II construction is accomplished in much the same manner as the latter stages of Phase I. Many of the components of equipment and machinery are proposed to be installed in Phase II, depending on the water depth available in the channel and the route to the deep water Phase III and IV site. In essence, as much equipment and basic shell structure as possible will be built and installed in Phase II, being only limited by the draft of the light ship shell and the channel depth. When the maximum draft is reached, at which the Tuned Sphere may be loated to Phase III and IV construction site, then Phase $I I$ will be considered complete and the Tuned Sphere moved to the third site in deep water.

Phase III is accomplished in deep water. Most of the heavy equipment will be installed with large barge mounted marine cranes and a mobile large capacity crane or cranes put aboard for use in Phase III operations. The centerwell crane will be retained for use in handling smaller components and general utility materials handling.

Phase IV involves the installation of the substructure in several pieces (at least four), which will be erected with the barge mounted marine cranes; and later, after removing 
the bottom disc pad or plug, the CWP will be installed in the centerwell. The study of the design of a self erected special centerwell crane of large capacity, which could remain aboard and lift the heavier components from barges during Phase $N$, would certainly be a valid consideration for saving a substantial amount of time and marine barge crane rental. The method outlined does not appear to require any technology or equipment not available now and should be a satisfactory construction method.

\subsubsection{Operability.}

\section{(a) Maintenance}

A maintenance capsule (hemispherical blister-type with pneumatic seal shaped to mate hull spherical external radius) approximately $10 \mathrm{~m}$ in diam. is stored (when not in use) in the cold water well vent at approximately the $81-\mathrm{m}$ elevation; see Fig. 2-45. A portable major equipment maintenance trunk/cofferdam, $12 \mathrm{~m} \mathrm{D} \times 18 \mathrm{~m}$ length, is also stowed in the cold water well vent $(88-\mathrm{m}$ elevation) when not in use. When used, it is positioned by the heavy-duty deck crane around a warm water inlet and secured water tight to the warm water gallery deck. After de-watering its internal volume and that of the associated evaporator loop, major internal equipments are safely accessed for cleaning, inspection, or replacement. Three-quarters of the power plant remains in operation while one power module is serviced. Removal of heat exchangers requires removal of one or more stability columns, installation of a cofferdam, and removal of a soft patch on the hull. Direct vertical lift of the heat exchangers can be accomplished by this somewhat complex process.

\section{(b) Performance}

(1) Towing Resistance - Fluid imposed towrope resistance was determined for the Tuned Sphere, with and without CWP, at a velocity of 3.5 knots; these values were $1736 \mathrm{LT}$ and $507 \mathrm{LT}$, respectively; at operating drafts. These are reduced to $1622 \mathrm{LT}$ and $393 \mathrm{LT}$ at tow draft; 35,051 and 9462 horsepower, respectively. The CWP is seen to add a horsepower requirement of 25,589 when towing at $3 . j$ loots at tow draft, no-wind conditions. 
It is seen that a 20 -knot opposing wind adds $2334 \mathrm{HP}$ to the towing requirement at tow draft. This makes required tow horsepower, enroute site without CWP, at 3.5 knots at tow draft in a 20 knot opposing wind, 11,796 horsepower.

(2) Intact Stability - Intact, initial stability was investigated with respect to the normal physical parameters that effect it and with respect to its affect on the motion response of the vessel. Placement of major components was as low as practicable within the hull to reduce the KG of the vessel's lightship to a minimum, while sufficient liquid ballast capacity was prnvided to alter tho opcrating ISG eillier up or dówn.

The gallery desiunn lud to allow sulticient traneporcncy of strusture whlle maintäning enough waterplane area and inertia for stability requirements at the operating draft. Additionally, the diameter of the gallery columns had to be such that positive intact stability was maintained over the entire range of draft. While the waterplane inertia value for the operating draft met minimum stability standards it was found during initial examination that GM was negative at the draft where the columns adjoin the gallery deck rim. In order to correct this deficiency the column diameters were increased giving an initial GM of $2.13 \mathrm{~m}$ with free surface correction at the $73.2 \mathrm{~m}$ operating draft.

(3) Damage Stability - Although the probability of damage to the main hull appears relatively low, normal considerations to-damage stability were given to ensure that the vessel remained floating when in the damaged state at the upner levels. It was felt that damage from surface vessel collision could cause the gallery columns to be flooded or destroyed. Vertical flooding is minimized by doolgning watertight flats within the columns, however the analysis investigated the total destruction of two columns. With the absence, or flooding of two complete columno, the vessel takes on a level sinkage of $1.25 \mathrm{~m}$ and immediately heels to an angle of 5 deg. Such damage can readily be compensated by deballasting and flooding opposite tanks to regain a level operating draft. The total effect to the plant and the vessel from a collision by a surface vessel having a draft of $40 \mathrm{ft}$ or less would thus be minimal and would not require the shut-down of plant or evacuation of 
personnel. Similarly, the removal of complete heat exchangers or other major components could be achieved by their withdrawal vertically through the bolted dished head openings in the gallery deck, followed by either their vertical movement to the superstructure deck or their lateral movement out through the warm water gallery. In the latter case, removal of one or two buoyancy columns would be required. Installation design would provide for this. As noted above, compensating ballast rearrangement would prevent listing in the course of column and equipment removal and would preclude necessity for shut-down of other power modules.

The design shows a double skin concrete hull from the gallery level down to the $36.9 \mathrm{~m}$ elevation. The distance from the external shell to the inner shell is $4.6 \mathrm{~m}$. It was felt that the probability of damage from collision at this level was extremely small since most surface vessels sail at drafts of $40 \mathrm{ft}$ or less, particularly vessels serving the southeast and Gulf Coast areas of the United States. Large tankers would be the only surface vessel that could possibly damage the vessel below the $40-\mathrm{ft}$ depth level.

Since the vessel is constructed from reinforced concrete of at least $0.75 \mathrm{~m}$ thickness in this area, it was felt that the absorption of energy from collision at this depth would be such that penetration into the vessel could be limited to less than $4.6 \mathrm{~m}$. This philosophy is weighed against the standard U.S. Coast Guard requirement for surface vessels to maintain adequate stability after collision with a penetration depth of $1 / 5$ the beam. Meeting such a standard would of course result in a large increase in vessel size, regardless of platform type.

The double skin structure surrounds the major machinery components from the 39.6-m depth level to the $61-\mathrm{m}$ level and is sub-divided into vertical watertight segments of about $5.5 \mathrm{~m}$. This degree of subdivision was chosen to allow for damage at a watertight bulkhead, thereby flooding two tanks or $11 \mathrm{~m}$ of perimeter. Initial heel in this condition would be limited to less than $7 \mathrm{deg}$ which can be readily compensated by deballasting about 1200 tons of ballast from a lower tank directly below the damaged area.

The possibility of damage to the shell below the $36.9 \mathrm{~m}$ level from an external source appears extremely small. Certainly a surface vessel could not penetrate this area and it would be most unlikely for a submerged vessel to accidently collide 
with a 282,000 ton charted vessel. Additionally, should penetration of the outer skin occur for some reason, cellular design of the concrete structure in this area would prohibit the entrance of water through the inner shell. For these reasons, the determination of the effects of damage in the area below the 39.6-m level was not investigated. However, if it is later proven that the probability of damage to this lower region of the sphere was greater than initially thought, then the $4.6-\mathrm{m}$, double skin structure would be extended to protect levels below the 36.9-m elevation.

(4) Motions and Loads. The motions of the platform are summarized in Talle 2-80 as well as the loads in a flexible-joint, concrete cold water pipe. The motions of the Tuned Sphere are generally small and among the smallest of the several platforms. The dynamic loads in the cold water pipe are moderate. Optimizing the loads in the CWP by variations in attachment location and stiffness may improve the loads and the resulting costs for the GWP. Platform pitch motions liave been shown to increase as the loads in the cwp are reduced. The overall optimum CWP/platform requires integrated power system and platform optimization.

2.4.4.5 Risks. The only serious risk associated with the Tuned Sphere is related to construction. This is largely attributable to the unique shape of this platform for the size under consideration. It is the only configuration given a "beyond the current state of the art" rating by T.Y. Lin in their evaluation of concrete construction feasibility. The $100 \mathrm{MW}(\mathrm{e})$ plant would be marginally constructable in the GD Quincy graving dock. Any larger platforms must be modularized or constructed in specially developed facilities, barges, etc. Modularization of the sphere will require ingenuity.

2.4.4.6 Costs. Platform costs for Tuned Sphere for 100-MW(e), 200-MW(e) and 500-MW(e) outputs are presented in Table 2-61. A summary of weights and subsystem costs os presented in Table 2-62 for first units and Table 2-63 for subsequent units. 
Table 2-60

CALCULATED SEAWAY RESPONSE FOR TUNED SPHERE PLATFORM IN HEAD AND BEAM SEAS, CONCRETE CWP, $\mathrm{E}=0.3 \times 10^{6} \mathrm{PSI}, 10^{9} \mathrm{LB}-\mathrm{FT} / \mathrm{RADLAN}$ CWP ATTACHMENT STIFFNESS

\begin{tabular}{|c|c|c|c|c|c|}
\hline \multirow{2}{*}{ Response } & \multirow{2}{*}{ Units } & \multicolumn{4}{|c|}{$\begin{array}{l}\text { Significant Amplitude for } \\
\text { Significant Wave Height }\end{array}$} \\
\hline & & $20 \mathrm{ft}$ & $35.9 \mathrm{ft}$ & $45.8 \mathrm{ft}$ & $58.1 \mathrm{ft}$ \\
\hline \multicolumn{6}{|c|}{ HEAD SEAS } \\
\hline Surge & $\mathrm{ft}$ & 2.0 & 5.7 & 8.2 & 12.6 \\
\hline Heave & $\mathrm{ft}$ & 0.5 & 1.0 & 1.3 & 3.0 \\
\hline Pitch & deg & 0.5 & 1.7 & 2.6 & 5.7 \\
\hline Max. Acceleration & $\mathrm{ft} / \mathrm{sec}^{2}$ & 1.0 & 2.2 & 2.9 & 3.9 \\
\hline CWP Rotation & deg & 0.4 & 1.5 & 2.1 & 4.6 \\
\hline Max. Bending Moment & $1 b-f t$ & $2.17 \times 10^{8}$ & $5.49 \times 10^{8}$ & $7.54 \times 10^{8}$ & $1.01 \times 10^{9}$ \\
\hline Max: Bending Stress & psi & $3.16 \times 10^{2}$ & $8.01 \times 10^{2}$ & $1.10 \times 10^{3}$ & $1.47 \times 10^{3}$ \\
\hline Max. Shear Force & lb & $1.30 \times 10^{6}$ & $2.98 \times 10^{6}$ & $4.06 \times 10^{6}$ & $5.48 \times 10^{6}$ \\
\hline \multicolumn{6}{|c|}{ BEAM SEAS } \\
\hline Sway & $\mathrm{ft}$ & \multirow{8}{*}{\multicolumn{4}{|c|}{ Same as Head Seas }} \\
\hline Heave & $\mathrm{ft}$ & & & & \\
\hline Roll & deg & & & & \\
\hline Max. Acceleration & $\mathrm{ft} / \mathrm{sec}^{2}$ & & & & \\
\hline CWP Rotation & deg & & & & \\
\hline Max. Bending Moment & $1 b-f t$ & & & & \\
\hline Max. Bending Stress & psi & & & & \\
\hline Max. Shear Force & Ib & & & & \\
\hline
\end{tabular}


Table 2-61

BASELINE PLATFORM COSTS - TUNED SPHERE

Platform

$100 \mathrm{MWe}$ Steel, 1st Unit

$100 \mathrm{MWe}$ Concrete, lst Unit

$100 \mathrm{MWe}$ Concrete, Others

$200 \mathrm{MWe}$ Concrete, 1st Unit

$500 \mathrm{MWe}$ Concrete, lst Unit
Dollars, 1978

$129,080,000$

$58,787,000$

$54,387,000$

$93,231,000$

$435,051,000$

2.4.4.7 Mobilization Cost Estimates. Except to the degree that outfitting, mooring, rigging for power distribution ashore, and CWP installation are facilitated or encumbered by the platform design under consideration, mobillzation costs for the various platform candidates will be nominally the same. Absolute (quantitative) molilization cost estimating has not been performed for Tuned Sphere OTEC platforms. Comparative (qualitative) cost estimating can only be done by persons familiar with designs for each of the six candidate platforms. In that instance, the evaluator can rank platforms as to ease of outfitting, mooring, CWP installation, etc., with the resultant weighted rankings inferred to be a ranking of candidates as to mobllization costs. T.S.I. studles on uutflting, mooring, and CWP installation, reported in Reference 1, would indicate favorable motilization oosts can be anticipated, e.g., the CWP can be installed without recourse to a 3000 ton crane barge.

2.4.4. 8 Schedule. It is estimated that approximately 30 months will be required for construction of the Tuned Sphere subsequent to all engineering and faullity preparation.

2.4.4.8 Summary. The Tuned Sphere point design adequately accommodates the buscline power system and the vertical heat exchangers. The vertical flow heat exchangers appear to be more readily arranged than at the horizontal flow heat exchangers.

Integration with a power system should allow more efficient use of the displacement. 
Table 2-62

FIRST UNIT COS'T LSTIMATES, FOUR PLATFORMS - TUNED SPHERE

\begin{tabular}{|c|c|c|c|c|c|c|c|c|c|}
\hline \multirow{2}{*}{\multicolumn{2}{|c|}{$\begin{array}{l}\text { HULL /STRUCTURE } \\
\text { COST ELEMENT }\end{array}$}} & \multicolumn{2}{|c|}{$\begin{array}{l}100 \mathrm{MWe} \\
\text { (Steel) }\end{array}$} & \multicolumn{2}{|c|}{$\begin{array}{c}100 \mathrm{MWe} \\
\text { (Concrete) }\end{array}$} & \multicolumn{2}{|c|}{$\begin{array}{l}200 \text { MWe } \\
\text { (Concrete) }\end{array}$} & \multicolumn{2}{|l|}{$\begin{array}{l}500 \mathrm{MWe} \\
\text { (Concrete) }\end{array}$} \\
\hline & & MT & $\mathrm{KS}$ & $\mathbf{M T}$ & $\mathrm{KS}$ & MT & $\mathrm{KS}$ & $\mathrm{MT}$ & \\
\hline 1.1 & Shell \& Support Structure & 16.236 & 52,949 & 30,267 & 21,650 & 80,485 & 46,980 & 356,751 & 192,620 \\
\hline 1.2 & Hull Structural Bulkheads & 5.748 & 17,818 & 13,459 & 16,604 & 6,878 & 12,314 & 107,964 & 108,025 \\
\hline 1.3 & Hull Dock: & 1,717 & 5,321 & 1,814 & 793 & 2,268 & 991 & 4,535 & 1,982 \\
\hline 1.4 & Hull Platform \& Flats & 11,716 & 36,321 & 26,275 & 11,482 & 40,513 & 17,704 & 174,254 & 76,149 \\
\hline 1.5 & Dock House & 381 & .990 & 381 & 990 & 476 & 1,238 & 952 & 2,476 \\
\hline 1.6 & Special Structurea & 596 & 1,551 & 302 & 786 & 887 & 2,305 & 1,735 & $4 ; 510$ \\
\hline 1.7 & Maste, Kingposts, etc. & 91 & 236 & 91 & 236 & 147 & 383 & 238 & 619 \\
\hline 1.8 & Foundations & 2,863 & 8,875 & 8,549 & 3,215 & 15,465 & 5.815 & 98,241 & 36.939 \\
\hline 1.9 & Special Purpose Syatem. & 111.645 & 5,017 & 31,759 & 3.031 & 102,336 & 5,501 & 255,061 & 11,731 \\
\hline & TOTALS & 150,993 & 129,080 & 112,898 & 58,787 & 249,454 & 93,231 & 999,731 & 435,051 \\
\hline
\end{tabular}


Table 2-63

COST ESTIMATES, SUBSEQUEN'T UNITS - TUNED SPIIERE

L/STRUCT URE COST ELEMENT

1.1 Shell \& Support Structure

..2 Hull St ructural Bulkheads

1.3 Hull Decks

10
1
$\stackrel{2}{0}$
$1+$

1.4 Hull Platform \& Flats

1.5 Deck House

1.6 Special St ructures.

1.7 Maste, Kingposts, etc.

1.8 Foundations

1.9 Special Purpose Syotems TOTALS

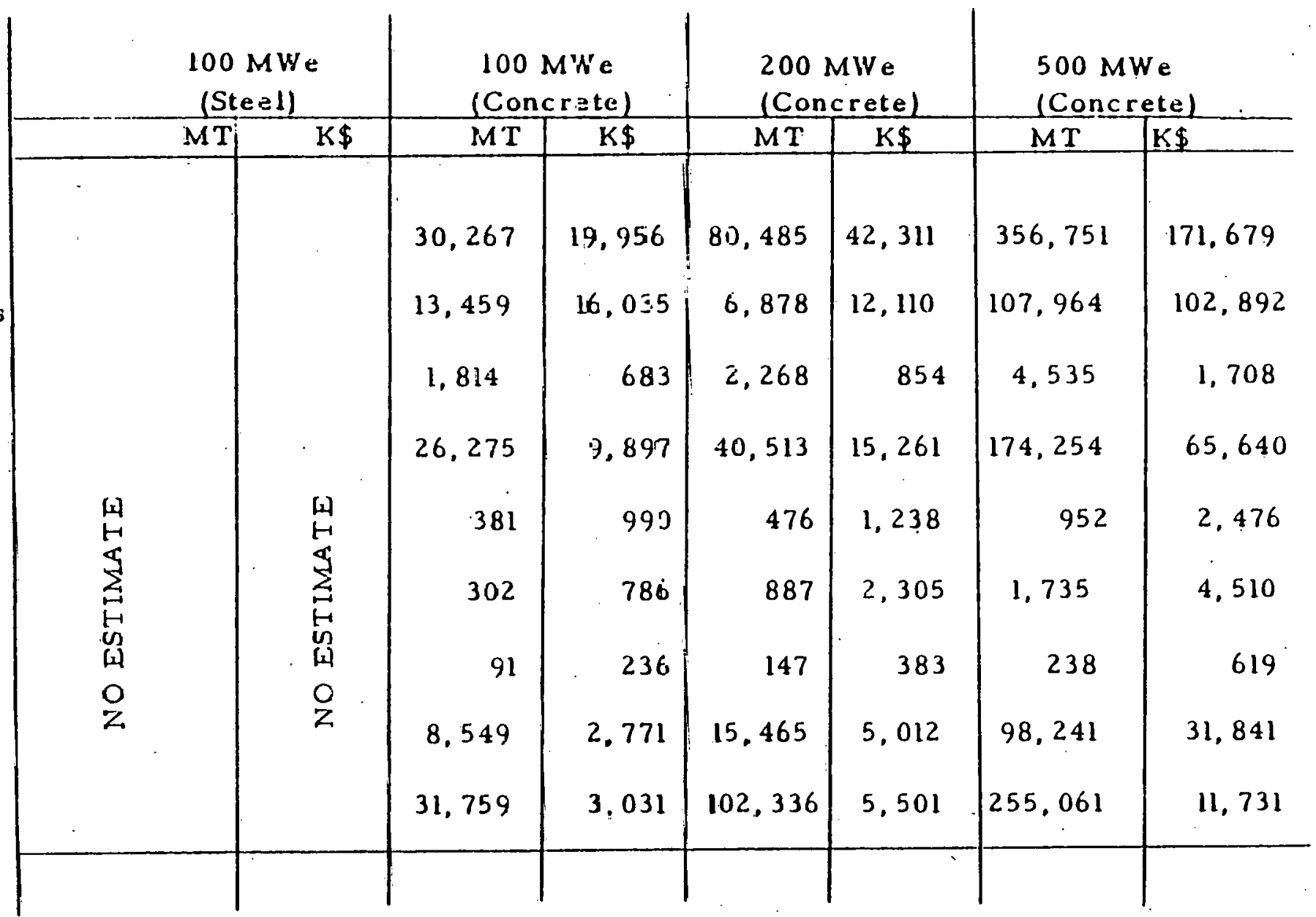




\subsubsection{Submersible Configuration}

2.4.5.1 General Description. The 100-MW(e) submersible configuration is presented in Fig. 2-46; $200 \mathrm{MW}(\mathrm{e})$ and 500-MW(e) configurations are presented in numerical form. Major sizing and cost data (see Table 2-64) and general arrangements are shown in keeping with the pre-conceptual nature of the present phase of the OTEC Study. Mass properties for the three configurations are given in Tables 2-65, 2-66, and 2-67, in the order $100 \mathrm{MW}(\mathrm{e}), 200 \mathrm{MW}(\mathrm{e})$, and $500 \mathrm{MW}(\mathrm{e})$.

The OTEC plant components, their size, and proper orientation to each other was the overriding consideration in determining the arrangements and the principal dimensions of the platform. The principal dimensions were minimized to reduce construction, maintenance, and operation costs. In this preliminary stage of the design, the results of naval architecture calculations have not required that changes be made in the OTEC plant arrangements or platform principal dimensions. Double shell or approximate location of watertight one-compartment subdivision bulkheads were considered in the design of arrangements. Requirements imposed on the OTEC plant in the baseline design are identical to those presented in Section 2.4.2.1.

\subsubsection{Design Features. The main pressure hull envelope will be constructed of} higher strength steels, welded throughout. A double shell will be provided on the ends. Higher strength steels will also be used as required at the hull/CWP interface and any other critical areas. The shell will be framed circumferentially with deep web ring frames and intercostal longitudinals.

Main watertight bulkheads will be located as shown on the general arrangement drawing. Bulkhead scantlings will be designed for the hydrostatic head at the maximum submerged depth. Details of continuity and tightness of the bulkheads will be developed to provide necessary strength and watertight subdivision. 


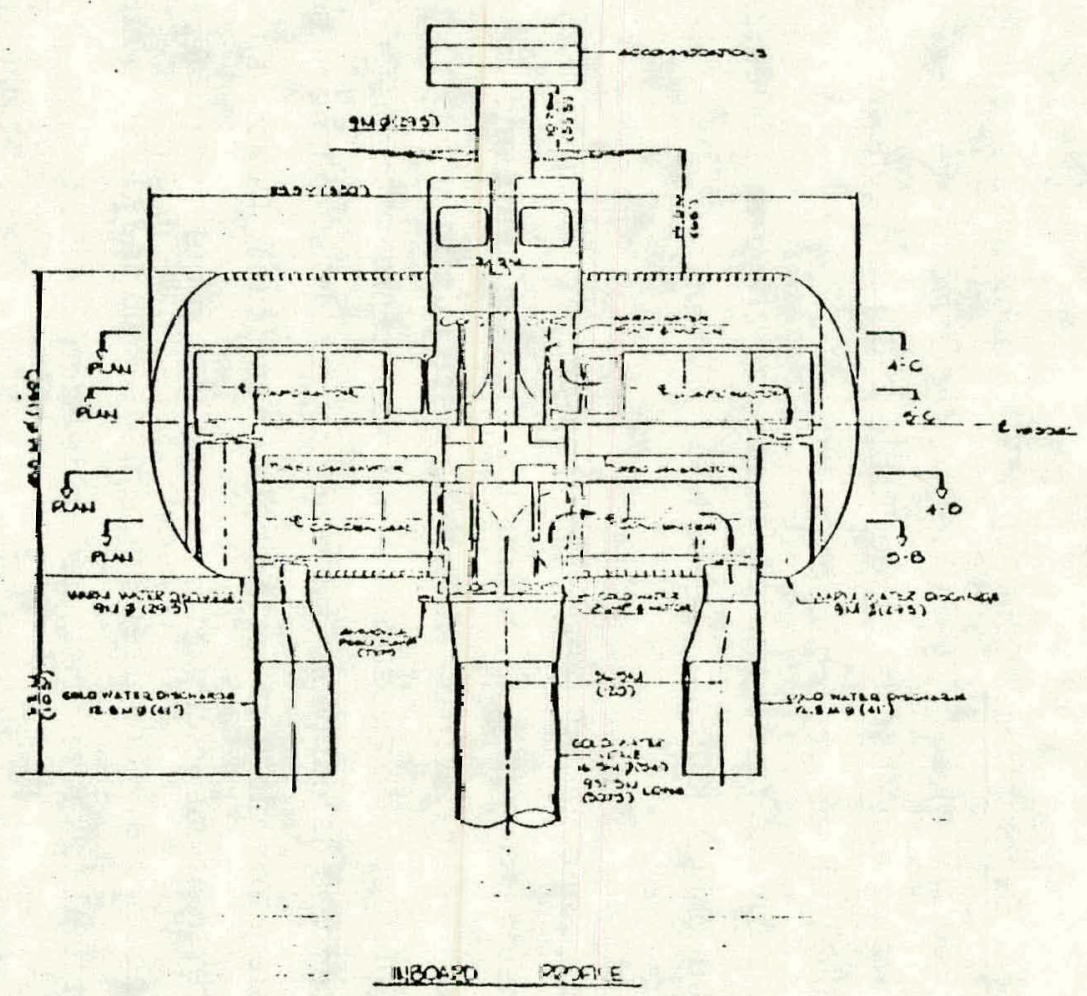

Fig. 2-46 Submersible 100 MW(e) (Net) Steel 
Table 2-64

PRINCIPAL CHARACTERISTICS OF 100-,

200-, AND 500-MW(e) (NET)

\begin{tabular}{|l|c|c|c|}
\hline \multirow{2}{*}{\multicolumn{1}{c|}{ Item }} & \multicolumn{3}{|c|}{ SUBMERSIBLE } \\
\cline { 2 - 4 } & $100 \mathrm{MW}(\mathrm{e})$ & $200 \mathrm{MW}(\mathrm{e})$ & $500 \mathrm{MW}(\mathrm{e})$ \\
\hline Length (Width) (m) & 104 & 195 & 335 \\
Breadth (m) & 49 & 49 & 119 \\
Height (m) & & & \\
Draft (m) & 69 & 69 & 69 \\
Displacement (MT) & 254,000 & 463,000 & $1,354,000$ \\
Cost $\left(\times 10^{-6}\right.$ ) & $\$ 247$ & $-\$ 398$ & $\$ 887$ \\
Cost/KW(e) (Net) & $\$ 2,470$ & $\$ 1,990$ & $\$ 1,774$ \\
\hline
\end{tabular}


Table $2-65$

MASS PROPERTIES (100-MW(e) SUBMERSIBLE

Length $103.6 \mathrm{M} .\left(340^{\circ}\right)$; Diameter $48.8 \mathrm{M.}\left(160^{\prime}\right)$.

Approximate weight estimate and prelimiarny characteristics:

Hull Steel Welght

Shell

Decks

Bulkheads

Superstructure

Full strugture

Power System Foundations

Cold Water Pipe (Dry) 16.5M. I.D.

Sea Water liping

Fixed Ballast

Power System (Dry)

Light Ship (Dry)

Power System Water (Internal)

Power System Water (Extemal)

Power System Water (Exchangers)

Warm Water Intake Box

Variable Ballast

TOTAL WEIGHI (OPERAIING)

$$
\begin{array}{r}
26,417 \\
3,048 \\
7,112 \\
1,016 \\
\hline
\end{array}
$$

37,593

$37, \mathrm{n} n$

12,193

55,883

6,096

$=0-$

32,514

32,000

12,000

- 55,000

6,000

- 0 -

\begin{tabular}{rr}
144,279 & 142,000 \\
19,305 & 19,000 \\
15,241 & 15,000 \\
7,112 & 7,000 \\
$9,1.44$ & 9,000 \\
58,931 & 58,000 \\
\hline
\end{tabular}

254,012

250,000 
Table 2-65 (Cont.)

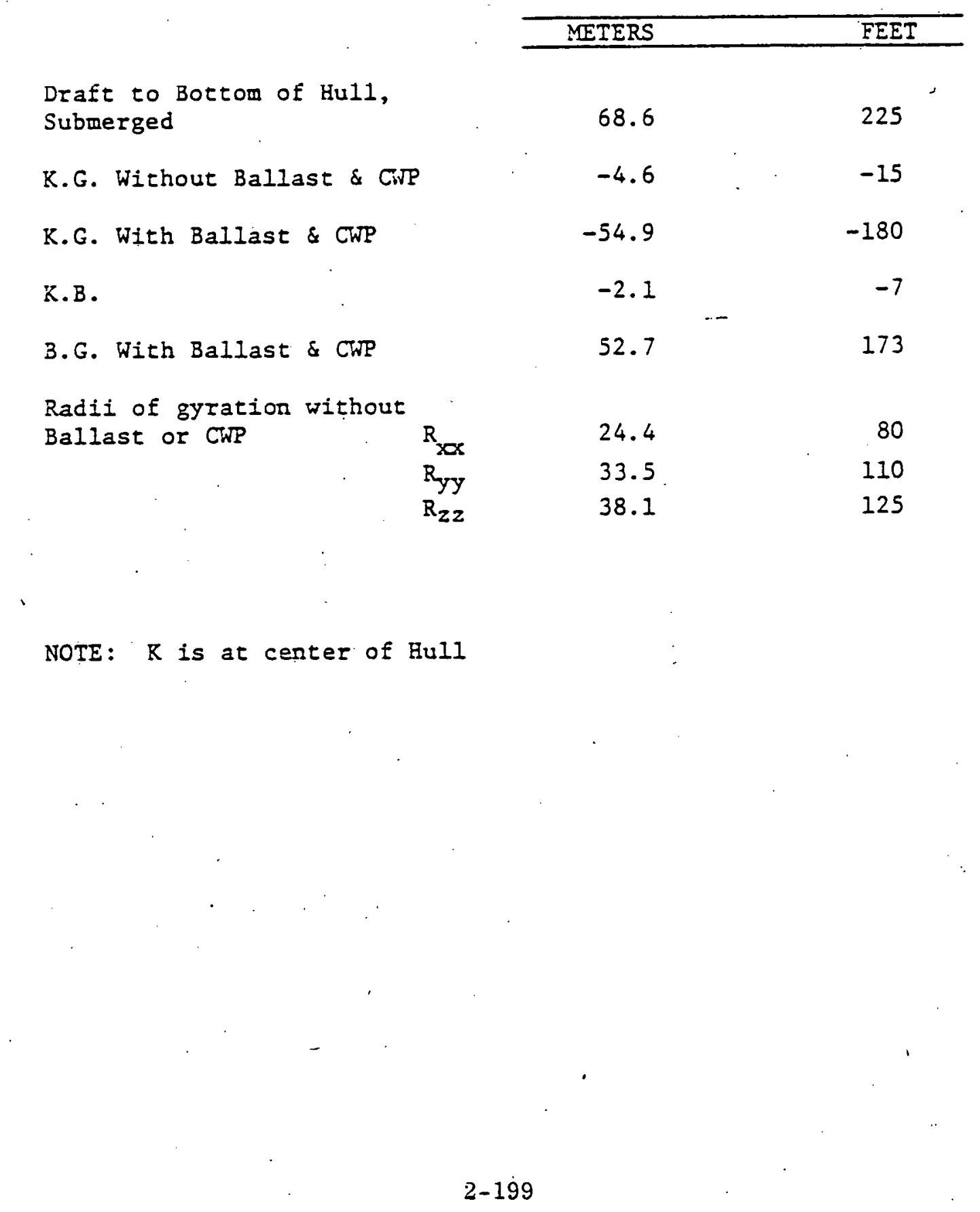

$2-199$

LOCKHEED MISSILES \& SPACE COMPANY. INC. 
Table 2-66

$200 \mathrm{MW}(\mathrm{e})$ (NET) OFF-BASELINE DESIGN

Mass Properties for 200 MWe Submersible

Length $=195.1 \mathrm{M} .(640 \mathrm{ft.}) ;$ Diameter $=48.8 \mathrm{M} .(160 \mathrm{ft}$.

METRIC TONNES LONG TONE

HulI Structure:

Shell

Decks

Bulkheads

Superstructure

Hull Structure

Power System Foundations

Cold Water Pipe (Dry)

3ea Water Piping

Fixed Ballast

Power System (Dry)

Light Ship (Dry)

Power System Water (Internal)

Power System Water (External)

Power System Water (Exchangers)

Cold Water Pipe Attachment Box

Variable Ballast

TOTAL WEIGHT (OPERATING)

\begin{tabular}{rr}
40,642 & 40,000 \\
5,080 & 5,000 \\
10,160 & 10,000 \\
1,016 & 1,000 \\
\hline
\end{tabular}

\begin{tabular}{rr}
56,890 & 56,000 \\
20,321 & 20,000 \\
79,252 & 78,000 \\
11,177 & 11,000 \\
$=0-$ & $-0-$ \\
65,027 & 64,000 \\
\hline
\end{tabular}

\begin{tabular}{rr}
232,675 & 229,000 \\
41,658 & 41,000 \\
25,401 & 25,000 \\
14,225 & 14,000 \\
20,321 & 20,000 \\
129,038 & 127,000 \\
\hline 1 & \\
463,317 & 456,000
\end{tabular}

Draft to bottom of Hull, Submerged $=68.6 \mathrm{M} .(225 \mathrm{ft}$. 
Table $2-67$

HLILI CHARACTERISTICS (500-MWV(e) SUBMERSIBIE, TWIN HLILS)

Mass Properties for 500 :We Subrersible:

Langri $=335.3 \mathrm{M} .(1100 \mathrm{EL.}) ;$ Diamerer $=45.7 \mathrm{M.}(150 \mathrm{fe.})$ (Twin

tuIIs).

Afproximate weight estimate and preliminary characteristics:

NETRIC TONNES IONG TONS

Hull Structure:

She11

Decks

121,926

5,080

120,000

Bulkireads

20,321

5,000

Superstructure

2,032

20,000

HuII Seructure

Power System Foundations

$\$ 47,000$

44,706

44,000

Cold wacer Pipe (Dry)

124,974

123,000

Sec iater ?iping

30,481

30,000

Fixed Ballast

- 0 -

- 0 -

Power System (DFy)

162,568

160,000

Light Ship (DTy)

512,088

504,000

Power System Vater (Internal)

195,081

192,000

Dower System Water (External)

34,332

33,000

Rower System Water (Exchangers)

36,578

30,000

Cold wazer Pipe diclachment 3oxes

73,155

72,000

Variable Ballast

453,157

446,000

TOTAI NEIGRT (ORERATIHG)

$1,354,391$

$1,333,000$

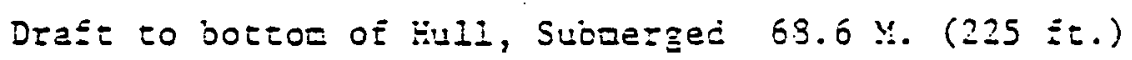

$$
2-201
$$


Strength decks will be located at four levels as shown on the general arrangement drawing and designed for the hydrostatic head at the maximum submerged draft. Deck penetrations will be compensated by insert plates of extra thichness. Platforms and flats will be provided as required to suit axuiliary machinery arrangements.

A deck house will be provided above the waterplane surface that will contain all accommodations, store spaces, communications and navigation spaces. and miscellaneous service areas. Bulkheads and decks will be steel, and all boundaries will be watertight. The house structures will be supported by the house boundaries, bulkheads, trunks and casings, and by a system of pillars, beams, and girders. The entire deck house will be supported on the submerged hull by a $9-\mathrm{m}$-diam column. This column will also be an access and ventilation trunk between the surface and the submerged hull. The above-surface deck house location was chosen to provide better habitability and more convenient air and sea access for replenishment.

Masts and kingposts will be provided as required to support the antenna arrays, aids to navigation, and ventilation systems. Service platforms, decks, and gratings will be included as required to provide access to all equipment for operation and maintenance.

Foundations for the heat exchangers, pumps, tanks, turbo-generators, and other heat equipment will be of welded steel construction throughout. Foundation girders and webs will be integrated with basic hull structure and will have long tapers in reducing to primary structure.

Adequate access will be provided in all foundations for cleaning, maintenance. and proper operation of equipment. Foundation structures will be designed to act as complete supports for all static and dynamic loads and will be suitably tuned to minimize vibrations caused by rotating machinery. A detailed finite-element structural analysis will be required for the cold water pipe foundation to insure a suitable transition between the foundation and the surrounding hull structure. 
2.4.5.3 Constructability. Existing domestic construction facilities include graving docks that will accommodate lengths up to $1200 \mathrm{ft}$, breadths up to $200 \mathrm{ft}$ and drafts up to $40 \mathrm{ft}$. Submerged pressure hull beam (diameter) is the one critical dimensions that will have a major impact on selection of existing facilities. The number of hulls to be constructed will also be of major importance in determining whether to adopt construction methods to existing facilities or incur the cost of a specially built construction yard.

Restricting constructability concepts to existing facilities, it is entirely within the state-of-the-art to build the pressure hull partially in a graving dock (up to drydock weight limits or float-out draft limits) and complete the hull afloat.

Shipyards with existing facilities for this type of construction include the BethlehemSparrows Point Yard in Baltimore, Maryland. Sun Shipbuilding and Drydock Co. in Chester, Pa.; Ingalls Shipbuilding. Corp. in Pascagoula, Miss.; and National Steel and Shipbuilding Co. in San Diego, Ca.

The construction sequence would provide for bottom shell, dished end shell, and interior decks and bulkheads to be erected in a graving dock up to a depth to be determined by the contractor. Major power system and seawater system components would be installed in timely sequence as the hull is erected. This would continue until the drydock weight limitations or float-out draft limitations were reached.

After float-out, construction of the upper portion of the shell, installation of the evaporators, and construction of the warm water system would continue at an outfitting pier or in sheltered waters, depending upon draft limitations. Preliminary weight estimates indicate that the entire hull (excluding the cold water pipe projections) could be completed in this manner within the limits of domestic facilities.

Installation of the cold water intahe'pipe and the cold water discharge pipes would have to be carried out afloat on-site. The installation sequence would also require that the accommodation superstructure and the supporting column for same would have to be 
fabricated ashore and installed on-site. The pressure hull would remain on the surface until the cold water pipes had been installed down through the hull. The superstructure and supporting column would then be installed, sealing the pressure hull. The hull would then be ballasted down to operating depth.

2.4.5. 4 Operability. I permanent mooring system will be used to keep the platform on station and to minimize loads on the power transmission system cables. A positioning system of rotatable thrusters may be used to orient the platform so that sea currents at the surface are perpendicular to the intakes for warm water. The positioning system may also orient the platform to minimize loads on the transmission cable and cold water pipe and weather affect on crew comfort.

Because of the size of this platform and the cold water pipe hull maintenance can not be performed in a normal shipyard. For steel hulls periodic maintenance will be required at $4-y r$ intervals at the platform moored site. This will require cleaning, sandbiasting and painting in an artifical dry environment. Underwater vehicles with devices which can scrape off large growth will be required to precede vehicles which move over the surface of the hull and form a large sealed dry space for sandblasting and painting. This will be a continual hull maintenance program so that each area of the submerged hull will be cleaned and painted very $\neq$ yrs. At these perinds ultrasonic gaugings will be taken to check for any deterioration of hull material. Cold water and warm water discharges will be made of low maintenance concrete and should not require maintenance to preserve material.

For periodic maintenance of the OTEC plant components, overhead cranes will be installed from the overhead of each deck to assist in removal and installation of large items. The arrangements of each deck will allow for removal of major components. The pressure hull will have to surface by blowing ballast and major components will be removed thru a soft patch in the pressure hull. This allows direct vertical removal of the beat exchangers. However, plant operations must be shut dorn completely for removal of most power system components. 
Motions of the 100-iVW(e) submersible and the loads in a flexible-joint, concrete cold water pipe are presented in Table 2-68. The motions are small except for roll motions in beam seas which are moderate. The dynamic loads in the CWP are smail:

2.4.5.j Risks. The submersible configuration may be easily fit into the GD Quincy graving dock for the 100- $\mathrm{MWW}(\mathrm{e})$ plant and probably for plants as large as 250-MIV(e). Also, the type of construction required is not new except for the large dimensions involved. Costs, schedule and feasibility are reasonably predictable and therefore constitute little risk.

The time that the platform is surfaced and open during removal of power system components requires that the hull, CWP, and the CWP/Hull attachment must be designed for some degree of severe environmental exposure. This double set of design requirements may cause the final platform design to be less efficient than it might be if it were optimized as a true submersible. This risk becomes an uncertainty in the outcome of future design efforts to yield a platform which would display the qualities present in this preliminary conceptual study. In addition, a power system which requires regular (rather than occasional) removal/replacement will cause considerable loss of power availability.

2. 1.5.6 Costs. Cost estimates for the 100-MW(e), 200-MW(e), and 500-MIW(e) platforms are presented in Tables $2-69,2-70$, and $2-71$ respectively.

2.4.5.7 Schedule. It is estimated that 42 months will be required for the construetion of the $100-\mathrm{MW}(\mathrm{e})$ submersible.

2.4.5.8 Summary. The submersible configuration of platform provides an adequate platform for the internal baseline power system. The arrangement makes very good use of the volume of the submersible. The cylindrical structural arrangement makes this the most efficient hull design for submerged or near surface platforms. The efficiency of the submersible platform seems to be limited to arrangements that are tailored to the power system. Variations in power system developments would likely cause changes in the proportions for a submersible which could cause some loss of optimization. Smaller length vertical demisters or other apes could be expected to allow eren more packaging efficiency. 
Table ?-6s

CALCULATED SEAWAY RESPONSE FOR SUBMARINE PLATFORM

IN HEAD AND BEAMI SEAS, CONCRETE CWP,

$E=0.3 \times 10^{6}$ PSI, $10^{9} \mathrm{LB}-\mathrm{FT} / \mathrm{RADIAN}$

CWP ATTACHMIENT STIFFNESS

\begin{tabular}{|c|c|c|c|c|c|}
\hline \multirow{2}{*}{ Response } & \multirow{2}{*}{ Units } & \multicolumn{3}{|c|}{$\begin{array}{l}\text { Significant Amplitude for } \\
\text { Significant Wave Height }\end{array}$} & \multirow{2}{*}{$39.1 \mathrm{ft}$} \\
\hline & & $20 \mathrm{ft}$ & $35.9 \mathrm{ft}$ & $45.8 \mathrm{ft}$ & \\
\hline \multicolumn{6}{|c|}{ HEAD $3 E A S$} \\
\hline Surge & $f t$ & 2.1 & 3.0 & 3.4 & $y .5$ \\
\hline Heave & ft & 1.0 & 3.5 & 5.4 & 9.6 \\
\hline Pitch & $\operatorname{deg}$ & 0.6 & 1.6 & 2.2 & 3.4 \\
\hline Max. Acceleration & $\mathrm{it} / \sec ^{2}$ & 0.6 & 1.3 & 1.8 & 2.3 \\
\hline CWP Rotation & $\operatorname{deg}$ & 0.9 & 2.4 & 3.3 & 5.1 \\
\hline Max. Bending Moment & $1 b-f t$ & $1.79 \times 10^{8}$ & $5.22 \times 10^{8}$ & $7.12 \times 10^{8}$ & $9.48 \times 10^{8}$ \\
\hline Max. Bending Stress & psi & $2.61 \times 10^{2}$ & $7.61 \times 10^{2}$ & $1.04 \times 10^{3}$ & $1.38 \times 10^{3}$ \\
\hline Max. Shear Force & lb & $8,00 \times 10^{5}$ & $3.31 \times 10^{6}$ & $3.17 \times 10^{6}$ & 4. $13 \times 10^{6}$ \\
\hline \multicolumn{6}{|c|}{ BEAM SEAS } \\
\hline Sway : & $\mathrm{ft}$ & 1.4 & 4.2 & 6.2 & 10.2 \\
\hline Heave & $\mathrm{ft}$ & 1.6 & 4.7 & 6.9 & 11.2 \\
\hline Roll & deg & 0.7 & 3.7 & 6.1 & 10.5 \\
\hline Max. Acceleration & $\mathrm{ft} / \mathrm{sec}^{2}$ & 0.6 & $1 . \hat{\jmath}$ & 2.2 & 3.4 \\
\hline CWP Rotation & $\operatorname{deg}$ & 0.8 & 3.7 & 6.2 & 11.0 \\
\hline Max. Bending Moment & $1 b-f t$ & $6.03 \times 10^{7}$ & $3.11 \times 10^{3}$ & $4.03 \times 10^{3}$ & $7.60 \times 10^{5}$ \\
\hline Max. Bending Stress & psi & $8.7 \times 10$ & $3.51 \times 10^{2}$ & $5.38 \times 10^{2}$ & $1.11 \times 10^{3}$ \\
\hline Max. Shear Force & $1 b$ & $3.13 \times 10^{5}$ & $1.21 \times 10^{6}$ & $2.05 \times 10^{6}$ & $3.52 \times 10^{6}$ \\
\hline
\end{tabular}


Table 2-69

100 IIW(e) (NET) SUBMIERSIBLE COST ESTMMATE - STEEL HULL

\section{ITE:}

1. Lower Hul1

2. Upper Hull

3. Power System

Foundation

4. Superstructure and Support Stzucture

5. Accomodations

6. Discharge ?ipes
WT.

15,892

21,040

12,200

3,100

1,000

3,100

3.0

1.0

$E^{1}$

1.0

2.0

$37,800 \times 10^{3}$ $\$ 49,265 \times 10^{3}$ $130,448 \times 10^{3}$

TOTAI:

$\$ 246,784,000$

NOTE: (1) Erection Conplexity Factor is used to correct \$/MT values Eor varying construction condicions. We have assigned a factor of 1.0 for erection in graviag dock, 2.0 For collpletion afloat in sheltered water, and 3.0 for all construction required on-site.

(2.) Total Cost Estimare does not include Power System costs; Sea varer Systen coses or Electrical Iransaission Syscen. costs. 
Table $2-70$

$200 \mathrm{MW}(\mathrm{e})$ SUBMERSIBLE COST ESTMIATE - STEEL HULL

IIEM

1. Lower Hull

2. Iกกกร EuL1

3. Power System

Foundacions

4. Superstructure \& Colum

5. Accomodations

6. Dischazge Pipes
WT.

29,914

20,146

20,300

3,100

1.5

$1,143 \quad 3,100$

3.0

$-$

3.0

$3,768 \quad 3,100$

$E C E$

1.0

2.0
$94,400 \times 10^{3}$

IOTAI COSI

$\$ 92,733 \times 10^{3}$

$162,105 \times 10^{3}$

$10,630 \times 10^{3}$

$2,975 \times 10^{3}$

$35,042 \times 10^{3}$

\section{TOT.IL: $\quad \$ 397.885 .000$}

NOTE: (1) Erestion ramplaxiey Factui ds used to correct ST/MT values For varying construction conditions. we have assigned a factor of 1.0 for erection in graving dock, 2.0 for corpletion afloat in sheltered water, and 3.0 for ell cunsisuction requirad on-site.

(2) Total Cost Estimate does not include Power Sysţ̣m costa, Sea Water system cósts or Electrical Transmission System costs. 
Table 2-71

500 MW(e) SUBMERSIBLE COST ESTIMA TES - STEEL HULI

\begin{tabular}{lcccc} 
IIEM & WT. & S/MT & ECE & \multicolumn{1}{l}{ IOTAL COST } \\
1. Lower Hull & 102,830 & $\$ 3,100$ & 1.0 & $\$ 318,773 \times 10^{3}$ \\
2. Upper Hull & 46,500 & 3,100 & 2.0 & $288,300 \times 10^{3}$ \\
3. Power System \\
$\begin{array}{l}\text { Foundations } \\
\text { 4. Superstructure \& }\end{array}$ & 44,700 & 3,100 & 1.5 & $207,900 \times 10^{3}$ \\
$\begin{array}{l}\text { Colum } \\
\text { 5. Accommodations }\end{array}$ & 2,032 & 3,100 & 3.0 & $18,900 \times 10^{3}$ \\
6. Discharge Pipes & - & - & - & $3,500 \times 10^{3}$ \\
& 5,307 & 3,100 & 3.0 & $49,355 \times 10^{3}$ \\
\hline
\end{tabular}

TOTAL $\$ 886.728 .000$

NOTE: (1) Erection Complexity Factor is used =o correct $\$ / M T$ values for varying construction conditions. We have assigned a factor of 1.0 for erection in graving dock, 2.0 for conpletion afloat in sheltered water, and 3.0 for all construction required on-site.

(2) Total Cost: Estimate does not include ?ower Sysrem costs, Sea Water System costs or Electrical Iransaission Systen. costs. 


\section{4.6 Spar Configuration}

2.4.6.1 General Description. The 100-iVW(e) spar configuration is presented in Fig. $2-47$ and $2-43$. 200- $\mathrm{MLW}(\mathrm{e})$ and $500-\mathrm{MLW}(\mathrm{e})$ configurations are summarized in the text. Major sizing data and general arrangements are shown, in keeping with the preconceptual nature of the present phase of this OTEC Study. A summary of the key sizing data for the three platform is presented in Table 2-72.

The stze of the proposed OTEC Spar is essentially determined by size of the heat exchangers and the sea-water pumps. Growth of these components would require an equivalent increase in the Spar dimensions.

The pre-shaped segments in the hull of the Spar are not very efficient for arrangement of large pleces of equipment. Smaller modules might allow for a more efficient use of the space similar to the arrangement shown for the 500-MW(e) Spar. Vertical heat exchangers could not be accommodated without major redesign of the Spar concept.

The 200-MIW(e) is an enlarged version of the 100-MW(e) Spar. The arrangement and operations are the same as those described for that platform.

The 500-MW(e) Spar is similar to the 100-MW(e) Spar in operation; however, there are some differences in the arrangement. The heat exchangers are stacked and staggered to provide a more efficient use of the hull volume. The demisters are mounter directly uver the evaporators and are enclosed by the hull, and the re is no annular sectiun around the column. The ammonia storage tanks are stored adjacent to the demisters. The space for support systems is provided at the same level as the demister, above the heat exchangers.

The hydrostatic properties were computed for the vessel with and the cold water pipe (CIVP) attached. The curves of form are presented on Fig. 2-49. All values plotted reflect the molded volume of the vessel. 


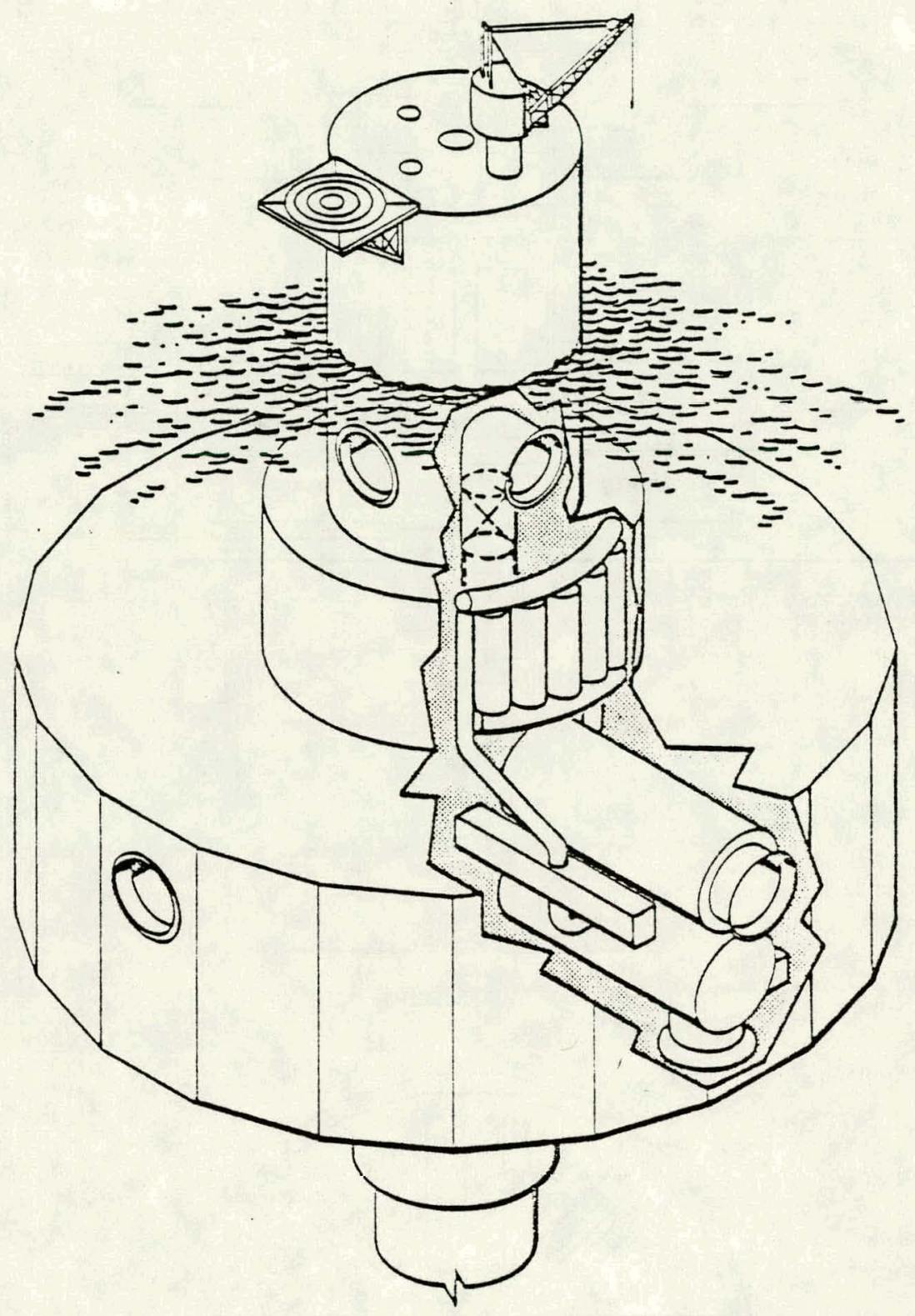

Fig. 2 -47 OTEC Internal Spar for $100-\mathrm{inW}(e)$ (Net) Commercial Plant 


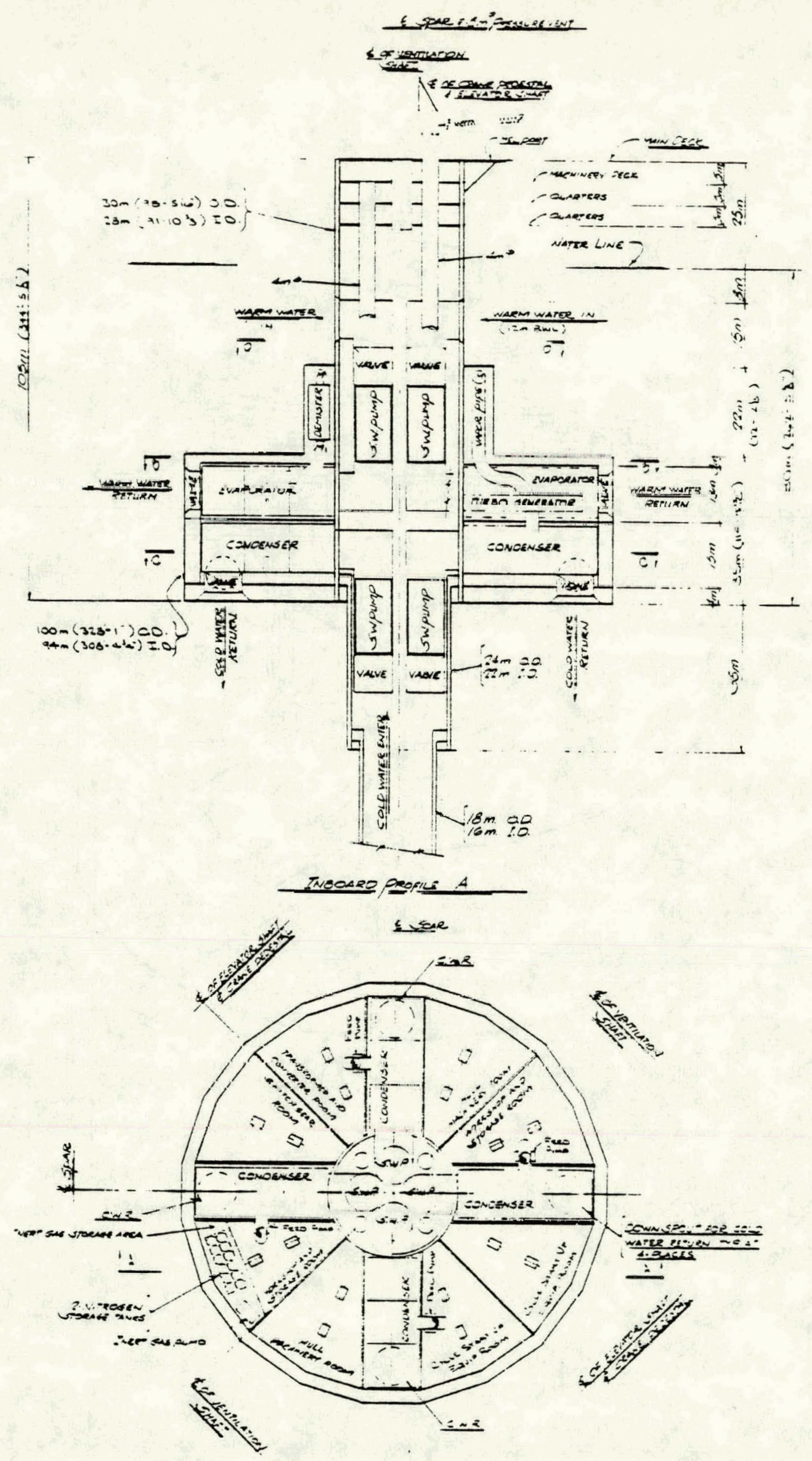

Fig. 2 48 Spar 100-MTT(e) (Net) Steel 
Table $2-72$

PRINCIPAL CHARACTERISTICS OF 100, 200 AND 500 VIW(e) (NET) SPARS

\begin{tabular}{|c|c|c|c|}
\hline \multirow{2}{*}{ Item } & \multicolumn{3}{|c|}{$S P A R$} \\
\hline & $100 \mathrm{irWe}$ & $200 \mathrm{irWe}$ & $500 \mathrm{VWWe}$ \\
\hline Length (Width) (m) & 100 & 118 & 156 \\
\hline Breadth $(\mathrm{m})$ & 100 & 118 & 156 \\
\hline Height $(\mathrm{m})$ & 105 & 100 & 120 \\
\hline Draft (m) & 80 & 80 & 100 \\
\hline Displacement ( $\mathrm{VIT}$ ) & 234,000 & 520,000 & $1, \pm 40,000$ \\
\hline Cost $\left(\times 10^{-6}\right)$ & $S 442$ & $\$ 735$ & $\$ 2,323$ \\
\hline Cost/KWe (Net) & $\$ 4,320$ & $\$ 3,600$ & $\$ 4,6.50$ \\
\hline
\end{tabular}



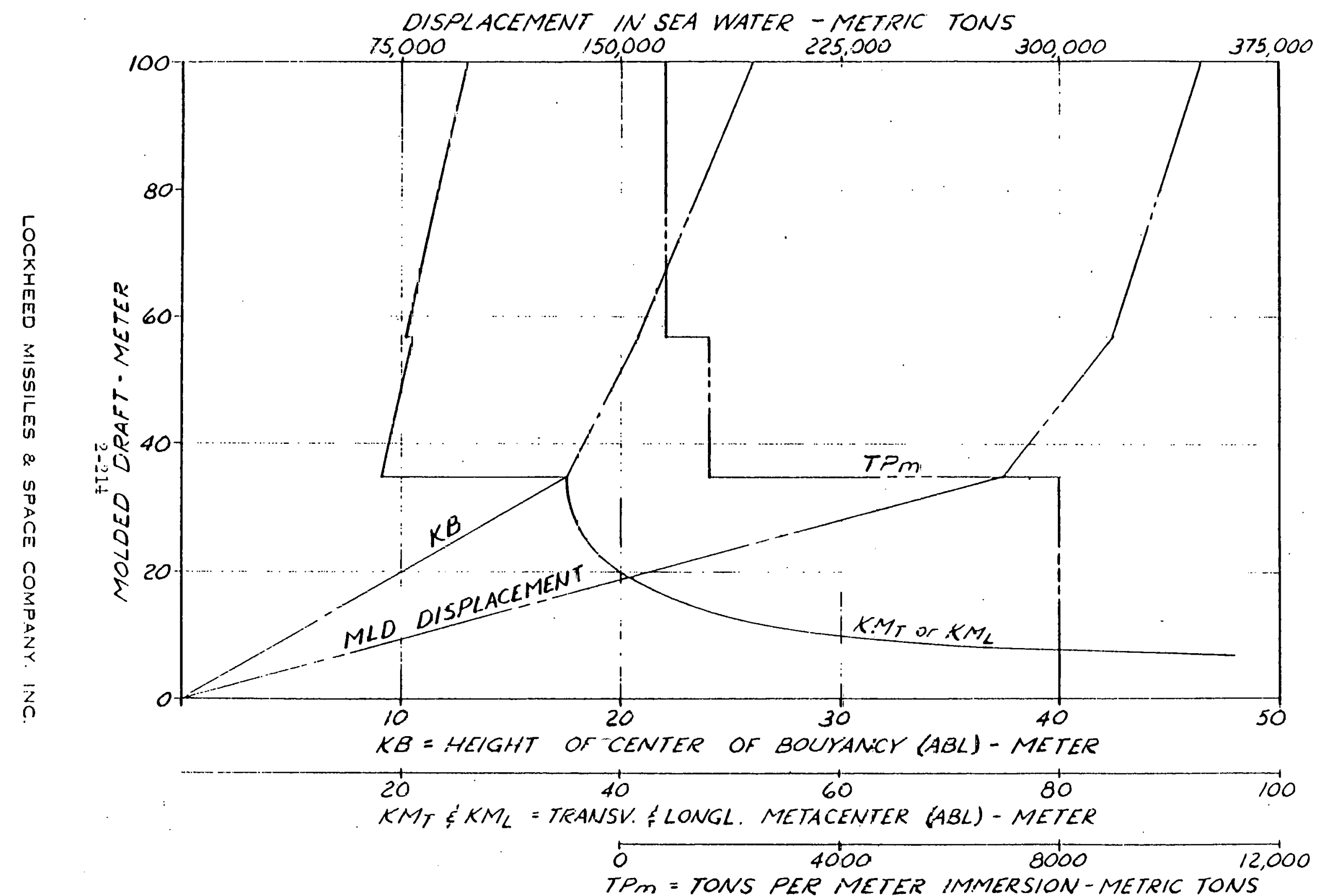

Fig. 2-4! OTEC Spar $100 \mathrm{MW}(\mathrm{e})$ (Net) Curves of Form 
The 100-MW(e) Spar weight summary is presented in Table $2-i 3$.

2.4.6.2 Design Features. The Spar platform measures $105 \mathrm{~m}$ from the base of the hull to the top of the column, and normally operates at an $80 \mathrm{~m}$ draft. The platform consists of a 100-m-diam by 35-m-deep hull, which supports a 30-m-diam by 70-mhigh column. The bottom $22 \mathrm{~m}$ of the column is surrounded by a $\pm 5-\mathrm{m}$-diam annular section. A freeflooding central core $29 \mathrm{~m}$ in diameter passes through the hull and column.

The scantlings have been sized for mild steel throughout. With an adequate cathodic protection system, and proper design and detailing, the Spar can be designed and constructued of steel to meet a $40-y r$ operating life.

The structure is enclosed by cofferdams of $3 \mathrm{~m}$ on the top and sides, and $4 \mathrm{~m}$ on the bottom. All three decks, the top hull, mid deck, and bottom hull, are framed similarly. The condenser/evaporator spaces, enclosed by parallel watertight walls, separate each level into four quadrants. Each quadrant is bisected by a radial wall into two segments. These segments are further divided by radial girder/column systems at the upper level and truss systems at the lower level. Each of the 20 segments is framed by a rectangular grid of beams the full depth of the cofferdams at the top and bottom, and $2 \mathrm{~m}$ deep at the mid-deck. Each rectangular space is further divided by deck plating supports.

The primary framing of the circumferential cofferdam spans vertically from top hull to bottom hull, the full width of the cofferdam, and is aligned with the rectangular grid beams of the decks. These vertical beams support borizontal stiffeners located on each face of the cofferdam. The section of the stiffeners and the thichness of the wall plating increases with depth.

The CIVP is supported at the base of the hull and extends $920 \mathrm{~m}$ below the hull to reach the cold water intake depth of $1000 \mathrm{~m}$. The top $30 \mathrm{~m}$ of the CWP is enlarged to $32 \mathrm{~m}$ diam to provide sufficient area for installing the cold water systems four seawater 
Table 2-73

100-MW(e) SPAR WEIGHT SUMLMLARY

LiMSC

WBS

Iightship Operating

weight weight

0.1 OTEC PLATSORM

1. 0 she11

1.9.1 Bull

1.1.2 rolumn

49,000

6,600

49.000

6.600

1.2 Bulkheads

8,000

8,000

1. 3 Decks

10.400

10.400

1.4 Not Used

1.5 Deck Bouses

500

500

1.6 Special structures

1.6. 1 Demister colunn

1.6 .2 Access/Vent Shafts

9,800

1,800

1.000

1,000

1.7 Not Osed

1.8 Foundations

1.8 .1 Cold water Pipe

1.8 .2 Equipment

2.500

4,700

2,500

4,700

1.9 Ballast

1.9.1 Fixed Ballast $92,000 \quad 92.000$

1.9 .2 Freeflooding seawater $\frac{--}{176,300} \frac{46,000}{222,500}$

2.0 Seawater System

2. 1 Cold Water Pipe

2. $1.124 \mathrm{~m}$ O.D.

$2.1 .218 \mathrm{~m}$ OD

2,200

51,600

1,000

2.2 cold water pumps

700

22,300

2.3 Not Used

2.4 Warm Water Pumps

700

700 
Table 2-73 (Cont.)

\begin{tabular}{|c|c|c|c|c|}
\hline & $\begin{array}{l}2.5 \\
2.5 \cdot 1 \\
2.5 .2\end{array}$ & $\begin{array}{l}\text { Water Ducts } \\
\text { Cold water } \\
\text { Warm Water }\end{array}$ & $\begin{array}{r}1,000 \\
3,000 \\
59,200\end{array}$ & $\begin{array}{r}700 \\
2,100 \\
27,500\end{array}$ \\
\hline & 3.0 & \multicolumn{3}{|l|}{ Position Control system } \\
\hline & $\begin{array}{l}3.1 \\
3.2\end{array}$ & \multicolumn{2}{|l|}{$\begin{array}{l}\text { Mooring } \\
\text { Thrusters }\end{array}$} & $\begin{array}{l}0 \\
0\end{array}$ \\
\hline & 4.0 & Support Subsystems & 3,500 & 3,500 \\
\hline & 5.0 & \multicolumn{2}{|c|}{ Outfit and Furnishings 1,000} & 1,000 \\
\hline & & PLATFORM TOTAL & 240,200 & 254.500 \\
\hline 0.2 & \multicolumn{2}{|c|}{ ELECTRICAL TRANSFER SYSTEM } & 200 & 200 \\
\hline 0.3 & \multicolumn{2}{|c|}{$\frac{\text { POWER SYSTEM }}{\text { (See Table 3-1 for Details) }}$} & 19.600 & 32,300 \\
\hline 0.4 & \multicolumn{3}{|c|}{ MISCELIANEOOS } & \\
\hline & 1.0 & \multicolumn{2}{|l|}{ Seawater Ballast } & 39,000 \\
\hline & 2.0 & \multicolumn{2}{|l|}{ Consumables } & 5.000 \\
\hline & 3.0 & CWP Install. Equip. & $\frac{3,000}{3,000}$ & $\frac{3,000}{47,000}$ \\
\hline & TOT & II WEIGRT WITH CWP & $213,000 \mathrm{MT}$ & $334,000 \mathrm{MT}$ \\
\hline & TOTAL & WEIGET WITEOOT CWP & $161,400 \mathrm{MT}$ & $310,700 \mathrm{MT}$ \\
\hline
\end{tabular}


pump modules. Each SW pump drives the cold water through a 90-deg elbow into the condenser, and out the seawater discharge, which is at right angles to the condenser. The cold seawater discharges at a depth of $80 \mathrm{~m}$ and is directed downward which should satisfy the requirement of cold water discharge at $100-\mathrm{m}$ depth.

The centerline of the warm water intakes is $12 \mathrm{~m}$ below the operating water line. This depth can easily be varied by ballasting or deballasting to reach the optimum intake elevation as dictated by the environments or site location. The warm water system SW pumps are installed in the critical core of the column at right angles to the warm water intake. The SW pump drives the warm water through a 90-deg elbow into the evaporator, and out the seawater discharges. The warm seawater discharges horizontally at a $55-m$ depth, and is parallel to and $43 \mathrm{~m}$ from the warm water intake, which exceeds the limits set up to prevent mixing and recirculation of the warm water intake and discharges.

The Spar is a symmetrical platform; and therefore, there is no need to orient the platform to minimize aero and hydrodynamic drag. It is also doubtful whether recirculation of the warm water intake and discharge would be affected by platform orientation, so there is no provision for azimuthing thrusters on the Spar.

The Spar will be held on location by a multipoint fixed mooring system.

The electrical power generated by the OTEC system is conditioned before it is transmitted from the platform. The switchgear, transformers, and conversion equipment for the entire 100-inW(e) system is located in the lower level of the hull in two adjacent segments. The power cables are routed to a common cable junction box which penetrates the hull for transmission from the platform.

The OTEC utilizes a closed-loop ammonia system for its power generation. The ammonia is vaporized in the evaporators, which are located on the upper lerel in the bull. The vapor leaves the evaporator and passes through the demisters which are located in the annular section above the hull. After the vapor is condensed. it is pumped back into the evaporator to complete the cycle. The total length of the ammonia vapor piping for a $100-\mathrm{AW}(\mathrm{e})$ Spar is $475 \mathrm{~m}$; the total length of ammonia liquid piping is $130 \mathrm{~m}$. 
The main power system auxiliaries are all located in the hull. The ammonia storage tanks are segregated in two segments of the upper level of the hull. The inert gas purge system is located on the lower level of the hull, along with the system startup power supply.

\subsubsection{Constructability.}

(a) Facility. Requirements

Due to the large diameter of the Spar hull, $100 \mathrm{~m}(328 \mathrm{ft})$, few of the facilities surveyed are of sufficient size in which to build the spar hull as a single unit. Drydocks of sufficient size do exist, such as the Blount Island, Jacksonville, Florida, Offshore Power Systems facility. Facilities of this size are few and possibly not available when needed. By dividing the bull into modules, each $71 \times 40 \mathrm{~m}(233 \times 132 \mathrm{ft})$ module will fit within existing drydocks.

The draft of a module including machinery and with eight 10-m-diam spheres attached for added flotation is $12.2 \mathrm{~m}(40 \mathrm{ft})$. The following docks, from an LMSC list, meet this requirement: Newport News Shipbuilding and Drydock Co., $1100 \times 135 \times 40 \mathrm{ft}$; Triple A Shipyard, Hunters Point, $1092 \times 143.2 \times$. $43 \mathrm{ft}$. After launch, a shallow water shoreside depth of $14.3 \mathrm{~m}(47 \mathrm{ft})$ is required before towing out to sea.

A new drydock capable of containing the 100-m-diam spar bull would require a draft selected from the following requirements. Hull machinery at launch draft $14.3 \mathrm{~m}(47 \mathrm{ft})$. Hull and machinery with flotational assistance of $15,803 \mathrm{MT}$ displacement at launch - draft $12.2 \mathrm{~m}(40 \mathrm{ft})$.

(b) Construction Methods

Three construction options are described. A summary of these optional methods is shorva in Table 2-74. 
Tiable 2-74

SUMMARY OF CONSTRUCTION ME'THODS - SPAT

\begin{tabular}{|c|c|c|c|c|c|}
\hline \multirow{2}{*}{ 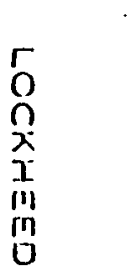 } & & & \multicolumn{2}{|c|}{$\begin{array}{c}\text { Modular } \\
\text { Construction } \\
\end{array}$} & \multirow{2}{*}{$\begin{array}{c}\text { Single Unit } \\
\text { Construction } \\
\text { Option 1.A }\end{array}$} \\
\hline & & & Option I & Option II & \\
\hline 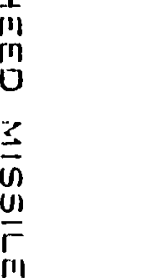 & $\begin{array}{l}\text { DRY } \\
\text { DOCK }\end{array}$ & $\begin{array}{l}\text { Draft Required } \\
\text { Facility Pequired } \\
\text { Flotation } \\
\text { Work Portion } \\
\text { Work Completed } \\
\end{array}$ & $\begin{array}{c}12.2 \mathrm{~m}\left(40^{\prime}\right) \\
71 \times 40 \mathrm{~m}\left(233 \times 132^{\prime}\right) \\
\text { Existing } \\
\text { 8 Splieres } 10 \mathrm{~m} \text { dia. } \\
78.6 \% \\
78.6 \% \\
\end{array}$ & $\begin{array}{c}122 \mathrm{mi}\left(40^{\circ}\right) \\
71 \times 40 \mathrm{~m}\left(233 \times 132^{\prime}\right) \\
\text { Existing } \\
8 \text { spheres } 10 \mathrm{~m} \text { dia. } \\
78.6 \% \\
78.6 \% \\
\end{array}$ & $\begin{array}{c}12.2 \mathrm{~m}\left(40^{\prime}\right) \\
100 \times 100 \mathrm{~m}\left(328 \times 328^{\prime}\right) \\
\text { New } \\
32 \text { Spheres } 10 \mathrm{~m} \text { dia. } \\
82.3 \% \\
82.3 \% \\
\end{array}$ \\
\hline 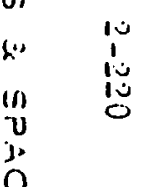 & $\begin{array}{c}\text { SHELTERED } \\
\text { WATER }\end{array}$ & $\begin{array}{l}\text { Draft Required } \\
\text { Flotation } \\
\text { Wort Portion } \\
\text { Wort Completed } \\
\end{array}$ & $\begin{array}{c}12.2 \mathrm{~m}\left(40^{\prime}\right) \\
8 \text { Spheres } 10 \mathrm{~m} \text { dia. }(\times 4) \\
3.7 \% \\
82.3 \% \\
\end{array}$ & $\begin{array}{c}13: 4 m_{1}(44) \\
8 \text { Spheres: } 10 \mathrm{~m} \text { dia. }(\times 4) \\
3.7 \% \\
82.3 \%\end{array}$ & $\begin{array}{c}12.2 \mathrm{~m}\left(40^{\prime}\right) \\
32 \text { Spheres } 10 \mathrm{~m} \text { dia. } \\
0 \% \\
82.3 \%\end{array}$ \\
\hline م & $\begin{array}{l}\text { DEEP } \\
\text { WATER }\end{array}$ & $\begin{array}{l}\text { Work: Portiori } \\
\text { Work: Completed }\end{array}$ & $\begin{array}{l}7.7 \% \\
00 \%\end{array}$ & $\begin{array}{l}17.7 \% \\
103 \%\end{array}$ & $\begin{array}{l}17.7 \% \\
100 \%\end{array}$ \\
\hline
\end{tabular}

- Excluding mobilization - CWP installation, crane installation and removal, towing. 
(1) Option I - Modular Construction Using Existing Facilities

The cylindrical 100-m-diam hull is built as four separate, structurally identical modules, each containing a condenser, evaporator. and associated equipment. A module measuring $71 \times 40 \mathrm{~m}(233 \times 132 \mathrm{ft})$ fits within existing dock facilities having 40-ft draft capability. Assuming an average density of each module equal to that of the hull as a whole, additional flotation is needed to achieve a maximum $40-\mathrm{ft} d r a f t$. Spheres, $10 \mathrm{~m}$ in diam, or bags or vessels of equal volume, are required. They are placed alongside the module and are completely submerged at $40-\mathrm{ft}$ draft. The symmetry and duplication of the hull segments lend themselves to modular construction with reuse of tools and jigs and berthing supports.

Each module consists of a quarter-hull pie-shaped segment containing all equipment and machinery including de-misters. Without the additional flotation a 47 -ft-deep dock is required.

After floating out, the modules are connected together in protected

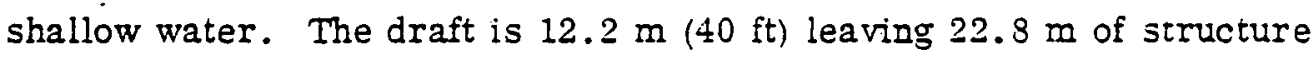
above water for connections. Since each module needs its own walls to at least water level, the assembled modules are separated by double walls to that level, the space between the walls being flooded below $12.2 \mathrm{~m}$, requiring cofferdams in these areas for damage protection. IThe hull central well wall at this stage is up to the level of the demister compartment top. A crane or derrick is assembled over the well. This arrangement is advantageous in that the crane or derrick, being tied to the hull, does not experience motions relative to the hull, unlike a separate barge crane alongside the hull. This is of great importance at the deep water site when relative motion between the hull and sections being installed, such as the CWP and saltwater pumps, would make construction difficult. Sections being installed are placed aboard the hull top des: by barge 
crane and from there lifted and lowered down the well by the onboard crane. The upper CWP section is loaded and suspended in the hull column, while the hull is still in shallow water.

The saltwater pumps located in the upper CWP are installed and the section is lowered to the well base, where the connection is made underwater. Saltwater pumps are installed in the hull well and the crane is disassembled and removed. The flotation bags or collars are removed and eoncrete and water ballast aeded until the water level iz jugt below the top of the well. Using a barge crane, the upper column above the liull well is installed. The liull is furller ballasted aud lie quarles's and heliport are installed on the column top.

(2) Option I-A - Unit Hull Construction Lising Vew Facilities

The hull is fabricated as one unit in a $350 \mathrm{ft} \times 350 \mathrm{ft} \times 40 \mathrm{ft}$ dock, which would have to be constructed. The upper CWP section is suspended within the hull well. All power plant and auxiliary machinery is installed. This results in a vessel draft of $47 \mathrm{ft}$. To reduce the draft to $40 \mathrm{ft}$ for float-out, 32 spheres, $10 \mathrm{~m}$ in diam, or a peripheral collar, $10 \times 5 \mathrm{~m}$, are attached to the vessel sides. After float-out, the construction. sequence follows that of Option I.

(3) Option II - Construction at Sea Without Integrated Crane

This option differs from I and $I$ in that no crane or derrick is assembled on board. All lifts are accomplished from shore or barge cranes. Since the large diameter of the hull makes it difficult for a crane at sea to reach the center well, the hull would be ballasted to below the waterline to allow a barge crane to approach the top of the well. Deballasting would occur after certain lifts to allow connections to be made between components in the well and the hull, above water level. 


\section{4 .6 .4 Operability.}

\section{(a) Maintenance}

All power system, electrical transmission system, and vessel service systems are accessible from within the hull of the vessel. Access to the sea water pumps is not convenient on the Spar. The pump must be isolated from the sea by closing the valves above and below the pump, the seawater must removed, and then the pump be accessed through the seawater piping. As described previously for the Ship, the Spar will have sufficient on board facilities to handle all minor repairs and complete equipment overhauls. The Spar can also be serviced by a mobile support vessel for major repairs.

The size of a removable component is limited by the $4 \mathrm{~m}$ diam access shafts, while the Spar is operating. If the Heat Exchangers have to be removed, the Spar will deballast to expose the hull; and predetermined access hatches will be opened in the hull, and the heat exchangers will be removed by a floating crane barge. The existing arrangement on the Spar will allow the heat exchangers to be retubed in place, so removal should be a very rare occurrence.

\section{(b) Operation}

The only significant difference between the operation of the Spar and the Ship is in the location of the work spaces. The extreme depth of the lower bull of the Spar at operating draft, and the limited access to and from the hull present problems which will affect the operation of the Spar.

Emergency escape procedures will have to be developed for hull, as well as the overall vessel. Ventilation contingencies for continued air supply, as well as isolation of gas leaks will also be extremely critical for the Spar. The great distance between the Nork spaces and the Quarters should be provide a buffer from noise and vibration. which would be a benefit not realized on the Ship; however, in general the Spar will have more potential operation problems than the Ship. 
(c) Performance

(1) Intact Stability

This vessel is designed to satisfy the requirements of the American Bureau of Shipping. ABS measures intact stability by the ability of the vessel to withstand the overturning forces of a severe wind and accompanying waves.

A measure of the stability of the intoct vessel is a comparison hetwean the nverturning energy created by wind and waves and the righting energy created by the heeled vessel. The amount by which the righting energy exceeds the overturning energy upto the limiting angle is a measure of the vessel's ability to resist capsizing or downflooding. The ABS rules require that the area under the righting moment curve at be least 30 percent greater than the area under the heeling moment curve upto some limiting angle. The heeling moment curve used is that of a $51.5 \mathrm{~m} / \mathrm{sec}$ (100 knots) wind. The limiting angle is that corresponding to either the second intersection of the two curves, beyond which the overturning moment exceeds the righting moment, or the occurence of downflooding, whichever is less.

The intact stability of the vessel has been evaluated for three conditions:

- Light draft (in transit)

- Operating draft $(80 \mathrm{~m})$ with CWP

- Operating mode without CWP (breaks off)

For each case, the KG value was calculated. In each case, the area ratio botweon the righting moment and the heeling moment curves was gitule that 1.3. The ressel has sutficient stability in the latuct condition to withstand anticipated environmental loads to a degree established as acceptable by ABS. 


\section{(2) Damaged Stability}

Damaged stability calculations are performed to assure that the vessel will survive llooding of certain spaces due to damage without capsizing or sinking or flooding into additional spaces. The extent of damage which a vessel should be able to tolerate and the environment loads which it should be able to resist are established in the ABS Rules.

This assumes that damage can occur at exposed portions of column located on the periphery of the vessel. The vertical range in which damage may occur extends from $1.5 \mathrm{~m}$ above the waterline to $1.5 \mathrm{~m}$ below. The vertical extent of damage is assumed to be $3.0 \mathrm{~m}$ occuring anywhere within the assumed vertical range. The horizontal extent is assumed to be $45 \mathrm{deg}$ and the assumed depth of penetration if $1.5 \mathrm{~m}$.

Therefore, if a horizontal flat is within the vertical range of damage, it must be assumed damaged. Also, interior bulkheads must be located inboard of the assumed depth of damage if they are to be assumed intact.

The overturning energy of wind and wave is assumed to act upon the damaged vessel, adding a heeling moment to that caused by the flooding water. The wind heeling moment computed in the same manner as for the intact stability, is that created by a $25.8 \mathrm{~m} / \mathrm{sec}(50$ Loots) wind. The ABS Rules require that the flooded vessel have sufficient stability to sustain the heeling energy of the wind without capsizing or heeling over to an angle at which down flooding can occur.

At operating draft, annular sections of the column is partitioned by horizontal and vertical watertight flats, so flooding is limited to less than $300 \mathrm{MT}$. 
At transit draft the hull cofferdam protects the interior spaces from flooding. Flooding is limited to less than $1000 \mathrm{MIT}$ if the hull is damaged. The study shows that the vessel has sufficient stability in the damaged condition to withstand anticipated environmental loads to a degree established as acceptable by $A B S$.

(3) Spar Motions and Cold Water Pipe Loade

The motions of the 100 iWWe Net spar platforma are summarized in Table $2-75$. The pitch and roll motions are the smallest of the platiforms when sompared with the deep attachument of the CWF. The loads in the CWP are moderate for the deep attachment point. The pipe dynamic loads are greatly reduced $(1 / 2)$ by location of the attachment of the CWP near the center of the hull.

2.4.6.j Risks. A power availability risk, as for the submersible is related to the necessity for surfacing by blowing ballast for removal of major power system components or other maintenance activities involving surfacé support facilities. 
Table 2-75

CALCULATED SEAWAY RESPONSE FOR SPAR PLATFORM

IN HEAD AND BEAM SEAS, CONCRETE CWP,

$E=0.3 \times 10^{6}$ PSI, $10^{9}$ LB-ET/RADIAN

CWP ATTACHMIENT STIFFNESS

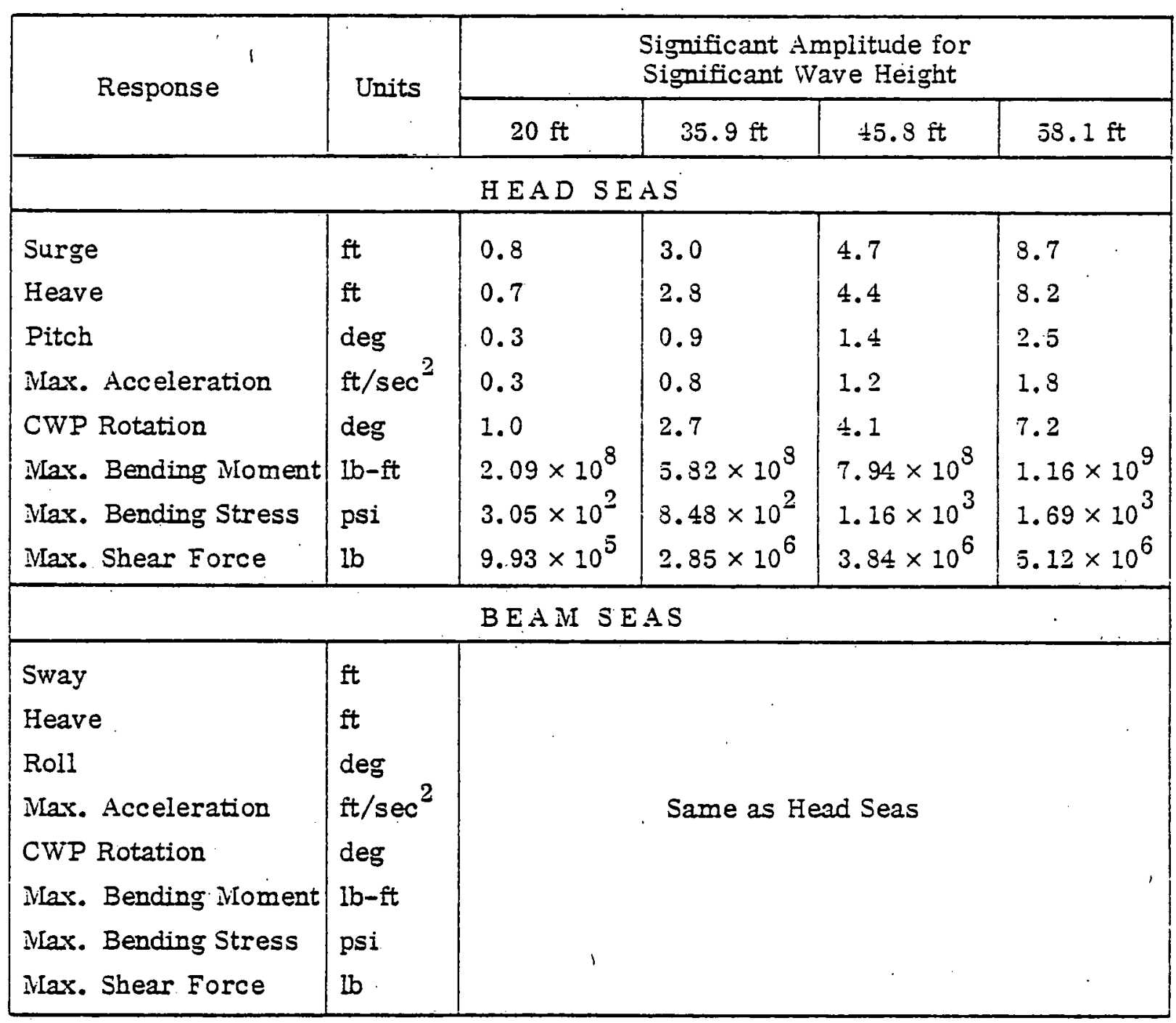




\section{4 .6 .6 Costs.}

(a) Construction Cost - SPAR

The estimated costs to construct the OTEC spar in an existing facility, assumming no draft, width or length limitations are shown in Table 2-76 This is the base used in estimating the cost to build the Spar when considering construction facility capabilities.

Using the cost factors discussed in Section 2.4.1.7 and the percent construction completed in each phase as shown in Table 2-74, a cost of each iunstiuction option wo devcloped. A cummary of those sosts is shown in Table $2-77$.

(b) Mobilization Costs - Spar

In addition to the costs mentioned in Section 3.6.2, the re are additional costs in the case of the Spar due to construction that must be delayed until after CWP installation, namely, sea-water pumps and quarters installation. Employing the mobilization times presented in Section 2.4.6.7 the following costs are determined:

$$
\begin{aligned}
& \text { Cost, } \min .=300,000 \times 26.25=\$ 7,875,000 \\
& \text { Cost, max. }=300,000 \times 70=\$ 21,000,000
\end{aligned}
$$

Total mobilization costs - Spar:

$$
\begin{gathered}
39,750,000+7,875,000=47,625,000 \\
96,000,000+21,000,000=117,000,000 \\
\$ 48-117 \text { million }
\end{gathered}
$$


Table 2-76

PLATFORII CONSTRLCTION COSTS - SPAR - STEEL (UNCORRECTED FOR ERECTION COMPLEXITY)

\begin{tabular}{ll} 
S/MT $\quad M T \quad \begin{array}{l}\text { COST } \\
\times 105\end{array}$ \\
\hline
\end{tabular}

1.0 Hull and Structure

1.1 shel1

1.1.1 Bull.

1.1 .2 Column

1.2 Bulkheads

1.3 Decks

1.4 Not Üsed

1.5 Deck Houses

1.6 Special Structures

1.6.1 Demister CoIunn

1.6 .2 iccess/Vent: Shafts 2,600

3,100

4,300

49,000

6,600

151.9

3,100

$\varepsilon, 000$

3,100

10,400

24.8

1.7 Not Used

1.8 Founcations

$1.8 .1 \operatorname{CNP}$

1.8 .2 Ecuipment

2,600

500

1.3

1.9 permanent Ballast
1,800

1,000

$7: 8$
2.5

32.2

$\begin{array}{lll}4,300 & 1,800 & 7.8 \\ 2,600 & 1,000 & 2.5\end{array}$


Table 2-76 (Cont.)

4.2 Machinery and related piping
a Elevators
a Deck Cranes
a Diesel Generators (Quarters)
a Emergency Generators (Quarters)
a Hoists, Tuggers, Forkifits
a Compressed air system

3.0

4. 3 Hull Piping Systems/w Machinery

13.0

- Ballasst

- Bilge

- De-Ballast Vent

- Sonndry

- Engine cooling

- Compressed Air

- Lube OiI

- Fuel 0il

- Fresh Water

4. 4 BVAC

13.4

4.5 Safety Equipment

1.0

- Fire protection

- Life Boats

- Life Rafts

4.6 Electrical Work (Misc.) 1.3

4.7. Vesse 1 Management 3.6

4.8 Accomodation 2.5

4.9 Workshops (Misc.) 1.0

4. 10 Fadio and Communications 0.2

49.5

5.0 Installation of OFE

\begin{tabular}{lllll} 
- DACS & 500 & 26,000 & 13.0 \\
- Sea water system & & & \\
- CNP Fanding Eouipment & & \\
Energy Transfer System & \\
\hline
\end{tabular}

TOTAL

$5344,50 \Omega, 000$

$2-230$

LOCKHEED MISSILES E SPACE COMPANY. liV. 
Table $2-77$

SUMMARY OF COSTS OF CONS'TRUC'TION OP'TIONS- S'PAR - STEEL

\begin{tabular}{|c|c|c|c|c|c|c|c|c|c|c|c|}
\hline \multirow{3}{*}{ 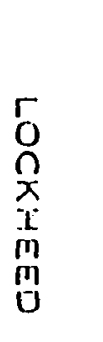 } & \multirow{2}{*}{$\begin{array}{l}\text { Consiruction } \\
\text { Location }\end{array}$} & \multirow{2}{*}{$\begin{array}{c}\text { Work } \\
\text { Description }\end{array}$} & \multicolumn{3}{|c|}{ Option I } & \multicolumn{3}{|c|}{ Option 1.A } & \multicolumn{3}{|c|}{ Option II } \\
\hline & & & Weight & $\begin{array}{l}\text { Unit } \\
\text { Cost }\end{array}$ & Cost & Weight & $\begin{array}{l}\text { Unit } \\
\text { Cost }\end{array}$ & Cost & Weight & \begin{tabular}{|l|} 
Unit \\
Cosi \\
\end{tabular} & Cost \\
\hline & $\begin{array}{c}\text { DAY } \\
\text { DOCK } \\
\text { (Cost Factor) } \\
=1\end{array}$ & $\begin{array}{l}\text { Structure } \\
\text { Equip. Instl. }\end{array}$ & Modular & & & $\begin{array}{l}80,215 \\
24,500\end{array}$ & $\begin{array}{r}3,200 \\
500\end{array}$ & $\begin{array}{r}256.7 \\
12.3\end{array}$ & Modular & & \\
\hline 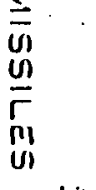 & $\begin{array}{c}\text { SHORE } \\
\text { Site } \\
\text { (Cost Factor) } \\
=1.25 \\
\end{array}$ & $\begin{array}{l}\text { Structure } \\
\text { Equip. !nstl. }\end{array}$ & $\begin{array}{l}80,215 \\
24,500\end{array}$ & $\begin{array}{r}3,200 \\
500\end{array}$ & $\begin{array}{r}320.9 \\
15.3\end{array}$ & & & & $\begin{array}{l}80,215 \\
24,500\end{array}$ & $\begin{array}{r}3,200 \\
500\end{array}$ & $\begin{array}{r}320.9 \\
15.3\end{array}$ \\
\hline 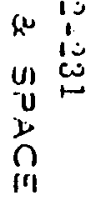 & $\begin{array}{l}\text { SHALLOW } \\
\text { WATER } \\
\text { (Cost Factor) } \\
=2\end{array}$ & $\begin{array}{l}\text { Structure } \\
\text { Equip. Instl. } \\
\text { Concrete } \\
\text { Ballast } \\
\end{array}$ & & & & & . & & & & \\
\hline $\begin{array}{l}0 \\
0 \\
3 \\
0\end{array}$ & $\begin{array}{c}\text { ON-SITE } \\
\text { (Cost Factor) } \\
=3\end{array}$ & $\begin{array}{l}\text { Structure } \\
\text { Equip. InstI. } \\
\text { Concrete }\end{array}$ & $\begin{array}{c}7,285 \\
1,500^{*} \\
92,000\end{array}$ & $\begin{array}{r}3,200 \\
500 \\
115\end{array}$ & $\begin{array}{r}41.1 \\
2.3 \\
31.7\end{array}$ & $\begin{array}{c}4,285 \\
1,500^{*} \\
92,000\end{array}$ & $\begin{array}{r}3,200 \\
500 \\
11.5\end{array}$ & $\begin{array}{r}41.1 \\
2.3 \\
31.7\end{array}$ & $\begin{array}{c}4,285 \\
1,500 \\
92,000\end{array}$ & $\begin{array}{r}3,200 \\
500 \\
115\end{array}$ & $\begin{array}{r}41.1 \\
2.3 \\
31.7\end{array}$ \\
\hline 2 & \multicolumn{2}{|l|}{ Subtotal } & & & 411.3 & & & 344.1 & & & 411.3 \\
\hline$\frac{z}{n}$ & \multicolumn{2}{|c|}{ Sup.poort Subsystems } & & & 49.5 & & & 49.5 & & & 49.5 \\
\hline & \multicolumn{2}{|l|}{ Totial } & & & 460.8 & & & 393.6 & & & 460.8 \\
\hline & & Units & $m t$ & $\$ / i n t$ & $\begin{array}{l}\$ \\
\text { million }\end{array}$ & int & $\$ / m t$ & $\begin{array}{c}\$ \\
\text { million }\end{array}$ & $\mathrm{mt}$ & $\$ / m t$ & $\begin{array}{c}\$ \\
\text { million }\end{array}$ \\
\hline
\end{tabular}

- Sea-Water Pumjos 
2. 4.6.7 Schedule. Schedules for mobilization are based on the following breakdown of construction sequence times:

Lift CW sea-water pumps on-board:

1 day

Lower CW sea-water pumps down column:

1 day

Make Connections between pumps and hull:

3 days

Lift WW sea-water pumps on-board:

1 day

Lower WW sea-water pumps dowh column:

1 day

Nake connections between pumps and hull:

¿ days

Remove on-board gantry crane:

j days

Lift and place quartoro onboard,

1 तay

Make connections between quarters and Spar:

5 days

21 days

Min. worktime $=21 / 80$ percent $=26.25$ days

Max. worktime $=21 / 30$ percent $=70$ days

2.4.6.8 Summary. The Spar configuration provides an adequate platform for the specified internal power system. The accomodation of the height of the demisters and the length of the heat exchangers has driven the size of the equipment area. The large displacement of this Spar is a result of the sizes and proportions of the power system components. Integration of an internal power system with the Spar concept should reduce the comparatively high cost for the Spar. Construction methods which avoid the high complexity factor $(3 \mathrm{x})$ could provide further reduction in platfuru custs. 


\subsubsection{Spar - Detachable Power Miodule}

2.4.7.1 General Description. The general arrangement of the 100-NW(e) OTEC Spar with detachable power modules is shown on Fig. 2-50. There are four detachable modules for the $100 \mathrm{MW}(\mathrm{e})$ (net) configuration. The heat exchangers, seawater pumps, demisters, and turbine-generators are housed within the detachable modules. The modules are attached to a central Spar which contains the ammonia storage tanks, inert gas purge system, data acquisition and control system, electrical conversion and transmission equipment, cycle startup power plant, and miscellaneousvessel support systems. The accommodation spaces, and material handling system are also on the Spar.

2.4.7.2 Desion Features. The Spar and power modules are made up of cylindrical shapes. The $40-\mathrm{m}$ and $22-\mathrm{m}$-diam columns are double-skin watertight construction throughout their entire height. The detachable modules are single-skin watertight construction.

The principal characteristics of the Spar and detachable modules are:

Spar

Lower column diameter:

Upper column diameter:

$40 \mathrm{~m}$ (131 ft)

Overall height:

$140 \mathrm{~m}(459 \mathrm{ft})$

Operating Displacement:

$105,900 \mathrm{NIT}$

Lightship weight:

$80,300 \mathrm{NT}$

Power Module

Column Diameter:

$13 \mathrm{~m}(43 \mathrm{ft})$

Overall height:

$95 \mathrm{~m}(312 \mathrm{ft})$

Displacement (Submerged):

18,000 MIT

Lightship weight:

$11,000 \mathrm{IIT}$

Spar With Power Modules ( $t$

Operating Draft:

$115 \mathrm{~m}(459 \mathrm{it})$

Operating Displacement: 


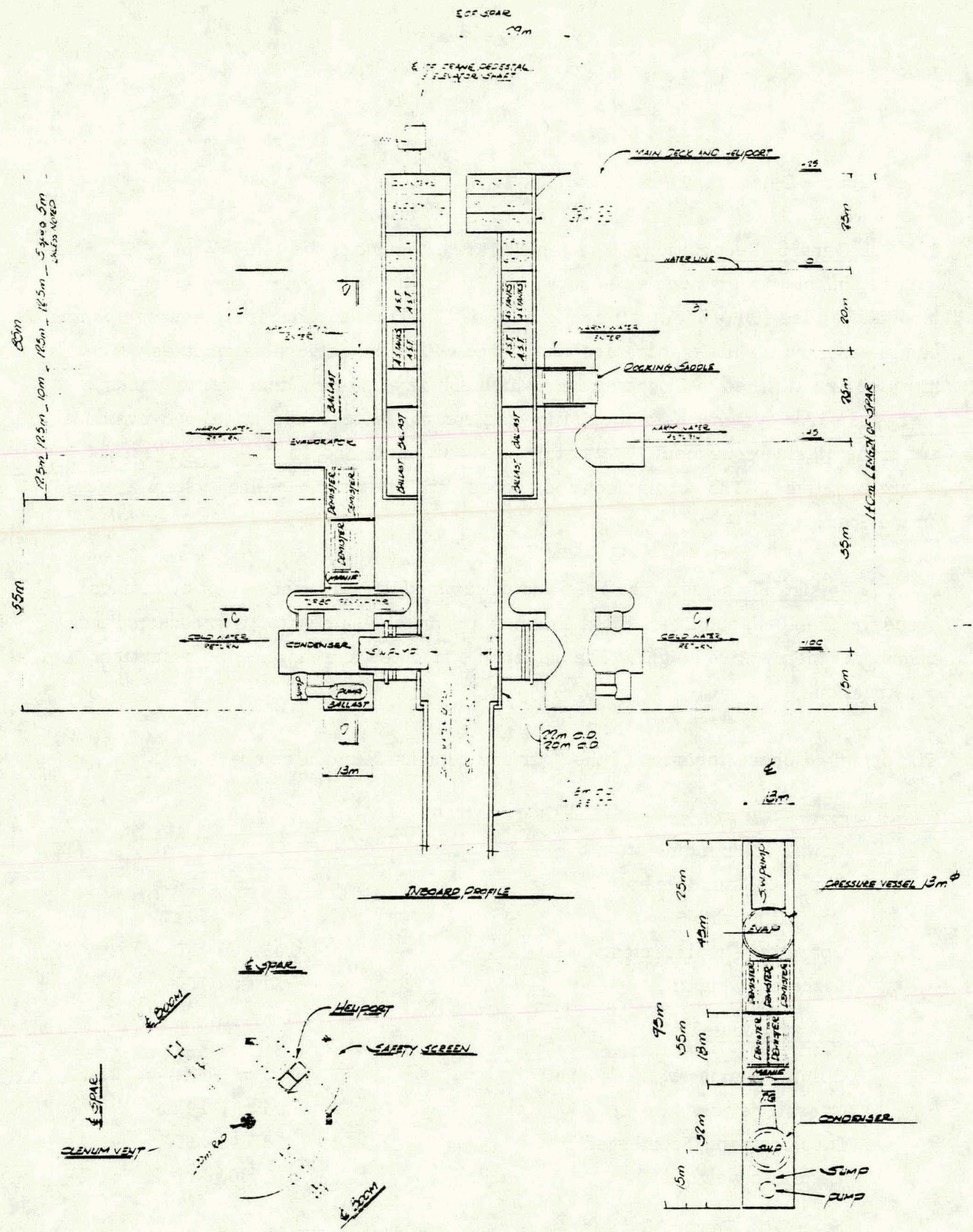

Fig. 2-50 General Arrangement of 100-1MW(e) Spar Power Modules 

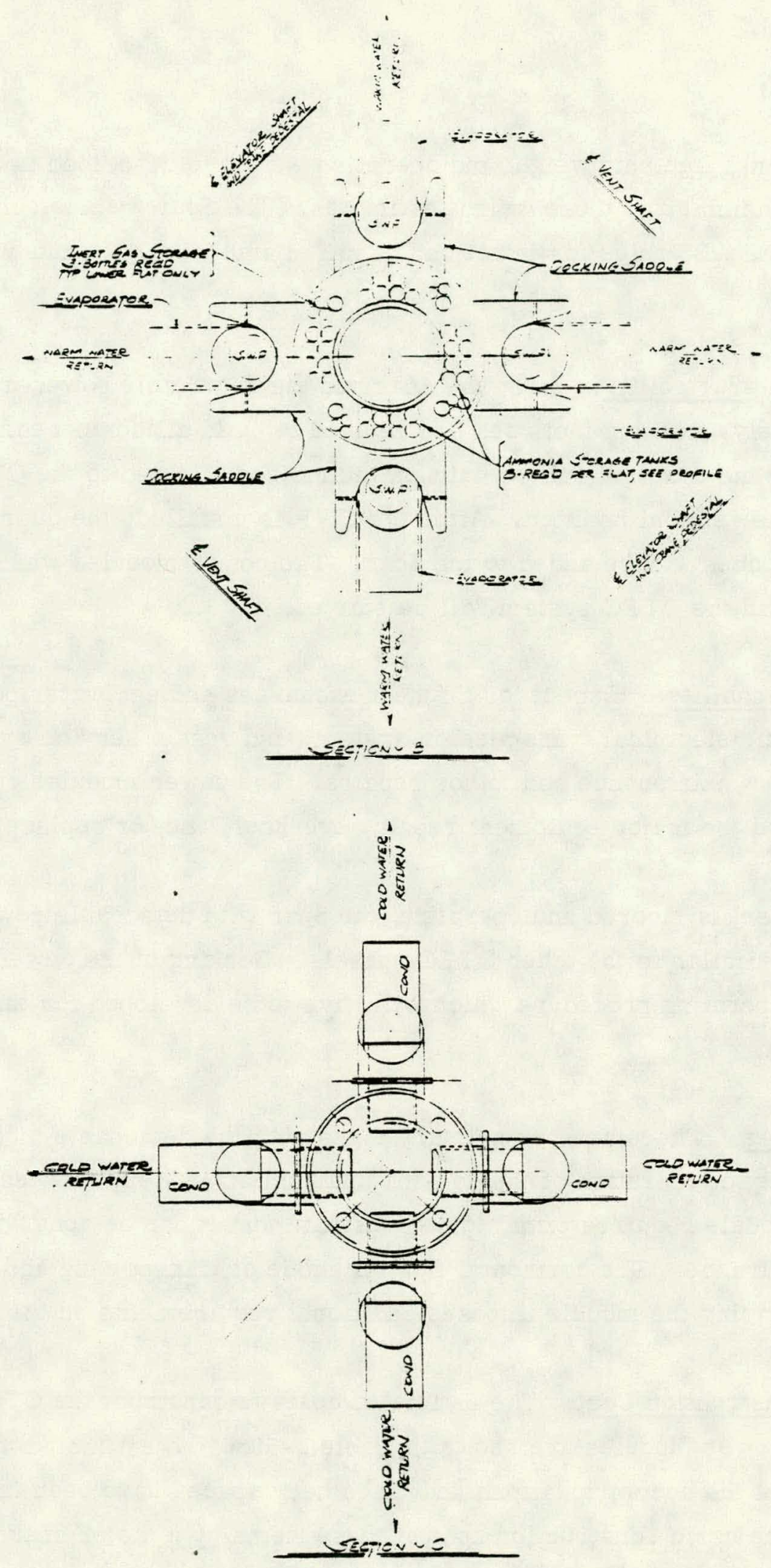

Fig. 2-50 (Cont.) 
The definition of lightship weight and operating weight is described in Section 2.4.6. Table 2-78 summarizes these weight estimates. The Spar with detachable power modules meets $A B S$ rules for intact and damaged stability, with and without the CWP attached.

2.4.7.3 Constructability. Since the Spar and the detachable power modules will be built separately, existing facilities can be used to build all components of the system. The Spar and the modules will be built on their sides, floated to the OTEC site, and upended to the vertical position. After the CWP is installed, the quarters and machinery spaces will be added to the Spar. The power modules will then be attached to the Spar and the OTEC system will be startexi.

2.4.7.4 Operability. Except for the heat exchanges and sea water pumps, all power system, electrical transmission system, and vessel service systems are accessible for maintenance and minor repairs. The power modules can be detached and drydocked for major equipment repair, overhaul, and/or replacement.

Once the vessel is moored and operating, the Spar with detachable power modules will operate similar to the other OTEC vessels. Docking of the power modules will be a major operating procedure which will have to be developed for this OTEC configuration.

2.4.7.5 Rishs. There are two primary risks with the detachable module Spar. The reliability of operation of the docking and seal off system between the Spar and the power module requires effort to domonstrute that it can be done with high or fail safe assurance. The hnrizontal floating uude of transporting and the horizontal mode of servicing the module imposes additional requirements on the porver system.

2.4.7.6 Construction Cost. The estimated costs to construct the OTEC Spar with detachable Power Modules are shown in Table 2-79. The estimated cost for instailation of the accommodations and machinery spaces have been included by increasing the basic construction cost of these items by a factor of three. Mobilization costs developed for the other OTEC configurations can be used for the Spar. 
2. 4.7.7 Schedule. It is estimated to require 43 months to construct the spar hull.

2. 4.7 .3 Summary. The detachable power modules on the spar present a way of optimizing the use of the volume inside the basic spar. Some additional structure must then be provided for the detachable module. The design approach presented here has satisfactorily accommodated the specified baseline power system. Further reductions in platform (core + module) costs should be attainable with power system components which are fully integrated into the platform. 
Table $2-78$

SPAR WTH DETACHABLE POWER MODULES WEIGHT ESTMMATE

C.IA OTEC PEATEOPN SPAR

$\begin{array}{cc}\text { Lightship coerating } \\ \text { Veight } & \text { reight } \\ \text { letric } & \text { getric } \\ \text { Tons } & \text { gons }\end{array}$

1.0 SEEII

$1.1 \quad 22 m \phi$ solum

1. 2 40m spar

$\begin{array}{rr}2060 & 2080 \\ 11040 & 11040\end{array}$

$1.3-1.4$ not iseci

1.5 Desk Houses

1.6 Special Structures

1.6.1 Docking Saddle (Lpper)

1.6.2 Docking Disc (Lower)

1.6.3 Access/vent Shaits

I.7 Not Used

1.8 Founcations

1.8 .1 Ccld hater Pipe

1.8 .2 Equipment

1.9 3allast

1.9.1 Fixed Ballast

1.9 .2 Freetlooding Ballast

TOTAL

11040

11040

2500

2500

$\begin{array}{rr}400 & 400 \\ 1930 & 1930 \\ 260 & 260\end{array}$

$\begin{array}{ll}2500 & 2500 \\ 1500 & 1500\end{array}$

2.0 SEAWATER SYSTEY:

2.1 Cold water Pipe $51,300 \quad 22,200$

3.0 POSITION COITROT SYS ---

4.0 SUPPORT SLESYSEEIS $\quad 2000 \quad 2000$

5.0 OUTEIT AUD FURIISHINGS $500 \quad 500$

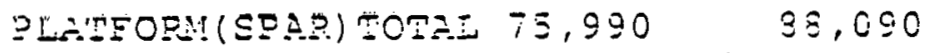

0.2 EEECESICEI TPASSEEP SYSTE: $200 \quad 200$

0.3 ECRES SVESE:?

$3.0-3.0$ Yot $i \equiv \equiv \bar{c}$

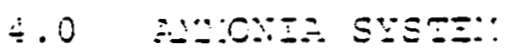

$\therefore \therefore \quad$ : $\therefore$ :

$\div 2 \quad \because 0 \div \because \equiv \equiv c$ 


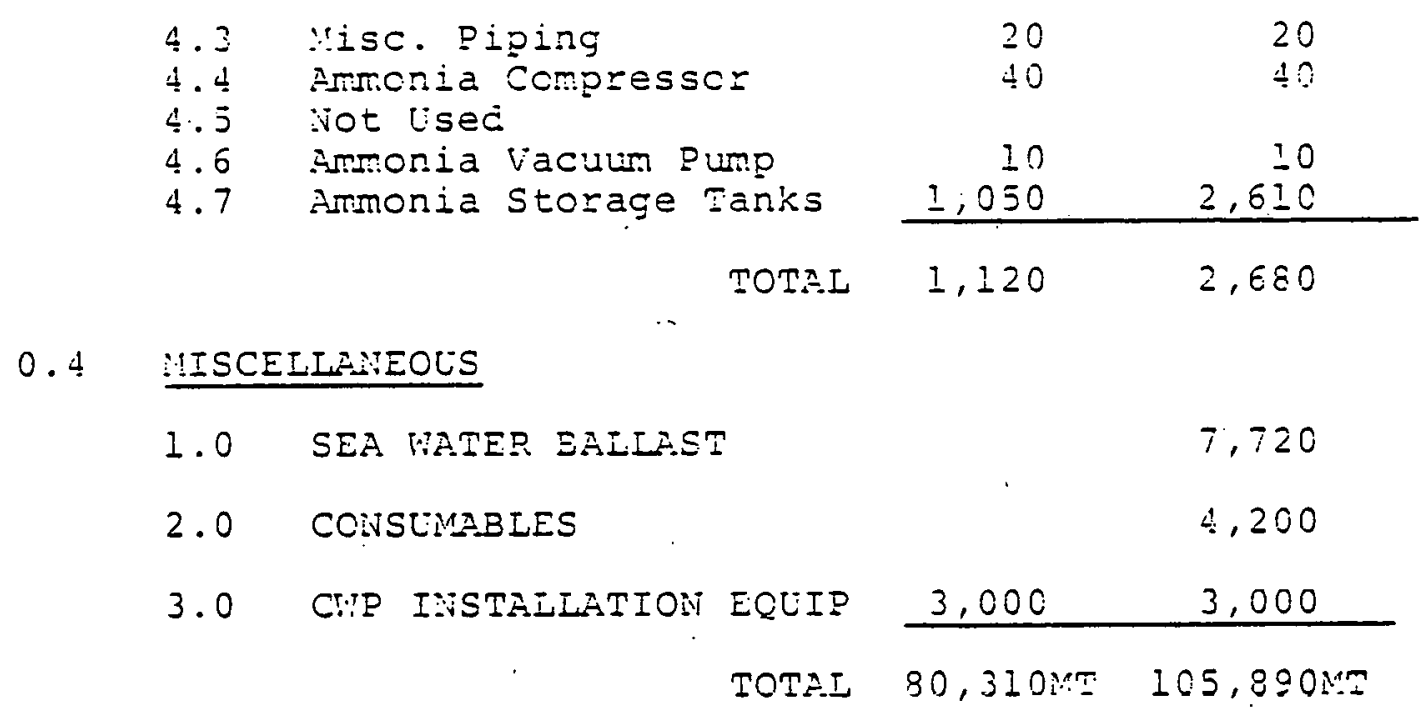


Table 2-7s (Cont

C.IB CTEC PIITEORM

DETACFABLE POTER :OOLLE

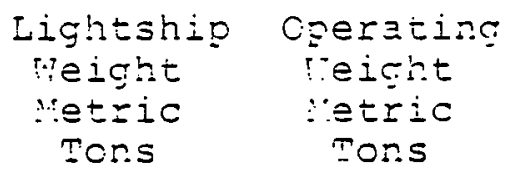

3,660

$T \in O$

250

3, 560

760

250

$1.2-1.7$ Not Usea

1.8 . Eoundations

1.8 .1 Not Ised

1.8 .2 Ectipment

1.9 Ballast

1.9.1 Fired Ballast

1.9.2 Freeflooaing Ballast

2.0 SEATATER SYSTEY

4.360

$\frac{4,360}{4,970 \quad 9,330}$

2.1 Not used

2.2 Cold nater Purps

175

i 75

2.3 :iot Çseg

2.4 warm liater pumps

175

175

2.5 .1 Not Used

2.5 .2 Narm Water

\begin{tabular}{ll}
175 & 175 \\
175 & 175 \\
300 & 300 \\
\hline 650 & 650
\end{tabular}

3.0 POSITION COINTROI SYSTEN

$3.1-3.2$ Not Lsed

3.3 Docking Fonito.

$\frac{200}{200}$

4.0 GLPPORT SEESYSTEYS

\begin{tabular}{rr}
400 & 400 \\
100 & 100 \\
\hline $6,320$. & $10, \varepsilon \varepsilon 0$
\end{tabular}

0.2 :OOT $\because \leq E D$

0.3 ECHEP SYSTEY
I. 0

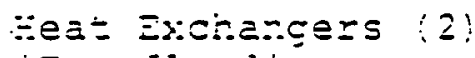

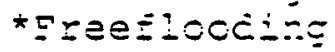
$\therefore, \therefore \Xi$
$\div$ :ニミ゙

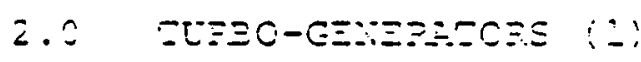
$\because \vdots \vdots$
ミミ

LOCKHEED MISSILES a SEACE COMPANY. INC. 
Table $2-7.8$ (Cont.)

3.0 DEYISTERS (5)

210

215

4.0 AMONIA SYSTE:

4 .1 Vapor Piping

4.2 Liquic Pifing

4.3 ijot lised

4.4 innonia Compresscr (1)

4.5 inmonia Eeec Dur?

\begin{tabular}{rr}
35 & 40 \\
25 & 75 \\
10 & $\frac{10}{25}$ \\
\hline 45 &, \pm 695
\end{tabular}

0.4 MISCELIANEOUS

1.0 SEP WATER EALLAST 2,425

2.0 CO:ISUMEIES 200

3.0 VOT LSED

\begin{tabular}{|c|c|c|}
\hline \multicolumn{2}{|c|}{ TOTAI } & 2,525 \\
\hline TOTAL ORE UODUIE & $10,955 \mathrm{MT}$ & $18,000: 15$ \\
\hline POTAL FOUR MODULES & $43,980: 1$ & $72,000: 1:$ \\
\hline
\end{tabular}


Table 2-79

SPAR WITH DETACHABLE MODULES COST ESTIMATE 0. IA OEEC PLATEORN SPAR

1.0. SHEII

1.1 23m Colunn $4300 \quad 3060 \quad 3.9$

i.2 40m spar $\quad 3100 \quad 11040 \quad 34.2$

$1.3-1.4$ not lised

1.9 Berk rouses

*Instaliled on. Site

$7800 \div \quad 2500 \quad$ I9.5

1.6 Special Structures

1.5 .1 Doeking Sacilo

(Lipper)

1.6.2 Docking Disc

(Lower)
1.6 .3 Access/Vent

$2 /: 1$

$\cos \frac{\pi}{6}$

Shafts

1.7 not Used

1.8 Foundations

1.8 .1 Cold Viater Pipe

1.8.2 Equipment

$\begin{array}{lll}3100 & 2500 \quad 7.8\end{array}$

4.7

TOTAI

$22,1 \subseteq 0$

23.2

2.0 HOT USED

3.0 POSITION CONTPOL SYSME:

4.0 SUPDCRT SUESYSTEM

4.1 Cathodic grotectors/Coating 3.5

4.2 Machinery anc related plolng 2.e

Elevators

Deck Cranes

Dissel Eereratono (Qlarters)

Emergency Gererators (QLarters)

Foists, Fug

Comprassed

4.3 Full Pipine Eyster/s Wactinery

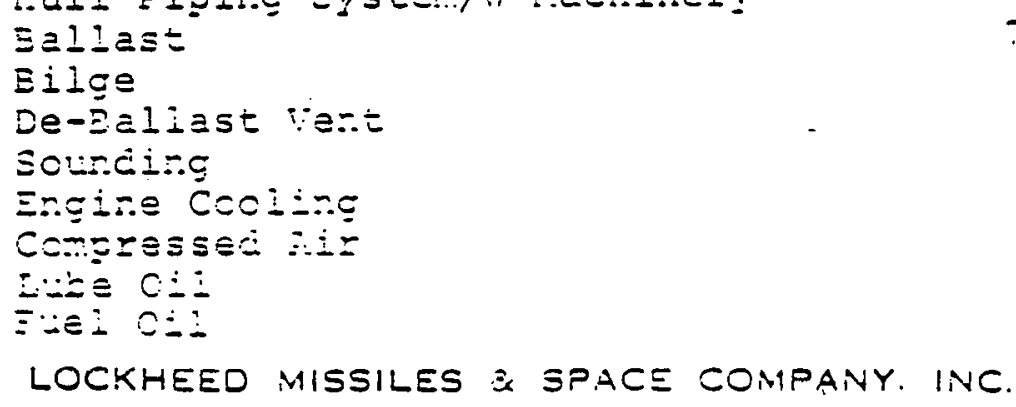

LOCKHEED MISSILES \& SPACE COMPANY. INC. 
Table 2-79 (Cont.)

Fuel oil

4.4 FVAC

2.4

4.5 Sajety Eciuiptient

1. 0

Fire Protection.

Life. Boats

Life P.afts

4.6 Electrical Hork (:isc.)

1.2

4.7 Vessel Management

3.6

4.8 Accomocation

2.5

4.9 Workshops (Misc.)

1.0

4.10 Radio and Communications

0.2

5.0 INSTALIATION OF OFE

(13,000:4T a $\$ 500 / \mathrm{MT})$

6.5

DECS

Sea Water System:

CTP Fanding Equipment

Energy Transfer System

Pcwer system.

$\begin{array}{ll}\text { TOTAL \& ANC } 5 & 31.7 \\ \text { TOTAL SPAR } & 114.7\end{array}$


Table 2-79 (Cont.)

O.1E OTEC PLATEORH - EXTEPAPL POMER YODLIE

1.0 SEEEI AID STPUCTURE

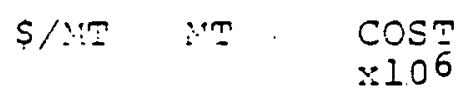

1.1.1 Vertical Cylinder

4300

4300

3660

760

$\pm 300$

250

15.7

1.1.3 Turbo-Gener. Enc.

$1.2-1.7$ irot Used

1.8 Folndations

1.8 .1 Not Used

1.8.2 Equipment

$\begin{array}{lll}3100 & 300 & 0.9 \\ 4.970 & 21.0\end{array}$

2.0 NOT USED

3.0 POSITION CONTROL SYSTEM

4.0 SUPPORT SLBSYSTE:S

4.1. Cathocic Protectors/Coatirg.

4.2 Machinery and relatee piping 0.1 Elevaturi Deck Cranes

Diesel Generators (Quarters)

Emergency Gererators (Quarters)

Foists, Tuggers, Eorklizts

Compressec Fir System

-.3 Eull pipirg systers/u ltactirery 1.1 Ballast

Bilge

De-Ballast Vent

Souncing

Engine Cooling'

Compressec in

Lube Cil

Evei Cii

$4.4 \quad \because 5 C$

0.3 
Table $2-79$ (Cont.)

i.j Safety Equipment
Fire Frotecticr
Iife Doats
Life Rafts

4.6 Electrical ficts (nisc.)

0.1

4.7 Vessel Varagement

4.8 Accormciation

4.9 rorkinops (lisc.)

$\div 10$ Radio and Communications

5.0 IINTAIIATIOIN OE OFE

$(10,000 \mathrm{M}$ a $\$ 500 / \mathrm{MT})$

DACS

Sea vater System

Energy mransfer system

Povier syster:

\begin{tabular}{lc} 
TOTAI 4 and 5 & $6 . \dot{\epsilon}$ \\
\hline TOTAI CIVE MODUEE & 27.6 \\
SOTAL FOUR MOCLIES & 120.4 \\
\hline
\end{tabular}

TOTAL SPAB ANI MODEZES

$\$ 225.1$ 


\section{4.3 Prestressed Concrete Hull}

T. Y. Lin International (TYLI) was given the task of studying and comparing the hull configuration for six different OTEC platforms in prestressed concrete. Five hulls have been designed in steel by the two naval architectural consultants on the Lockheed team. The sixth platform, the sphere, was designed in PC and steel by Tuned Sphere International.

Based upon data developed, the concrete versions of the OTEC platform syslem have been developed by TYLI, with consultation and input by the respective naval architects and LiMSC.

During the course of study, several pertinent points were presented and discussed, such as the state-of-the-art assessment of the concrete structure for OTEC; the design, construction, and installation of the cold water pipe; and the review of the Tuned Sphere Platform.

Effort has been made to develop conceptual prestressed concrete hull designs for the six OTEC platforms, to the extent that preliminary cost estimation can he made for each platform. The cost estimates for concrete hulls are presented in Table $2-\delta 0$.

\subsubsection{Desion Consideration in Concrete. The first point to consider is that the} hull configuration of a sea structure is very mich related to the mateitial with which it is to be built. The use of steel, for instance, would hetter permit an irregular structural form such as a ship-shaped vessel. On the other hand, a platform with concrete in mind would tend to assume simpler and bolder shapes, e.g., rectanoular and cylindrical configurations, that lend themselves better to the application of this material.

The first essential is good quality concrete and the consistency of such good quality concrete. Tecinologically, there is really no gap in the present status for maing high quality concrete, but certain safeguards are necessary to ensure that such high 
Talble 2-80

OTIC COST ANALYSIS - FIRST UNIT BASIS

\begin{tabular}{|c|c|c|c|c|c|c|c|c|c|c|c|c|c|}
\hline \multirow[b]{2}{*}{ Hlite } & \multirow{2}{*}{$\begin{array}{c}\text { Price pues' } \\
\text { cu yd } \\
8\end{array}$} & \multicolumn{2}{|c|}{ corcular Isirgst } & \multicolumn{2}{|c|}{ lulcioull siltar } & \multicolumn{2}{|c|}{ Sulmumatuls: } & \multicolumn{2}{|c|}{ Shipe } & \multicolumn{2}{|c|}{ Stmlsubmer sillte } & \multicolumn{2}{|c|}{ sphere } \\
\hline & & $\begin{array}{l}\text { Volumine } \\
\text { (cil yod) }\end{array}$ & $\begin{array}{l}\text { Price } \\
\text { (Elo00) }\end{array}$ & $\begin{array}{l}\text { Volumis: } \\
\text { (ccil yili) }\end{array}$ & $\begin{array}{l}\text { Pritec } \\
(\$ 1000)\end{array}$ & $\begin{array}{l}\text { Voluminc } \\
\left(1: 4 y^{\prime}(1)\right.\end{array}$ & $\begin{array}{l}\text { Pulce } \\
\text { (D) }\end{array}$ & 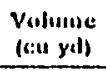 & $\begin{array}{l}\text { Prites } \\
\text { (\$10uos) }\end{array}$ & $\begin{array}{l}\text { Vuluturs } \\
(\text { (::1, yol) }\end{array}$ & $\begin{array}{l}\text { Price } \\
\text { (\$1 umol }\end{array}$ & $\begin{array}{l}\text { Vulumise } \\
\text { (cu ydl) }\end{array}$ & 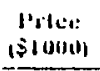 \\
\hline Slluell P.!.1P. & 1.090 & - & - & $20,8: 24$ & $24,2: 34$ & 6. 540 & 7.120 & - & - & - & - & 11. 135t & 45.414 \\
\hline silu:ll 1..e. & 760 & 9.261 & C. 9:3H & 50.280 & 37.715 & 1.1. 3:13 & 10.750 & $1.4,671$ & 11.003 & 10,9160 & H. $2: 0$ & -- & - \\
\hline W:ills & 750 & 40.277 & 30,208 & 201.754 & $2: .110$ & 50.171 & 37.620 & 50, 652 & 37.089 & 50.500 & 37.941 & 23,3445 & $17,6.10$ \\
\hline 1u:t:k & 750 & $\mid 1 i, 971$ & 政, & 33, 2:46 & 21.965 & 12.196 & 9.147 & 19.561 & 14.671 & 28,739 & 21.55 .1 & $34,+11 i$ & 25.8311 \\
\hline 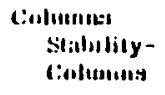 & 1.1900 & - & - & 1.687 & 1,839 & 1.076 & 1,173 & - & - & 10,706 & 18.45 .4 & 1.915 & $\therefore .06 \%$ \\
\hline 'luwal & & 6its. 41,9 & (13). $8^{\prime} / 1$ & III, vil? & 116,073 & Q.1, J115 & نิ5. $8 \geq 7$ & 8.1. NH.1 & 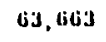 & IUti, 4t:5 & s(i.:2ivs & 101.153 & ist. Jiti \\
\hline 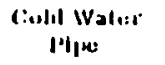 & 1.000 & Fiar all & termaltive & $20,000 \mathrm{e}$ & yil, \$2H, & 00,000 & & & & & & & \\
\hline 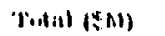 & & & 77.9 & & $1+1.1 .1$ & & 93.8 & & 91.7 & & 111.2 & & 118.9 \\
\hline
\end{tabular}


quality concrete would be produced for the entire structure involving perhaps some $100,000 \mathrm{cu} y d s$ of concrete. The safeguards are primarily concerned with the choice of the proper material for the concrete, and the implementation of a rigid quality control program of delivering and placing good quality concrete throughout construction.

For the North Sea platforms, the performance of concrete has been excellent so far. No maintenatice has been required. Inspections show the platforms to be in very good condition. There was some algae load, especially on prestressed concrete, as expected. Hence, it is now almost a universally established fact that concrete lasts very well at sea if the quality of concrete is properly controlled during production.

We are well acquainted with the fatigue strength of concrete. Prof. T. Y. Lin has personally conducted tests of the fatigue strength of prestressed concrete members up to 4 million cycles in Belgium. The results are excellent. With respect to the fatigue strength of prestressed concrete at sea, there is little recorded experience to date, simply because of the fact that large scale use of concrete at sea has only been a recent event. However, we have data for submerged concrete vessels, such as the "S. S. Selma", which show the concrete having essentially no damage after long submersion at sea and presumably under repetitive tidal load. Therefore, it can be expected that the fatigue strength of concrete should also be excellent at sea.

2.4.3.2 Construction. The method used so far in the North Sea, particularly Norway, in the construction of concrete platforms has been to build the lower portion of the platform in a shallow graving dock, then float it out to a deep wet dock for further construction and completion. Slipform is used extensively. This Norway method would be the simplest construction method, especially if graving dock and deep dock facilities are available. The situation in the Linited States is vastly different. There is hardly any sheltered water with sufficient depth for building concrete platform in the manner it was built in Nonvay. 
The technology gap here is primarily to find a way to construct the concrete platform with the facilities available in the United States, e.g., Puget Sound area. Tentatively, one might assume that facilities are available in the United States to provide a maximum floatout draft of $30 \mathrm{ft}$, and a maximum deep dock water depth of some $30 \mathrm{ft}$.

The tasks at hand would be (1) to make a survey of all available facilities around the U. S. for the establishment of the above construction constraints, and (2) to design the platform and hull configuration to satisfy these constraints. The Norway method would probably be the most economical construction method for the construction of a small number of sea structures. If the number of vessels to be built is large, it would overstrain available facilities and justify higher capital investment in plant, method, and equipment, to achieve better and more economical results. One strong possibility is the use of a construction cum launch barge. The sea structure is constructed on the barge which is tied up at some suitable point on the coast. When the structure is completed, the barge, with the structure on board, is towed to site by tugs, submerged by ballasting until it is detached from the self-floating structure, moved aside to clear the structure, refloated, and towed back to shore for re-use. The biggest advantage of the barge method is the freedom in the choice of a construction site, and of as many construction sites as required. It-will also simplify and speed up construction procedure with the one-step handling of the structure before actual placement, and with the construction of the structure entirely in the dry. Design by this method represents, however, a gap in SOA technology, and requires further work.

CWP Construction Several options are open, all of which represent to various degrees an advance on the SOA technology in constructing ofithore structures. The promising ones are as follows:

(1) Onshore Construetion and Launch Method. The CWP is constructed complete with ballasting arrangement on a gently sloping beach, possibly by prestressing together short precast segments. With both ends temporarily closed, the completed CWP is slowly rolled down the beach to float in the water. It is then towed to site, upended by ballasting, and moved into the center well position and secured. The 
end bulkheads and ballast compartments are removed, and the CWP is ready for . operation.

The serious problem areas associated with this method are:

(a) Positive control in launching and floating the CWP evenly along its length to avoid causing excessive transverse and longitudinal stresses

(W) Contrelling the towing of a 3, livن-tt-lupy vessel in opcn $c 00$, and ensuring that design conditions are not exceeded

(c) Upending and installing operations, which are ahead of the SOA.

For platforms without a direct access to the center well, the CWP will have to be given a negative buoyancy to bring it under the control uf barge cranes. It is then maneuvered beneath and across the vessel to the center well, raised to predetermined level to be locked into place. This method poses many problems. Two major ones are:

(a) A massive unit such as the CWP can be unmanageable at near equllibrium position dinring lowering. There are too many imponderables against this mietlod for it to be accepted with the same confidence as the next method described below. E.g., these include the change of water densities with depth due to different salinity, temperature, and silt content; the change of weight due to water jeuetration; and the behavior of the long CWP under subsurface currents in horizontal iuld vertieal directions. A small difference in the above factors can mean a weight change of hundreds of tons for a massive structure, and serious anxieties for the installation urew on the contrul biriges.

(b) The hitching of the CWP which is subjected to uncontrollable motion to the platform, which has its own uncontrollable motions. It will be exceedingly difficult to design a hitching arrangement with the necessary tolerances for these motions, which will also perform well during normal operation. 
(2) On-Site Assembiv Miethod. This method consists of building and transporting to the platform on site prefabricated segments of the CWP, which are as large as can be handled by the equipment used. The sections are picked up by heavy cranes on board the platform, placed in position over the completed section below, and joined to it by post-tensioned tendons. When jointing is completed, it is lowered into the water by jacks mounted around the center well to the position to receive the next segment. This method is considered closer to SOA than the previous method, although problems still abound if to a lesser degree.

(3) Variation of Onshore Construction and Launch Method. The long CWP may be made up in convenient lengths onshore, launched into water, and assembled afloat into the complete pipe by longitudinal prestressing. The joints may be made rigid by pressure grouting with underwater epoxy mortar, or given some flexibility by separating the segments at the joint with elastic materials, such as Neoprene.

This variation has the advantage of making up the CWP first in manageable lengths. This advantage may be more than offset by (a) the need to make every segment selffloating, and (b) the greatly magnified problem of matching and temporarily locking the segments together in water for longitudinal prestressing. Some of these difficulties could be reduced by assembling the segments progressively by adding one segment at a time to the pipe being assembled. It is nevertheless necessary to match one segment to the other by a positive matching device and securing the segments in the matched position long enough to enable stressing and grouting to be carried out.

\subsubsection{Conceptual Concrete Hull Designs and Cost. System drawings showing the} arrangement of power modules and piping configurations were furnished by the naval architects to $T$. Y. Lin International. Based upon this given information, the concrete designs were commenced. The proportioning of the concrete structures has been carried out by examining the critical sections within a given platform. 
The unit costs have been arrived at jointly by LMISC and T.Y. Lin International. Note that in the table of cost analysis, the cold water pipe has been singled out, not only because it is a constant element common to all the platforms, but also because its cost is quite substantial as compared to the hull proper; thus, it would obscure the various concrete hull costs if it were to be considered integrally. It should also be noted that the cost figures are based on the data of similar past constructions and adopting them to the $U$. S. working conditions. It has been assumed that the graving basin method will be used. The cost presently shown does not include towing, nor installation of the cold water pipe. The cost of each platform as estimated can be expected to vary $\pm 15 \%$. One of the main purposes of the present cost analysis is to provide data on the relative basis for comparison for each of the concrete hulls under consideration. 


\subsection{OPTIMUM PLANT SYSTEMI FOR NEW ORLEANS SITE}

The optimum OTEC commercial plant system for the conditions of the site located offshore New Orleans is presented in this section. This comparative assessment of several platform tvpes is based primarily on the specified, baseline power system which is internally mounted to the hull. To further narrow the breadth of the evaluation, the primary assessment is based upon horizontally mounted shell-and-tube heat exchangers. A later section (Section 3) presents a similar assessment for the other four potential sites. Section 4 examines the improvements that are available in the plant when advanced power or ocean system components are interjected into the definition of the plant.

The methodology applied to the process of evaluating the platforms is presented in Section 2.5.2.1. The cost base for the six platform types and two materials is developed and presented in the following sections. 


\subsubsection{Plant Costs}

This section presents a summary of the costs associated with constructing and deploying OTEC plants at the New Orleans site. Section 2.5.1.1 discusses cost estimates for plants of $100-\mathrm{MWW}(\mathrm{e})$ output using the baseline power system; Section 2.5.1.2 presents cost projections for $200-$ and $500-\mathrm{kWW}(\mathrm{e})$ plants; and Section 2.5.1.3 compares the cost of the LiISC baseline OTEC platform design with that of a $26.5-M W(e)$ versiun of the concrete spar with detachable power modules designed in the course of this study.

It should be stressed that the cost estimates presented in this section are intended to apply to commercial OTEC plants rather than to prototype units. Consequently, no estimates are presented for the cost of facilities dedicated to OTEC plant construction; rather, these facilitles are assumed to exist and to be available.

2.5.1.1 100-MWW(e) Plant Capital Costs. The capital costs of the ocean systems components of an OTEC power plant can be readily broken down into the following categories:

- Platform hull and structures

- Cold water pipe

- Seawater pumps and ducting

- Position control systems

- Auxiliary systems

- Outfit and furmishings

- Deployment and CWP assembly

The costs of steel-hulled platforms were estimated separately by the appropriate naval architect subcontractors, using the following common set of unit costs, expressed in cad $=1077$ dollars:

\begin{tabular}{|c|c|c|c|}
\hline Type of Structure & $S / 2[T$ & or & $3 / I T$ \\
\hline Hull & 3,100 & & $(3,1.50)$ \\
\hline Colums &, \pm 300 & & $(4,369)$ \\
\hline Superstructure & 2,500 & & $(2,6 \pm 2)$ \\
\hline
\end{tabular}


The specific costs listed above represent a consensus of the naval architects' recent experience, projected to end-1977 dollar values. They include allowances for contingency. home office and engineering, and contractor's fee. In the process of cost estimation, these unit costs were first applied to the various components of each platform. The resulting cost components were then multiplied by factors to account for the complexity of the construction procedures employed. These complexity factors are listed in the table below.

\section{COST FACTORS FOR CONSTRUCTION COMPLEXITY}

\begin{tabular}{|c|c|c|}
\hline Site of Construction & Approximate Drafts & $\begin{array}{c}\text { Construction Cost } \\
\text { Factor } \\
\end{array}$ \\
\hline Graving Dock & 0 to $6.7 \mathrm{~m}(22 \mathrm{ft})$ & 1.0 \\
\hline Shore Site (at Shipyard) & $6.7 \mathrm{~m}$ to $9-12 \mathrm{~m}$ (30 to $40 \mathrm{ft})$ & 1.25 \\
\hline Protected Shallow Water & $9 \mathrm{~m}$ to $25 \mathrm{~m}(80 \mathrm{ft})$ & 2 \\
\hline Unprotected Water & $25 \mathrm{~m}$ and greater & 3 \\
\hline
\end{tabular}

Finally, the naval architecture subcontractors also estimated the cost of the various auxiliary systems and platform outfitting. For the sake of comparability, LiISC has adjusted all estimates to put them on a common basis. These adjustments are as tollows:

- All concrete ballast costs have been re-estimated on the basis of a unit cost of $\$ 200 / \mathrm{m}^{3}\left(\$ 150 / \mathrm{yd}^{3}\right)$.

- Power system installation costs were excluded, as they are considered to be part of power system costs, rather than of platform costs.

- Estimates for auxiliary systems and outfitting of the circular barge, submersible, and tuned sphere configurations were re-estimated on the basis of the estimated cost for the ship, semisubmersible, and spar configuration.

The costs of all concrete-hulled platforms, as well as that of the concrete cold water pipe. were estimated by T.Y. Lin International. Based on previous experience of marine structures extrapolated to current $\tau$.S. Gulf and West Cost.conditions. the following unit costs were employed: 


\section{COSTS OF CONCRETE-HULLED PLATFORMS}

\begin{tabular}{l}
$\begin{array}{c}\text { Current U.S. Gulf } \\
\text { and West Coast }\end{array}$ \\
\hline
\end{tabular}

Hull

Columns

Superstructure

$\frac{\text { Ist Unit }}{\$ 980 / \mathrm{m}^{3}\left(\$ 750 / \mathrm{yd}^{3}\right)}$
$\$ 1361 / \mathrm{m}^{3}\left(\$ 1040 / \mathrm{yd}^{3}\right)$
$\$ 824 / \mathrm{m}^{3}\left(\$ 630 / \mathrm{yd}^{3}\right)$

Follow-on Units

$\$ 850 / \mathrm{m}^{3}\left(\$ 650 / \mathrm{yd}^{3}\right)$

$\$ 1177 / \mathrm{m}^{3}\left(\$ 900 / \mathrm{yd}^{3}\right)$

$\mathrm{s} 720 / \mathrm{m}^{3}\left(\$ 550 / \mathrm{yd}^{3}\right)$

All costs presented in this section are based on the second set of unit custs (follow-on units), since they are intended to represent the cost of commercial OTEC plants. It should be noted that concrete construction costs are expected to be 5 to 10 percent higher on the East Coast than on the Gulf or West Coasts.

LMISC has estimated separately the costs of the seawater and position control systems and of platform deployment and cold water pipe installation. A nominal baseline cold water pipe cost is used here. Detailed discussions of these cost items can be found in Sections 2.3 and 2.3 .4 of this report.

The total costs of all configurations for a $100-\mathrm{HWW}(\mathrm{e})$ net output of the baseline power system are summarized for comparison in Tables 2-81 through 2-37; Table 2-38 presents those costs in terms of dollars per kilowatt net output. It will be noted that the cost of all platform configurations is significantly smaller for concreie than for steel designs. In addition, the relative cost ranking of the various configurations is altered by changing the construction materials. The ship is by far the lowest cost steel platforms, followed by the Tuned Sphere and the spar with detachable modules, while the barge and submersible are the lowest cost concrete configurations. Three concrete platiorms - ship, barge, and submersible - fall in relatively narrow cost range between 185 and 200 million dollars; the remaining three configurations are 10 to 20 percent more costly. These comparisons apply for the baseline power at $100-$ $\mathrm{M} \Pi \mathrm{W}$ (e) net output. Reductions in these platform costs are projected to be obtained by careful integration with the power system alternatives, by refinement of the requirements on the platform, and by further optimization of seavater system components, specifically the CWP and the seawater pumps. Sections 2.6 and $\frac{1}{-}$ discuss in detail these reductions in platform costs. 
Tiable 2-81

100-MW(c) O'TLC PLA'PFORM CAPITAL, COST'S (\$M)

SHIP PLATFORM

\begin{tabular}{|l|c|c|}
\hline \multirow{2}{*}{ SUBSYSTEM } & \multicolumn{2}{|c|}{ HULL MATERIAL } \\
\cline { 2 - 3 } & STEEL & CONCRETE \\
\hline HULL \& STRUCTURE & 125.4 & 55.2 \\
\hline COLD WATER PIPE & 20.7 & 20.7 \\
\hline SEAW'ATER PUMPS \& DUCTING & 28.0 & 28.0 \\
\hline POSITION CONTROL SYSTEMS & 27.5 & 27.5 \\
\hline AUXILIARY SYSTEMS & 30.2 & 22.8 \\
\hline OUTFIT \& FURNISHINGS & 11.1 & 11.1 \\
\hline DEPLOYMENT \& CWP & 28.9 & 28.9 \\
\hline ASSEMBLYIINSTALIATION & 271.8 & 194.2 \\
\hline TOTAL & & \\
\hline
\end{tabular}


Table 2-81

100-MW(e) O'TLC PLATFORM CAPITAL COSTS (\$M)

CIRCULAR EARGE PLATFORM

\begin{tabular}{|l|c|c|}
\hline \multirow{2}{*}{ SUBSYSTEM } & \multicolumn{2}{c|}{ HULL MATERIAL } \\
\cline { 2 - 4 } & STEEL & CONCRETE \\
\hline HULL \& STRUCTURE & 206.1 & 43.2 \\
\hline COLD WATER PIPE & 20.6 & 20.6 \\
\hline SEAWATER PUMPS \& DUCTING & 28.0 & 28.0 \\
\hline POSITION CONTROL SYSTEMS & 32.9 & 32.9 \\
\hline AUXILIARY SYSTEMS & 27.7 & 21.2 \\
\hline OUTFIT \& FURNISHINGS & 11.1 & 11.1 \\
\hline DEPLOYMMENT \& CWP & 28.9 & 28.9 \\
\hline ASSEMBLYYIINSTALLATION & & 185.9 \\
\hline TOTAL & 355.3 & \\
\hline
\end{tabular}


100-MW(c) O'TEC PLATFORM CAPITAL COSTS $(\$ M)$

SEMISUBMERSIBIE PLATFORM

\begin{tabular}{|l|c|c|}
\hline \multirow{2}{*}{ SUBSYSTEM } & \multicolumn{2}{c|}{ HULL MATERIAL } \\
\cline { 2 - 3 } & STEEL & CONCRETE \\
\hline HULL \& STRUCTURE & 216.4 & 74.0 \\
\hline COLD WATER PIPE & 19.8 & 19.8 \\
\hline SEAWATER PUMPS \& DUCTING & 28.0 & 28.0 \\
\hline POSITION CONTROL SYSTEMS & 38.4 & 38.4 \\
\hline AUXILIARY SYSTEMS & 37.6 & 27.7 \\
\hline OUTFIT \& FURNISHINGS & 15.6 & 15.6 \\
\hline $\begin{array}{l}\text { DEPLOYMENT \& CWP } \\
\text { ASSEMBLYIINSTALLATION }\end{array}$ & 29.0 & 29.0 \\
\hline TOTAL & 384.8 & 232.5 \\
\hline
\end{tabular}


Talble $2-84$

101-MW(c) OTEC PLATFOIRM CAPITAL COSTS (\$M)

SPHERE PLATFORM

\begin{tabular}{|l|c|c|}
\hline \multirow{2}{*}{ SUBSYSTEM } & \multicolumn{2}{|c|}{ HULL MATERIAL } \\
\cline { 2 - 3 } & STEEL & CONCRETE \\
\hline HULL \& STRUCTURE & 155.1 & 76.9 \\
\hline COLD WATER PIPE & 19.7 & 19.7 \\
\hline SEAWATER PUMPS \& DUCTING & 28.0 & 28.0 \\
\hline POSITION CONTROL SYSTEMS & 33.3 & 33.3 \\
\hline AUXILIARY SYSTEMS & 29.2 & 22.8 \\
\hline OUTFIT \& FURNISHIINGS & 15.7 & 15.7 \\
\hline DEPLOYMENT \& CWP & 29.0 & 29.0 \\
\hline ASSEMBLYIINSTALLATION & 310.0 & 225.4 \\
\hline TOTAL & & \\
\hline
\end{tabular}


Tiable 2-85

100-MW(e) O'TEC PLATPORM CAPITAL, COSTS (\$M)

SUBMERSIBIE PLATFORM

\begin{tabular}{|l|c|c|}
\hline \multirow{2}{*}{\multicolumn{1}{c|}{ SUBSYSTEM }} & \multicolumn{2}{c|}{ HULL MATERIAL } \\
\cline { 2 - 3 } & STEEL & CONCRETE \\
\hline HULL \& STRUCTURE & 242.8 & 56.7 \\
\hline COLD WATER PIPE & 19.8 & 19.8 \\
\hline SEAWATER PUMPS \& DUCTING & 28.0 & 28.0 \\
\hline POSITION CONTROL SYSTEMS & 17.5 & 17.5 \\
\hline AUXILIARY SYSTEMS & 34.2 & 24.7 \\
\hline OUTFIT \& FURNISHINGS & 15.7 & 15.7 \\
\hline DEPLOYMENT \& CWP & 29.0 & 29.0 \\
\hline ASSEMBLYINSTALLATION & 387.0 & 191.4 \\
\hline TOTAL & &
\end{tabular}


Table 2-86

100-MW(e) OTEC PLATEORM CAPITAL COSTS (\$M)

SPAR PLATFORM: INTERNAL POWER MODUIES

\begin{tabular}{|l|c|c|}
\hline \multirow{2}{*}{ SUBSYSTEM } & \multicolumn{2}{c|}{ HULL MATERIAL } \\
\cline { 2 - 3 } & STEEL : & CONCRETE \\
\hline HULL \& STRUCTURE & 304.3 & 100.2 \\
\hline COLD WATER PIPE & 18.3 & 18.3 \\
\hline SEAWATER PUMPS \& DUCTING & 28.0 & 28.0 \\
\hline POSITION CONIROL SYSTEMS & 22.5 & 22.5 \\
\hline AUXILIARY SYSTEMS & 33.2 & 22.7 \\
\hline OUTFIT \& FURNISHINGS & 17.0 & 17.6 \\
\hline DEPLOYMENT \& CWIP & 29.1 & 29.1 \\
\hline ASSEMBLYIINSTALLATION & 453.0 & 238.4 \\
\hline TOTAL & & \\
\hline
\end{tabular}


Table $2-87$

100-MW(c) OTEC PLATFORM CAPITAL COSTS (\$M)

SPAR PLATFORMS: DETACHABLE POWER MODULES

\begin{tabular}{|l|c|c|}
\hline \multirow{2}{*}{ SUBSYSTEM } & \multicolumn{2}{c|}{ HULL MATERIAL } \\
\cline { 2 - 3 } & STEEL & CONCRETE \\
\hline HULL \& STRUCTURE & 167.0 & -77.4 \\
\hline COLD WATER PIPE & 18.3 & 18.3 \\
\hline SEAWATER PUMPS \& DUCTING & 28.0 & 28.0 \\
\hline POSITION CONTROL SYSTEMS & 22.5 & 22.5 \\
\hline AUXILIARY SYSTEMS & 33.2 & 22.7 \\
\hline OUTFIT \& FURNISHINGS & 17.6 & 17.6 \\
\hline $\begin{array}{l}\text { DEPOLYMENT \& } \\
\text { CWP ASSEMBLY I INSTALLATION }\end{array}$ & 29.1 & 29.1 \\
\hline & 315.7 & 215.6 \\
\hline
\end{tabular}


Table $2-88$

100-MW(e) OTEC PLATFORM CAPITAL COST SUMMARY [\$/KW(e)]

\begin{tabular}{|l|c|c|}
\hline \multirow{2}{*}{ CONFIGURATION } & \multicolumn{2}{|c|}{ HULL MATERIAL } \\
\cline { 2 - 3 } SHIP & STEEL & CONCRETE \\
BARGE & 2718 & 1942 \\
SEMISUBMERS IBLE & 3553 & 1859 \\
TUNED SPHERE & 3848 & 2325 \\
SUBMERSIBLE & 3100 & 2254 \\
SPAR & 3870 & 1914 \\
- INTERNAL POWER MODULES & 4530 & 2384 \\
- DETACHABLE POWER MODULES & 3157 & 2156 \\
\hline
\end{tabular}


2.5.1.2 200-and 500-irWV(e) Plant Capital Costs. L:MSC has projected the cost of building 200- and 500-iNW(e) OTEC plants of the six basic configurations discussed in this report. These costs, expressed in dollars per hilowatt of net output, are listed in Tables 2-89 and 2-90, respectively. Comparing these unit costs with those given in Table 2-88 for 100-MW(e) plants, it is apparent that OTEC platforms are subject to significant economies of scale. As plant output is increased by a factor of five, the unit cost of steel platforms decreases by approximately one quarter, and that of concrete platforms by roughly one third. It should be stressed here that the costs of platforms larger than 100-iVW(e) were estimated on the assumption of power system space requirements increasing linearly with net output. While this is correct if 25-MW (e) power modules are the largest available, it would appear that platforms designed to accommodate large individual power units might realize greater economies of scale than indicated in this study, as a result of increased packing efficiency.

LMISC believes the comparative costs presented in this section for the baseline power system can be reduced significantly through further integration, particularly with the power system. 
Table $2-89$

200-MW(e) OTEC PLATFORM CAPITAL COST SUMTMARY [\$/KW(e)]

\begin{tabular}{|l|c|c|}
\hline \multirow{2}{*}{ CONFIGURATION } & \multicolumn{2}{|c|}{ HULL MIATERIAL } \\
\cline { 2 - 3 } SHIP & STEEL & CONGRETE \\
BARGE & 2386 & 1666 \\
SEMISUBMERSIBLE & 3204 & 1532 \\
TUNED S PHERE & 3472 & 1957 \\
SUBMERSIBLE & & 1882 \\
SPAR & 2778 & \\
- INTERNAL POWER MODULES & 3912 & 2045 \\
- DETACHABLE POWER MODULES & 2655 & 1816 \\
\hline
\end{tabular}


Table 2-90

500-NIW(e) OTEC PLATFORMI CAPITAL COST SUMIMARY [S/KW(e)]

\begin{tabular}{|l|c|c|}
\hline & \multicolumn{2}{|c|}{ HULL MATERIAL } \\
CONFIGURATION & STEEL & CONCRETE \\
\hline SHIP & 2108 & 1405 \\
\hline BARGE & 2916 & 1287 \\
\hline SEMISUBMERSIBLE & 3136 & 1643 \\
\hline TUNED SPHERE & 2452 & 1574 \\
\hline SUBMERSIBLE & 3250 & 1322 \\
\hline $\begin{array}{l}\text { SPAR } \\
- \text { INTERNAL POWER MODULES } \\
- \text { DETACHABLE POWER MODULES }\end{array}$ & 3639 & 1801 \\
\hline
\end{tabular}




\subsubsection{Comparison Between LiMSC Baseline and Concrete Spar With Detachable}

Power Modules. The cost estimates presented in this report are substantially in excess of LMISC's expectations on the basis of earlier studies. To determine the cause of these discrepancies, the costs of LiISC's updated 265-MWW (e) baseline configuration (OTEC Test Facilities Study Program, SAN/1156-77/1) have been compared with those of the concrete spar configuration with detachable power modules developed under this contract. To this effect, the costs of a $265-\mathrm{i} / \mathrm{IW}(\mathrm{e})$ concrete spar with detachable modules were estimated, on the assumption of a cold water pipe length of $600 \mathrm{~m}$, roughly the same length of cold water pipe used in LișC's bașeline configuration. The dimensions and weights of power system components supplied by DOE were retained for the current spar configuration, although they are significantly different from those in LiISC's baseline design. It should be emphasized at the outset that the comparison that follows is less than fully valid, because the current configuration is at a preconceptual stage of development. Because the current configuration has neither been optimized nor fully integrated with a power system developed in conjunction with it, it is reasonable to expect that its costs would exceed in any case those of the LMSC baseline, which has benefited from such an iterative design optimization process in conjunction with the power system it houses.

Table 2-91 compares the various cost elements of the two platform designs. The estimate for the current design is roughly 50 percent higher than that for L:VLSC's baseline configuration. Wore than half of this difference is due to differences in hull structure costs, which in turn reflect differing material weights, as the same material unit costs have been used in developing both estimates. At least to some extent the greater material requirements of the current configuration appear to reflect the greater relative size of power system components used in this study.

The discrepancy in cold water pipe costs is due to its wall thichness being greater in the current study than in the original LiISC work (Ocean Thermal Energy Conversion (OTEC) Power Plant Technical and Economic Feasibility, :SSF/RANN/SE/GI-C937; $F R / 75 / 1)$. The cost of seawater systems is more than twice as high in the current configuration as reported earlier by LIISC. Economies of scale are believed to account 
Table 2-91

COMPARISON OF 265-MW(e) PLATFORM COSTS - \$M

\begin{tabular}{|c|c|c|}
\hline Component & $\begin{array}{l}\text { IMISC Baseline } \\
\text { Spar } \\
\text { 265-MW(e) (Net) }\end{array}$ & $\begin{array}{l}\text { OPCI Concrete } \\
\text { Spar } \\
\text { 265-MW(e) (Net) }\end{array}$ \\
\hline Hull and Structure & 103.3 & 198.8 \\
\hline Cold Water Pipe & 21.1 & 37.0 \\
\hline Seawater Pumps and Ducting & 29.8 & 66.3 \\
\hline Position Control Systems & 44.3 & 36.0 \\
\hline $\begin{array}{l}\text { Auxiliary Systems } \\
\text { Outflt and Furnishings }\end{array}$ & 31.7 & 46.5 \\
\hline $\begin{array}{l}\text { Deployment and CWP Assembly/ } \\
\text { Installation }\end{array}$ & 6.2 & 30.3 \\
\hline TOTAL & 236.4 & 414.9 \\
\hline
\end{tabular}


for a large fraction of the difference in pump costs. The seawater pumps contemplated in the LiVSC baseline are roughly three times larger than those used in this study. According to information presented in "Deep Water Pipe, Pump, and Mooring Study; Ocean Thermal Energy Conversion Program" (C00-2642-3), this should reduce their cost by roughly 50 percent. .

Cost estimates for position control systems appear to be in reasonably good agreement for both platforms. The discrepancy in the costs given for auxiliary systems and outfit and furnishings, however, is quite significant, and may be due to an underestimate of these costs in the early Lockheed studies. Finally, the enormous increase in deployment costs is almost entirely due to the method adopted for at-sea cold water pipe installation. It will be remembered that LiVSC's baseline telescopic cold water pipe was to be built inside the platform hull in a nested position; deployment would then involve no more than simple extension of the telescopic pipe. Unfortunately, adoption of a much longer pipe in the present study dictated the abandonment of this simple deployment concept; deployment is now assumed to take place as discussed in Section 2.3.3.1. Of course, further study will almost certainly result in an improved deployment procedure.

The last point discussed above highlights an important caveat to the cost estimates presented in this report. They represent the costs associated with first-order solutions to design requirements. As such, they are likely to overestimate the costs assoclated with final solutions, which will benefit from continuous design optimization and closer integration with power system component design concepts. 


\section{2. j. 2 System Optimization}

The process utilized in deriving the most satisfactory plant system for the New Orleans site is an adaptation of the Kepner-Tregoe Associates (KTA) procedure for decision analysis. This process is described and defined for this application in the next section.

2.5.2.1 Methodology of Evaluation Process. The evaluation of the most satisfactory configurations of the platform for the OTEC Commercial Plant will be based upon the data as described in the preceeding section and the evaluation criteria which are described in this section. The actual evaluation will utilize the Kepner-Tregoe Associates procedure for decision analysis. The procedure involves the following:

1. Formulation of an objective decision statement.

2. Preparation of a set of objectives which MUST be satisfied and all other objectives (which are termed WANTS since they are desirable but are not mandatory).

3. Establishment of weighting factors reflecting the relative importance of the wants.

4. Evaluation of comparative performance of the six configurations for each WANT.

j. Assessment of possible adverse consequences.

6. Comparison of total evaluation of WANTS with possible adverse consequences.

The objectives and criteria formulated for the New Orleans site are presented in the subsequent pages.

MUST 1 (Neet all general platform requirements) requires that the primary OTEC design and performance requirements be applied for all platform configurations that are being evaluated. The specific requirements, which vary among the several mission/site combinations, are presented as the $\lambda \Pi$ STS on the Decision Analysis Worksheets. 


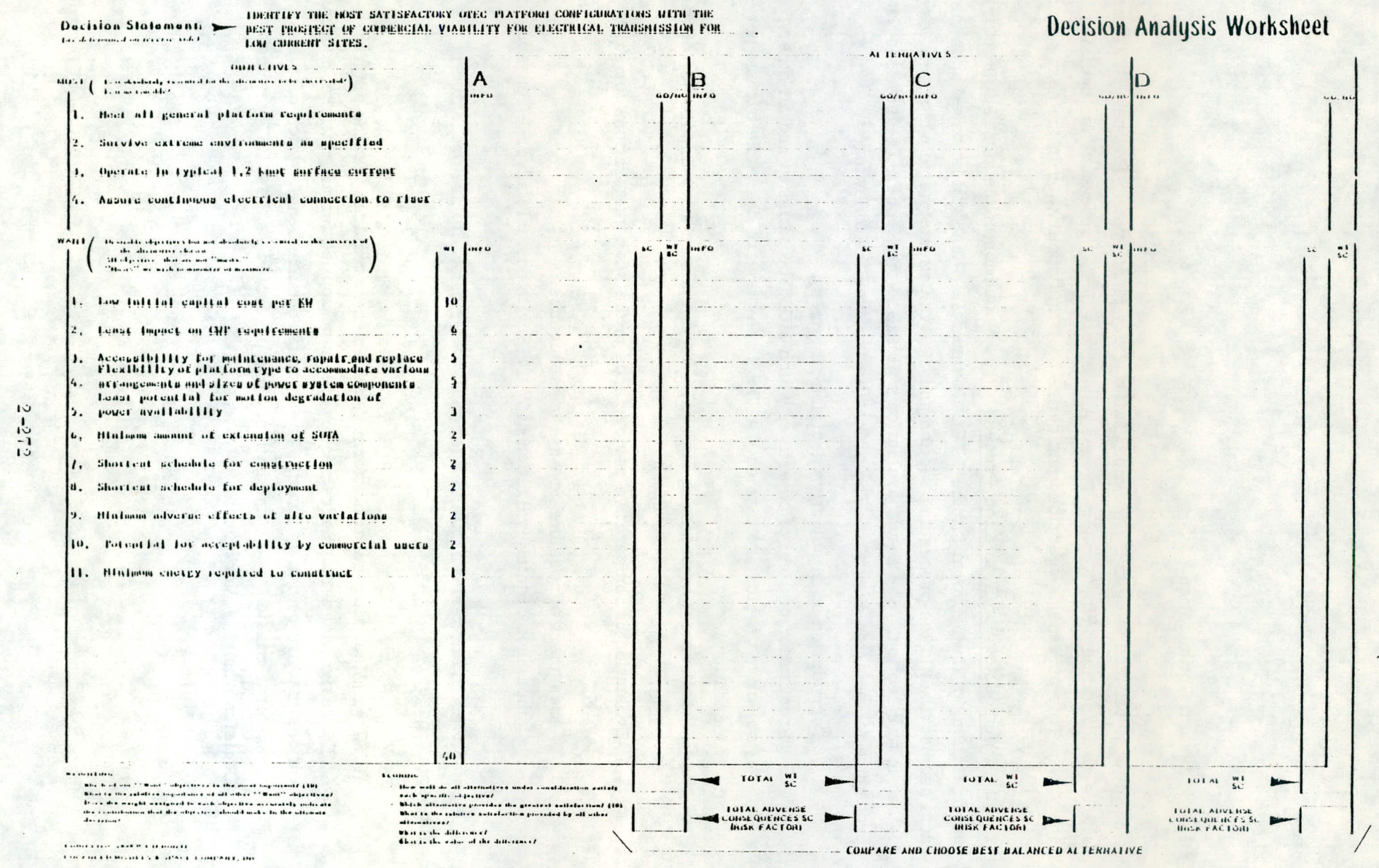


MIUST $\# 2$ (Survive extreme environments as specified) deals with the ability of a candidate to survive the extreme environment specified in the environmental description. Obviously, a platform that will not meet the envelope of conditions experienced at the various specified sites is not acceptable. All the platform candidates will be designed to survive hurricane conditions.

VIUST $\# 3$ (Operate in 1.2 (or 4.7) knot surface current) requires the platform candidates to be optimized for operation at specific current conditions.

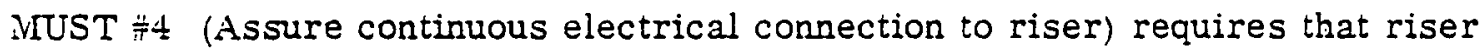
for the electrical transmission mission remain connected, even during the 100year storm. This requirement does not apply during planned maintenance, repair, or replacement operations of the electrical riser system.

All platform configurations will be designed to satisfy these specific MUSTS and the general OTEC system requirements. The resulting platforms will have properties, performance, and costs for which the desired objectives are the WANTS as shown on the Decision Analysis worksheets. These wants consider key parameters of commercial viability, development risk, acceptability, flexibility; convenience, and the energy cost of the platform in this order of importance.

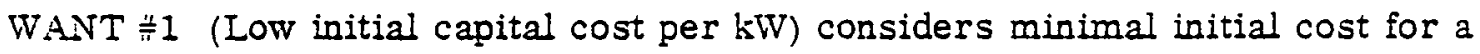
given power output. The material, construction, and deployment costs are included. CWP costs are estimated for each configuration.

WAVT $\nRightarrow 2$ (Least impact on CWP requirements) recognizes that the CWP is the major technical challenge for platform development. The less stringent the requirements that are imposed on the CWP, the lower will be the cost, schedule, deployment, and risks.

WAVT $\div 3$ (Accessibility for maintenance and repair) returns to the problem of platform internal geometry, in considering the ease with which on-site maintenance can be performed. A design with relatively unreachable external or submerged components will receire a smali penalty. 


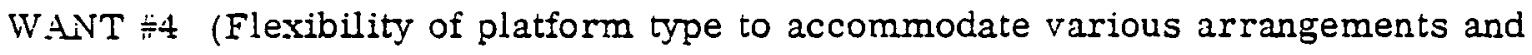
sizes of power system components) addresses the fact that this is a developing technology and that the precise power plants to be potentially incorporated can not now be fully determined. Future evolutionary developments may require various arrangements. This WANT will penalize candidates with relatively inflexible internal geometry or poor arrangements for external modules.

WAVT $\# 5$ (Least potential for motion degradation of power availability) favors the design that is least susceptible to sea motions which impair output of the power system. This accounts for maximum optimization of power systems which results from reduced motion characteristics.

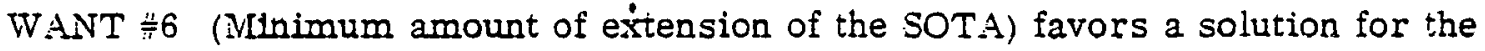
commercial plant which has minimum technical risk. Advances that are essential to commercial viability will be critically judged by this WANT as compared with platform reliability and costs.

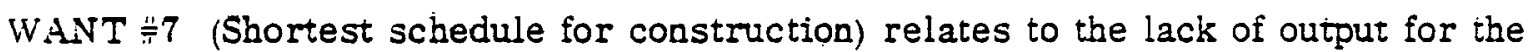
commercial plant during the construction period. In addition, the larger a construction span the more likely are further delays and/or changes in the economic situation, which are forms of program risk.

WANT $\# 8$ (Shortest schedule for deployment) relates to the same factors as in WANT $\div 7$ and to the additional concern that extended period of on-site worl will cause greater risks for unplanned delays resulting from weather intermptinns.

WAVT \#9 (MInimum adverse effects of site variations) is concerned with the potential for universality of the chosen platform candidate. Both in design and construction, it is cost-effective to have a platform which requires little or no tailoring or new development to meet the conditions of a specific site. 
WANT $\stackrel{\sim}{\approx} 10$. (Potential acceptability of configuration by commercial users) considers all the platform characteristics that affect the scaling to a commercially acceptable solution as well as the subjective judgments against innovation. The comments of potential commercial operators will be solicited in this conpection.

WAVT $=11$ (Vinimum energy required to construct) it is obviously desirable to make this net energy as large as possible in the platform for the commercial plant.

Many of these factors have already considered elements of potential risk and have costed/scheduled/planned alternatives to reasonable engineering practice. As an overall assessment of risk the possible adverse consequences for each configuration will be developed and qualified using the checklist presented below. The schedule, technical, and performance risks have been evaluated by this process.

\section{Checklist of Possible Adverse Consequences}

- Platform motions have potential to significantly reduce output

- Platform motions incapacitate personnel

- Complexity of platform/CWP interface

- Configuration implies risk to personnel

- Construction schedule longer than planned

- Initial costs greater than planned

- Technology advances lagging requirements

2. 5. 2.2 Evaluation of Comparative Performance. Each desirable objective (WANT) for the OTEC commercial plant has been evaluated comparatively among the six types of platforms and the detachable module for the spar. The following tables present all the data and considerations that have been used in the comparative evaluation process. This comparison is based on $100 \mathrm{MTV}$ (e) net output plants. Subsequent evaluations deal with other plant outputs and potential advances in the technology. 


\section{DECISION ANALYSIS METHODOLOGY}

- EACH PLAIFORM HUST (AND DCES):

- MEET AI.L GeNERAL PLATfORM REQUIREMENTS

- SURVIVE SPECIFIED EXTREME ENVIRONMENTS

- operATE IN SPECIFIED CURRENIS

- assure continnuOUS electrical conNection

- PLAIfORM SELECIION BASED ON DIFFERENCES IN ACHIEVING WANTS:

- LOW CAPITAL COSI

- LOW IMPACT ON CWP REQUIREMENIS

- ACCEsSIBILITr

- FLEXIGILITY

- LOW MOTIONS

- minimiUM teChinical adVA.NCE

- SHORTESI SCHEDULE FOR CONSTRUCTION

- SHORTEST SCHIEDULLE FOR DEF̈IOYMENT

- LOW SITE SENSIIIVITY

- ACCEPPJAEILITY FOR COMMEP.CIAL USE

- MINIMUM COHSTIUUCTION ENERGY USE

\begin{tabular}{lc}
\multicolumn{1}{c}{ FACTOR } & WEIGHT \\
\cline { 2 - 2 } COST & 10 \\
IECHNICAL FEASIBILITY & 6 \\
OPERABILIIY & 5 \\
OPERABILITY & 5 \\
OPERABILITY & 3 \\
IECHNICAL FEASIBILITY & 2 \\
SCHEDULE & 2 \\
SCHEDUIE/RISK & 2 \\
COST . & 2 \\
IECHNIICAL FEASIBILITY & 2 \\
TECHNICAL FEASIBILITY & 1
\end{tabular}




\section{LOW CAPITAL COST PER KW(e)}

\begin{tabular}{|c|c|c|c|c|c|c|c|c|c|}
\hline & & \multicolumn{4}{|c|}{ STEEL } & \multicolumn{4}{|c|}{ CONCRETE } \\
\hline & & $\$ / K W(e)$ & $\$ / \$$ LOW & RANK & SCORE & $\$ / K W(e)$ & $\$ / \$$ LOW & RANK & SCORE \\
\hline \multicolumn{2}{|l|}{ SHIP } & 2,981 LOW & 1.000 & 1 & 10 & 2,205 & 1.088 & 4 & 9 \\
\hline \multicolumn{2}{|c|}{ BARGE } & 3,720 & 1.248 & 4 & 8 & 2,026 LOW & 1.000 & 1 & 10 \\
\hline \multicolumn{2}{|l|}{ SEMI } & $3,9.56$ & 1.330 & 5 & 8 & 2,443 & 1.206 & 6 & 8 \\
\hline \multicolumn{2}{|c|}{ TUNED SPHERE } & 3,295 & 1.105 & 3 & 9 & 2,449 & 1.209 & 7 & 8 \\
\hline \multicolumn{2}{|l|}{ SUB } & 4,040 & 1.355 & 6 & 7 & 2,084 & 1.028 & 2 & 10 \\
\hline \multirow{2}{*}{ SPAR } & INTERNAL & 4,543 & 1.523 & 7 & 5 & 2,397 & 1.183 & 5 & 8 \\
\hline & I DETACHED & 3,170 & 1.063 & 2 & 9 & 2,169 & 1.071 & 3 & 9 \\
\hline
\end{tabular}


LOW CAPITAL COST PER KW(e)
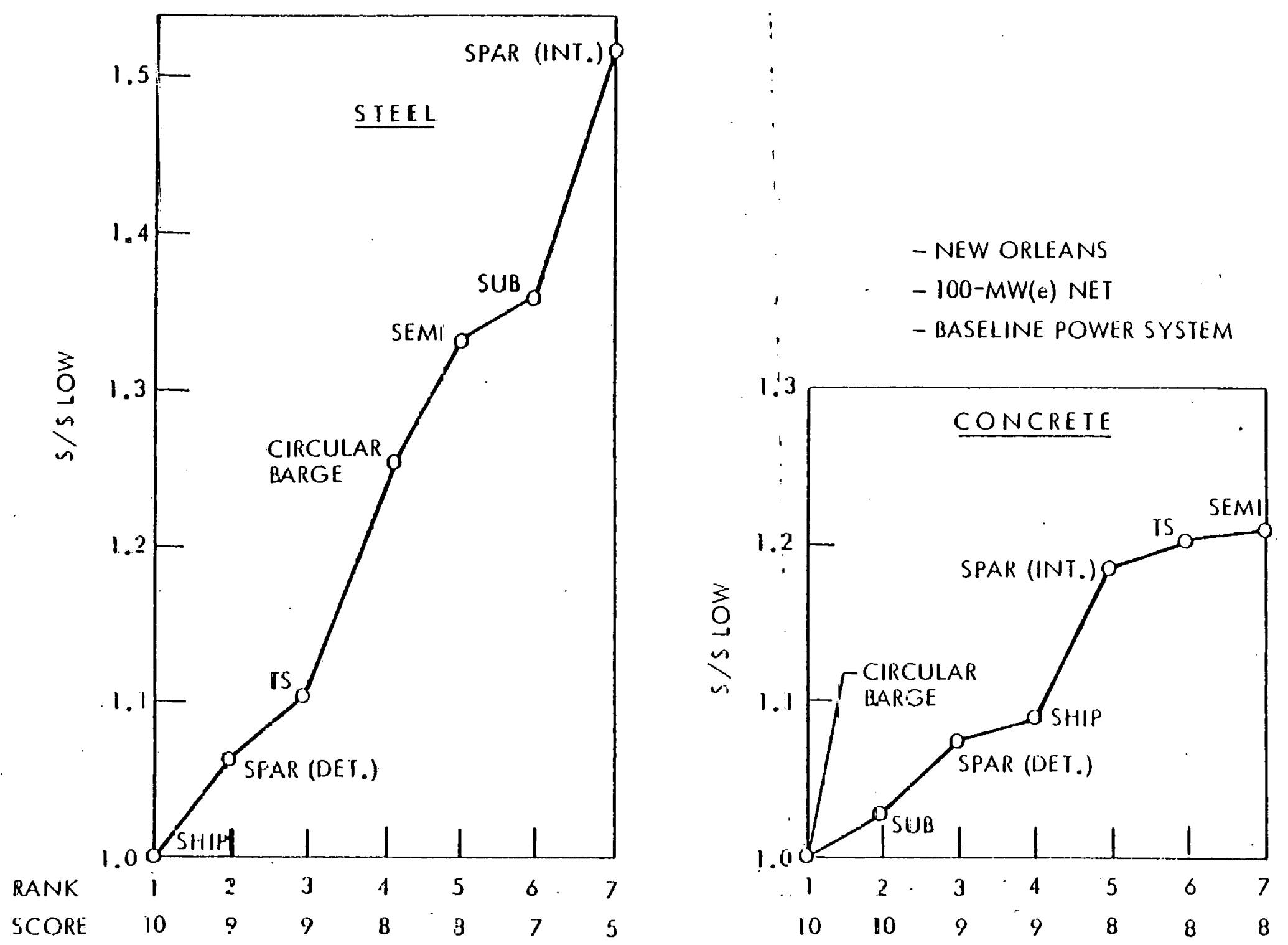


\section{LEAST IMPACT ON CWP REQUIREMENTS}

\begin{tabular}{|l|l|l|l|l|}
\hline \multicolumn{1}{|l|}{} & $\begin{array}{c}\text { MAX. SIGNIFICANT AMP - } \\
\text { LITUDE OF DYNAMIC BENDING } \\
\text { MOMENT IN HURRICANE IB-FT }\end{array}$ & $\frac{B M}{B M}$ & RANKING & SCORE \\
\hline SHIP & $1.21 \times 10^{\circ}$ & 2.327 & 7 & 4 \\
CIRCULAR & 0.96 & 1.846 & 5 & 5 \\
BARGE & 0.81 & 1.558 & 3 & 6 \\
SEMI & 1.01 & 1.942 & 6 & 5 \\
TUNED SPHERE & 0.95 & 1.827 & 4 & 5 \\
SUB & $0.52^{\circ} \mathrm{LOW}$ & 1.000 & 2 & 10 \\
SPAR - INT. & $0.52^{\circ} \mathrm{LOW}$ & 1.000 & 1 & 10 \\
\hline
\end{tabular}

HIGH ATTACHMENT POINT

$$
\text { SCORE }=\frac{\frac{10}{\frac{B M}{B M}}}{\text { LOW }}
$$




\section{LEAST IMPACT ON CWP REQUIREMENTS}

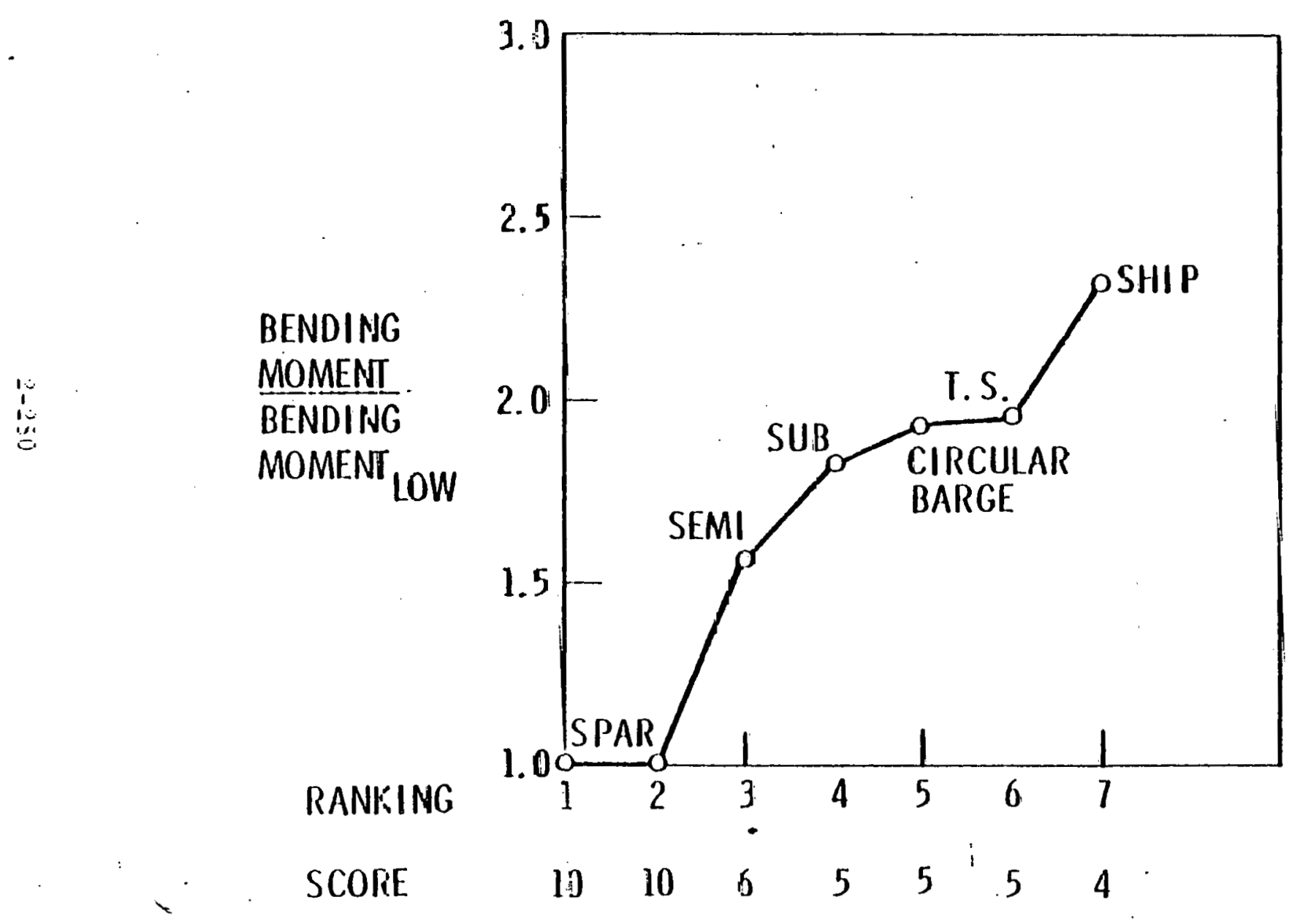




\section{ACCESSIBILITY FOR MAINTENANCE, REPAIR, AND REPLACEMENT}

\begin{tabular}{|c|c|c|c|c|c|c|}
\hline & $\begin{array}{c}\text { SPACE } \\
\text { AROUND } \\
\text { P.S. }\end{array}$ & $\begin{array}{l}\text { HEAT } \\
\text { EXCHANGER } \\
\text { IIFT ACCESS }\end{array}$ & $\begin{array}{l}\text { IMPACT ON } \\
\text { OPERATIONS }\end{array}$ & SUM & RANK & SCORE \\
\hline SHIP & 1 & + & + & $3+$ & 1 & 10 \\
\hline $\begin{array}{l}\text { CIRCULAR } \\
\text { BARGE }\end{array}$ & + & + & + & $3+$ & 1 & 10 \\
\hline SEMI & + & - & - & -1 & 3 & 3 \\
\hline TUNED SPHIERE & + & - & 0 & 0 & 2 & 5 \\
\hline SUB & 0 & - & - & -2 & 4 & 1 \\
\hline SPAR - INI. & + & - & - & -1 & 3 & 3 \\
\hline- DET. & - & 0 & + & 0 & 2 & 5 \\
\hline
\end{tabular}

SPACE AROUND POWER SYSTEM
$1=\mathrm{GOOD}$
$0=$ ADEQLATE
$-\quad=$ POOR

HEAT EXCHANGER

LIFT ACCESS

$$
\begin{aligned}
& +=\text { DIRECT } \\
& 0=\text { CONVENIENT } \\
& -=\text { COMPLEX }
\end{aligned}
$$

IMPACT ON OPERATIONS DURING HEAT EXCHANGER REMOVAL

$+=$ CONTINUE AT FULL CAPACITY

$0=$ CURTAILED OUTPUT

- = SUSPENDED OPERATIONS 


\section{ACCESSIBILITY FOR MAINTENANCE, REPAIR, AND REPLACEMENT}

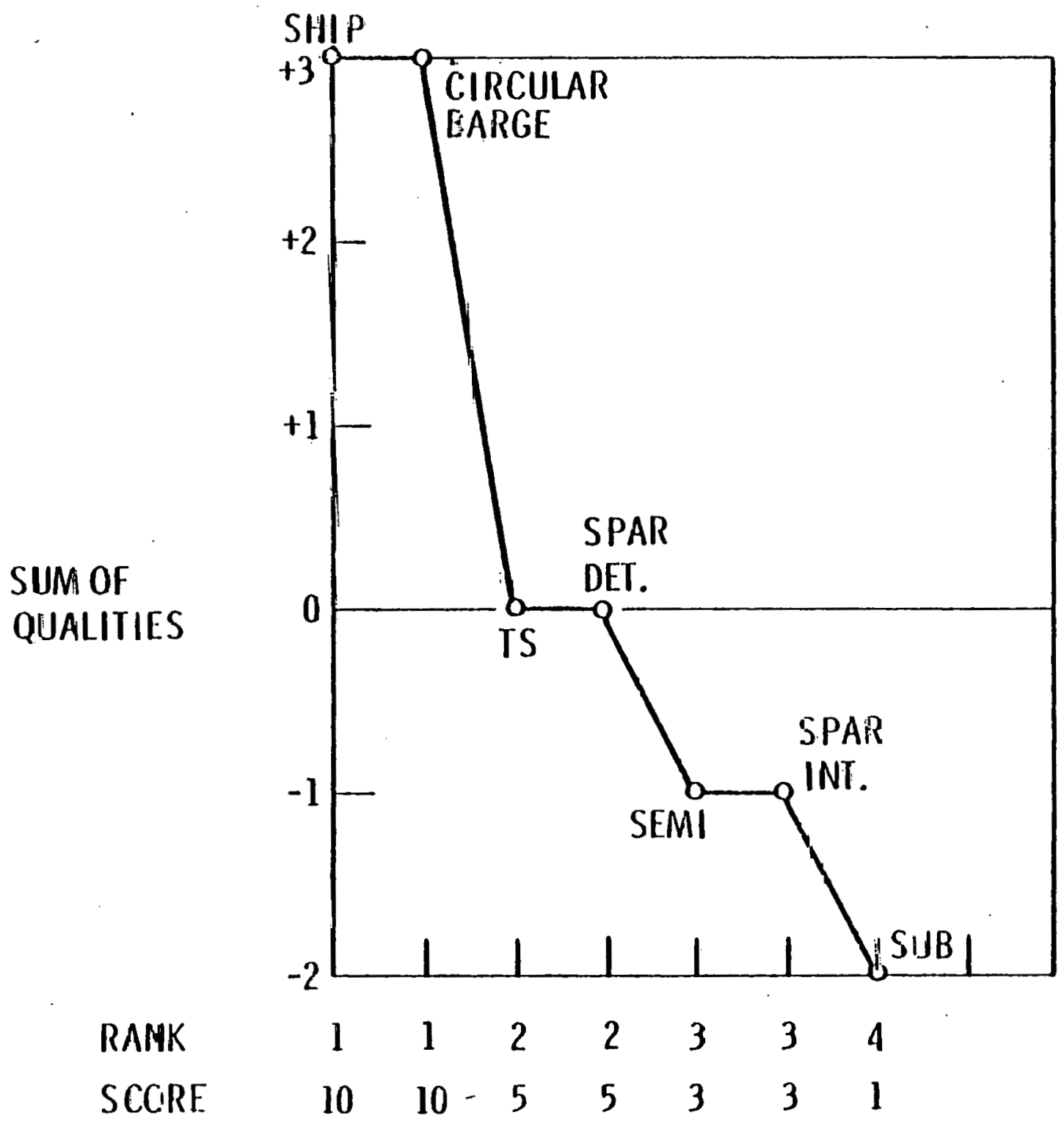


FLEXIBILITY FOR ARRANGEMENTS OF POWER SYSTEM

\begin{tabular}{|c|c|c|c|c|c|c|c|}
\hline & & $\begin{array}{c}\text { HORIZONTAL } \\
\text { \& VERTICAL HX }\end{array}$ & $\begin{array}{l}\text { LARGER } \\
\text { HX }\end{array}$ & $\begin{array}{c}\text { SMALLER } \\
H X\end{array}$ & SUM & RANK & SCORE \\
\hline & SHIP & - & + & + & +1 & 3 & 4 \\
\hline & $\begin{array}{l}\text { CIRCULAR } \\
\text { BARGE }\end{array}$ & - & + & + & +1 & 3 & 4 \\
\hline & SEMI & 0 & 0 & + & +1 & 3 & 4 \\
\hline & TUNED SPHERE & + & 0 & + & +2 & 2 & 7 \\
\hline & SUB & 0 & 0 & + & +1 & 3 & 4 \\
\hline & SPAR - INT. & + & + & + & +3 & l & 10 \\
\hline & DET. & + & $t$ & + & +3 & 1 & 10 \\
\hline
\end{tabular}




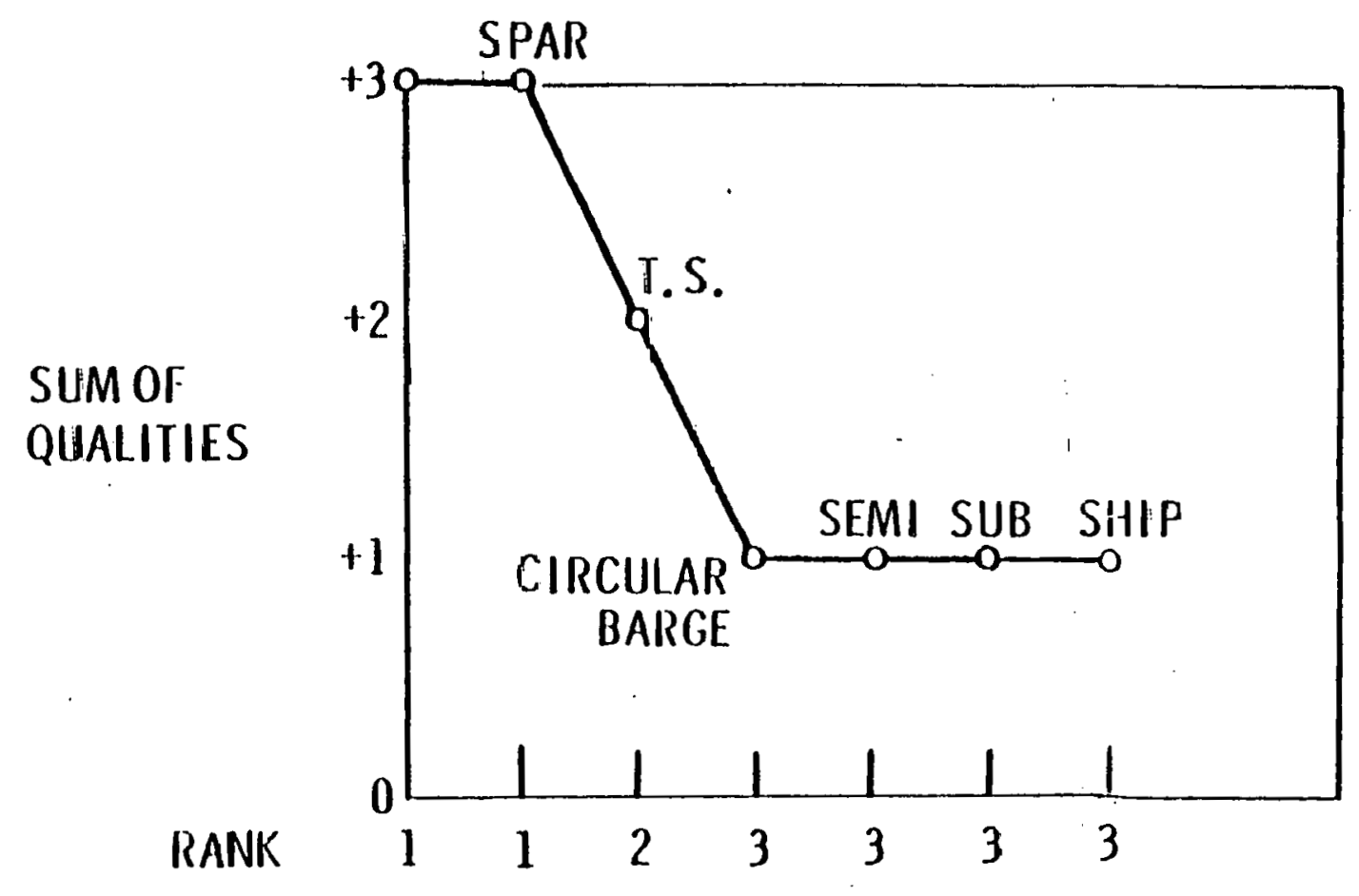

$\begin{array}{llllllll}\text { SCORE } & 10 & 10 & 7 & 4 & 4 & 4 & 4\end{array}$ 


\section{LEAST POTENTIAL DEGRADATION OF POWER AVAILABILITY}

\begin{tabular}{|c|c|c|c|c|c|c|}
\hline LEAST & SHIP & BARGE & SEM! & $\begin{array}{l}\text { TUNED } \\
\text { SPHERE }\end{array}$ & SUB & SPAR \\
\hline MAX. IHEAVE MOTION & 5 & 5 & 8 & 9 & 10 & 9 \\
\hline CENTER HEAVE MOIION & 5 & .4 & 8 & 10 & 9 & 9 \\
\hline PIICIIMOIION & 6 & 4 & 8 & 8 & 9 & 10 \\
\hline ROLL MOTION & 2 & 4 & 8 & 8 & 6 & 10 \\
\hline SURGE MOTION & 4 & 6 & 8 & 7 & 9 & 10 \\
\hline SUM OF MOIIONS & 22 & 23 & 40 & 42 & 42 & 48 \\
\hline RANKING & 6 & 5 & 4 & 3 & 2 & $\mathbf{I}$ \\
\hline SCORE & 2 & 2 & 6 & 7 & 8 & 10 \\
\hline
\end{tabular}




\section{LEAST POTENTIAL DEGRADATION OF POWER AVAILABILITY}

充

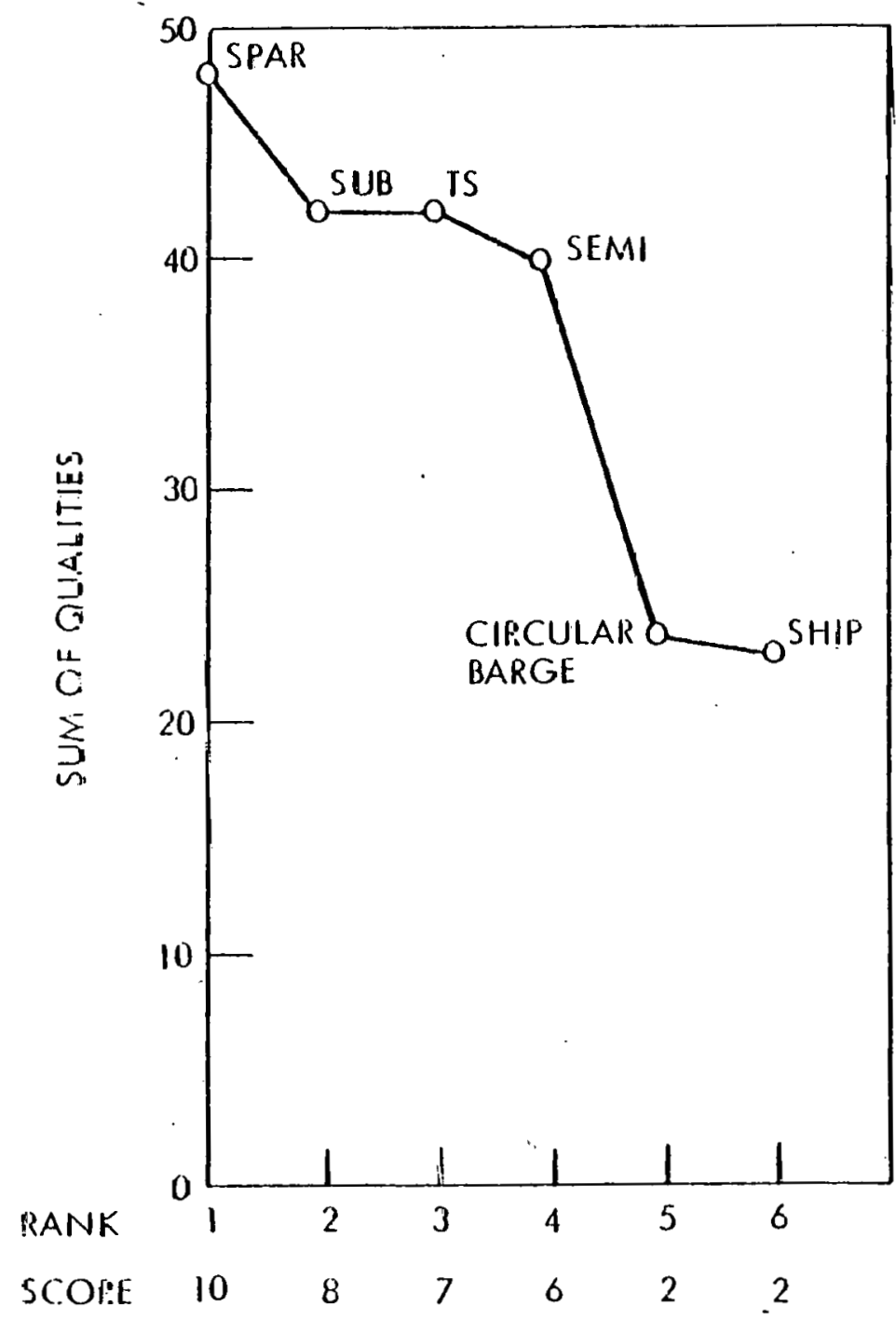




\section{MINIMUM SOTA EXTENSION}

\begin{tabular}{|l|c|c|c|c|c|c|c|}
\cline { 2 - 8 } \multicolumn{1}{l|}{} & SHIP & BARGE & SEMI & $\begin{array}{c}\text { IUNED } \\
\text { SPHIERE }\end{array}$ & SUB & SPAR INI & SPAR DET \\
\hline $\begin{array}{l}\text { CONCREIE } \\
\text { CONSTRUCIAUILIIY }\end{array}$ & + & 0 & 0 & - & + & 0 & - \\
\hline $\begin{array}{l}\text { SIEEL-ERECIION } \\
\text { COMPLEXIIY FACIOR }\end{array}$ & + & + & 0 & - & - & 0 & 0 \\
\hline SUM OF QUALIIIES & +2 & +1 & 0 & -2 & 0 & 0 & -1 \\
\hline RANKING & 1 & 2 & 3 & 4 & 3 & 3 & 4 \\
\hline SCORE & 10 & 0 & 6 & 2 & 6 & 6 & 4 \\
\hline
\end{tabular}




\section{MINIMUM SOTA EXTENSION}

岕

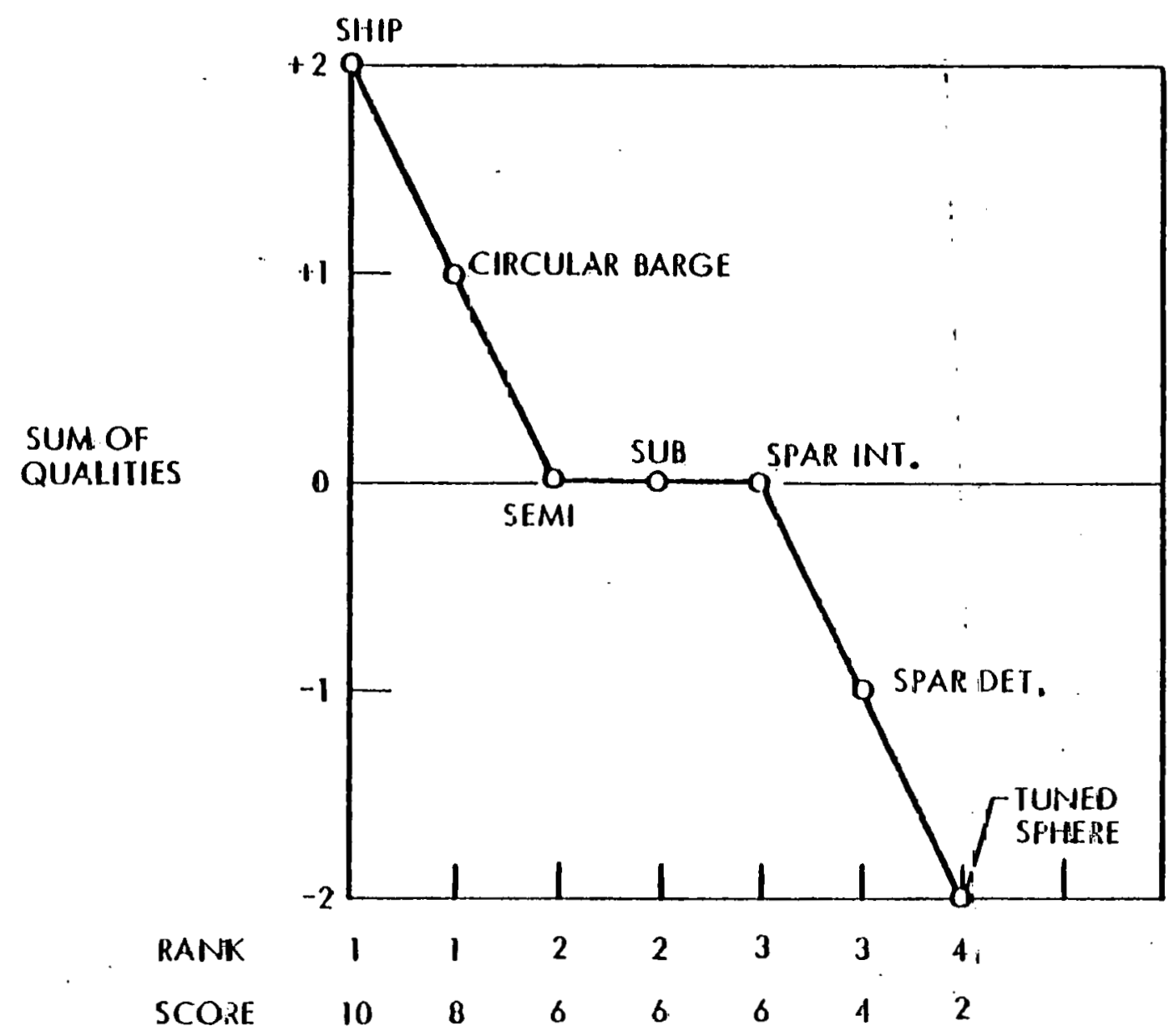




\section{SHORTEST CONSTRUCTION SCHEDULE}

\begin{tabular}{|c|c|c|}
\hline $\begin{array}{l}\text { RATIO OF } \\
\text { VOLUML OF } \\
\text { CONCRETE }\end{array}$ & RANK & SCORE \\
\hline 1.27 & 4 & 7 \\
\hline 1.00 & 1 & 10 \\
\hline 1.60 & 6 & 5 \\
\hline 1.51 & 5 & 0 \\
\hline 1.26 & 3 & 7 \\
\hline 2.12 & 7 & 4 \\
\hline 1.05 & 2 & 9 \\
\hline
\end{tabular}

SIORTEST DEPLOYMENT SCILDULE SCORE

\begin{tabular}{lr} 
SHIP & 10 \\
BARGE: & 6 \\
SEMI & 6 \\
T.S & 2 \\
SUIB & 3 \\
SPAli & \\
SPAR INT & 1 \\
\multicolumn{1}{c}{ DETT } & 1
\end{tabular}

MINIMUM NET LENERGY IS PROPORTIONAL TO INVERSE OF VOLUME OF CONCRETL (USE SCORE FOR CONSTRUCTION SCHEDULE) 


\section{MINIMUM ADVERSE EFFECTS OF SITE VARIATIONS}

\begin{tabular}{|c|c|c|c|c|c|c|c|}
\hline & & SHIIP & BARGE & SEMI & $\begin{array}{l}\text { TUNED } \\
\text { SPHERE }\end{array}$ & SUB & SPAR \\
\hline \multirow{4}{*}{$\begin{array}{l}\text { IEASI SIIE } \\
\text { EFFECIS ON }\end{array}$} & 1. CWP & 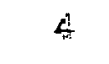 & 5 & 6 & $\xi$ & 5 & 10 \\
\hline & $\begin{array}{l}\text { 2. POSITION } \\
\text { CONTROL. }\end{array}$ & 7 & 7 & 6 & 7 & 10 & 8 \\
\hline & 3. MOTIONS & $\mathbf{I}$ & 4 & 6 & 7 & 8 & 10 \\
\hline & 4. DEPLOYMENTI & 10 & 5 & 4 & 2 & 3 & 1 \\
\hline \multirow{2}{*}{\multicolumn{2}{|c|}{ SUM OF }} & & & & & & \\
\hline & & 22 & 21 & 22 & 21 & 26 & 29 \\
\hline \multicolumn{2}{|l|}{ RANKING } & 4 & 6 & 3 & 5 & 2 & 1 \\
\hline \multicolumn{2}{|l|}{ SCORE } & 6 & 1 & 7 & 4 & 8 & 10 \\
\hline
\end{tabular}




\section{PLATFORM RISK ASSESMENT}

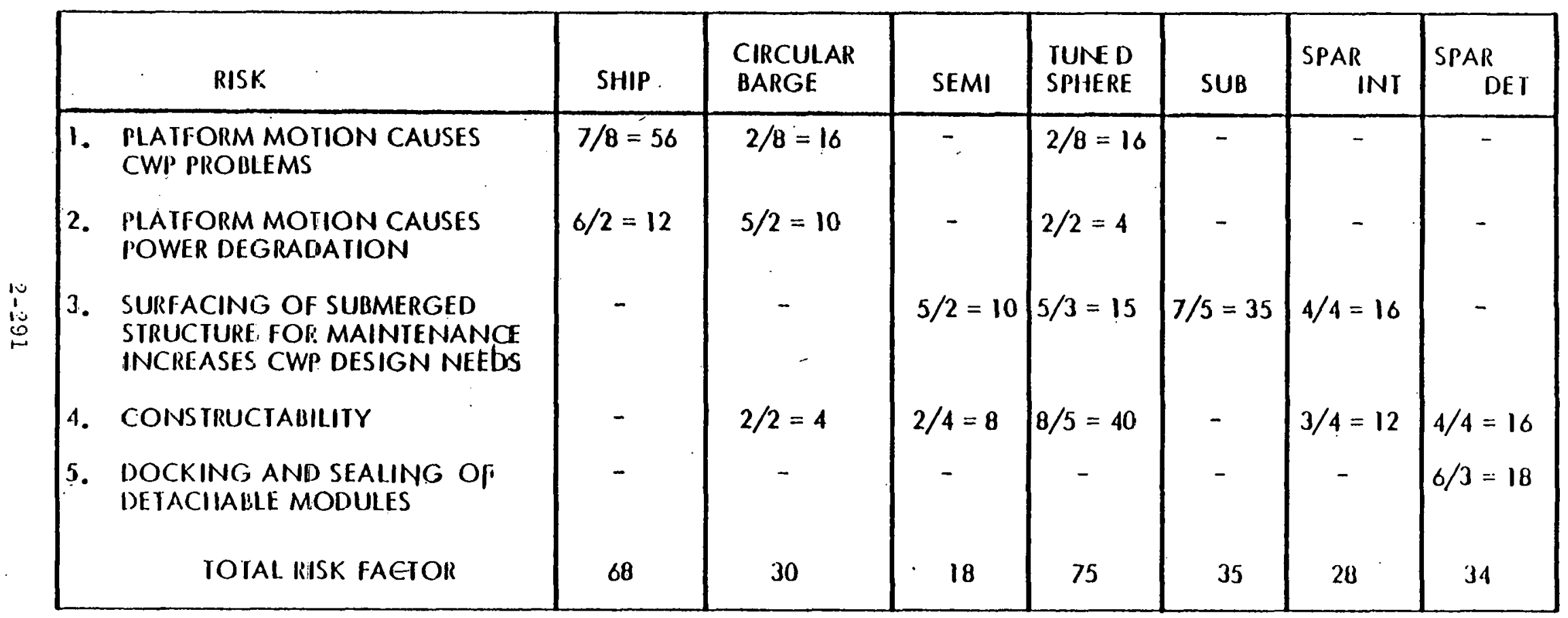

RISK FACIOR $=P \times S$ where $P=$ Probability of occurence

shown as $P / S=R F$

$$
S=\text { Severity of impact }
$$




\section{EVALUATION FOR OTEC PLATFORM-100 $M W(e)$ (NET), NEW ORLEANS}

\begin{tabular}{|c|c|c|c|c|c|c|c|c|c|c|c|c|c|c|c|}
\hline \multirow{2}{*}{$\begin{array}{l}\text { WANTS } \\
\text { CONCRETE }\end{array}$} & \multirow[t]{2}{*}{ WT } & \multicolumn{2}{|c|}{ SHIP } & \multicolumn{2}{|c|}{$\begin{array}{c}\text { CIRCULAR } \\
\text { BARGE }\end{array}$} & \multicolumn{2}{|c|}{ SEMI } & \multicolumn{2}{|c|}{$\begin{array}{l}\text { TUMED } \\
\text { SPHERE }\end{array}$} & \multicolumn{2}{|c|}{ SUe } & \multicolumn{2}{|c|}{$\begin{array}{l}\text { SPAR } \\
\text { (INT) }\end{array}$} & \multicolumn{2}{|c|}{$\begin{array}{l}\text { SPAR } \\
\text { (DET) }\end{array}$} \\
\hline & & $S$ & $p$ & $S$ & P. & $S$ & $P$ & 5 & $P$ & s & $P$ & $S$ & $P$ & $S$ & $P$ \\
\hline \multirow{11}{*}{$\begin{array}{l}\text { 1. LOW INITIAL COST/KW } \\
\text { 2. LEAST IMPACT ON CWP } \\
\text { 3. ACCESSIBILITY FOR P..S. } \\
\text { 4. FLEXIBILITY FOR P.S. } \\
\text { 5. LEAST MOTION DESRADINIS } \\
\text { 6. MINIMIUM EXIENSIOM OF SOTA } \\
\text { 7.. SHORTEST CONS. SCIHEDULE } \\
\text { 0. SHORTEST DEPLOYMENT SCHEDULE } \\
\text { 9. MINIMUM ADVERSE SIJE AFFECIS } \\
\text { 10. ACCEPTABILITY } \\
\text { 11. MINIMUM NET ENERGY }\end{array}$} & 10 & 9 & 90 & 10 & 100 & 8 & 80 & $B$ & 80 & 10 & 100 & 8 & 80 & 9 & 90 \\
\hline & 6 & 4 & 24 & 5 & 30 & 6 & 36 & 5 & 30 & 5 & 30 & 10 & 60 & 10 & 60 \\
\hline & 5 & 10 & 50 & 10 & 50 & 3 & 15 & $j$ & 25 & 1 & 5 & 3 & 15 & 5 & 25 \\
\hline & 5 & 4 & 20 & 4 & 20 & 4 & 20 & 7 & 35 & 4 & 20 & 10 & 50 & 10 & 50 \\
\hline & 3 & 2 & 6 & 2 & 6 & 6 & 18 & 7 & 21 & E & 24 & 10 & 30 & 10 & 30 \\
\hline & 2 & 10 & 20 & $8^{-}$ & 16 & 6 & 12 & 2 & 4 & 6 & 12 & 6 & 12 & 4 & 8 \\
\hline & 2 & 7 & 14 & 10 & 20 & 5 & 10 & $\varepsilon$ & 12 & 7 & 4 & 4 & 8 & 9 & 18 \\
\hline & 2 & 10 & 20 & 6 & 12 & 6 & 12 & 2 & 4 & 3 & 0 & 1 & 2 & 1 & 2 \\
\hline & 2 & 6 & 12 & 1 & 2 & 7 & 14 & 4 & $a$ & 8 & 16 & 10 & 20 & 10 & 20 \\
\hline & 2 & & & & & & & & & & & & & & \\
\hline & 1 & 7 & 7 & (1) & 10 & 5 & 5 & 6 & 6 & 7 & 7 & 4 & 4 & 9 & 9 \\
\hline SULIOTAL $(2-11)$ & 30 & \multicolumn{2}{|c|}{173} & \multicolumn{2}{|c|}{166} & \multicolumn{2}{|c|}{142} & \multicolumn{2}{|c|}{145} & \multicolumn{2}{|c|}{134} & \multicolumn{2}{|c|}{201} & \multicolumn{2}{|c|}{222} \\
\hline TOT.AL & 40 & \multicolumn{2}{|c|}{283} & \multicolumn{2}{|c|}{266} & \multicolumn{2}{|c|}{222} & \multicolumn{2}{|c|}{225} & \multicolumn{2}{|c|}{234} & \multicolumn{2}{|c|}{281} & \multicolumn{2}{|c|}{312} \\
\hline RANK & & \multicolumn{2}{|r|}{4} & \multicolumn{2}{|c|}{3} & \multicolumn{2}{|c|}{7} & \multicolumn{2}{|c|}{6} & \multicolumn{2}{|c|}{3} & \multicolumn{2}{|c|}{2} & \multicolumn{2}{|c|}{1} \\
\hline
\end{tabular}


EVALUATION FOR OTEC PLATFORMS - 100-iVW(e) (NET), VEW ORLEANS

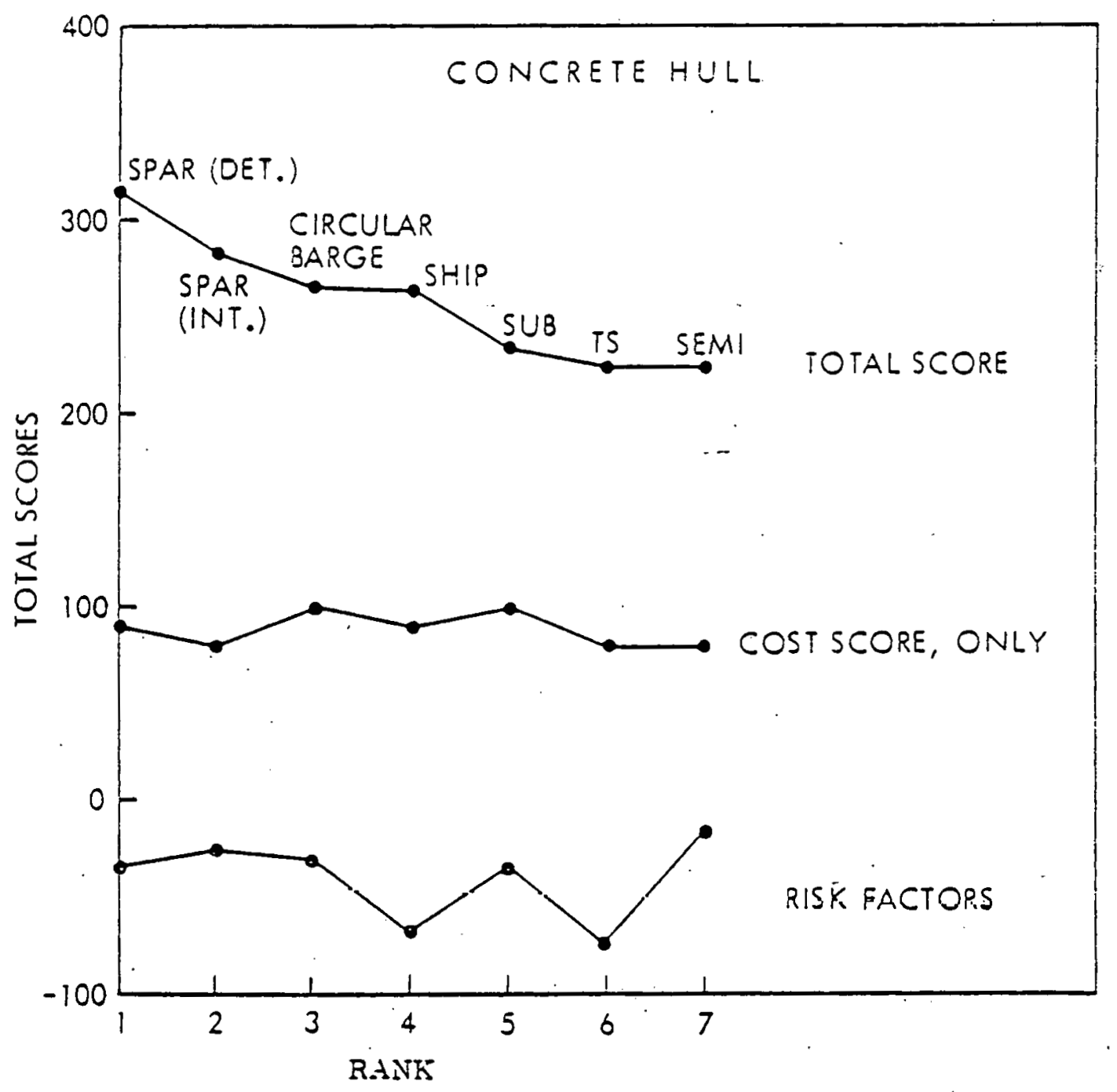




\subsection{SENSITIVITY TO REQUIREMENTS}

There are several requirements on the commercial OTEC plant which have an impact on the platform and are not related to the platform or specific features of the power system. The effect of these requirements is assessed in this section. The following sections ( 3 and 4 ) present sensitivities to site parameters and to system and subsystem characteristics. The requirements considered here a: the Eollowing

1. Constrution of majur components vill be in U.S. facilities

2. Power system component layout will be within the hull

3. Continual operational abtlltijy of power eycle

\subsubsection{Major Construction in U.S.}

There is a potential cost savings if major components such as the platform hull and cold water pipe were purchased from foreign facilities.

Several foreign countries offer shipyard construction costs significantly lower than those found in the United states. The lmpact of fore'ign construction on OTEC platform cost has been evalia:ed. TMS has available information on foreign shipyard costs collected in the course of an earlier Independent Development project. In partinular, Japanege, küeau and Spanisin shipyards' costs appear to be $20 \%$ to $25 \%$ lower than American shipyards'. However, this reduction in cost would apply only to platform hulls and to coily nater pipes; the cost of ali other items, Tables $2-81$ to $2-86$, would most likely remain unchanged. It is noted that hulls and cold water pipes account fot ruughly $60 \%$ of the cost of stesl platforms, but only for some $40 \%$ oi the cost of concrete units. Consequently, the cost reiuctiun to be expected from foreign construction of the platform and cold water plpe is of the order of $12 \%$ to $15 \%$ of total cost for steel platforms, and from $8 \%$ to $10 \%$ of to:al cost for concrete units.

\subsubsection{Power System Component Layout Within the Hull}

As a means of reducing platfon cost, LisC investigatej tine possioility of 
placing major power system components outside the hul1, housed in selfcontained,detachable modules. The effect of this arrangement on the costs of the spar plattorm configuration were discussed in Section 2.3.1. Platform hull cost decreased by nearly half for the steel structure, and by one qiarter for the concrete unit. The total cost of the steel platiorm was reduced by over $3: 5 \%$ a:nd that of the concrete platform by nearly $10 \%$. The magnitude of these reductions suggests that the detachable module alternative should be investigated seriously for all platroms which lend themselves to this approach of component layout. The optimization of porer system components for a detachable module arrangement could also be expected to produce lower plant costs.

\subsubsection{Continual Operational Ability of Power Cycle}

LMSC believes that the mooring systems discussed in thrs report will be capable of meeting the watch circle requirements specified by DOE to accommodate a free, catenary, electrical riser system. Relaxing these requirements would be. reflected in a decrease in mooring syscem costs, which account for roughly $5 \%$ to $10 \%$ of total steel platform cost, and $10 \%$ to $15 \%$ or concrete platform costs. While raductions in this cost item are thus unlikely to have a dramatic effect on overall platform costs, this is nonetheless a possible source of cost savings that should be investigated. Use of a single point noor would be a significant cost reduction. It would require, however, development of a electrically-connecting, mooring swivel. The net impact on the cost of the commercial plant must consider the potentially greater costs for the free, catenary riser for the electrical transmission systam as the watch circle is increased. 
Section 3

EFFECT OF STTE VARIATION ON OPTIMUMI PLANT SYSTEMI

This section summarizes the effects that site have on selection of and characteristics of an optimum plant or ocean system. In Section 3.1 these effects are exprcased primarily in terms of cost and characteristic variatinns, and in Seotlon 3.3 an uptiunum plant for each of the candidate sites is identified.

The site parameters that cause optimum choices and characteristics to vary with site include environmental and oceanographic characteristics such as weather, distance to port, current, and depth. These are summarized in Table $2-31$. The ocean systems considered in this section are the seawater system, particularly the cold water pipe, and the position control system options - mooring and dynamic positioning. Also treated is the variability of seawater and position control systems with platform type where such consideration contributes to identification of an optimum plant. Design variations are not considered for the hull and support systems or for the power system.

\subsection{OCEAN SYSTEMI VARIATIONS BETWEEN SITES}

The Ocean Systems principally affected by site - seawater and position keeping systemare treated in this section. Results discussed in Section 2 are summarized to illustrate system cost variation between candidate sites.

\subsubsection{Seawater System}

The cold water pipe is the component of the seawater system whose design and cost are most influenced by site variation. The baseline CIVP design concept (Section 2.3.3.1) is dependent on site conditions of waves, current, and temperature profile, as well as on platform type. 
The intensity of the 100-year storm determines, for a given platform, the extreme value of dynamic bending moment and stress in the pipe wall. This, in turn, may determine the required wall thickness over most of the pipe length. However, in a sample stress analysis of the CWP, the bending stress in the upper portion is less than the static tensile stress, indicating that a thinner pipe is adequate at least for portions of the pipe length. The lighter pipe would result in lower axial stress and lower bending stress since lower stiffness appears to reduce dynamic bending moment.

Costs of cold water pipes have been estimated for each platform type and several sea conditions, and are presented in Section 2.3.3.1. The various sites defined for this study are characterized by those extreme sea conditions. Hence, the effect of site on the cost of cold water pipes is shown in Section 2.3.3.1. Essentially the impact of site can be represented by a factor (relative to the New Orleans site) with the cost of CWP for each platform varying in relation to this factor as follows:

Site

New Orleans

Keahole Point, Hawaii

Puerto Rico

Key West

$$
\begin{aligned}
& \mathrm{H}_{\mathrm{S}}=58.1 \mathrm{ft} \\
& \mathrm{H}_{\mathrm{S}}=35.9 \mathrm{ft} \\
& \mathrm{H}_{\mathrm{S}}=44.2 \mathrm{ft} \\
& \mathrm{H}_{\mathrm{S}}=45.8 \mathrm{ft}
\end{aligned}
$$

\begin{tabular}{|c|c|}
\hline Platform & $\begin{array}{l}\text { Approximate } \\
\text { Cost Among }\end{array}$ \\
\hline Ship & $2 . \pm 0$ \\
\hline Barge & 1.90 \\
\hline Semi & 1.60 \\
\hline Tuned Sphere & 2.00 \\
\hline Submersible & 1.38 \\
\hline Spar - Internal, deep attachment & 2.17 \\
\hline - Detached, high attachment & 1.00 \\
\hline
\end{tabular}

Platform
CWP Cost Relative to New Orleans 
The effects of site on the costs of the cold water pipe are significant. Platform cost optimization should be affected by site since in some cases the CWP is 21 percent of the total platform cost.

\subsubsection{Position-Keeping System}

The two principal options are mooring and dynamic positioning. System characteristics and cost, derived in Section 2. 3.4, are summarized in this section to illustrate system variation between sites and platforms. The three-point-spread mooring system is sized to hold the platform in the 100-year storm on only one leg of the moor. For the Key West site, this criterion is conservative as the moor would be deployed in the unidirectional current with each of two legs partially reacting the current drag. In addition, the anchor requirements are less stringent for a unidirectional current site. Therefore, the system costs for Key ivest may be reduced with these considerations.

In all cases analyzed, the dynamic positioning system costs exceeded the mooring system costs, excluding component replacement costs for both systems. Mooring system costs are summarized in Table 3-1 for each nf six platform types and five sites for 100-MWW(e) (net) plant output.

In ail cases mooring system costs increase in the following order of sites.

Site 100-MWW(e) Platform Variation (SMI)

Hawaij

Puerto Rico

New Orleans

Braz11

Key West
13 to 21

18 to 32

18 to 38

34 to $\doteq 6$

62 to 30 
Table $3-1$

MOORING SYSTEM COST VARLATIONS WITH SITE (\$ MILLIONS)

(EXCLUDING REPLAC EMENT COSTS)

\begin{tabular}{|c|c|c|c|c|c|c|}
\hline Platform & $\begin{array}{c}\text { Net } \\
\text { Output } \\
{[\mathrm{MW}(\mathrm{e})]}\end{array}$ & Hawaii & New Orleans & Brazil & Puerto Rico & Key West \\
\hline \multirow[t]{3}{*}{ Ship } & 100 & 17 & 28 & 44. & 20 & 62 \\
\hline & $200^{\circ}$ & 21 & 34 & 57 & 29 & 85 \\
\hline & 500 & 35 & 63 & 109 & 54 & 184 \\
\hline \multirow[t]{3}{*}{ Barge } & 100 & 18 & 33 & 45 & 27 & 67 \\
\hline & 200 & 22 & 42 & 58 & 34 & 91 \\
\hline & 500 & 39 & 77 & 121 & 63 & 199 \\
\hline \multirow[t]{3}{*}{ Sphere } & 100 & 18 & 33 & 46 & 24 & 80 \\
\hline & 200 & 25 & 44 & 70 & 38 & 117 \\
\hline & 500 & 48 & 92 & 169 & 83 & 276 \\
\hline \multirow{3}{*}{$\begin{array}{l}\text { Semi- } \\
\text { submersible }\end{array}$} & 100 & 21 & 38 & 46 & 32 & 73 \\
\hline & 200 & 26 & 49 & 69 & 39 & 101 \\
\hline & 500 & 45 & 93 & 134 & 77 & 222 \\
\hline \multirow[t]{3}{*}{ Submersible } & 100 & 13 & 18 & 34 & 18 & 62 \\
\hline & 200 & 16 & 22 & 57 & 23 & 39 \\
\hline & 500 & 28 & 42 & 120 & 47 & 206 \\
\hline \multirow{3}{*}{$\begin{array}{l}\text { Spar } \\
0\end{array}$} & 100 & 16 & 23 & 45 & 22 & 74 \\
\hline & 200 & 18 & 29 & 59 & 28 & 111 \\
\hline & 500 & 36 & 59 & 156 & 62 & 267 \\
\hline
\end{tabular}


The submersible platform mooring costs are the lowest in all sites, and that for the sphere in Key West highest:

\begin{tabular}{ll} 
100-MIW(e) Platform & Site Variation \\
\hline Submersible & 13 to 62 \\
Spar & 16 to 74 \\
Ship & 17 to 62 \\
Barge & 18 to 67 \\
Splere & 18 to 80 \\
Semisubmersible & 21 to 73
\end{tabular}

Other site factors, such as fluctuation of current direction and frequency of storms, affect system functional life and therefore replacement costs, which over a 40-year plant life may exceed initial costs.

\subsection{OPTIMUM PIANT EVALUATION FOR FTVE STTES}

The evaluation process for the New Orleans site has been extended and applied to the other potential OTEC sites. Examination of the qualitative (non-cnst) factors (WANTS 2 to 11$)$ sluuws that they are comparatively applicable for all the sites. The evaluation scores for these items have been added to the comparative cost scores for the platforms at the several sites to develop the total evaluation score. These are presented in Table $3 \div 2$.

The detached spar configiration ranke firot for all sites. This is chiefly a result of the high qualitative score and the generally good cost scores. The internal spar ranles second at all sites for the same reassn even with a gencrally higher subt. Thc thirdranked configuration is the circular barge nosing out the ship by virtue of the barge being the lowest cost platform. The semisubmersible, Tuned Sphere, and the submersible rank lowest chiefly because of the low qualitative scores. High costs for tine semi and the Tuned Sphere further contribute to a low rank. The low cost of the submersible is not sufficient to overcome the lowest qualitative score. 
'Table 3-2

SUMMAITY OF LVAIUA'TION FOI COMMERCIAL PLANT [CONCRETE, 100 MW(e) (NET)]

\begin{tabular}{|c|c|c|c|c|c|c|c|c|}
\hline & & Ship & $\begin{array}{l}\text { Circular } \\
\text { Barge }\end{array}$ & Semi & $\begin{array}{l}\text { Tumed } \\
\text { Sphere }\end{array}$ & Sub & $\begin{array}{l}\text { Spar } \\
\text { (Lut.) }\end{array}$ & $\begin{array}{l}\text { Spar } \\
\text { (Det.) }\end{array}$ \\
\hline \multicolumn{2}{|c|}{ Sulstotal of Qualitative Factors } & 173 & 160 & 142 & 145 & 134 & 201 & 222 \\
\hline \multirow[t]{3}{*}{ New Or-lcams } & Costs & 90 & 100 & 80 & 80 & 100 & 80 & 90 \\
\hline & Total & 263 & 260 & 222 & 225 & 234 & 281 & 312 \\
\hline & Rank & 4 & 3 & 7 & 6 & 5 & 2 & 1 \\
\hline \multirow[t]{3}{*}{ Pucrto Rico } & Costs & 90 & 100 & 80 & 80 & 90 & 80 & 90 \\
\hline & 'l'otial & 263 & 266 & 222 & 225 & 224 & 281 & 312 \\
\hline & Rauk & 4 & 3 & 7 & 5 & G & 2 & 1 \\
\hline \multirow[t]{3}{*}{ Key West } & Costs & 90 & 100 & 80 & 80 & 90 & 80 & 90 \\
\hline & 'Tutil & 263 & 260 & 222 & 225 & 224 & 281 & 312 \\
\hline & liank & 4 & 3 & 7 & 5 & 6 & -2 & 1 \\
\hline \multirow{3}{*}{$\begin{array}{l}\text { Kicalhole Point, } \\
\text { llatwatii }\end{array}$} & Costs & 90 & 100 & 80 & 80 & 90 & 70 & 80 \\
\hline & Tolitl & 263 & 266 & 222 & 225 & 224 & 271 & 302 \\
\hline & Raarlis & 4 & 3 & 7 & 5 & (j & 2 & 1 \\
\hline \multirow[t]{3}{*}{ Bi:aryil } & Cossts & 90 & 100 & 80 & 80 & 90 & 80 & 90 \\
\hline & T'ctill & 263 & 260 & 222 & 225 & 224 & 281 & 312 \\
\hline & liank & 4 & 3 & 7 & 5 & G & 2 & 1 \\
\hline
\end{tabular}




\section{Section 4 \\ IMIPACT OF TECHNICAL ADVANCES}

There are several potential technical advances in the areas of power generation and distribution which could have a salutary affect on platform cost of energy. In the following discussion only those advannes which would have a sigulflcant impact on total cost are considered. Included in thio scetion are proposed changes to power system components (e.g., heat exchangers).

\subsection{HEAT EXCHANGER SELECTION}

Estimates of vertical heat exchangers volume/MNV(e) show a marked reduction relative ' to horizontal heat exchangers. For example, Gilbert Associates' data furnished to OTEC Commercial Plant contractors by the Government for their use in sizing studies show horizontal and vertical shell and tube beat exchangers to have volumes per megawatt of 3500 and 2770 , respectively.

Even a greater potential improvement in heat exchanger pover output may be derived through replacement of horizontal shell and tube by plate-fin heat exchangers leading to an improvement in volume per megawatt from 3500 to 670 . The impact of platform costs for each of these possible power system modifications is described below.

\subsubsection{Vertical Heat Exchangers}

The Improvement in platform dollars per hilowatt of net outnut power is prcaented in Table 4-1. Old $\$ / K W$ refers to that attainable employing horizontal heat exchangers while New $\$ / K W$ refers to the vertical heat exchanger equivalent. The latter data vere obtained in the following manner.

The replacement of the horizontal heat exchanger by one of a higher power density has a number of side effects in addition to its main purpose of increasing total power output. 
Table 4-1

PLANT \$/MW(e) IMPIROVLMLNT THROUGI RLPLACEMENT OF HOIZZONTAL. BY VER'TCAL SIIELL AND TUBE IIEAT' LXXCHANGERS

\begin{tabular}{|c|c|c|c|c|c|c|c|c|c|c|c|c|c|c|c|}
\hline \multirow{2}{*}{$" 0$} & \multirow{2}{*}{${ }^{N} / P_{O}$} & \multirow{2}{*}{${ }^{\prime N}$} & \multirow{2}{*}{ Pliallusm } & \multicolumn{2}{|c|}{ 'reveint Costy } & \multirow[b]{2}{*}{ sivp } & \multicolumn{3}{|c|}{$\triangle \operatorname{Cosity}$} & \multicolumn{3}{|c|}{ Plint costy } & \multicolumn{2}{|c|}{$\$ \angle L W(\omega)$} & \multirow{2}{*}{ 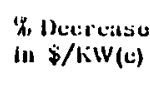 } \\
\hline & & & & IIX & civp & & $11 x$ & cwp & swP & Olul & & New & Old & New & \\
\hline I01) MIIV(c) & 9.064 & 106.4 & · & & & & & & & & & & & & \\
\hline Cinncicts & & & $\$$ IUENI & $\$ 3-1.7 \mathrm{AI}$ & $\$ 20.4 \mathrm{MI}$ & $\$ 25.0 \mathrm{AI}$ & $\$ 2.22 \mathrm{M}$ & $\$ 1.33 \mathrm{M}$ & $\$ 1.6 \mathrm{M}$ & $\$ 210.7 \mathrm{M}$ & $\$$ & $224.9 M$ & 2.147 & 2.114 & 3.3 \\
\hline St:t::l & & & $\$ 4: 3 \mathrm{M}$ & $\$ 34.7 \mathrm{Ml}$ & $\$ 20.4 \mathrm{MI}$ & $\$ 25.0 \mathrm{MI}$ & $\$ 2.22 \mathrm{M}$ & $\$ 1.33 \mathrm{M}$ & $\$ 1.6 \mathrm{M}$ & $\$ 457.7 \mathrm{M}$ & $\$$ & 4L2. UM & 4.579 & 4.351 & 4.5 \\
\hline 2100 ill'(c) & 1.060 .1 & 212.0 & & . & & & & & & & & & & & \\
\hline Contertets & & & $\$ 301 \mathrm{Al}$ & I. G9.4MI & $\$ 43.5 \mathrm{AI}$ & $\$ 50.0 \mathrm{M}$ & $\$ 4.44 \mathrm{M}$ & $\$ 2.78 \mathrm{M}$ & $\$ 1.2 \mathrm{M}$ & $\$ 376.4 \mathrm{M}$ & $\$$ & $386 . \mathrm{MM}$ & 1.882 & 1.818 & 3.4 \\
\hline stctel & & & $\$ 7 y: 21$ & $\$ 69.41$ & $\$ 49.5 \mathrm{MI}$ & $\$ 50.0 \mathrm{M}$ & $\$ 4.4+M$ & $\$ 2.78 \mathrm{M}$ & $\$ 3.2 \mathrm{M}$ & $\$ \quad 851.4 \mathrm{M}$ & $\$$ & $861.8 M$ & $4.25 \%$ & 4.050 & 4.4 \\
\hline gou $\mathrm{NMW}^{\prime}(\mathrm{C})$ & 1.064 & $5: 32.0$ & & & & & & & & & & & & & \\
\hline Comeruls & & & $\$ \quad$ GZUM & \$1731.5M1 & $\$ 100.1 \mathrm{M}$ & $\$ 125.0 \mathrm{M}$ & $\$ 11.1 \mathrm{M}$ & $\$ 0.41 \mathrm{M}$ & $50.0 \mathrm{M}$ & $\$ 402.5 \mathrm{MI}$ & $\$$ & $828.0 \mathrm{M}$ & 1,605 & 1,550 & 3.1 \\
\hline Slt::ll & & & $\$ 1,815 \mathrm{M}$ & $\$ 17 \mathrm{s.6M}$ & $\$ 100.1 M$ & $\$ 125.0 \mathrm{MI}$ & $\$ 11.1 \mathrm{M}$ & $\$ i .41 \mathrm{M}$ & $\$ 1.0 \mathrm{M}$ & $\$ 1.984 .5 M$ & & $.014 .0 \mathrm{M}$ & 3.477 & 3,780 & 4.8 \\
\hline
\end{tabular}


First of all, any increase in power output will require an essentially proportionate increase in CWP and seawater pump sizes. Note that such increases have been accounted for in Table 4-1.

A more subtle impact of increasing power density, is the corresponding increase in size of all the non-heat exchanger equipments in the power package-piping, demisters, turbogenerator, etc. In order to maintain a fixed power package volume, ther eby eliminating necessity for redesigning the platform to accept the increased package size, an increase in the non-heat exrhanger elomonta voluue ls necessary, thereby decreasiuy the total volume allotted to heat exchangers. Relationships which take this into account when computing the new power output arc 93 follows:

$$
\frac{\mathrm{V}_{\mathrm{HXX}}}{\mathrm{V}_{\mathrm{HX}}}=\frac{\left[1-.375 \frac{\mathrm{V}_{\mathrm{P}}}{\frac{\mathrm{P}_{\mathrm{O}}}{\mathrm{V}_{\mathrm{P}_{\mathrm{N}}}}}\right]}{.625}
$$

and

$$
\frac{P_{N}}{P_{O}}=\frac{V_{H X_{N}}}{V_{H X}} \cdot \frac{{ }^{P_{O}}}{V_{P_{N}}}
$$

where

$$
\begin{aligned}
& \mathrm{V}_{\mathrm{HX}}=\text { Volume of present HX (horizontal shell aud tube) } \\
& \mathrm{V}_{\mathrm{HX}_{\mathrm{N}}}=\text { Voliume of proposed } \mathrm{HX} \\
& V_{P_{O}}=\text { Volume/MTV(e) for present } H X \text { (horizontol shell and tube) } \\
& V_{P_{N}}=\text { Volume/MNV(e) for proposed } \mathrm{HXS} \\
& \dot{\mathrm{P}}_{\mathrm{O}} \quad=\text { Output of present Power System } \\
& \mathrm{P}_{\mathrm{N}} \quad=\text { Output of proposed Power System } \\
& .625=\text { Ratio of present HX to Power System Volume }
\end{aligned}
$$

$$
\pm-3
$$


Referring now to Table $4-1$, the old and new $S / K W$ were computed as follows. Replacing the horizontal (at 3,500 $\mathrm{ft}^{3} / \mathrm{MHW}(\mathrm{e})$ ) with the vertical (at 2,770 $\mathrm{ft}^{3} / \mathrm{MWW}(\mathrm{e})$ ) shell and tube heat exchangers, we substitute the ratio $V_{\mathrm{P}_{\mathrm{O}}} / \mathrm{V}_{\mathrm{P}_{\mathrm{N}}}=1.264$ into Equation $4-1$, deriving a $\mathrm{P}_{\mathrm{N}} / \mathrm{P}_{\mathrm{O}}$ of 1.064. $\mathrm{P}_{\mathrm{N}}$ is presented for $\mathrm{P}_{\mathrm{O}}$, $\mathrm{s}$ of 100,200 , and $500 \mathrm{MTV}(\mathrm{e})$ which are the three plant sizes described in Section 2.4. For each plant size two platform costs are given - the lowest (cheapest platform in concrete) and highest (costliest platform in steel) - to provide a suitable range of potential cost improvements.

Also shown in the table are present heat exchanger, cold water pipe and seawater pump costs. The basic heat exchanger cost of $\$ 8,675 \mathrm{~K}$ per $25 \mathrm{MTW}(e)$ power package has been scaled up proportionately for the 100, 200, and $500 \mathrm{MWW}(\mathrm{e})$ plants. Delta cost increases for these three elements have been obtained based on a linear extrapolation from present costs. The deltas are also shown in Table 4-1. The platform new costs are readily obtained by combining the deltas with the platform old costs. Finally, old and new $\$ / K W$ and percentage improvement in $\$ / K W$ are presented in the table and the latter are plotted in Fig. 4-1. It is apparent that the replacement of horizontal by vertical shell and tube exchangers at constant power package volume leads to only a minimal improvement in platform $\$ / \mathrm{KW}$.

\subsubsection{Plate-Fin Heat Exchangers}

A similar analysis to that previously described was conducted assuming a replacement of horizontal shell and tube by plate-fin heat exchangers. Gilbert Associates data predicts the plate-fin heat exchanger to provide power at $250 \mathrm{ft}^{3} / \mathrm{kJW}(\mathrm{e})$. It ivas necessary to resize this heat exchanger to provide a common base with the shell and tube. The result of this effort was a $670 \mathrm{ft}^{3} / \mathrm{MTV}$ (e) power density for the plate-fin. The results of the $\$ / \mathrm{KW}$ and percentage improvement computation are presented in Table 4-2 and plotted in Fig. 4-1. A definite potential improvement is evident.

\subsection{DENISTERS}

There is reason to believe that demister volumes called out in the Gilbert Associates Power System data pachage are conservative. It is likely that demisters ultimately

$$
\pm-1
$$




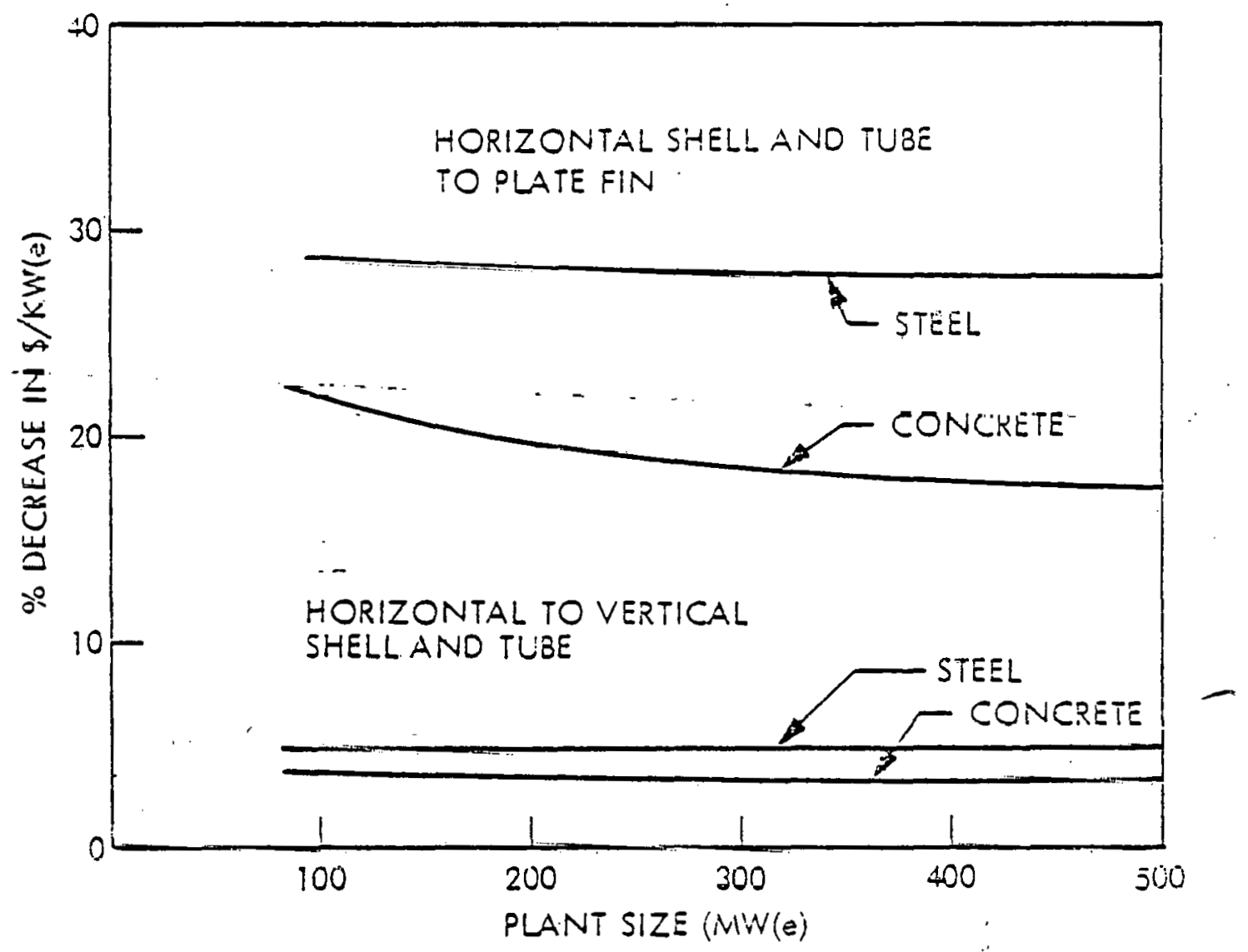

Fig. 4-1 Percent $\$ / \mathrm{MWW}(\theta)$ Inprovement Through Replacement of Horizontal Shell and Tube Heat Exchangers

empinyed in OTEC plants will be substantially smaller (predicted as low as 6.5 percent or luwer of present values). If this is true, the extra volume could be devoted to increased power output through increase in size of heat exchangers and other Fower System components. Employing the volume and cost data presented in Table $4-1$ for $100-\lambda \Pi$ (e) steel and concrete platforms, Fig. 4-2 was prepared showing percent improvement in $\mathrm{S} / \mathrm{KW}(e)$ as a function of reduction in demister volume. The percent increase in heat exchanger volume, from which the new net power output was determined, was based on the portion of the demister volume reduction which could be apportioned to the heat exchangers. The remainder of the reduction was apportioned to the remaining Fower System components. 
'able $4-2$

PLAN'T $\$ / M W(G)$ IMPROVEMENT THROUGII REPI.AC EMENT OF HORIZON'TAI. SIIEIL, AND TUBB BY PLATE-FIN HEAT EXCHANGEISS

\begin{tabular}{|c|c|c|c|c|c|c|c|c|c|c|c|c|c|c|}
\hline \multirow{2}{*}{$\mathbf{r}_{0}$} & \multirow{2}{*}{${ }^{1}{ }_{N} !^{1} O$} & \multirow{2}{*}{$\mathbf{P}_{\mathbf{N}}$} & \multicolumn{3}{|c|}{ Prgent Costs } & \multirow[b]{2}{*}{ SWP } & \multicolumn{3}{|c|}{$\Delta$ Cosity } & \multicolumn{2}{|c|}{ Plime custy } & \multicolumn{2}{|c|}{$\$ / 1976(1)$} & \multirow{2}{*}{ 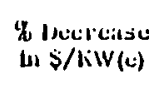 } \\
\hline & & & Plitlur'm & in & civp & & $11 x$ & Cwp & $\operatorname{siv} P$ & Oll & N:w & Old & Neiv & \\
\hline $100 \mathrm{~N}(\mathrm{~V}(\mathrm{~N})$ & $1.5 \%$ & 153.4 & & & & & & & & & & & & \\
\hline comerutu & & & $\$ 185.8$ & $\$ \mathrm{M4} .7 \mathrm{M}$ & $\$ 20.8 \mathrm{AI}$ & $\$ 25.0 \mathrm{NI}$ & $\$ 18.5 \mathrm{M}$ & $\$ 11.1 \mathrm{MI}$ & $\$ 13.4 M$ & $\$ 210.7 \mathrm{M}$ & $\$ 262.7 \mathrm{M}$ & 2,1105 & 1.713 & 22.0 \\
\hline silect & & & $\$ 42 \mathrm{JM}$ & $\$ 34.7 \mathrm{M}$ & $\$ 20.8 \mathrm{~N}$ & $\$ 25.0 \mathrm{N1}$ & $\$ 18.5 \mathrm{M}$ & $\$ 11.1 \mathrm{M}$ & $\$ 13.4 M$ & $\$ 457.7 \mathrm{M}$ & $\$ 500.7 \mathrm{M}$ & 4.577 & $3,2 \mathrm{Grt}$ & 28.7 \\
\hline 200 MIIV(E) & $1.5 \mathrm{J4}$ & J06. 8 & & & & & & & & & & & & \\
\hline Comitrute & & & $\$$ JU7N & $\$ 60.4 \mathrm{MI}$ & $\$ 43.5 \mathrm{M}$ & $\$ 50.0 \mathrm{M}$ & $\$ 37.1 \mathrm{M}$ & $\$ 23.2 \mathrm{M}$ & $\$ 26.7 \mathrm{M}$ & $\$ 376.4 \mathrm{M}$ & $\$ 403.1 \mathrm{NI}$ & $1.68 \%$ & 1.510 & 19.8 \\
\hline Sitcel & & & $\$ 7 \mathrm{~B} 2 \mathrm{AE}$ & $\$ 69.4 M$ & $\$ 43.5 \mathrm{MI}$ & $\$ 50.0 \mathrm{Al}$ & $\$ 37.1 \mathrm{M}$ & $\$ 23.2 \mathrm{MI}$ & $\$ 26.7 \mathrm{M}$ & $\$ 8.51 .4 \mathrm{MI}$ & $\$ 938.4 \mathrm{M}$ & 4.257 & 3,059 & 28.1 \\
\hline 500 MII'(c) & 1.531 & $76 \% .0$ & & & & & & & & & & & & \\
\hline Cumbrote & & & $\$ 629 \mathrm{M}$ & $\$ 173.5 \mathrm{M}$ & $\$ 100.1 \mathrm{M}$ & $\$ 125.0 \mathrm{M}$ & $\$ 02.6 \mathrm{M}$ & $\$ 53.6 \mathrm{M1}$ & $\$ 00.8 M$ & $\$ 802.5 \mathrm{M}$ & $\$ 1,016.0 \mathrm{M}$ & 1.605 & 1.323 & 17.6 \\
\hline Sitcul & & & $\$ 1,8 \mid \delta M !$ & $\$ 173.5 \mathrm{MI}$ & $\$ 100.1 \mathrm{M}$ & $\$ 125.0 \mathrm{M}$ & $\$ 22.6 \mathrm{MI}$ & $\$ 53.5 \mathrm{M}$ & $\$ 60.6 \mathrm{M}$ & $\$ 1.984 .5 \mathrm{M}$ & $\$ 2,201.0 \mathrm{M}$ & $3, .977$ & 2,870 & 27.8 \\
\hline
\end{tabular}




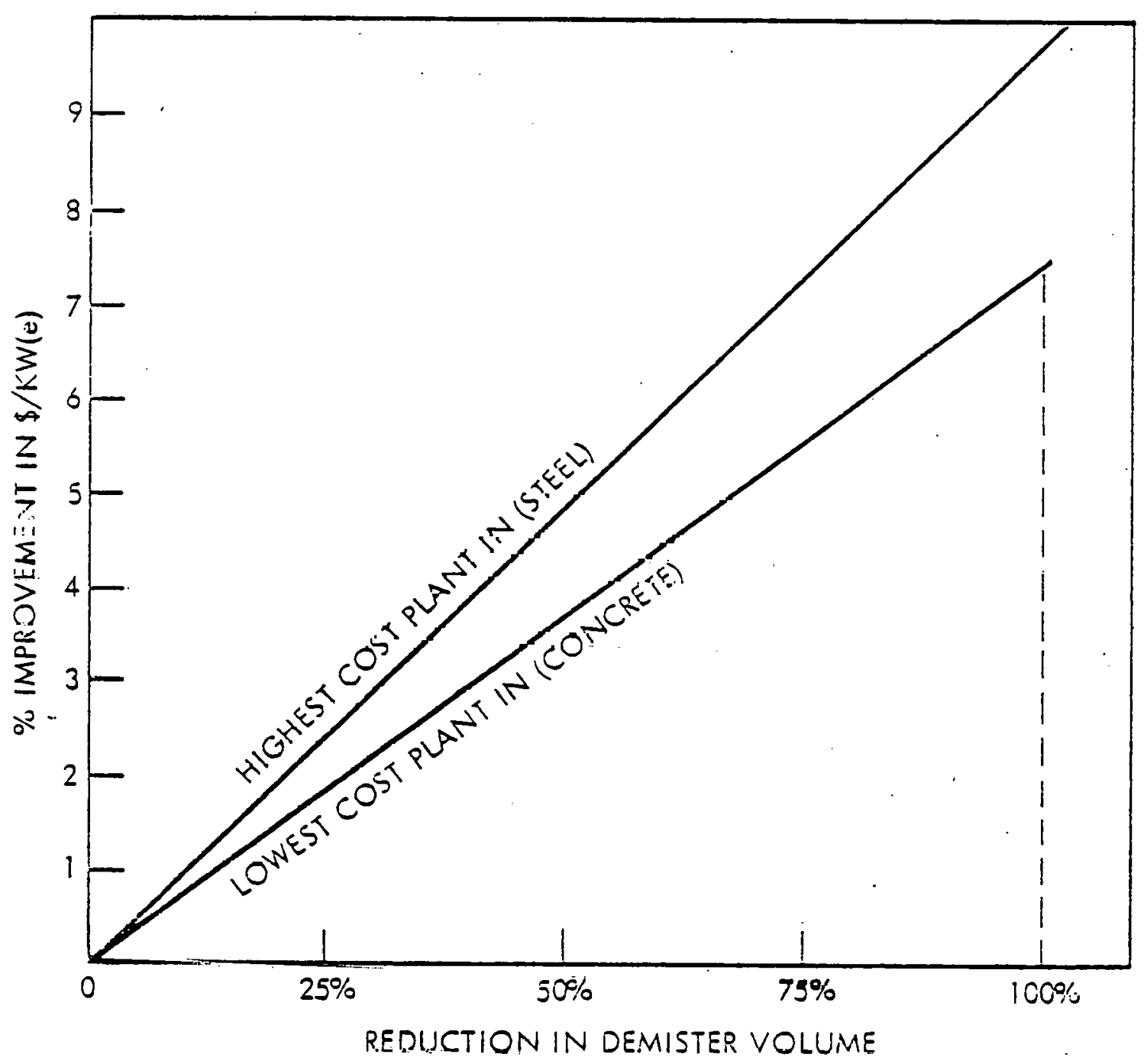

Fig. 4-2 Percent Improvement in $\$ / \mathrm{KW}(e)$ Through Reduction in Demister Volume (for 100-MNW(e) Plant) 


\section{Section 5}

\section{SUMIMARY OF CONCLUSIONS}

The following conclusions were derived in this study:

1. The requirements for the hull and structure are significantly affected by the requirements of the power system and the seawater system.

2. The requirements for the seawater system are significantly affected by the requirements of the hull-and-structure system and the power system.

3. The hull arrangements are primarily dictated by the requirements of the seawater system.

4. The size of the hull is primarily dictated by the size of the power system components, chiefly the heat exchangers and the turbine generators.

5. The optimum seawater ducting should be short and small in diameter.

6. The optimum cold water pipe is strongly affected by motions of the platform in high sea state conditions.

7. A concrete hull is estimated to be a significantly lower cost than a steel bull.

8. Four concrete platform configurations have essentially the same $(\neq 5 \%$ ) initial capital cost. These are the circular barge, submersible, spar with detachable power modules, and ship, in order of increasing cost.

9. Three concrete configurations are significantly (10 to $20 \%$ ) more costly than the four low-cost configurations. These are the spar with internal power module, tuned sphere, and semisubmersible, in order of increasing cost.

10. The larger the output of the power modules or of the OTEC plant, the lower is the cost of the platform per unit of output in the range of 50 to $500 \mathrm{MWW}(\mathrm{e})$ (net). 
The following recommendations bave been developed in this study:

1. The most promising platform configurations for commercial OTEC plants are the spar with detachable power modules and the ship.

2. The promising potential cost effectiveness of lightweight concrete for the hull should be verified.

c

$$
5-2
$$

LOCKHEED MISSILES \& SPACE COMPANY. INC. 